\title{
ICE DYNAMICS AND OCEAN PRODUCTIVITY DURING THE LATE MIOCENE, OFFSHORE WILKES LAND, EAST ANTARCTICA
}

\author{
by \\ Rebecca Frances Pretty
}

\author{
A thesis submitted to \\ Victoria University of Wellington \\ in partial fulfilment of the requirements for the degree of \\ Master of Science \\ in Geology
}

Antarctic Research Centre

Victoria University of Wellington

2019 


\begin{abstract}
The middle Miocene Climatic Transition ( $14 \mathrm{Ma})$ is commonly interpreted to represent the significant advance of the East Antarctic Ice Sheet (EAIS), and the transition to a hyper-arid climate and a stable polar-styled ice sheet. However, an increasing number of studies provide evidence for continued instability and abundant meltwater processes influencing the low-lying margins of the EAIS during the Late Miocene ( 11.6-5.3 Ma). The history of the EAIS during this period remains ambiguous due to the sparse number of records, and those that do exist have poor age resolution. This thesis investigates Integrated Ocean Drilling Program Site U1361 (64 $\left.24.5^{\circ} \mathrm{S} 143^{\circ} 53.1^{\circ} \mathrm{E}\right)$, located on the lowermost continental rise of the Wilkes Land margin. It aims to assess the variability of the EAIS and associated changes in palaeoceanography offshore one of the largest marine-based sectors of East Antarctica, the Wilkes Subglacial Basin, and to establish if the EAIS was responding to orbital forcings during the Late Miocene.

The study period ( $\sim 11.7$ to $10.8 \mathrm{Ma}$ ) contains six intervals of nannofossil-rich mudstones, interbedded with laminated mudstones and diatom-rich mudstones. Nannofossils are absent elsewhere in core U1361A, which covers the past $\sim 14$ Ma. To identify the sedimentary and depositional processes which influenced this anomalous interval of calcareous biological productivity, a high-resolution record (using $\sim 450$ samples) of Iceberg Rafted Debris (IBRD), grain size analysis and bulk geochemistry XRF analysis have been developed.

A lithofacies scheme has been established and used to provide an interpretation of the shifting sedimentary processes through time. Repeating cycles of faintly laminated mudstones were interpreted to represent the influence of bottom current activity on overbank turbidites, that spill onto a channel leeve, during glacial periods. The contouritic nature of the facies is likely associated with the low-relief channel-levee system at this time. Interglacial sedimentation is characterised by an increase in biogenic content, IBRD and bioturbation, with deposition occurring during biologically productive open marine conditions. Two types of biogenic productivity are present over the interval (silica and/or carbonate). The intervals of diatom-rich mud were interpreted to be associated with enhanced upwelling of Circumpolar Deep Water (CDW). While, the nannofossil-rich mudstones suggest a significantly warmer climate, with coccolithophore production
\end{abstract}


proposed to represent the influence of meltwater and shifting Southern Ocean frontal systems, acting to restrict nutrient upwelling and increase water temperatures.

Nannofossil-rich muds are only present for a short interval (700 kyr), suggesting that the anomalous depositional environment between $\sim 11.7$ to 11.0 Ma was potentially related to the significant retreat and surface meltwater processes at the EAIS margin. Interglacial sedimentation at Site U1361 is also accompanied by an increase in grain size (i.e. silt), interpreted to represent oceanic current intensification which acts to restrict the deposition of finer material, relative to glacial intervals. This intensification of ocean current strength may have resulted in increased heat delivery to the EAIS margin triggering a terrestrial based ice sheet, and the delivery of nutrients stimulating marine productivity. Spectral analysis of the mean grain size (MGS) and IBRD Mass Accumulation Rate (MAR) records revealed that during the Late Miocene ( 11.7 to $10.8 \mathrm{Ma}$ ), the ice sheet was paced by $\sim 100 \mathrm{kyr}$ eccentricity cycles, and a low frequency $\sim 20 \mathrm{kyr}$ processional component. This is consistent with two Late Miocene $\delta^{18} \mathrm{O}$ records that are also paced by eccentricity, suggesting that the Antarctic Ice Sheet was contributing a significant signal to the global $\delta^{18} \mathrm{O}$ record during this interval of the Late Miocene. However, the presence of nannofossil suggests a warmer world, rather than the colder climate state that are often inferred to lead to eccentricity/precession variability. A recent hypothesis proposed by Levy et al., (2019) invokes that a warmer climate may lead to surface melt processes which at high latitudes are dominated by eccentricity/precession. Although this style of climate is commonly thought to have occurred prior to $14 \mathrm{Ma}$ in East Antarctica, the evidence presented in this study suggests such a state existed at the Wilkes Land margin until at least $\sim 11.0 \mathrm{Ma}$. 


\section{ACKNOWLEDGMENTS}

This thesis would not have been possible without the support and guidance of so many people. First and foremost, a massive thank you to my supervisors, Rob McKay and Gavin Dunbar. Rob, thank you for your constant support and guidance through this project. Your encouragement and enthusiasm helped to bring down my stress level and made this project very enjoyable to be part of. Gavin, thank you for your helpful insight into lab work, particularly with XRF lab work, and useful discussions on data interpretations.

I would also like to thank many others who contributed to this research. A big thank you to Jane Chewings for your endless help and encouragement in the laboratory. Without your guidance I don't think my lab work would have been possible. A massive thank you to Bella Duncan for spending hours teaching me the methods of biomarker analysis and data processing. Lastly, thank you to the SGEES and ARC staff and students who made my time as an undergraduate and postgraduate student at VUW a very enjoyable experience.

To my family, I could not have done this without you. Mum and Dad, thank you for your love and support over the years, allowing me to strive for excellence and to never give up. To Benjamin and William, the best brothers an older sister could have! Thank you for checking up on me, it has been great having you both in Wellington over the last couple of years. To my friends, each one of you has been amazing, providing endless encouragement, love, laughter and some much-needed proofreading. A special thank you to Damian, for your support and love throughout this project.

I would like to acknowledge the Rutherford Discovery Fellowship to Rob McKay for funding this project. Lastly, the shipboard scientists of the International Ocean Drilling Program Leg 318 for successful recovery and previous analysis on such an amazing sedimentary core. 


\section{TABLE OF CONTENTS}

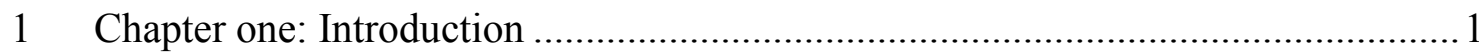

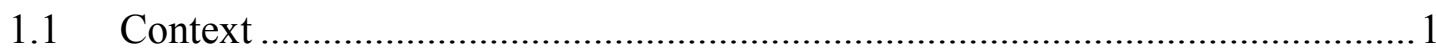

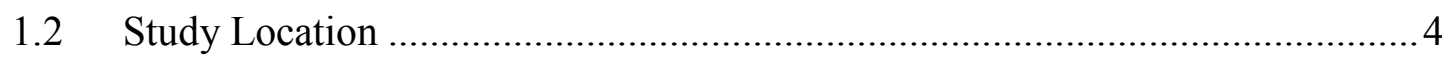

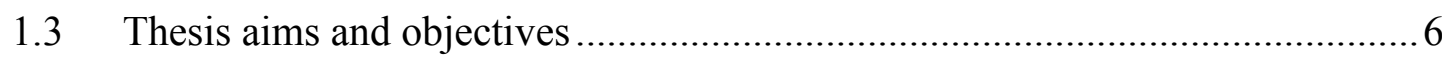

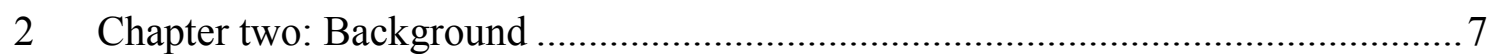

2.1 Antarctic ice sheet history - proximal and far-field records ..........................

2.1.1 Cenozoic climate and initiation of the Antarctic Ice Sheets ...................... 8

2.1.2 Mid-Miocene Climatic Optimum............................................................ 11

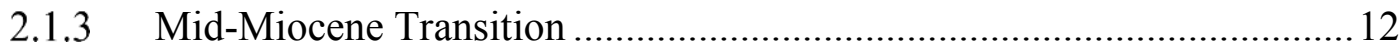

2.1.4 Late Miocene - was the EAIS dynamic or stable? ............................... 12

2.1.5 Pliocene climate and ice sheet style ................................................... 14

2.2 Global productivity during the Late Miocene .............................................. 15

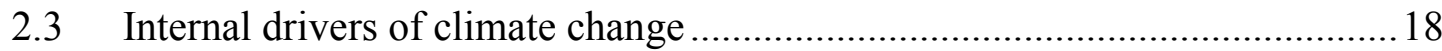

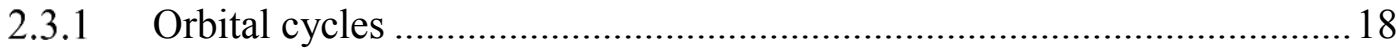

2.3.2 Milankovitch theory of the Ice Ages...................................................... 19

2.3.3 Milankovitch cycles- the pre-100 kyr world .........................................20

2.3.4 Orbital patterns deep sea records during the Late Miocene .....................2 21

2.3.5 Southern oceans role in atmospheric $\mathrm{CO}_{2}$ concentrations .......................22

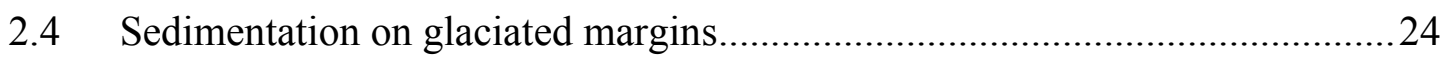

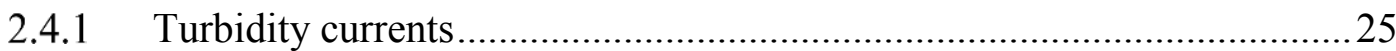

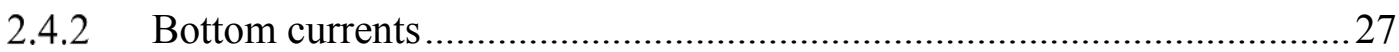

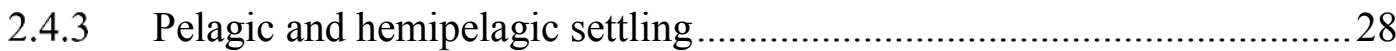

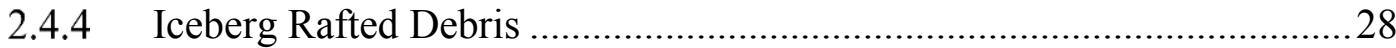

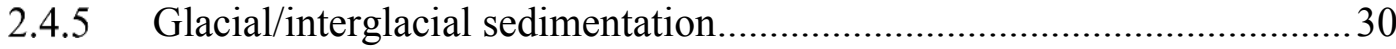

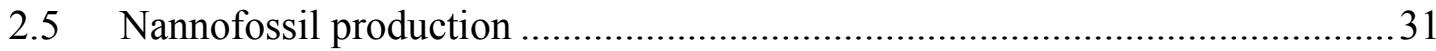


2.5.1 Significance of nannofossils in Antarctica................................................. 32

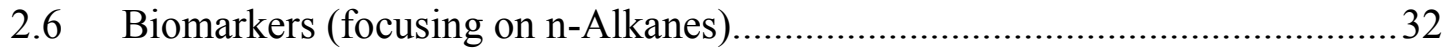

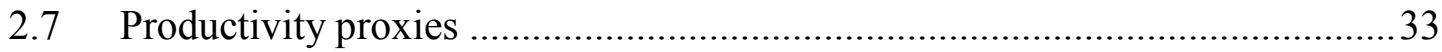

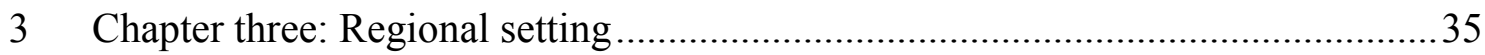

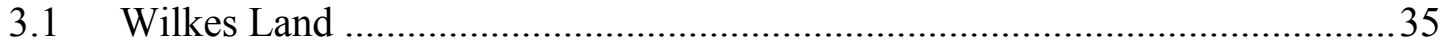

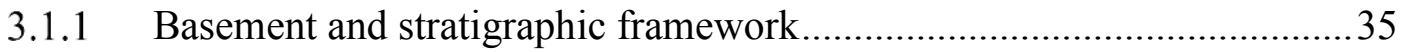

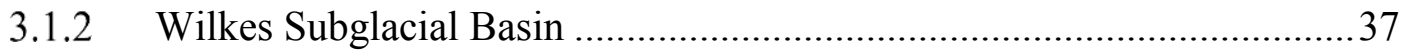

3.1.3 Bathymetry offshore Adélie coast..................................................... 38

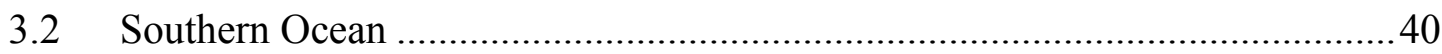

3.3 Antarctic bottom water formation and ocean circulation at Wilkes Land .......40

3.3.1 Bottom water formation in Antarctica ................................................. 40

3.3.2 Formation of the Adélie Land Bottom Water ........................................ 41

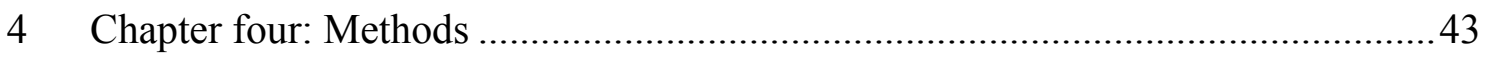

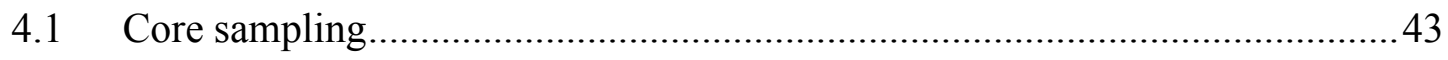

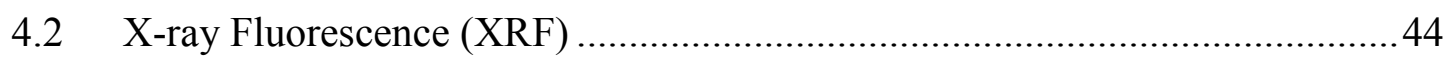

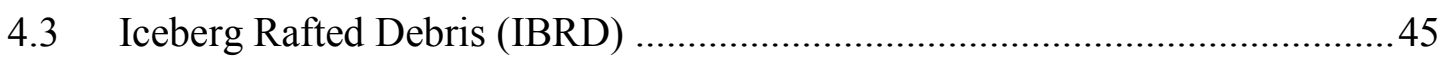

4.3.1 Iceberg Rafted Debris Mass Accumulation Rate (IBRD MAR)...............46

4.3.2 Analytical Scanning Electron Microscope (SEM) .................................46

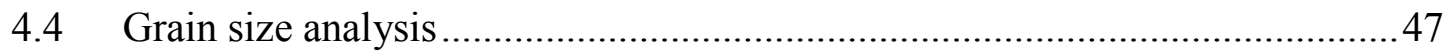

4.4.1 Removal of organic, carbonate and biogenic material ............................47

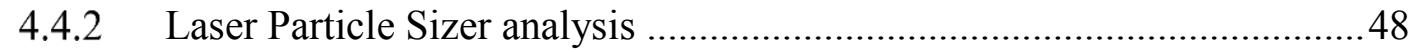

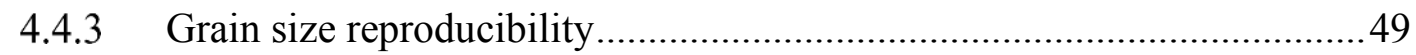

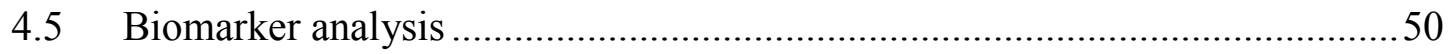

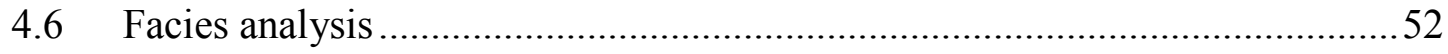

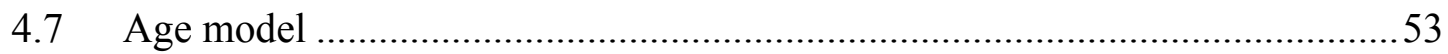

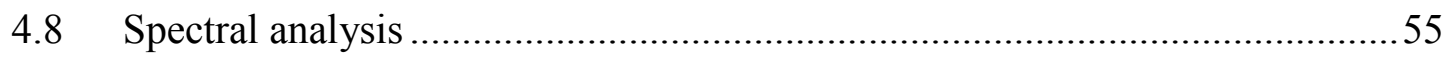




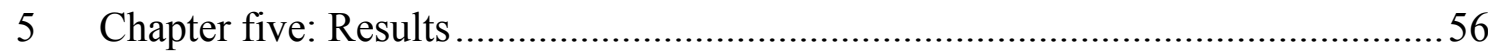

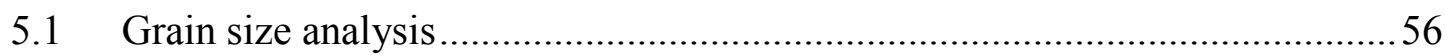

5.1.1 Iceberg Rafted Debris Mass Accumulation Rate ....................................59

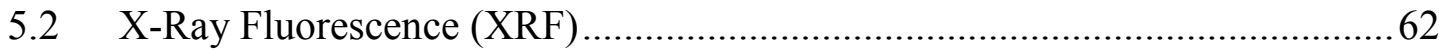

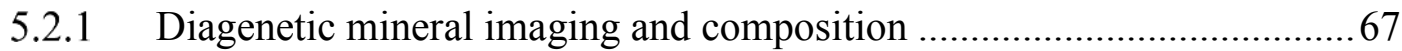

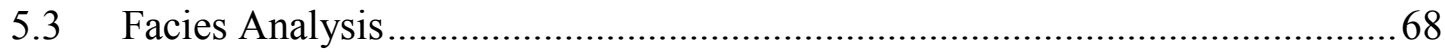

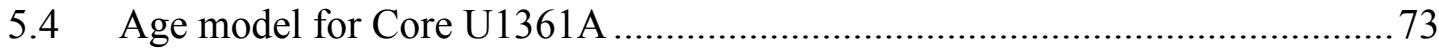

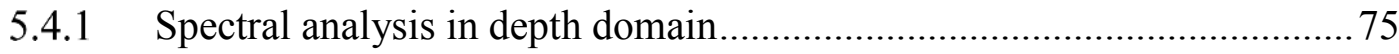

5.5 Evolutionary Spectral Analysis in the time domain .................................... 78

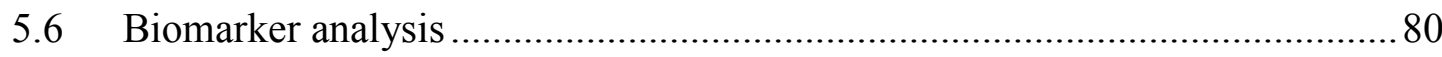

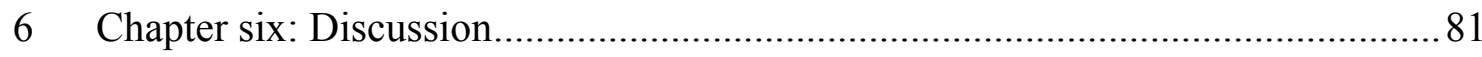

6.1 Interglacial to glacial sedimentation and depositional processes .................... 83

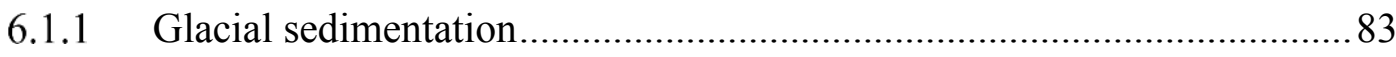

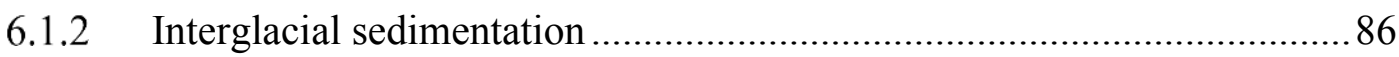

6.1.3 Significance of nannofossils during the Late Miocene interglacials ........ 89

6.2 Iceberg Rafted Debris as a proxy at Site U1361 .........................................92

6.3 Orbital forcing of glacial-interglacial cycles.............................................. 93

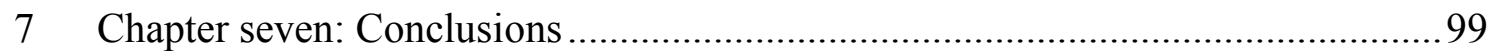

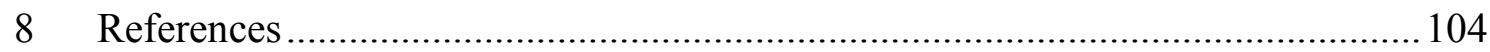

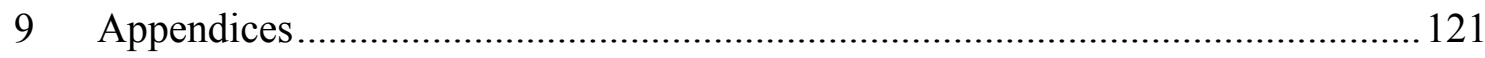




\section{LIST OF FIGURES}

Figure 1. 1 Composite of deep-sea benthic foraminiferal oxygen-isotope records for the Cenozoic (0 to $65 \mathrm{Ma}$ ). 3

Figure 1. 2 Location of Site U1361 and bathymetry offshore Wilkes Land, East Antarctica.

Figure 2. 1 Reconstruction of global climate for the Cenozoic (0-65 Ma). 9

Figure 2. 2 Climate and carbon cycle changes from Late Miocene to present. 16

Figure 2. 3 Turnover pulses of diatoms in the Southern Ocean and Antarctic margin over the last $15 \mathrm{Ma}$.

Figure 2. 4 Schematic showing the three orbital parameters

Figure 2. 5 Illustration of the biological pump 23

Figure 2. 6 Cartoon of glaciomarine sedimentation processes. 25

Figure 2. 7 The classic Bouma turbidite sequence 26

Figure 2. 8 Contourite facies model 27

Figure 3. 1 Interpreted and uninterpreted high-resolution mulitchannel seismic profile across the Wilkes Land continental shelf. 36

Figure 3. 2 A) Bathymetry of the Wilkes Land margin, including the location of Site U1361 and the depth profile of the WSB (with ice removed) 37

Figure 3. 3 Bathymetric map and pathways of water masses that contribute to the formation of the ALBW offshore Wilkes Land.

Figure 3. 4 Schematic diagram illustrating ocean circulation in the Adélie Depression.41

Figure 4. 1 Non-IBRD aaterial found in the $250 \mu \mathrm{m}$ to $2 \mathrm{~mm}$ fraction. 47

Figure 4. 2 Reproducibility of grain size data 
Figure 5. 1 Ternary diagrams and grain size frequency distributions. 57

Figure 5. 2 Site U1361 grain size data, including percentage of clay $(<4 \mu \mathrm{m})$, silt (4$63 \mu \mathrm{m})$ and sand $(63-200 \mu \mathrm{m})$ fractions. 58

Figure 5. 3 Cross plot of coarse sand percentage (CS\%) and sorting at Site U1361 ... 59

Figure 5. 4 Site U1361 Iceberg Rafted Debris (IBRD) Mass Accumulation Rate (MAR)60

Figure 5. 5 Site U1361 XRF ratios 64

Figure 5. $6 \mathrm{CaCO}_{3}$ values for Site U1361 65

Figure 5. 7 Physical properties: Magnetic suscepitability (MS) and Natural gamma radiation (NGR) from Site U1361 66

Figure 5.8 SEM and EDS results for Site U1361. 67

Figure 5. 9 Example sections of core from Site U1361 69

Figure 5. 10 Age-depth plot for Site U1361 and magnetostratigraphic tie points. 74

Figure 5. 11 MTM plots for the four datasets. 76

Figure 5. 12 ASM results for silt \% and MGS for Site U1361 78

Figure 5. 13 EHA of mean grain size (MGS) for Site U1361. 79

Figure 6. 1 Stratigraphic log and core images at Site U1361, with facies, degree of bioturbation, stratigraphic cycles, elemental ratios and grain size. 82

Figure 6. 2 Ternary grain size diagram highlighting differences between the Late Miocene and the Plio-Pleistocene records. 85

Figure 6. 3 Schematic diagram illustrating the interpretation of a) glacial, b) deglaciation and c) interglacial maximum climate stages influence on sedimentation at Site U1361 88

Figure 6. 4 Graphic and environmental proxy logs from $\sim 313$ to $318 \mathrm{mbsf}$ from Site U1361. 91

Figure 6. 5 EHA and MTM comparison between Site U1361 IBRD MAR dataset and $\delta^{18} \mathrm{O}$ from Site 1146 and 1158 
Figure 6. 6 Depth series of IODP Site U1361 sediment core datasets between $\sim 11.7$ and $10.8 \mathrm{Ma}$

\section{LIST OF TABLES}

Table 1 Site U1361 core data information for the selected study interval, including the hole, core number and the top depth (mbsf).....

Table 2 Solvent used to extract each fraction during columns 51

Table 3 Late Miocene Site U1361 tie points. 54

Table 4 Characteristics of grain size frequency distributions.. 56

Table 5 R Pearsons Linear correlation between XRF-scanned elements. 62

Table 6 Summary table of the four facies. 68

Table 7 Wavelengths of the cycle $(m)$ identifed during the Late Miocene interval at Site U1361, attributed to Milankovitch cycles for each dataset. 75 


\section{LIST OF ABBREVIATIONS}

\section{Text Abbreviations}

AABW

ACC

ACL

$\mathrm{AD}$

AIS

ALBW

$\mathrm{Al} / \mathrm{Ti}$

AND

AS

ASM

$\mathrm{Ba} / \mathrm{Al}$

bSi

$\mathrm{CaCO}_{3}$

$\mathrm{Ca} / \mathrm{Al}$

CCD

CDW

$\mathrm{CO}_{2}$

CPI

CS \%

DBD

DI $\mathrm{H}_{2} \mathrm{O}$

DSW

EAIS

ECO

EDS

EHA

EOT

HCL
Antarctic Bottom Water

Antarctic Circumpolar Current

Average Chain Length

Adélie Depression

Antarctic Ice Sheet

Adélie Land Bottom Water

Ratio of aluminium to titanium

ANtarctic geological DRILLing (ANDRILL)

Adélie Sill

Average Spectral Misfit

Ratio of barium to aluminium

biogenic silica

calcium carbonate

Ratio of calcium to aluminium

Carbonate Compensation Depth

Circumpolar Deep Water

Carbon dioxide

Carbon Preference Index

coarse sand wt $\%$

Dry Bulk Density

Deionization water

Dense Shelf Water

East Antarctic Ice Sheet

Eocene Climatic Optimum

Energy Dispersive C-Ray Spectrometry

Evolutive harmonic analysis

Eocene Oligocene Transition

Hydrochloric acid 
HSSW

$\mathrm{H}_{2} \mathrm{O}_{2}$

IBRD

IODP

ISW

LSR

MAR

$\mathrm{Mg} / \mathrm{Ca}$

MCDW

$\mathrm{MCO}$

MCT

MGT

MGS

MPT

MS

MTM

$\mathrm{NaOH}$

NGR

ODP

$\mathrm{Si} / \mathrm{Al}$

SST

$\mathrm{Sr} / \mathrm{Ca}$

TIC

TLE

VUW

WAIS

WL-U

WSB

XRF
High Salinity Shelf Water

hydrogen peroxide

Iceberg Rafted Debris

Integrated Ocean Drilling Program

Ice Shelf Water

Linear Sedimentation Rate

Mass Accumulation Rate

Ratio of magnesium to calcium

Modified Circumpolar Deep Water

Mid Miocene Climatic Optimum

Mid Miocene Climatic Transition

Mertz Glacier Tongue

Mean grain size

Mid Pleistocene Transition

Magnetic susceptibility

Multi Taper Method

sodium hydroxide

Natural Gamma Radiation

Ocean Drilling Program

Ratio of silica to aluminium

Sea Surface Temperature

Ratio of strontium to calcium

Total Ion Current

Total Lipid Extract

Victoria University of Wellington

West Antarctic Ice Sheet

Wilkes Land Unconformity

Wilkes Subglacial Basin

X-ray Fluorescence 

$\delta^{18} \mathrm{O}$
Ratio of oxygen-18 to oxygen-16
$\delta^{13} \mathrm{C}$
Ratio of carbon-13 to carbon-12

\section{Units of measurements}

\begin{tabular}{|c|c|}
\hline$\%$ & percentage (fraction of 100) \\
\hline$\%$ & Percentage (fraction of 1000) \\
\hline${ }^{\circ} \mathrm{C}$ & Degrees Celsius \\
\hline$\alpha$ & alpha \\
\hline $\mathrm{cm} / \mathrm{ka}$ & centimetre per thousand years \\
\hline$\beta$ & beta \\
\hline $\mathrm{g}$ & gram \\
\hline $\mathrm{g} / \mathrm{cm}^{2} / \mathrm{kyr}$ & grams per centimetre squared per thousand years \\
\hline $\mathrm{g} / \mathrm{cm}^{3}$ & grams per centimetre cubed \\
\hline $\mathrm{g} / \mathrm{L}$ & gram per litre \\
\hline $\mathrm{ka}$ & Thousands of years before present \\
\hline kyr & Thousands of years \\
\hline $\mathrm{kv}$ & Kilowatt \\
\hline $\mathrm{Kyr}^{-1}$ & per thousand years \\
\hline Lmy & Lineage-million-years \\
\hline $\mathrm{ml}$ & millilitres \\
\hline M & Molar concentration defined as $\mathrm{mol} / \mathrm{L}$ \\
\hline $\mathrm{Ma}$ & Millions of years before present \\
\hline mbsf & Meters below sea floor \\
\hline Mbsl & Meters below sea level \\
\hline $\mathrm{ms}^{-1}$ & Meter per second \\
\hline myr & Millions of years \\
\hline $\mathrm{PgC} \mathrm{yr}^{-1}$ & petagram of carbon yearly \\
\hline ppm & Parts per million \\
\hline wt $\%$ & Weight percent \\
\hline$\mu \mathrm{m}$ & Micronmeter \\
\hline$\mu 1$ & microliter \\
\hline
\end{tabular}




\section{CHAPTER ONE: INTRODUCTION}

\subsection{CONTEXT}

The Antarctic Ice Sheets (AIS) are fundamental components of the Earth's climate system and are strongly coupled with oceanic and atmospheric circulation of the Southern Hemisphere (Golledge et al., 2015; Pollard and Deconto, 2016). Since the inception of the AIS, $>34$ million years ago (Ma), both the East Antarctic Ice Sheet (EAIS) and West Antarctic Ice Sheet (WAIS) have fluctuated significantly, especially along the margins of the WAIS (Shackleton and Kennett, 1976; Zachos, et al., 2001a; Miller et al., 2005). However, geological evidence for the timing and magnitude of AIS variability is still unconstrained, especially in the case of the EAIS, as well-dated continuous proximal records are sparse and spatial coverage is poor.

Incursions of Circumpolar Deep Water (CDW) onto the Antarctic Continental shelf are proposed to be the main driver of ice shelf instability in the modern day (Jacobs, et al., 1996; Pritchard et al., 2012). Oceanic warming at the base of ice shelves results in thinning, reducing their buttressing effect and enhancing the seaward flow of grounded ice sheets into the ocean (Weertman, 1974; Mercer, 1978; Pollard and Deconto, 2016). Once triggered, marine ice sheet retreat in Antarctica can be rapid, as continental shelves commonly exhibit a reverse-sloping/over-deepened bathymetry. This promotes Marine Ice Sheet Instability, with accelerated runaway retreat resulting in rapid sea level rise during deglaciations (Thomas and Bentley, 1978). Geological data supported by ice sheet model experiments indicate that the marine-based WAIS has periodically collapsed in the past (Naish et al., 2009; Pollard and Deconto, 2016). However, the complete collapse of the marine-based sectors of the WAIS would only result in $\sim 3.4 \mathrm{~m}$ sea level rise above present-day, as majority of its mass is already compensated for via buoyancy (Fretwell et al., 2013).

In contrast to WAIS, the majority of the much larger EAIS is grounded on bedrock above present-day sea level, making it is less vulnerable to rapid collapse via oceanic warming (Pollard et al., 2015). The potential contribution of the EAIS to sea level rise is $\sim 53.3 \mathrm{~m}$, with $\sim 19 \mathrm{~m}$ grounded below sea level and therefore more vulnerable to marine melting 
by oceanic-induced processes (Fretwell et al., 2013; Golledge et al., 2017). Although considered stable relative to the WAIS, recent studies have suggested that the EAIS is also vulnerable to warmer than present ocean temperatures (Golledge et al., 2015) and that sectors of the EAIS retreated several kilometres inland during the Pliocene warmth (Cook et al., 2013) and the last interglacial (Wilson et al., 2018). Instability of the marinebased sectors of EAIS is modelled to occur within the large subglacial basins, which exhibit reverse-sloping beds (Pollard et al., 2015), such as the Wilkes Subglacial Basin (WSB). The eastern sector of the Wilkes Land margin is located at the seaward termination of one of the largest East Antarctic subglacial basin is a key region for analysis of long- and short-term behaviour of the EAIS. Models indicate the WSB is less stable than other EAIS regions, holding $\sim 3$ to 4 meters of sea level equivalent ice volume (Mengel and Levermann, 2014; Golledge et al., 2015; Pollard and Deconto, 2016).

In 2010, the Integrated Ocean Drilling Program (IODP) Expedition 318 recovered a sediment core from $\sim 3,465$ metres water depth on the continental rise offshore of the Adélie Coast at the Wilkes Land margin (Escutia et al., 2011b). An almost continuous record from the present day back to the middle Miocene $(\sim 14 \mathrm{Ma})$ was obtained, providing an opportunity to assess the stability of the EAIS and the relationship to paleoclimatic and palaeoceanographic changes at the East Antarctic margin at orbitalscale resolution. The selected core U1361A is characterised by alternating beds of laminated mudstones and diatom-rich to bearing mudstones. However, the Late Miocene contains an anomalous interval of nannofossil-rich beds, with $\mathrm{CaCO}_{3}$ representing up to $24 \mathrm{wt} \%$ of the total sediment composition (DeCesare and Pekar, 2016), whereas all other

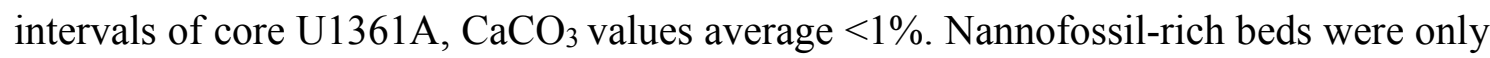
identified for several discrete intervals between $\sim 313.60$ and 342.04 meters below the sea floor (mbsf). Preliminary interpretations suggest that the diatom-bearing intervals indicate biologically productive open-marine conditions (Cook et al., 2013; Patterson et al., 2014), and the occurrence of carbonate suggests that the depositional setting was favourable to the production of biogenic $\mathrm{CaCO}_{3}$ in surface waters at the margin for brief, potentially orbitally-paced intervals during the Late Miocene.

The Miocene period represents a fundamental shift in climate state over the Cenozoic (Figure 1. 1). A relative cool climate during the early Oligocene, with a highly oscillatory 
EAIS was interrupted by the middle Miocene Climatic Optimum (MCO), considered as warmest internal of the Neogene (Flower and Kennett, 1994). However, this warmth was terminated at the Miocene Climatic Transition (MCT) at 14 Ma (Shevenell et al., 2004). The MCT has been interpreted as the expansion and development of a more persistent EAIS during a period of rapid cooling, although variations in ice extent at the EAIS marine margin have also been noted during the Plio-Pleistocene warmer interglacial climates (e.g. Cook et al., 2013; Patterson et al., 2014; Wilson et al., 2018). The behaviour of the EAIS and adjacent Southern Ocean during the Late Miocene remains understudied, in large part due to the lack of well-dated geological archives of this time. Outcrops along the EAIS margin in the Ross Sea and Prydz Bay hint at a warmer and more dynamic climate and ocean than the Pliocene (Hambrey and McKelvey, 2000b; McKay et al., 2009). This study aims to provide an insight into the behaviour of the EAIS at the Wilkes Land margin during a short interval of the Late Miocene.

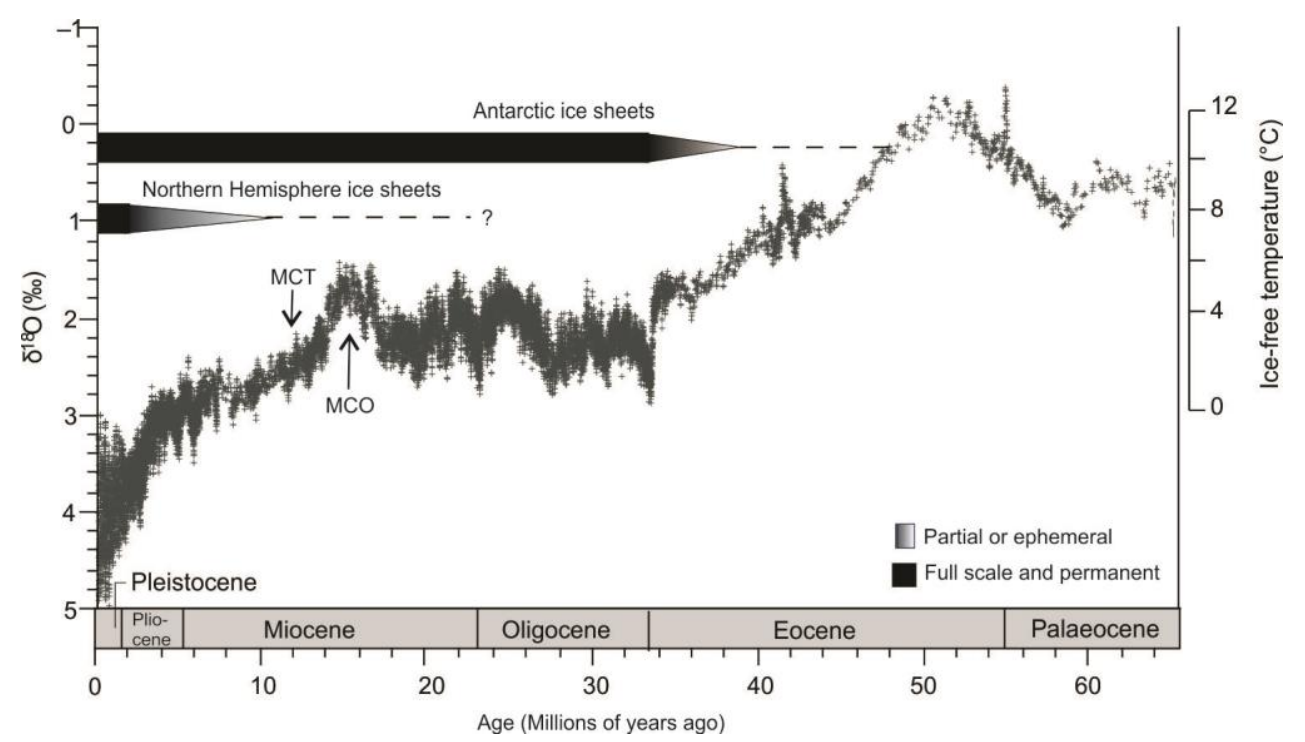

Figure 1. 1 Composite of deep-sea benthic foraminiferal oxygen-isotope records for the Cenozoic (0 to $65 \mathrm{Ma}$ ), with broad ice sheet history labelled. Figure modified from Zachos et al., (2008). 


\subsection{STUdY LOCATION}

IODP Site U1361 $\left(64^{\circ} 24.5^{\circ} \mathrm{S} 143^{\circ} 53.1^{\circ} \mathrm{E}\right)$ is located on the lower continental rise, $\sim 280$ $\mathrm{km}$ north of the eastern Wilkes Land margin in East Antarctica ( Figure 1. 2; Escutia et al., 2011b). The core was recovered from the east (right) levee bank of the Jussieu submarine channel: one of the many canyon systems along the margin. These canyons are the main conduits for water masses and sediment transportation from the continental shelf to the deep ocean. Long term changes in the volume and composition of the sediment accumulating at the end of this source-to-sink pathway provide insights into the vigour of bottom water production cascading down the canyons and sediment delivery by ice sheets on the continental shelf edge (Donda et al., 2003; Escutia et al., 2003). The present-day coastline of the EAIS at Wilkes Land is characterised by 20-30 $\mathrm{m}$ high marine terminating ice cliffs and is proximal to two large EAIS outlet glaciers: the Mertz and the Ninnis (Escutia et al, 2011a). These glaciers extend seaward, becoming large ice tongues that contribute to drainage and sediment delivery from the EAIS to the ocean at present day, as well as in the geological past (Escutia et al., 2005).

Site U1361 is located $200 \mathrm{~km}$ south of the modern Antarctic Circumpolar Current (ACC) southern Boundary Front (Bindoff et al., 2000b). The presence of a large polynya to the west of the Mertz Glacier is responsible for the formation of High Salinity Shelf Water (HSSW) and the upwelling of Circumpolar Deep Water (CDW) onto the continental shelf leading to highly productive surface waters. These waters ultimately sink off the continental shelf, passing down the continental rise canyon system forming Antarctic Bottom Water (AABW), acting to transport nutrients and organic carbon towards deeper environments. This location is one of the three primary regions on the Antarctic continental shelf where the AABW is formed (Bindoff et al., 2000b; Caburlotto et al., 2010). 


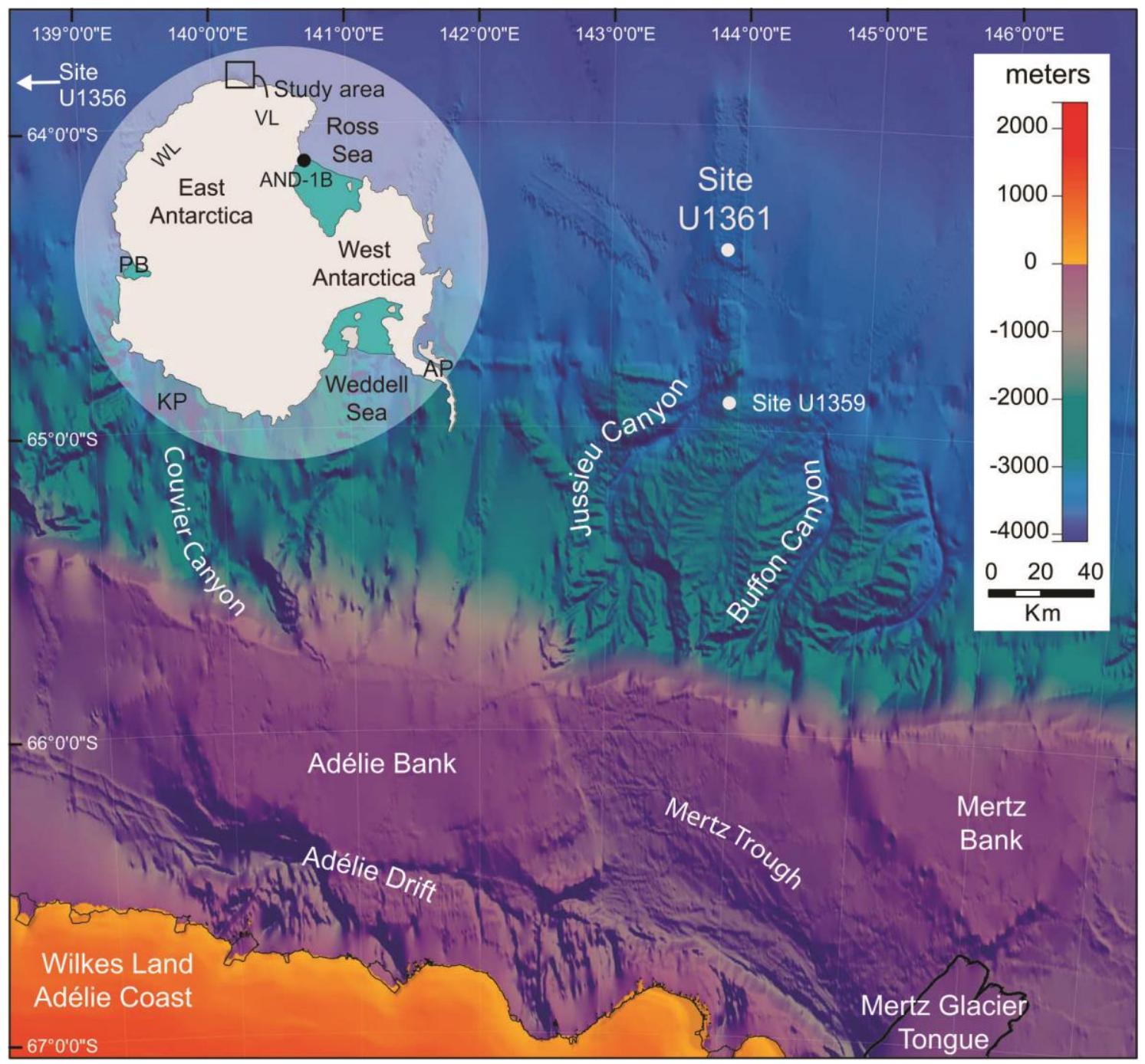

Figure 1. 2 Location of Site U1361 and bathymetry offshore Wilkes Land, East Antarctica (=EAIS). Modified from Taylor-Silva and Riesselman, (2018). Insert map provides all locations mentioned in this thesis. $K P=$ Kerguelen Plateau; PB $=$ Prydz Bay; $W L=$ Wilkes Land; $V L=$ Victoria Land; $A P=$ Antarctica Peninsula; $A N D-I B=$ Andrill Drilling Project (Ross Island). 


\subsection{THESIS AIMS AND OBJECTIVES}

The primary aim of this thesis is to assess Late Miocene ice sheet variability and sedimentary processes at Site U1361 to (a) understand the environmental conditions that led to the preservation of the anomalous nannofossil interval during the Late Miocene and (b) to determine if these intervals are associated with a major shift in ice sheet variability on the East Antarctic margin.

To achieve this overarching aim three main objectives have been outlined below and IODP sediment core U1361A recovered from the Wilkes Land continental rise was used:

1) Interpret the sedimentary processes operating during the Late Miocene on the margin of the Wilkes Land Subglacial Basin using sedimentary facies analysis to distinguish phases of turbidity current deposition and bottom water activity

2) Characterise shifts in the plankton productivity proximal to EAIS during the Late Miocene, and identify the potential leads and lags of productivity with nutrient delivery processes associated with ice sheet retreat (e.g. iceberg rafted debris and sedimentary facies) and mass water indicators (using XRF data)

3) Investigate the dynamic response of the East Antarctic Ice Sheet to orbital forcing during the Late Miocene, using an Iceberg Rafted Debris Mass Accumulation Rate (IBRD MAR) record. 


\section{CHAPTER TWO: BACKGROUND}

\subsection{ANTARCTIC ICE SHEET HISTORY - PROXIMAL AND FAR-FIELD RECORDS}

The history of the Cenozoic Antarctic Ice Sheet (AIS) has been established by using an array of proxies, many of which are obtained from regions remote to the Antarctic continent, including: the oxygen isotope composition $\left(\delta^{18} \mathrm{O}\right)$ from benthic foraminifera in deep-sea sediments, which varies with global ice volume and local water temperature (Shackleton and Kennett, 1976; Zachos et al., 2001a); and far-field sea level records (Miller et al., 2008). However, numerous marine and terrestrial sedimentary archives from proximal Antarctic margin sites have been collected, and although these records are often discontinuous they provide a direct indication of sedimentary, geochemical and biological response to changes in the volume of the AIS (Mckay et al., 2016). Through the integration of both 'far-field' and 'near-field' proxy records, an assessment can be made of the relative timing, influence and response of the AIS to global climate change over the Cenozoic. This section will discuss the various lines of evidence that have been used to determine the history of the AIS since its inferred inception near the EoceneOligocene boundary, $34 \mathrm{Ma}$ (Zachos et al., 1996), with emphasis on the Miocene epoch as it is the focus of this study.

The highest resolution and most continuous record of Cenozoic climate originated from the development of the deep sea oxygen $\left(\delta^{18} \mathrm{O}\right)$ and carbon $\left(\delta^{13} \mathrm{C}\right)$ isotope records (Shackleton and Kennett, 1976; Zachos et al., 2001a). Since its initial development, the $\delta^{18} \mathrm{O}$ record has served as a primary resource for reconstructing the AIS history on geological time scales. The deep-sea $\delta^{18} \mathrm{O}$ record is a measure of oxygen incorporated into the tests of benthic foraminifera and preserved. The lighter ${ }^{16} \mathrm{O}$ is evaporated and precipitated as ice during colder conditions, resulting in the ice sheets preferentially accumulating ${ }^{16} \mathrm{O}$ during ice sheet growth, leaving the ocean enriched in ${ }^{18} \mathrm{O}$ relative to interglacial periods. The opposite occurs during warm periods as ${ }^{16} \mathrm{O}$ enriched ice melts and flows back into the ocean, making the average ocean isotopic composition lighter (Ravelo and Hillaire-Marcel, 2007). However, a complication with using $\delta^{18} \mathrm{O}$ as a proxy for ice volume is that it is also influenced by water temperature at the time of deposition. 
Distinguishing the relative contribution of these two variables in the oxygen isotopic signature through the Cenozoic is difficult (Zachos et al., 2001a; Winnick and Caves, 2015; Gasson et al., 2016).

\subsubsection{CENOZOIC CLIMATE AND INITIATION OF THE ANTARCTIC ICE SHEETS}

Since the start of the Cenozoic Era $\sim 65 \mathrm{Myr}$ ago global climate is characterised by a global cooling trend, transitioning from a 'Greenhouse' to an 'Icehouse' world (Zachos et al., 2001a; Zachos et al., 2008). In Antarctica, the shift manifested as a change from a warm, ice-free climate with vegetation coverage (Pross et al., 2012), to the establishment of a permanent ice-covered pole (Zachos et al., 2001b; Miller et al., 2008). The change coincided with a decline in carbon dioxide $\left(\mathrm{CO}_{2}\right)$, from a high $\mathrm{CO}_{2}(<1000)$ to a low $\mathrm{CO}_{2}$ world ( 180-280 ppm; Pagani, 2011). Over the Cenozoic, $\delta^{18} \mathrm{O}$ values have increased by $\sim 5.4 \%$ o (Figure 2. 1), with $\sim 3.1 \%$ o (equivalent to $13^{\circ} \mathrm{C}$ ) estimated to represent the deepsea cooling trend, and the remaining from the development of the polar ice sheets (Antarctica $\sim 1.2 \%$ and Northern Hemisphere $\sim 1.1 \%$ ) during glacial periods (Zachos et al., 2001a; Cramer et al., 2009). The global cooling trend is punctuated by three large steps in the $\delta^{18} \mathrm{O}$ and $\delta^{13} \mathrm{C}$ records (Figure 2. 1) occurring during the: 1) Late Eocene early Oligocene (c. $34 \mathrm{Ma}$ ); 2) Miocene Climatic Transition (c. $14 \mathrm{Ma}$ ); and 3) the PlioPleistocene (c. $2.6 \mathrm{Ma})$.

Peak temperatures occurred in the early Cenozoic, with global cooling initiating during the middle Eocene, 55-48 Ma (Figure 2. 1; Zachos et al., 2001a; Pross et al., 2012). The Eocene-Oligocene Transition ( $\sim 34 \mathrm{Ma}$; EOT) is marked by a rapid $>1.5 \%$ decrease in $\delta^{18} \mathrm{O}$ (Liu et al., 2009), interpreted to represent a $\sim 4-5^{\circ} \mathrm{C}$ cooling of deep ocean temperatures, atmospheric $\mathrm{CO}_{2}$ falling below $\sim 750 \mathrm{ppm}$ (Zachos et al., 2001b), and the growth of the terrestrial EAIS in less than $\sim 400,00$ years (DeConto et al., 2008; Miller et al., 2008; Liu et al., 2009). 'Far-field' sea level records inferred the establishment of the substantial AIS resulted in a 55-70 m eustatic sea fall (Miller et al., 2008; Zachos et al., 1996). Sedimentological evidence obtained during ODP Leg 119 from Prydz Bay, East Antarctica, provided direct evidence of iceberg calving during the early Oligocene (Hambrey et al., 1991), consistent with the increase in ice-rafting on the Kerguelen Plateau (Southern Indian Ocean; Zachos, 1992). 


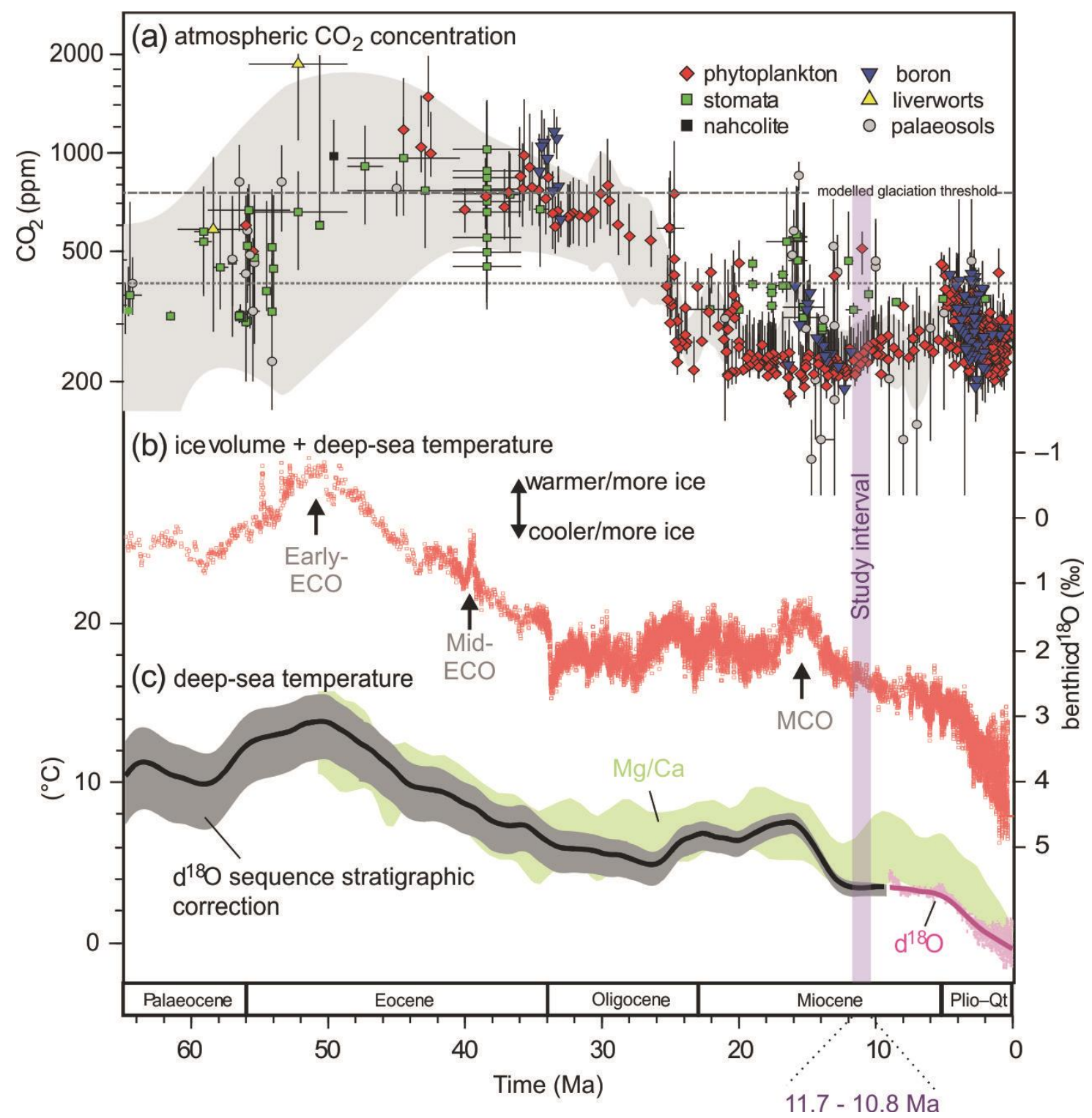

Figure 2. 1 Reconstruction of global climate for the Cenozoic (0-65 million years ago). a) atmospheric $\mathrm{CO}_{2}$ concentrations; b) composite benthic $\delta^{18} \mathrm{O}$ record representing a combined signal of global ice volume and deep-sea temperature; c) deep-sea temperatures with the removal of the ice volume component of the benthic $\delta^{18} \mathrm{O}$ and $\mathrm{Mg} / \mathrm{Ca}$ estimates of deep-sea temperatures. ECO = Eocene Climatic Optimum, MCO = Miocene Climatic Optimum. Figure modified from Mckay, et al., (2016). Purple bar illustrates the study interval for this thesis 
A rapid decline in atmospheric $\mathrm{CO}_{2}$ is strongly implicated in the evolution of the global climate over the EOT (Figure 2. 1; Pagani et al., 2011), although the driver of this carbon cycle shift is still poorly understood. A numerical model developed by DeConto and Pollard, (2003) suggests that a $\mathrm{CO}_{2}$ threshold was crossed (modelled to between $\sim 1000$ and $750 \mathrm{ppm}$ ) before the rapid expansion of ice caps took place, suggesting the relationship between atmospheric $\mathrm{CO}_{2}$ and ice sheet volume is non-linear. Once the AIS became established to a critical height, the subsequent increase in elevation meant the ice surface was sufficiently cold enough to prevent summer melt and create high albedo. This led to the initiation of a positive cooling feedback loop, allowing the rapid expansion of the EAIS without a proportionate fall in $\mathrm{CO}_{2}$ (DeConto and Pollard, 2003; DeConto et al., 2008; Pagani et al., 2011). DeConto and Pollard, (2003) also identified a two-step cooling trend, marked by two positive $\delta^{18} \mathrm{O}$ steps separated by $\sim 200,000$ years. The first was associated with a temperature decrease (Lear et al., 2008), while the second reflects the onset of a prolonged interval of maximum ice extent (Liu et al., 2009). This is consistent with proximal sedimentological evidence in the western Ross Sea, which demonstrated that the EAIS was initially restricted to its terrestrial margins, until a further drop in $\mathrm{CO}_{2}$ (below $\sim 600 \mathrm{ppm}$ ) allowed the ice sheet to stabilise and become continental in scale (Galeotti et al., 2016).

The opening of Southern Ocean gateways between South America and Antarctica (Drake Passage) and Australia and Antarctica (Tasmanian Passage) is also believed to be a significant contributor to the initiation of the AIS. The timing of gradual cooling since the Early Eocene Climatic Optimum ( $52-50 \mathrm{Ma})$ and onset of glaciation correlates to the opening of the Southern Ocean and climatic changes in the southern high latitudes (Bijl et al., 2013; Houben et al., 2013). This tectonic change is believed to have led to the reorganisation of the ACC and consequently the thermal isolation of Antarctica continent (Kennett, 1977; DeConto and Pollard, 2003; Bijl et al., 2013; Scher et al., 2015). However, there is still a disagreement as to whether the $\mathrm{CO}_{2}$ decrease alone was sufficient enough to trigger the EOT climatic conditions, or if the Southern Ocean gateways opening coincided with favourable orbital configurations, resulting in glaciation (Coxall et al., 2005; Pagani et al., 2011). 
Following the initiation of the AIS, atmospheric $\mathrm{CO}_{2}$ concentrations continued to decline ( 600-300 ppm; Pagani et al., 2011), and the AIS expanded, resulting in a sea level drop of $\sim 30-60 \mathrm{~m}$ (Miller et al., 2005). This progressive cooling led to a shift in vegetation, with the expansion of Nothofagus forests and tundra on the continent (24-23 Ma; Prebble et al., 2006; Anderson et al., 2011). The Oligocene/Miocene boundary is marked by a large transient glaciation (Mi-1 event; $\sim 23 \mathrm{Ma}$; Figure 2. 1) identified by a positive oxygen isotope shift ( $\sim 0.6-1 \%$; Kennett, 1977). This event is attributed to declining $\mathrm{CO}_{2}$, coinciding with a node in obliquity and a minimum in eccentricity, favourable conditions for ice sheet growth (Zachos et al., 2001b). An erosional hiatus in the Cape Roberts Project drill core provided the first direct evidence for major cooling and ice sheet expansion of the EAIS outlet glaciers into the western Ross Sea at 23.7 Ma (Naish et al., 2001). However, the Mi-1 event did not eradicate vegetation from the continent, with Nothofagus still present in the early Miocene, suggesting refugium must have existed during this large transient glacial event (Askin and Raine, 2000).

\subsubsection{Mid-Miocene Climatic Optimum}

The Middle Miocene Climatic Optimum (MCO; 17-14 Ma) represents a significant departure from relatively cool climates with periodic large-scale transient glaciations to an interval of prolonged global warming ( $\sim 3 \mathrm{Myr})$, with oxygen isotopes suggesting it was the warmest interval of the Neogene (Figure 2. 1; Miller et al., 1991; Zachos et al., 1992; Pälike et al., 2006; Holbourn et al., 2015; Shevenell et al., 2008; Zachos et al., 2001a). During the MCO atmospheric $\mathrm{CO}_{2}$ concentrations reached between $\sim 400-600$ ppm (Zhang et al., 2013; Levy et al., 2016), mean annual sea surface temperatures (SST) were $\sim 3-4^{\circ} \mathrm{C}$ higher than present (You et al., 2009), with $\sim 6^{\circ} \mathrm{C}$ warming in mid-latitudes (Flower and Kennett, 1994). Sedimentological, palaeontological and geochemical data from the AND-2A core indicated that these changes resulted in the AIS retreating its terrestrial margins (Levy et al., 2016) and modelling experiments suggest the volume reduced by $\sim 30-36 \mathrm{~m}$ of equivalent sea level compared to the present day (Gasson et al., 2016). Palynology and leaf wax biomarkers indicate there was increased freshwater input during the MCO (Warny et al., 2009), consistent with geomorphological and stratigraphic evidence from the Transantarctic Mountains interpreted as large meltwater channels that eroded into bedrock of the present-day ice-free Dry Valleys region, terminating between $\sim 14.4$ and 12.2 Ma (Lewis et al., 2006). 


\subsubsection{Mid-Miocene Transition}

The global climate began to cool following the MCO, signifying the onset of the Middle Miocene Climatic Transition (MCT), characterised by a stepwise $\sim 1.5 \%$ increase in benthic $\delta^{18} \mathrm{O}$ between $\sim 14.2$ to $13.8 \mathrm{Ma}$ (Figure 2. 1; Shackleton and Kennett, 1976). Paired isotope and $\mathrm{Mg} / \mathrm{Ca}$-based reconstructions reveal that $\sim 70 \%$ of the $\delta^{18} \mathrm{O}$ shift reflects an increase in the AIS volume (Shevenell et al., 2008), associated with $\mathrm{CO}_{2}$ falling below $\sim 300 \mathrm{ppm}$ (Badger et al., 2013), and a period of low obliquity and eccentricity minima (Levy et al., 2019). Mg/Ca-based estimates indicate Southern Ocean bottom waters cooled by $\sim 2^{\circ} \mathrm{C}$ and surface waters by $\sim 6-7^{\circ} \mathrm{C}$ (Shevenell et al., 2004, 2008). The growth of the AIS at the MCT has been linked to sea level lowering between 30 and $60 \mathrm{~m}$ recorded in sequence stratigraphy from low latitudes (John et al., 2011).

The MCT is interpreted to represent the development of a "permanent" EAIS (Zachos et al., 2001a; Shevenell et al., 2004), with geomorphic, stratigraphic and palaeontological evidence supporting the transition from a wet-based to cold-based style glaciation. Glacial deposits from the Olympus Range (dated by an interbedded ash-fall) indicate that the transition to cold-based glaciation was localised, representing the permanent shift to hyper-arid conditions in high elevations of the Transantarctic Mountains, equivalent to an $\sim 8^{\circ} \mathrm{C}$ local temperature drop (Lewis et al., 2007). Evidence suggests that MCT represents regional and possibly continental scale extinction of tundra plants at high elevations in the Transantarctic Mountains between $\sim 14$ and 13.8 Ma (Lewis et al., 2007, 2008). Anderson et al., (2011) inferred that pockets of tundra lasted until at least to $\sim 12.8$ Ma on the Antarctic Peninsula and went extinct no later than 5.3 Ma (Anderson et al., 2011). Unfortunately, these inferences are hindered by a lack of well-dated Late Miocene records, allowing a potential refugium to have existed through this event suggesting vegetation persisted into the Late Miocene (Sangiorgi et al., 2018) and perhaps the Pliocene (Francis and Hill, 1996). However, by 13.6 Ma the ice sheet retreated in-land, and the EAIS recorded dimensions similar to the present day (Sugden and Denton, 2004; Wilson et al., 2012).

\subsubsection{LATE MiOCENE - WAS THE EAIS DYNAMIC OR STABLE?}

The nature of EAIS variability and Antarctic climate evolution following the MCT has long been a topic of great uncertainty, with two opposing views dominating scientific 
discussions since the 1980s. One view held is that the EAIS has been stable for the last 14 Myr (Sugden et al., 1993), with the opposing view being that the ice sheet was significantly reduced in periods as recently as $\sim 3 \mathrm{Myr}$ (Webb et al., 1984; Barrett, 2013). The presence of Pliocene marine diatoms in the Sirius Group, a series of wet-based glaciogenic deposits in the Transantarctic Mountains, led to a hypothesis that the EAIS was significantly smaller than present during the Pliocene. Webb (1984) proposed that the Pliocene diatoms were sourced from sediments deposited during periods of open water $\sim 3$ Myr ago in the WSB. These sediments were subsequently eroded and redeposited by the expansion of the EAIS across the WSB and Transantarctic Mountains. However, this was contradicted by geomorphic evidence and tephrochronology from the McMurdo Dry Valleys with minimal slope erosion since $\sim 11.3$ Ma (Marchant et al., 1996a), and the preservation of cold-based glacial till suggests a hyper-arid polar climate at high elevations since 14 Ma (Marchant and Denton, 1996). Recent observations of superficial regolith in the Transantarctic Mountains interpreted that diatoms in the Sirius Group were emplaced post-deposition by aeolian processes. Interpreted to be sourced from marine sediments in the Ross Embayment, exposed when the Ross Ice Shelf retreated during the Pliocene (McKay et al., 2008).

However, it has been demonstrated that the marine margin of the EAIS may have retreated in the past $\sim 14 \mathrm{Ma}$ (T. Williams et al., 2010; Cook et al., 2013; Patterson et al., 2014), while still maintaining a stable polar climate at higher elevations in the Transantarctic Mountains (Marchant et al., 1996a). The sedimentary facies in the Late Miocene interval of AND-1B are indicative of increased subglacial meltwater, and terrigenous sediment supply from the Ross Embayment and EAIS outlet glaciers. The transition from diatomite to mud-rich deposits during glacial minima suggest a significantly warmer glacial regime, whereby the climate was warm enough to create surface melt on the EAIS and significant meltwater runoff from lower elevated margins during the Late Miocene (McKay et al., 2009). Similar meltwater glacial facies appear to outcrop in Prydz Bay (Hambrey and McKelvey, 2000a, 2000b), while seismic stratigraphies and sediment cores offshore of the Totten Glacier region of East Antarctica also indicate significant glacial outwash deposits during this time (Gulick et al., 2017). Unfortunately, the relative contribution of ice volume and temperature to the $\delta^{18} \mathrm{O}$ record is difficult to constrain during the Late Miocene, due to the lack of continuous records. 
However, $\delta^{18} \mathrm{O}$ values continued to trend toward higher values over the Late Miocene, although between $\sim 12.9$ and $8.4 \mathrm{Ma} \delta^{18} \mathrm{O}$ variability is inferred to be responding to a dynamic EAIS margin.

Iceberg rafted debris (IBRD) records from three locations around Antarctica provide supporting evidence of a dynamic EAIS during the Late Miocene. Site U1356 (Wilkes Land, cored during Expedition 318) identified at least three pulses ( 14.1, 13.8 and 10.8 $\mathrm{Ma}$ ) of IBRD, although poor recovery prevents the identification of further IBRD pulses. Regardless, these pulses combined with seismic stratigraphy suggest EAIS glaciers were marine terminating, expanding to near the edge of the continental shelf during the Late Miocene. This was a dramatic increase from the $\mathrm{MCO}$, where there was a general lack of IBRD at this site (Sangiorgi et al., 2018). Geochemical provenance analysis of an IBRD record at Prydz Bay identified massive discharge of icebergs at $\sim 7$ Ma from Wilkes Land and the Adélie Coast located $\sim 1500-3000 \mathrm{~km}$ away (T. Williams et al., 2010; Cook et al., 2014), reflecting destabilisation along the margin. Maximum accumulation of IBRD at the Kerguelen Plateau after $\sim 6 \mathrm{Ma}$, suggests that the Lambert Glacier/Amery Ice Shelf were larger than at present for a short- interval (Joseph et al., 2002). However, these records are discontinuous, either due to intervals of poor core recovery or depositional hiatuses, and the sparse number of Late Miocene records, makes it difficult to correlate between events.

\subsubsection{Pliocene CLIMATE AND ICE SHEET STYLE}

Gradual cooling since the MCT was terminated during the Pliocene (5.3-2.6 Ma), with the average global temperature $\sim 2-3^{\circ} \mathrm{C}$ warmer than present-day during the mid-Pliocene (Haywood and Valdes, 2004) and atmospheric $\mathrm{CO}_{2}$ concentrations ranging between 250-450 ppm (Seki et al., 2010; Figure 2. 1). The Pliocene marks the most recent time that Earth was significantly warmer than today and therefore is often studied as an analogue for the climate anticipated by the end of the century (IPCC, 2014). As discussed above, the extent of EAIS variability is hotly debated, however, recent geochemical provenance work offshore from the WSB identified active erosion of subglacial bedrock, now several kilometres inland. This inferred that the actively eroding margin of the EAIS must have retreated significantly inland during the warmth of the Pliocene (Cook et al., 2013). This was consistent with sedimentological studies offshore Wilkes Land, where 
peaks in IBRD and marine productivity (i.e. diatom) represent the increase in calving and inland retreat of the margin (Patterson et al., 2014; Bertram et al., 2018). The AND-1B core provided the first direct evidence that the WAIS extent oscillated at $40 \mathrm{kyr}$ periods through the mid-Pliocene and that between $\sim 3.3$ and $2.5 \mathrm{Ma}$ a SST cooling of $\sim 2-3^{\circ} \mathrm{C}$ is combined with a drawdown of $\mathrm{CO}_{2}(\sim 400$ to $280 \mathrm{ppm})$ allowed the further expansion of the WAIS and development of seasonal sea ice (Naish et al., 2009). This cooling trend in Antarctica is hypothesised to have led to numerous changes to Southern Ocean surface and deep water circulation, that in turn affected heat transportation between major ocean basins (e.g. Pacific, Atlantic and Indian Ocean) and contributed to the intensification of Northern Hemisphere glaciation at 2.7 Ma (McKay et al., 2012; Woodard et al., 2014).

\subsection{GLOBAL PROdUCTIVITY DURING THE LATE Miocene}

The Late Miocene is characterised by a notable shift in the benthic foraminifera $\delta^{13} \mathrm{C}$ gradient between the Pacific and Atlantic Ocean basins (Zachos et al., 2001a; Herbert et al., 2016). A recent alkenone-based SST reconstruction shows this shift coincided with the increasing equator-pole temperature gradient in both hemispheres between $\sim 12$ to 7 Ma (Herbert et al., 2016; Figure 2. 2). The shift also corresponds with a large-scale turnover in terrestrial vegetation and the expansion of grasses that utilize the $\mathrm{C}_{4}$ photosynthesizing pathway (Figure 2. 2; Cerling et al., 1997; Herbert et al., 2016). The environmental parameters leading to use of $\mathrm{C}_{4}$ rather than the $\mathrm{C}_{3}$ photosynthesizing pathways is associated to a decline in atmospheric $\mathrm{CO}_{2}$. It is recorded that a threshold of $\sim 500$ ppm triggers this change (Cerling et al., 1997), although other studies suggest increased aridity and seasonality is a more significant control (Shen et al., 2018). The threshold of $\sim 500 \mathrm{ppm}$ atmospheric $\mathrm{CO}_{2}$ is interpreted to have been breached during the Oligocene, yet updated evidence suggests that $\mathrm{C}_{4}$ grasses did not expand globally until the Late Miocene (Pagani et al., 1999; Herbert et al., 2016). Unfortunately, there is a relative lack of reliable $\mathrm{CO}_{2}$ records that document such a decrease in $\mathrm{CO}_{2}$ during the Late Miocene, although, Herbert et al., (2016) did infer the shift to $\mathrm{C}_{4}$ pathways was the likely a consequence of a decline in Late Miocene atmospheric $\mathrm{CO}_{2}$ (Figure 2. 2). This is supported by a recent coccolith study in the North Atlantic documenting a significant decrease in calcification between $\sim 6$ and $4 \mathrm{Ma}$, with production dependent on low $\mathrm{pH}$ and 
high $\mathrm{CO}_{2}$ conditions (Bolton et al., 2016). However, obtaining a fuller picture of EAIS and Southern Ocean dynamics would help understand the possible role of global acidification at high latitude during this major shift in the global carbon cycle.

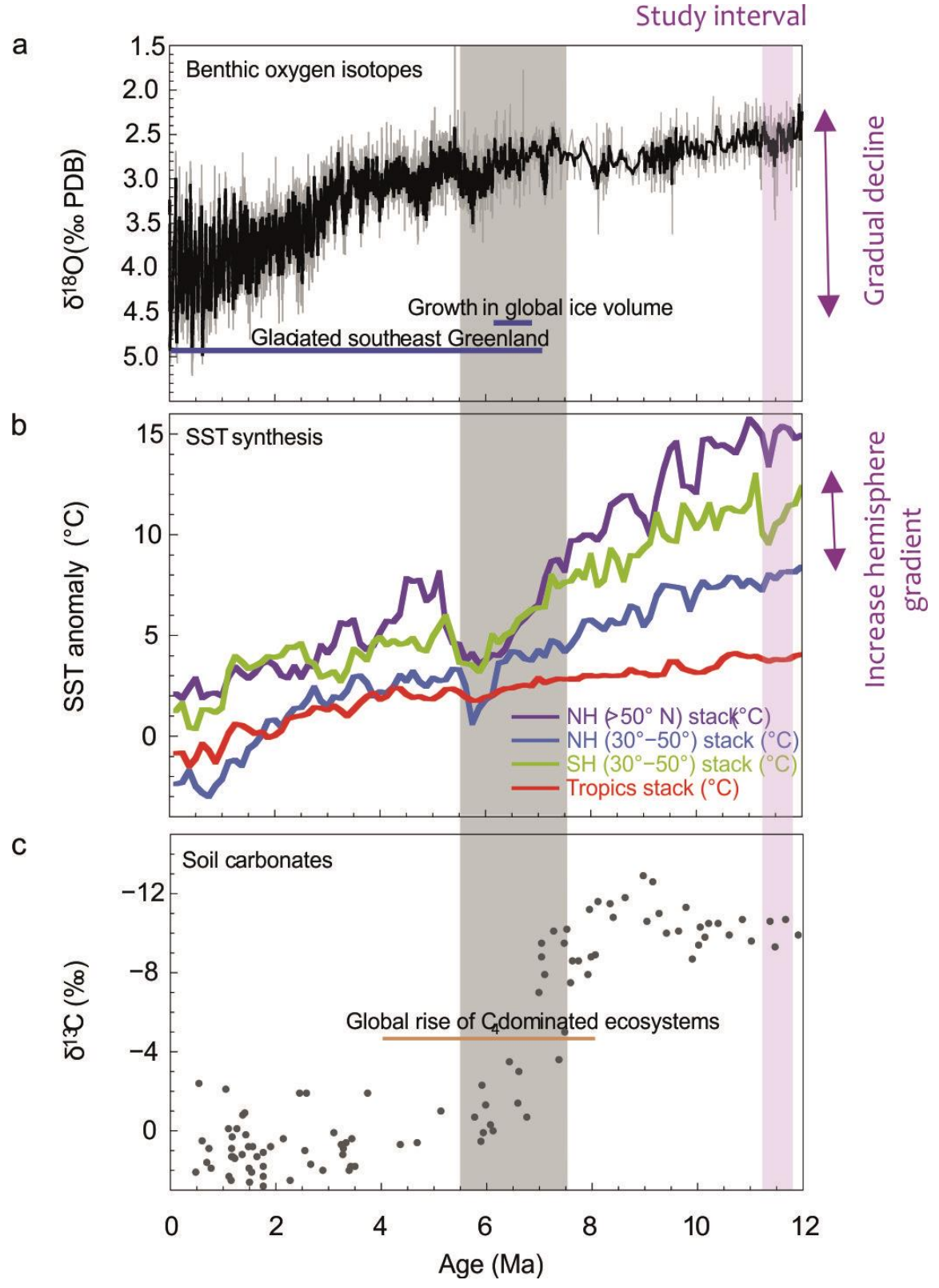

Figure 2. 2 Climate and carbon cycle changes from Late Miocene to present a) benthic $\delta^{18} O$ composite; b) sea surface temperature anomaly (SST); and c) soil $\delta^{13} \mathrm{C}$ data, an indication of $\mathrm{C}_{4}$ grass expansion. Modified from Herbert, et al., (2016), to highlight the gradual cooling and temperature gradient changes. Purple bar identifies study interval ( 11.7 to $10.8 \mathrm{Ma})$. 
Diatoms preserved in geological records along the Antarctic margin can help express long-term $\mathrm{CO}_{2}$ patterns and rates of turnover since the Middle Miocene (Lazarus, 2014). Diatoms are the dominant phytoplankton group in the Southern Ocean generating $\sim 20 \%$ of global primary productivity and are a fundamental component of the carbon cycle (Armbrust, 2009; Lazarus et al., 2014). Using quantitative bio-stratigraphic methods, Crampton et al., (2016) identified five distinctive biological turn over pulses in the Southern Ocean for the last 15 Myrs (termed turnover Pulses A-E; Figure 2. 3). The episodes of species turnover (origination rate plus extinction rate), are defined by a turnover rate exceeding 0.5 species lineage-million-year (lmy). Turnover pulses A and $\mathrm{B}$ are consistent with cooling steps of the MCT during positive excursions of $\delta^{13} \mathrm{C}$, while $\mathrm{C}$ through $\mathrm{E}$ can be linked to high latitude cooling and increased sea ice formation in the Southern Ocean during over the past 5 Myr.

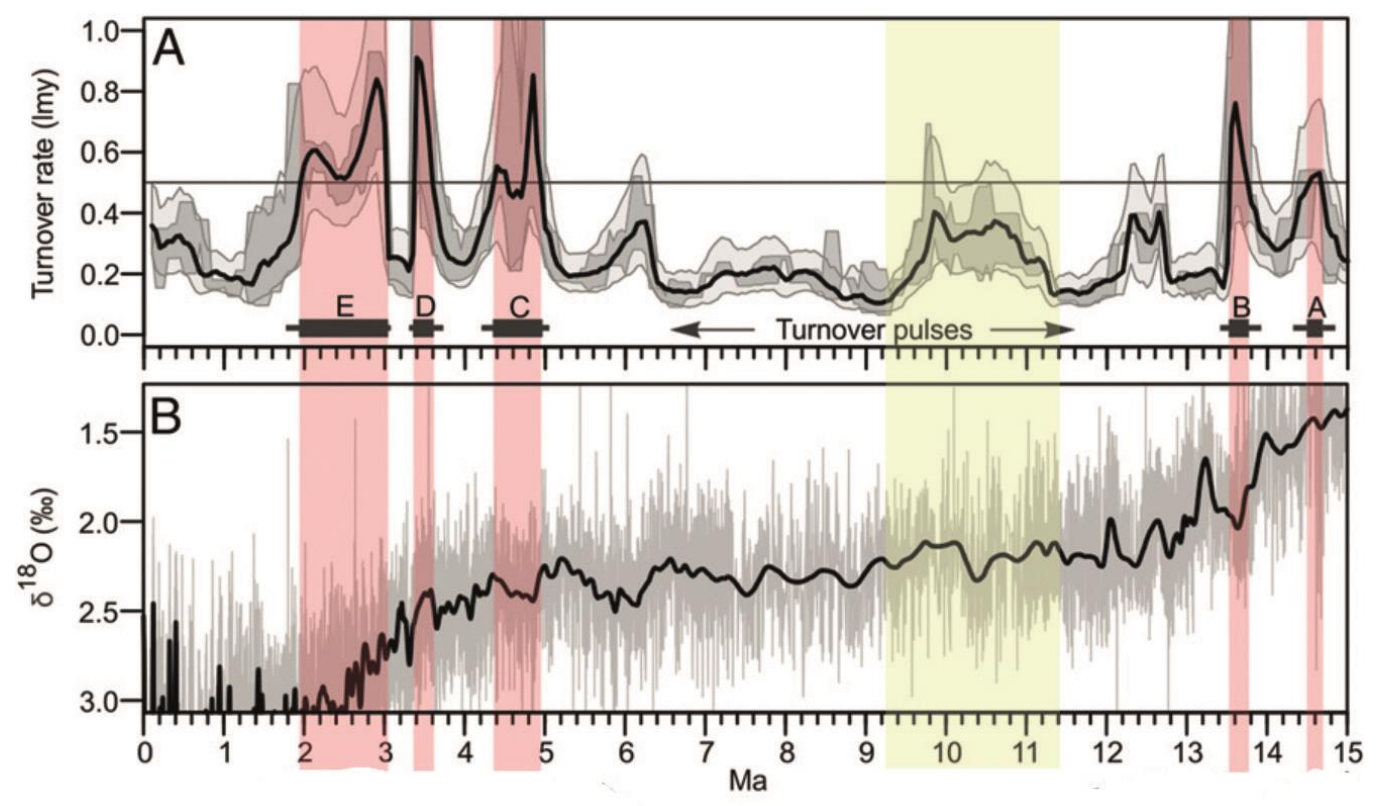

Figure 2. 3 Turnover pulses of diatoms in the Southern Ocean and Antarctic margin over the last $15 \mathrm{Ma}$; A) Species turnover pulses (refer to text explanation); B) Benthic $\delta^{18} \mathrm{O}$ curve. Pink bars =Five major turnover pulses. Yellow bar= undefined pulse that spans the study interval. Modified from Crampton, et al., (2016). 
It was proposed that the turnover pulses occur at the termination of warm periods, when the increased extent of sea ice restricts the open ocean habitat south of the Antarctic Polar Front, driving diatoms to regional or global extinction, allowing new species to occupy ice-dominated environmental niches (Crampton et al., 2016). Interestingly, there is a well-defined turnover event during the study interval $11.5-9.5 \mathrm{Ma}$ (Figure 2. 3; yellow shading). Although it is smaller in magnitude ( $0.4 \mathrm{lmy})$, it is prolonged compared to pulses A through to E. The mechanism that drove this event is unconstrained, and the benthic $\delta^{18} \mathrm{O}$ record does not indicate any significant excursions over this interval (Figure 2. 3; Cramer et al., 2009). However, the timing of this turnover pulse appears to correlate to the series of anomalous nannofossil deposited at Site U1361, which forms the focus of this thesis, suggesting that this event may have affected other planktonic systems in the Southern Ocean, beyond diatom flora.

\subsection{INTERNAL DRIVERS OF CLIMATE CHANGE}

\subsubsection{ORBITAL CYCLES}

Periodic changes in the Earth's orbit and rotation; known as the Milankovitch cycles, play a central role in pacing glacial-interglacial variability (Hays, Imbrie and Shackleton, 1976). Eccentricity refers to the shape of the Earth's orbit around the sun (Figure 2. 4), varying between a more circular (low eccentricity) and a more elliptical (high eccentricity) orbit, at a cycle of $\sim 100 \mathrm{kyr}$ (Berger and Loutre, 1991; Laskar et al., 2004). It influences when seasons occur relative to perihelion (nearest to the Sun) and aphelion (farthest from the Sun; Huybers, 2006).

Precession refers to the wobble of the axis of rotation $(23 \mathrm{ky})$ and the rotation of the elliptical orbital of the earth (19 ky) which averages to a period of $\sim 21 \mathrm{kyr}$ (Figure 2. 4). Precession alters the timing of the seasons relative to the location on the orbital pathway, which in turn controls the intensity and duration of the seasons. The amplitude of precession cycles is modulated by eccentricity, as during a more eccentric orbits (i.e. more elliptical), the greater the climatic effects of precession will be and vice versa (Ruddiman, 2001). 
Obliquity is the change in the axial tilt relative to the axis of rotation, varying between $22.1^{\circ}$ and $24.5^{\circ}$, at a dominant frequency of $41 \mathrm{kyr}$ (Figure 2. 4; Berger and Loutre, 1991; Laskar et al., 2004) Tilt controls the latitudinal distribution of insolation, with effects stronger in high-latitude polar regions. Obliquity plays an important role in the polarequator temperature gradient, as a higher angle of tilt will increase the seasonal contrast e.g. winters will be colder, and summers will be hotter in both hemispheres.

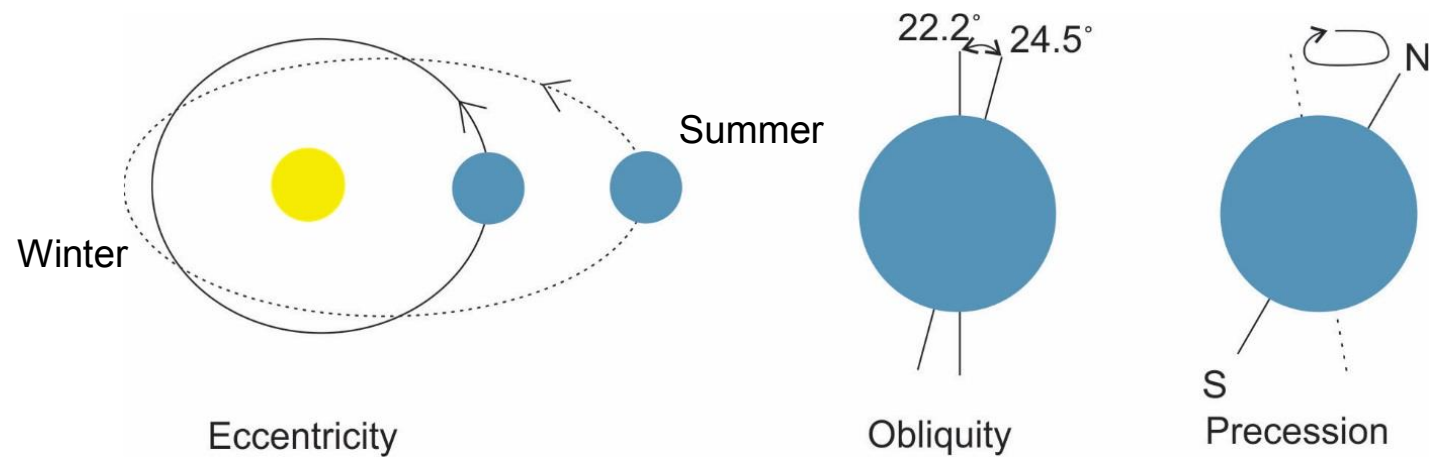

Figure 2. 4 Schematic showing the three orbital parameters; a) eccentricity b) obliquity c) precession. Figure was redrawn from (Zachos et al., 2001a)

\subsubsection{MilankovitCH THEORY OF THE ICE AgES}

In the 1930s, Milutin Milankovitch proposed that glaciation occurs during periods of low obliquity and summer coinciding with aphelion, stating that the magnitude of summer insolation was the primary control on climate and critical for growth/ decay of Northern Hemisphere ice sheets (Milankovitch, 1941). Milankovitch argued that during weak summer insolation (i.e. reduced summer temperatures), snow and ice can persist throughout the year leading to the formation of ice sheets (Milankovitch, 1941; Ruddiman, 2001). The opposite occurring during strong summer insolation, as increased temperatures will accelerate ablation, melting winter snowfall reducing pre-existing ice sheets or preventing glaciation.

Hays et al., (1976) established the first statistical correlation between astronomical forcing and the $\delta^{18} \mathrm{O}$ records. It was concluded that in the past 500,000 years variations in $\delta^{18} \mathrm{O}$ corresponded to $100 \mathrm{kyr}$ (eccentricity), $41 \mathrm{kyr}$ (obliquity) and $21 \mathrm{kyr}$ (precession) frequencies, related to the predicted frequency changes expected if insolation was driving Northern Hemisphere summer ice sheet extent. Whilst Milankovitch theory predicted the frequency of change (Milankovitch, 1941), two additional factors were evident in the 
$\delta^{18} \mathrm{O}$ record. First, ice sheets behave in an asymmetrical fashion (unlike insolation), taking $\sim 90,000$ years to grow but only $\sim 10,000$ years to collapse, at a dominant frequency of $100 \mathrm{kyr}$ (eccentricity). Secondly, eccentricity has the weakest influence on solar insolation compared to the other Milankovitch cycles. Thus, the dominance of the 100 kyr cycle in the amplitude spectra demonstrated a highly non-linear response of the climate system to eccentricity driven insolation changes (Hays et al., 1976).

\subsubsection{MILANKOVITCH CYCLES- THE PRE-100 KYR WORLD}

A shift in the frequency of the ice ages occurred during the Mid-Pleistocene Transition (MPT; 1.2-0.8 Ma), and although the mechanism which caused of this event remains debated, several studies point to the role of AIS expansion and the dynamics of the Southern Ocean carbon cycle in driving this switch (Raymo et al., 2006; Elderfield et al., 2012; Hasenfratz et al., 2019). Regardless of the mechanisms for the MPT, the Pliocene to early Pleistocene ( 1-3 Ma) was a period of more linear response of Glacialinterglacial (G-I) cycles to orbital forcing, as G-I cycles lasted $\sim 41$ kyrs and were more symmetrical in shape (Laskar et al., 2004). However, outstanding problems with Milankovitch theory remain during this period, as the $\delta^{18} \mathrm{O}$ record varies at a dominant $41 \mathrm{kyr}$ frequency and the precession signal (23 kyr) is less significant.

Huybers, (2006) hypothesized that the direct influence of precession on mass balance is reduced under certain boundary conditions, suggesting that ice-sheets are more sensitive to insolation integrated over the duration of summer, rather than intensity of summer insolation, varying primarily on $\sim 40 \mathrm{kyr}$ obliquity frequencies. Proposing that given a lower melt threshold scenario, the duration of summer melt becomes increasingly more sensitive to obliquity. A 'summer day' is defined when insolation exceeds a melt threshold that may result in a positive degree day (presently $\sim 275 \mathrm{~W} / \mathrm{m}^{2}$ for latitudes between $40-60^{\circ} \mathrm{N}$; Huybers, 2006). This is also dependent on the background climate state as an increase in atmospheric $\mathrm{CO}_{2}$ will increase the number of melt days received for the same amount of insolation (i.e. a lower melt threshold value).

An alternative hypothesis was proposed by Raymo, Lisiecki and Nisancioglu in 2006, who suggested that variations of the EAIS terrestrial margin responded directly to local summer insolation intensity, controlled by both orbital precession (23 kyr) and obliquity 
(41 kyr). Despite precession playing a role in ice volume variation, the lack of the $\sim 21$ kyr cycle in the $\delta^{18} \mathrm{O}$ record may be the result of out of phase ice sheet growth between the poles (Raymo et al., 2006). As a result, the growth of an ice sheet in one hemisphere is cancelled by melt in the other. Since precession is out of phase between hemispheres, and obliquity is not, obliquity dominates the globally integrated signal $\delta^{18} \mathrm{O}$. It was argued that the differences in $\delta^{18} \mathrm{O}$ between ice sheets in different hemispheres is related to the fact that a small change in AIS volume would mask a much larger increase/decrease in the Northern Hemisphere processional signal (Raymo and Huybers, 2008).

Patterson et al., (2014) tested these hypotheses by developing an orbital scale record of IBRD at the EAIS margin in Wilkes Land, and recorded a switch from obliquity to eccentricity/precession dominance after $\sim 3.5 \mathrm{Ma}$. It was proposed this was due to an increase in the insolation melt threshold response for perennial sea ice after $\sim 3.3 \mathrm{Ma}$, leading to an increase modulated by precession (in the same way Huybers, (2006) proposed for ice sheet mass balance). Sea ice is a critical mass balance control for marine based ice sheets, as it acts to reduce upwelling of warm water that promotes marine ice sheet retreat (Patterson et al., 2014; Levy et al., 2019). As upwelling is driven by zonal wind-driven currents, which is forced by obliquity-paced changes in latitudinal temperature gradients (Naish et al., 2009). It was proposed by Patterson et al., (2014) that increased precession modulated sea ice coverage at 3.5-3.0 Ma reduced this obliquity influence. The section of drill core described in the thesis is older (Late Miocene) than the focus of the conceptual models discussed above, the direct records of glacial variability in each hemisphere under a range of climate boundary conditions will contribute to further testing of these models, and models proposed further back in geology time (e.g. (Levy et al., 2019, discussed below)

\subsubsection{ORbITAL PATtERnS DEEP SEA RECORdS DURING THE LATE Miocene}

The $\delta^{18} \mathrm{O}$ record at ODP Site 1146 (South China Sea) shows high-latitude cooling behaving in a step-like fashion, but with intense warming between $\sim 10.8-10.7$ Ma during a period of high amplitude $\sim 100 \mathrm{kyr}$ (eccentricity; Holbourn et al., 2013). A similar cooling trend was identified in the $\delta^{18} \mathrm{O}$ record at ODP Site 1085 (southwest African continental margin), with a shift to a less variable $\delta^{18} \mathrm{O}$ after $\sim 10.8 \mathrm{Ma}$. This $\delta^{18} \mathrm{O}$ record also exhibits strong 400 and $100 \mathrm{kyr}$ bands, suggesting eccentricity driven AIS variability. 
A recent assessment of frequency and amplitude variability in a global $\delta^{18} \mathrm{O}$ stacked record from 34 Ma to present (De Vleeschouwer et al., 2017) was undertaken by Levy et al., (2019). They defined a parameter of obliquity sensitivity based on the obliquity variance in the $\delta^{18} \mathrm{O}$ record relative to the variance in the theoretically obliquity solution from (Laskar et al., 2004). This could further be related to presence of terrestrial versus marine terminating ice sheets, with the mass balance of these styles controlled by different forcings. Obliquity sensitivity peaks during geological evidence of marine-based ice sheets in the Ross Seas, including during the MCT ( $14 \mathrm{Ma})$, leading Levy et al., (2019) to hypothesize that obliquity sensitivity increases when AIS outlet glaciers extend into marine environments. This model characterises the Late Miocene by low obliquity sensitivity, interpreted to reflect a colder climate and increased sea ice cover, reducing the oceanic influence on the ice sheet (Levy et al., 2019). Regardless of exact mechanisms, this assessment demonstrates that astronomical forcings play a significant role on benthic $\delta^{18} \mathrm{O}$ variability, and thus on global ice volume and climate during the Late Miocene, and the frequency response of the AIS to orbital forcing has varied throughout the Neogene.

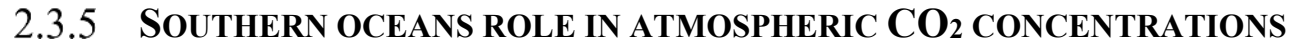

The ocean covers over $70 \%$ of the earth's surface and is the largest dynamic carbon reservoir. Globally, the oceans absorb about $2 \mathrm{Pg} \mathrm{C} \mathrm{yr}^{-1}$ (petagram of carbon yearly), equivalent to $\sim 2$ billion tons in the form of $\mathrm{CO}_{2}$ gas annually. The Southern Ocean south of $60{ }^{\circ} \mathrm{S}$ up takes about $1 \mathrm{Pg} \mathrm{C} \mathrm{yr}^{-1}$, thus playing a crucial role in the long-term storage of $\mathrm{CO}_{2}$ and regulates $\mathrm{CO}_{2}$ levels on G-I timescales (Takahashi et al., 2012). Evidence suggests stronger upwelling of deep water vents $\mathrm{CO}_{2}$ back into the atmosphere during interglacials (Lüthi et al., 2008) with the opposite is recorded during glacial periods (e.g. $\mathrm{CO}_{2}$ varies between $\sim 180$ and 280 ppm over the late Pleistocene G-I cycles) (Anderson and Burckle, 2009; Rintoul, 2018).

Three processes drive the transport of carbon to depth; the solubility pump (SP), the biological pump (BP); and the carbonate counter pump. The removal of dissolved $\mathrm{CO}_{2}$ at the surface is partitioned towards the deep sea by the first two methods (SP and BP). The SP operates due to cold water having the ability to absorb more $\mathrm{CO}_{2}$ and easily sink compared to warmer water (Nodder and Boyd, 2001). Through ventilation and upwelling, these waters are transported through the oceans eventually returning the ocean surface 
hundreds to thousands of years later. The BP relies on phytoplankton to take up dissolved $\mathrm{CO}_{2}$ during photosynthesis, converting it to organic carbon (Figure 2. 5; Chisholm, 2000). The majority of the organic carbon is converted back to dissolved inorganic carbon through consumption or dissolution, as only a small portion (10-30\%) of the converted organic carbon reaches the deep sea, where it accumulates in bottom waters and sediments (Nodder and Boyd, 2001; Watson et al., 2006; Sigman, et al., 2010). The carbonate counter pump results in the production and transportation of $\mathrm{CaCO}_{3}$ to great depths. On geological time scales, the export and burial of $\mathrm{CaCO}_{3}$ is a significant control on the exchange of $\mathrm{CO}_{2}$ between the atmosphere, playing a critical role in amplifying the effects of insolation on global climate (Falkowski et al., 2000; Rost and Riebesell, 2004).

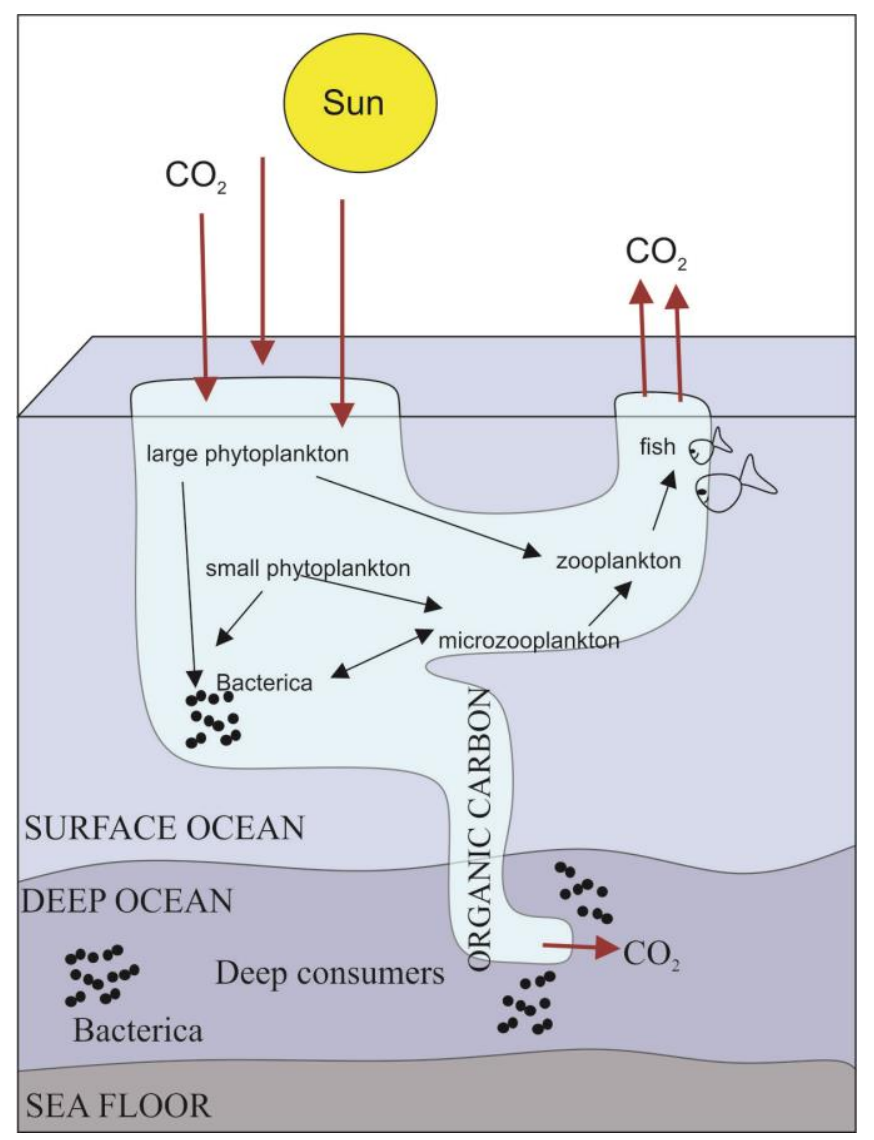

Figure 2. 5 Illustration of the biological pump (BP). Phytoplankton convert $\mathrm{CO}_{2}$ to organic carbon through photosynthesis, to either be 1) converted by to $\mathrm{CO}_{2}$ or 2) settled in the deep sea. This figure was adopted and modified from Chisholm, (2000). 
At the Wilkes Land margin, the production of dense waters forming the Antarctic Bottom Water (AABW) (refer to section 3.3 for more detail) act as an important process for the long-term storage of $\mathrm{CO}_{2}$ in the region. A study by Takahashi and Chipman, (2012) demonstrated that at present the surface waters proximal to the Wilkes Land margin have low partial pressure of $\mathrm{CO}_{2}$ and silica content, allowing the uptake of atmospheric $\mathrm{CO}_{2}$. However, these surface waters are not dense enough to reach the deep ocean alone and are mixed into the larger $\mathrm{AABW}$ body. This process constitutes the pathway of atmospheric $\mathrm{CO}_{2}$ transportation to the deepest sections of the AABW and abyssal ocean (Ruddiman, 2006).

\subsection{SEDIMENTATION ON GLACIATED MARGINS}

In high-latitude continental glaciated margins water masses and their circulation are strongly influenced by ice sheet growth and retreat, which ultimately affects sediment transport process, pathways and deposition in deep marine environments (Drewry and Cooper, 1981). The primary sources and processes of sedimentation can be separated in three main groups (Figure 2. 6); 1) pelagic/hemipelagic rain; 2) the redistribution of sediment from the seafloor by contour and/or turbidity currents and; 3) iceberg rafted debris. Contourites, turbidites and pelagites represent extremes in a continuum of deepsea sedimentary facies, as the settling of pelagic particles characterize the background processes (dominant in abyssal depths), usually superimposed by high-energy density flows or bottom water activity (Stow and Piper, 1984; Rebesco et al., 2014) Facies analysis can be used to distinguish between these three depositional processes and provides an important tool for understanding past oceanographic change. 


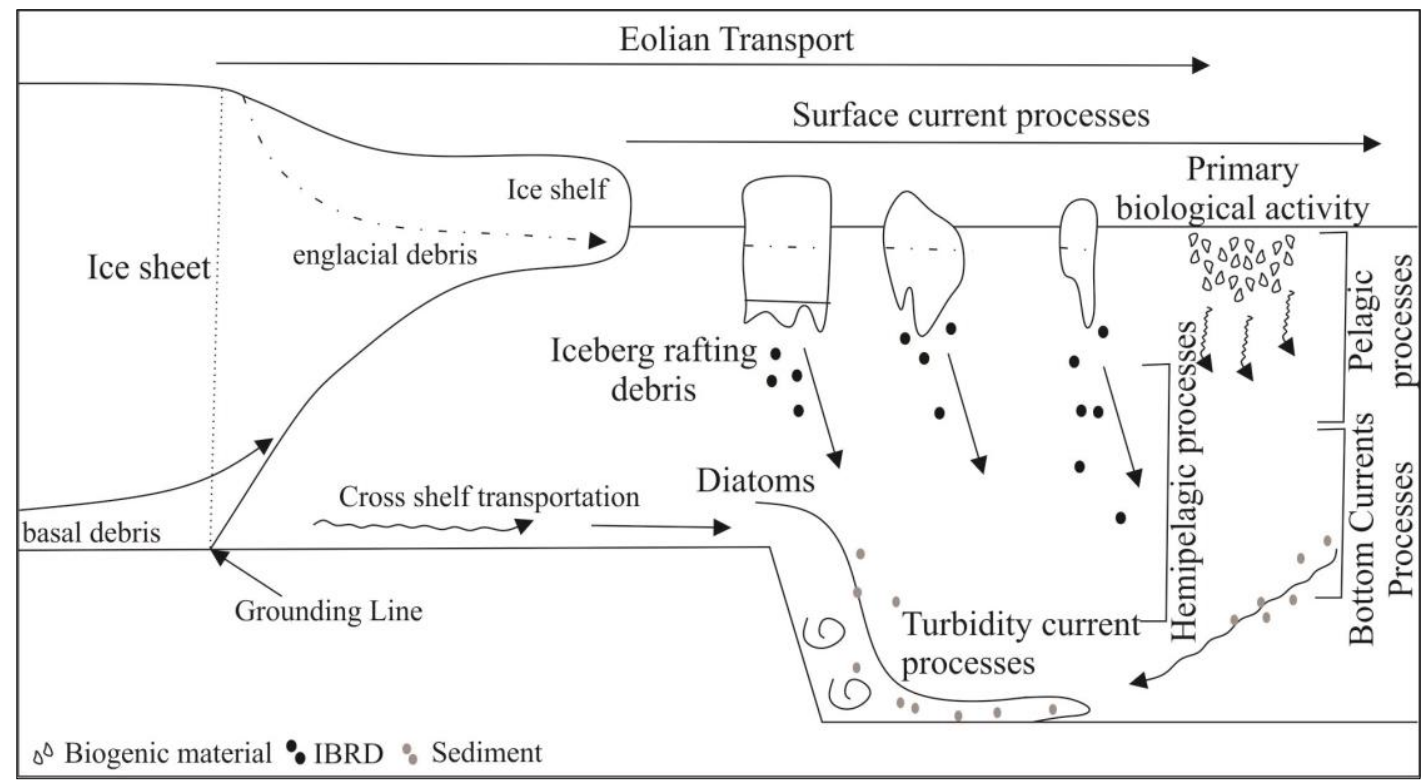

Figure 2. 6 Cartoon of glaciomarine sedimentation processes; turbidity currents, bottom water currents, hemipelagic/pelagic settling and IBRD. Adopted and modified from Drewry \& Cooper, (1981) and Boggs, (2006).

\subsubsection{TURBIDITY CURRENTS}

Turbidity currents are downslope density flows (Figure 2. 6), formed by the contrast in density between the turbid suspension of sediment and the surrounding water, with turbulence acting as the supporting mechanism for flow (Lowe, 1982; Middleton, 1993). Muddy dense water moves as a surge or uniform flows accelerating downslope, with the eroded and entrained sediment remaining in suspension until either the density contrast is lost or transportation ceases (Boggs, 2006; Talling et al., 2012). Turbidity currents are usually generated on the outer shelf or upper slope and act to transport sediment to the continental rise and abyssal plain (Shanmugam, 2008). Antarctic studies have suggested such currents originate from slope failure caused by sediment discharge at the glacier termini (Drewry and Cooper, 1981), and density-driven water flows from vigorous phases of bottom water production (Budillon et al., 2002). At the Wilkes Land margin, stratigraphic and seismic evidence suggests that in the past turbidity currents transported sediment from the outer shelf to the continental rise forming the channel levee system, that Site U1361 is located upon (Escutia et al., 2003; see Chapter 3 for site specific considerations). 
Turbidites are the sediment deposited by turbidity currents. The Bouma sequence represents the ideal facies assemblage, through five structural units interpreted to represent variations in current strength and flow regimes (Bouma, 1964; Figure 2. 7). However, the geological record rarely provides the 'perfect' turbidity deposit, and more often only base-cut-out and top-cut-out sequences are recovered (Stow and Piper, 1984). Fine-grained turbidite deposits are dominated by silt and clay sized grains, in thin ( $\mathrm{mm}$ ) to thick $(\mathrm{m})$ beds. Turbidites are generally characterised by a laminae and beds containing sharp lower bases, that fine upwards into a gradational upper contact and contains sedimentary structures and features that are foreign to the depositional environment (Stow and Piper, 1984). Non-erosive turbidite deposition occurs as an overbank spill on channel levees, whereby a mud-rich turbidity sequence is preserved, as the majority of the sand sized fraction is deposited in the channel system (Piper and Normark, 1983). This is consistent with the base-cut-out turbidite facies model developed in Stow and Piper, (1984).

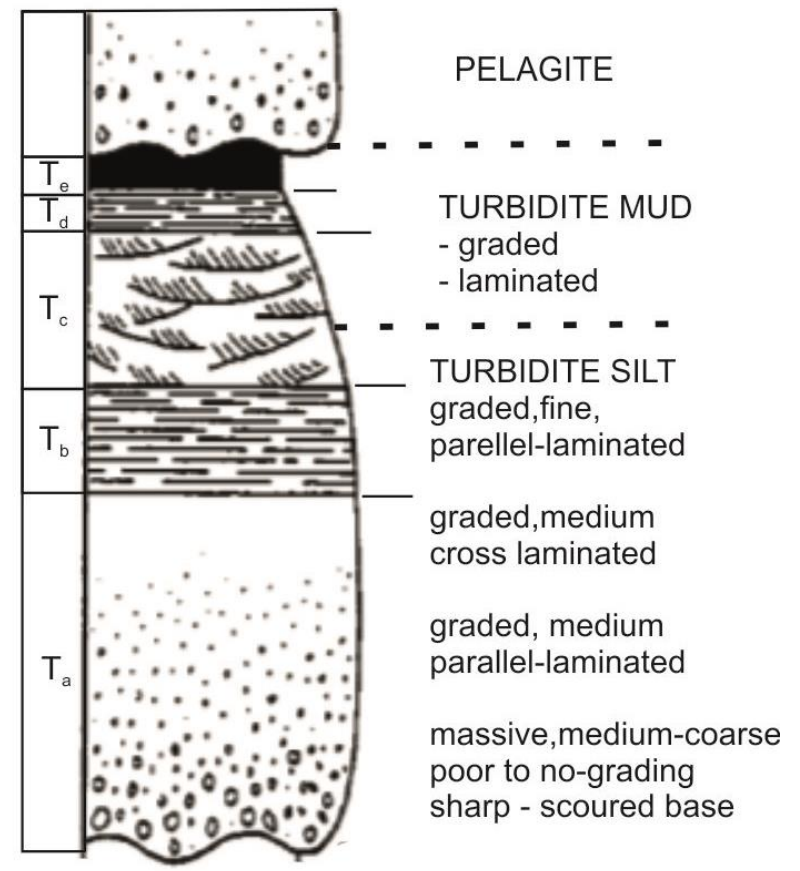

Figure 2. 7 The classic Bouma turbidite sequence (Bouma, 1964). The text has been retyped to make legible. 


\subsubsection{BOTTOM CURRENTS}

Bottom currents flow parallel to the continental margin following bathymetric contours, driven by thermohaline circulation, wind, wave and tidal forces. Bottom currents move sediment alongslope, and/or along submarine canyons. Transportation occurs primarily by traction (along the seafloor) entraining both fine grained and organic material (Shanmugam, 2000, 2008). This process commonly results in well-sorted sediment, due to the reworking behaviour and the windowing of the finer grained material (Rebesco et al., 2014).

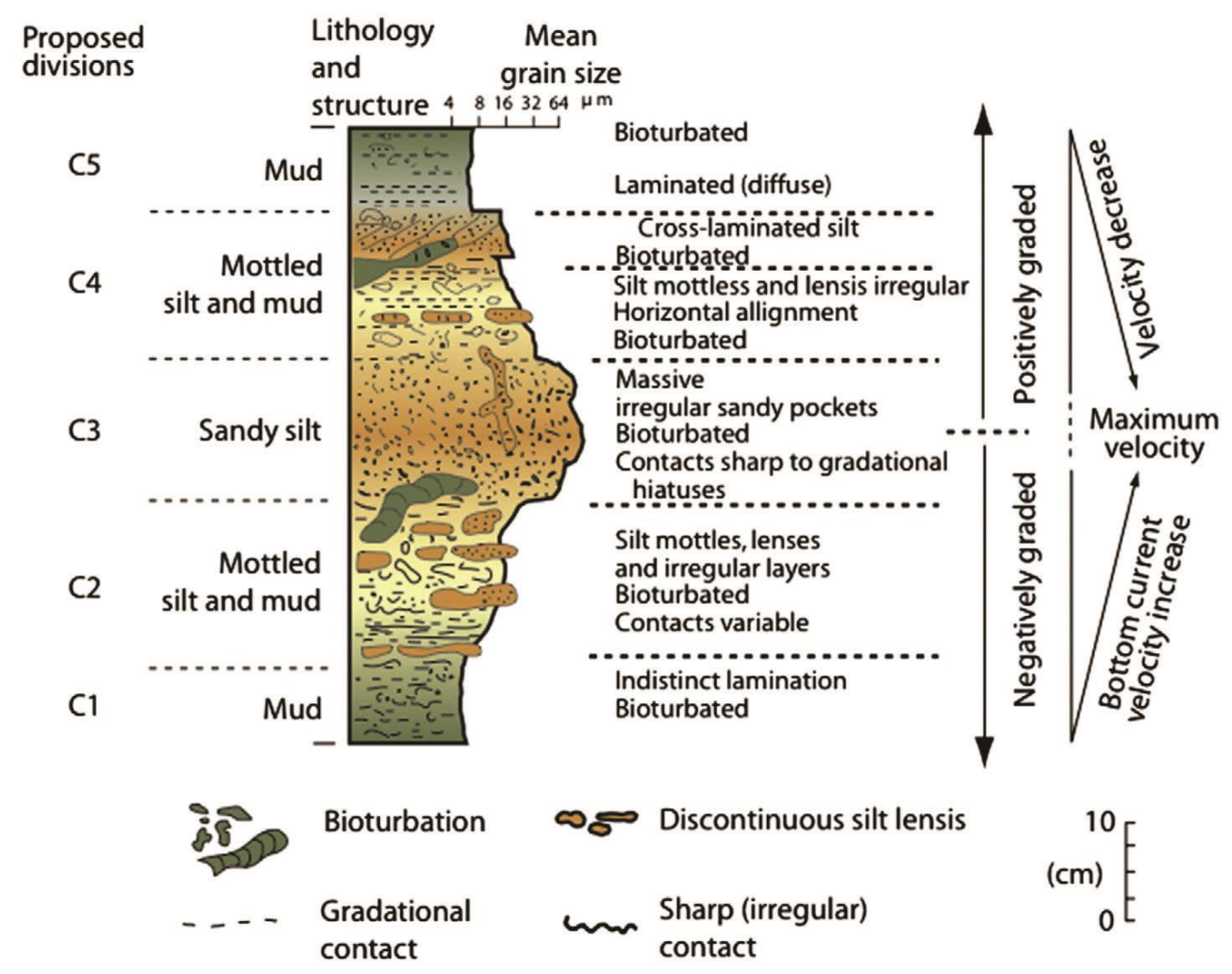

Figure 2. 8 Contourite facies model originally from Stow, (2002), retrieved from Rebesco et al., (2014). The text has been re-typed to make legible.

Contourites are the material deposited or substantially reworked by the persistent action of bottom currents, but their low preservation makes identification in the geological record difficult (Stow and Piper, 1984; Rebesco et al., 2014). The criteria for distinguishing contourites from other deep-sea facies include: irregular vertical succession with negative and positively grading; continuous bioturbation; and features that suggest both in situ and exotic origin. The common sandy contourite facies model 
(Figure 2. 8) has been separated into five divisions by Stow (2002), however, it is expected only partial base or top sequences will be recognised in the geological record (Rebesco, 2005). However, in glaciated regions, contourites can contain gravel-rich material, due to ice rafting processes, and may be highly laminated with a lack of bioturbation depending on the amount of bottom water oxygenation (Rebesco et al., 2014). Contourites are important for palaeoclimatology studies, as they record variability of circulation patterns, current velocity and oceanographic change.

\subsubsection{PELAGIC AND HEMIPELAGIC SETTLING}

Pelagic and hemipelagic sediments are widespread throughout the oceans and are deposited by slow settling in the water column due to a reduction/absence of current activity. Hemipelagic sediments are deposited on continental margins (Figure 2. 6) close to a terrigenous sediment source, composed of a mixture of biogenic $(>5 \%)$ and silt and clay sized material $(>40 \%)$. Pelagic sediments accumulate in the open ocean $(\sim 4500$ meters below sea level, mbsl), comprised of skeletal remains and very fine silt and clay sized particles. Hemipelagites and pelagites are often associated with slow sedimentation rates: indicative of a low energy environment, which results in a lack of primary sedimentary structures or current control deposition. Such processes are associated with a high degree of bioturbation due to the increase in productivity at the ocean surface and seafloor (Stow and Bowen, 1980; Stow and Piper, 1984).

\subsubsection{ICEBERG RAFTED DEBRIS}

Iceberg Rafted Debris (IBRD) is a common feature of glacimarine environments (Figure 2. 6; Drewry, 1981). Previous Antarctic and Arctic studies have shown that the presence of anomalous coarse-grained terrigenous clasts (drop-stones) in fine-grained pelagic/ hemiplegic sediments provide direct evidence of sediment transportation by floating ice (Krissek, 1995). At present the AIS loses 50-60\% of its mass from iceberg calving, occurring by the release of ice from fast-flowing glaciers, during major deglacial events or the collapse of ice sheets (Depoorter et al., 2013). The stratigraphic distribution of dropstones collected in sedimentary cores from the outer/continental shelf can be used to interpret ice sheet variability and changes in AIS extent relative to the present day. It is expected that the highest intensity of IBRD occurs during the transition from glacial to interglacial conditions when the ice sheet is losing most of its mass (Cook et al., 2013; 
Patterson et al., 2014; Weber et al., 2014). One limitation with IBRD records is that the ice sheet volume cannot be determined, as it is only a direct record of calving from the Antarctic margin, and/or of icebergs reaching the Southern Ocean (Licht, 2009).

At present, icebergs are entrained in the Antarctic Coastal Current and are transported westward around the East Antarctic coastline. Some icebergs travel great distances in the cold surface waters south of the southern Boundary Front of the ACC, while others are deflected out of current and advected further north melting rapidly in the warmer waters (Gladstone et al., 2001). It is the large tabular icebergs from the floating ice shelves which have the potential to travel greater distances although they usually have low debris concentrations (Warnke, 1970). Icebergs calved closer to the grounding line are more debris-rich, but are smaller in size remaining close to the source (T. Williams et al., 2010; Weber et al., 2014; Williams, 2014).

Based on previous work completed in the region, the Wilkes Land continental rise is an ideal region to use IBRD as proxy for three main reasons: 1) The site is proximal to outlet glaciers which produce small icebergs containing basal debris and more than one glacier is present so the IBRD record it is not overly influenced by single dumping events (Wilson et al., 2018). 2) The site is located in the Antarctic Coastal Current that transports larger icebergs to the region in a predictable manner and is not influenced by more random processes associated with eddies and deflection of icebergs northwards (Gladstone, et al., 2001). Finally, 3) the site is located south of the ACC, which reduces the influence on ocean temperatures and iceberg melt rates (Gladstone et al., 2001; Cook et al., 2014; Weber et al., 2014). Patterson et al., (2014) developed an IBRD record for the Pliocene interval at Site U1361, indicating that peaks in IBRD immediately preceded open marine conditions and peaks in productivity (e.g. diatom-rich facies). Critically this study included statistical testing of the orbital signal manifested in the IBRD record, illustrating that iceberg calving was not a 'random' process occurring along the Wilkes Land margin, rather occurred in a highly cyclic pattern at orbital frequencies. This thesis expands on this early work to develop an IBRD record for the Late Miocene interval to assess if orbital signatures are present in this earlier period, and how iceberg calving rates relate to the intervals of anomalous nannofossils being investigated. 


\subsubsection{GLACIAL/INTERGLACIAL SEDIMENTATION}

Several studies have been undertaken on the continental rise around the Antarctic margin investigating the 'typical' sedimentary facies in order to identify changes in the climatic state (deglaciation, interglacial, glaciation, glacial). Nonetheless, many of the physical processes influencing the depositional settings in this type of environment remain unconstrained. However, integrated geophysical, sedimentological and geochemical studies have largely been focused on the Antarctic Peninsula (Lucchi et al., 2002; Lucchi \& Rebesco, 2007), Wilkes Land (Escutia et al., 2000; Caburlotto et al., 2010; Patterson et al., 2014), Weddell Sea and Prydz Bay margins (G. Williams et al., 2010; Duncan et al., 2019).

Interglacial sediments are commonly characterised by 1) moderately bioturbated mud with IBRD-rich layers (deglaciation); or 2) highly bioturbated mud with sparse IBRD (interglacial). The significance of IBRD during deglaciation suggests that iceberg calving intensifies during the initial stages of warming. Interglacial sedimentation is often dominated by hemipelagic settling of mud, a lack of sedimentary structures/laminations and an increase the biogenic content, (i.e. diatom rich-bearing facies) due to higher surface productivity (Cook et al., 2013). The exposed continental shelf (e.g. due to the reduced ice sheet) allows oxygenated dense bottom waters to form and pass down the shelf, encouraging strong bioturbation (Caburlotto et al., 2010). Grain size variations suggest turbidity current activity may still be present, with cascading dense water production confined to the shelf, however, primary depositional structures are obscured by higher bioturbation activity (Patterson et al., 2014). Sparse IBRD expresses the continuous, yet subordinate sediment input from iceberg calving during warm and stable conditions (Lucchi et al., 2002; Caburlotto et al., 2010).

Glacial sediments are often represented by two characteristic facies 1) laminated terrigenous muds (glacial); and 2) massive terrigenous muds with sparse IBRD and low biogenic content (glacial transition). During the glacial onset, sedimentation is inferred to be the result of sediment-laden meltwater plumes or density flows at the ice sheet margin as it advances, while ice-rafted debris and pelagic sedimentation are reduced (Lucchi and Rebesco, 2007; Caburlotto et al., 2010). It is proposed that slope failure occurs as the ice sheet delivers a significant volume of fine-grained sediment to its marine 
terminating marine and this sediment is focussed down the canyon system (e.g. Wilkes Land margin; Patterson et al., 2014). In some intervals this deposition of sediment is subsequently influenced by bottom currents and bioturbation. Glacial facies are thus influenced by a range of processes in any given setting and can be divided into a number of subfacies including: 1) laminated mud with silty layers, laminae and lenses; 2) laminated mud including IBRD layers; 3) cross stratified muds; 4) slump deposits; and 5) sand/gravelly-grained turbidites (Lucchi et al., 2002). While some of these laminated interval conform with base-cut out Bouma sequences, and are consistent with spill out onto the channel levees, other laminated facies are characterised by regular spaced sub$\mathrm{mm}$ to $\mathrm{mm}$-scale silt laminae which is more consistent with contourites forming in poorly oxygenated bottom waters (Lucchi et al., 2002; Lucchi and Rebesco, 2007).

Caburlotto et al., (2010) noted the contrast between glacial facies at Wilkes Land and the Antarctica Peninsula, which were identified as pervasive wispy laminae with no bioturbation. It was suggested that in areas where polynyas are maintained (region of intense sea ice production, refer to section 3.3), glacial facies are not always welllaminated, due to continuous dense water production. Deposits at Wilkes Land were found to be bioturbated and contained maghemite (oxidized from magnetite), indicating that highly oxygenated waters continued to flow downslope promoting benthic productivity and bioturbation (Caburlotto et al., 2010). In respect to the present day Site U1361 is located near the Mertz Polynya, an area where the combination of HSSW and CDW produce the cold and saline Antarctic Bottom Water (Bindoff et al., 2000b).

\subsection{NANNOFOSSIL PRODUCTION}

Nannofossils are calcareous fossils that are less than $20 \mu \mathrm{m}$ in size. Although this includes a variety of organisms the most important calcareous nannofossils in the pelagic environment are coccolithophores, a haptophyte algae that produces disc-like calcite plates, coccoliths (Baumann et al., 2004). Coccolithophores inhabit the upper photic zone and are considered the most productive calcifying organisms on the Earth. They act as a crucial element of the global carbon cycle, and produce inorganic carbon during photosynthesis, leading to a reduction in atmospheric $\mathrm{CO}_{2}$ concentration of the upper 
photic zone (Rost and Riebesell, 2004; Wilks et al., 2017). Coccoliths also act to remineralize organic carbon as they sink through the water column, releasing $\mathrm{CO}_{2}$ to the deep ocean. Calcareous nannofossils are known to demonstrate a wide range of ecological tolerances. However, the production of coccolithophore is directly affected by light levels (intensity and duration), SSTs and nutrient availability and indirectly by salinity and water column stratification (Rost and Riebesell, 2004; Duncan et al., 2016).

\subsubsection{SignifiCANCE OF NANNOFOSSILS IN ANTARCTICA}

The current absence of coccolithophores in Antarctic waters suggests SSTs are cooler than $3^{\circ} \mathrm{C}$ (Kennett and Hodell, 1993), as experimental studies have shown that coccoliths do not precipitate below this temperature (Burckle and Pokras, 1991). Sedimentology evidence from the Antarctic margin specifies that coccolithophore do not thrive in surface water south of the Antarctic Divergence (Antarctic Polar Front) due to the corrosive nature of the water masses (Kennett and Hodell, 1993). Although sparse and sporadic nannofossil (i.e. coccoliths) occurrences have been noted in the Pleistocene (Scherer et al., 2008), these are usually only present in trace amounts. For example, nannofossils were recorded at Prydz Bay during the anomalous warming of Marine Isotope Stage 31 (Villa, et al., 2008). The focus of this thesis is the anomalous nannofossil preservation during the Late Miocene and such deposition indicates that past conditions were favourable for both the production and preservation of coccoliths and therefore suggests a significantly different environmental setting around Antarctica since $\sim 10$ Ma. Sediments recovered at Maud Rise (ODP Sites 689 and 690), identified calcareous nannofossils ooze during the Late Miocene interval, until $\sim 8$ to $10 \mathrm{Ma}$ (based on coarseresolution shipboard age models), with the termination of these intervals likely correlated to the cooling of Antarctic waters. The two taxa identified at Site 689 are thought to be associated with migration of warmer Antarctic waters across the shelf (Barker and Kennett, 1988).

\subsection{BIOMARKERS (FOCUSING ON N-ALKANES)}

Biomarkers are molecular fossils preserved in the geological record. Their structures and isotopic content can provide an indication of the environmental conditions that the organism experienced (Killops and Killops, 2013). This is fundamental for paleoenvironmental reconstructions, such as modelling SST and for the identification of 
possible terrestrial vegetation (Eglinton and Eglinton, 2008). Alkenones are long chained $\left(\mathrm{C}_{37}-\mathrm{C}_{39}\right)$ unsaturated ketones, produced in oceanic environments by haptophyte algae (Pagani, 2009). The geological range of alkenones extends to the early Cretaceous and the molecular structure can act as an indicator of water temperature in which the algae grew. n-Alkanes are one of the most abundant biomarkers, with different chain lengths representing varying biological sources (Eglinton and Eglinton, 2008).

Studies in the Ross Sea suggest that during the Oligocene variations in alkanes chain lengths could identify a contribution for both contemporary and reworked sources in relation to climatic cooling (Duncan et al., 2019). The presence of nannofossil-rich intervals at Site U1361 warranted the investigation into both alkenones and $n$-alkanes for SST estimates, to assess whether the climate that allowed the production of coccoliths could also sustain on-land vegetation on the Wilkes Land margin and therefore the discharge of contemporaneous leaf plant waxes offshore. However, within the scope of this thesis, only preliminary characterisation of n-alkane and alkenones content can be provided. It is intended only as a pilot study to identify the potential of Site U1361 as a location for more detailed analysis proxies in the future.

\subsection{PRODUCTIVITY PROXIES}

Commonly, barium $(\mathrm{Ba})$ has been used as a marine paleo-productivity proxy. For reasons that remain unclear the production of barite $\left(\mathrm{B}_{4} \mathrm{SO}_{4}\right)$ is strongly correlated with plankton productivity, as demonstrated in sediment (Dymond et al., 1992). Ba also occurs in lithogenic minerals, and usually the ratio of $\mathrm{Ba} / \mathrm{Al}$ (Aluminium) is used to estimate the amount of $\mathrm{Ba}$ excess due to biological productivity. This approach has been used in Antarctic sediments, with a peak in $\mathrm{Ba} / \mathrm{Al}$ indicating an increased productivity during warmer interglacials (Cook et al., 2013; Patterson et al., 2014; Bertram et al., 2018; Wilson et al., 2018), with the strong variance related to changing facies types (Cook et al., 2013; Patterson et al., 2014). Caution is required with Ba as it can be affected by the current intensity in contourite systems, preventing its use for a paleo-productivity proxy (Bahr et al., 2014) 
Wilson et al., (2018) observed that silica ( $\mathrm{Si}$ ) and calcium (Ca) enrichment is positively correlated to $\mathrm{Ba}$ in sediments offshore Wilkes Land. Diatoms are composed of silica; therefore $\mathrm{Si} / \mathrm{Al}$ can also be used as a proxy for marine biogenic production. This proxy is not widely used but provides a similar result as the ratio $\mathrm{Ba} / \mathrm{Al}$. When $\mathrm{Ca}$ is paired with $\mathrm{Ti}(\mathrm{Ca} / \mathrm{Ti})$ it measures the relative change in biogenic vs lithogenic sediments and $\mathrm{Al}$ $(\mathrm{Ca} / \mathrm{Al})$ it represents the biogenic/detrital ratio (Rothwell and Croudace, 2015). The ratio of $\mathrm{Sr} / \mathrm{Ca}$ (strontium) can be used to differentiate between terrigenous Ca sources (e.g. feldspars and clays) and biogenic carbonates (Rothwell and Croudace, 2015). The ratio varies widely between marine carbonate organisms (Bathurst, 1974).

Redox-sensitive elements can be used as a proxy to identify the establishment of deep water in the Southern Ocean, as they are balanced by the rate of oxygen supply and the rate at which oxygen depleted waters are removed (Jaccard et al., 2016). Manganese (Mn) is one of the most reactive metals: it is actively recycled between being oxidized and dissolved, with preservation associated with well-oxygenated sediments/bottom waters. Mn peaks generally occur during interglacials, suggesting an increase in oceanic ventilation under bottom water conditions (Calvert and Pedersen, 1996). 


\section{CHAPTER THREE: REGIONAL SETTING}

\subsection{WILKES LAND}

\subsubsection{BASEMENT AND STRATIGRAPHIC FRAMEWORK}

The Wilkes Land continental margin formed during the Late Cretaceous, as part of the separation of East Antarctica and the Australian continents ( $\sim 83 \mathrm{Ma}$; Colwell et al., 2006). The rifting resulted in the formation of the Southern Ocean and the insolation of the Antarctic continent (Kennett et al., 1975). The basement rock consists of blockfaulted continental and oceanic crust, with deep marginal rift basins that contain $>8 \mathrm{~km}$ sediment accumulation and areas of anomalously shallow bathymetry (Escutia et al., 2005; Donda et al., 2007). Precambrian metamorphic rocks dominate the East Antarctic Shield and form the eastern Wilkes Land margin, alongside early Cambrian granitoids (Ross Orogen). These were either intruded or derived from partial melting of the metamorphic basement (Goodge and Fanning, 2010).

Detailed seismic profiles of the eastern Wilkes Land margin (Adélie Coast) of Cenozoic strata identified nine sedimentary sequences separated by eight seismic unconformities termed WL-U1 to WL-U8 (Figure 3. 1; Escutia et al., 1997, 2005). Two main unconformities (WL-U3 and WL-U8) were interpreted to represent a major shift in grounded ice sheet activity on the continental shelf. WL-U3 is inferred as continental scale growth of a terrestrial, wet-based EAIS at the EOT and WL-U8 represents the advance of a large-scale marine-based ice sheet during a colder regime and a change in the outer shelf geometry sometime during the Late Miocene and Pliocene. The sedimentary sequences have been grouped into three intervals representing distinctive phases of margin evolution (Escutia et al., 1997; De Santis et al., 2003; Donda et al., 2003, 2007); 1) Prior to WL-U4: sediments suggest the EAIS was in a greenhouse climate with minimal ice sheet influence; 2) strata between WL-U4 and WL-U7 represents: maximum sediment supply, meltwater discharge and the development of the levee channel system, associated with East Antarctic continental interior that was occupied by oscillatory ice sheet in a warmer climate (e.g. polythermal ice sheet at Wilkes Land; 3) 
Above WL-U8, is characterised by reduced sediment supply to the continental rise, with sediment accumulating on the shelf. This reflects a cooling glacial regime and reduced turbid meltwater input (e.g. cold polar ice sheets). The transition between the polythermal and cold polar ice sheet across unconformity WL-U8 was the target of Site U1361 during the IODP Expedition 318 drilling (Escutia, et al., 2011a). The focus interval for this thesis is interpreted to be positioned between WL-U6 (385 mbsf) and WL-U7 (300 mbsf), based on shipboard interpretations, this coincides with Unit WL-S7 and seismic stratigraphy suggest a warmer, wetter climate, and enhanced turbid glacial meltwater. Units overlying WL-U7 represent a transition to a cold-polar ice sheet with less turbid outwash (Donda et al., 2003).

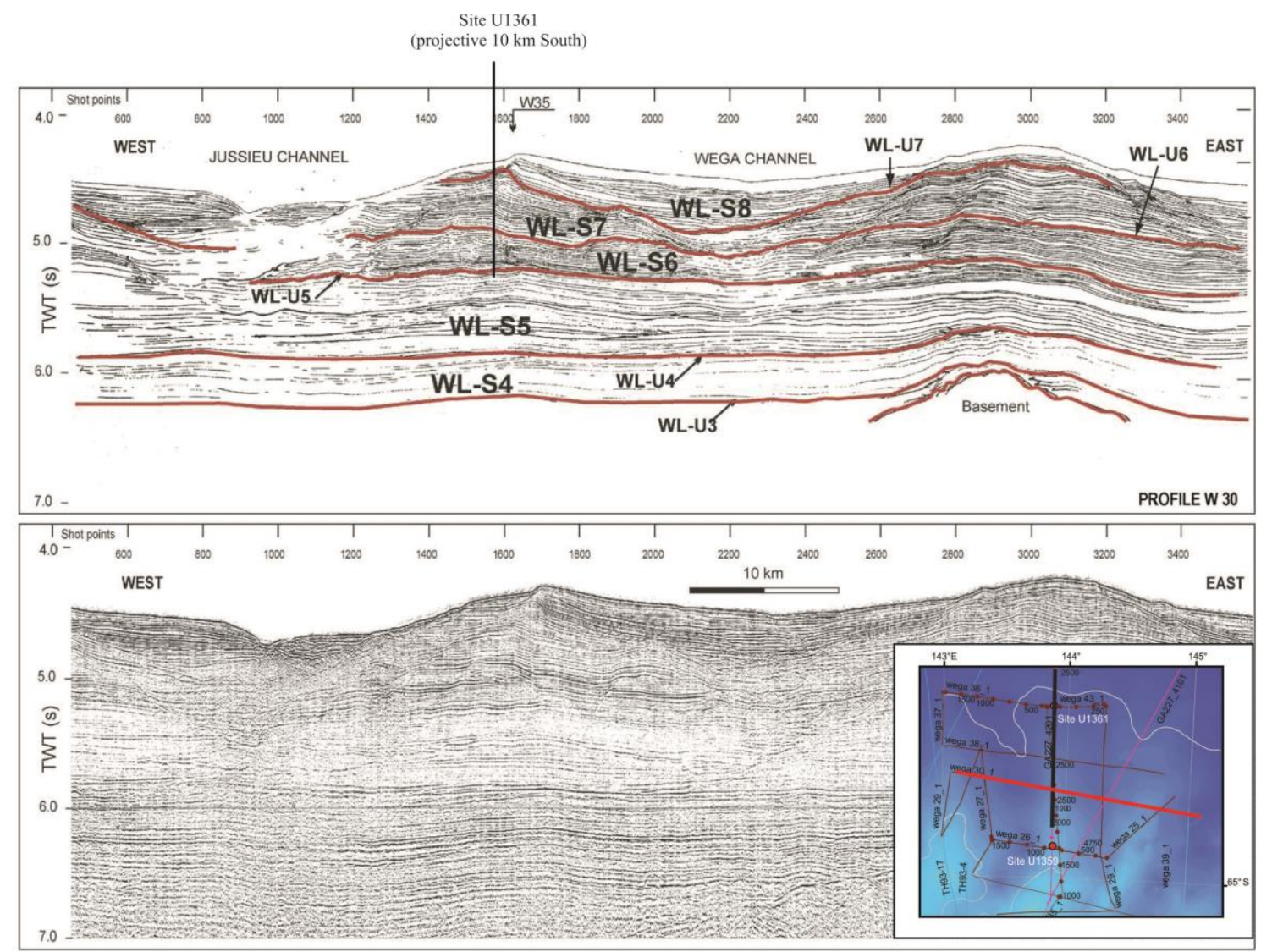

Figure 3. 1 Interpreted and uninterpreted high-resolution mulitchannel seismic profile across the Wilkes Land continental shelf (line profile 30). The Jussieu channel is located in the west of the image, with Site U1361 located on the eastern levee. The red lines indicate the eight interpreted sesimic unconformities, after Donda et al., (2003). Figure from Escutia, et al., (2011a), including insert map indicating location of profile (red) relative to the site. See text above for dicussion. 


\subsubsection{Wilkes Subglacial Basin}

The Wilkes Subglacial Basin (WSB) is situated to the west of the Transantarctic Mountains (East Antarctica; Figure 3. 2). The WSB is $\sim 1400 \mathrm{~km}$ long and up to $\sim 600 \mathrm{~km}$ wide with mean bedrock elevation $\sim 500 \mathrm{~m}$ below sea level (Ferraccioli et al., 2001, 2009). Buried beneath a $\sim 3 \mathrm{~km}$ thick EAIS, the basin drains through the Ninnis and Cook ice streams at the George V Coast (Rignot et al., 2013) and is the largest of the three major East Antarctic drainage basins, with the marine-based ice in this basin holding $\sim 3-4 \mathrm{~m}$ of sea level equivalent (Mengel and Levermann, 2014; Pollard et al., 2015). High-resolution mapping (BEDMAP2) of the deep subglacial troughs on which the ice sheet at Wilkes Land rests, suggest the WSB catchment is more vulnerable to change than other EAIS catchments (Fretwell et al., 2013).

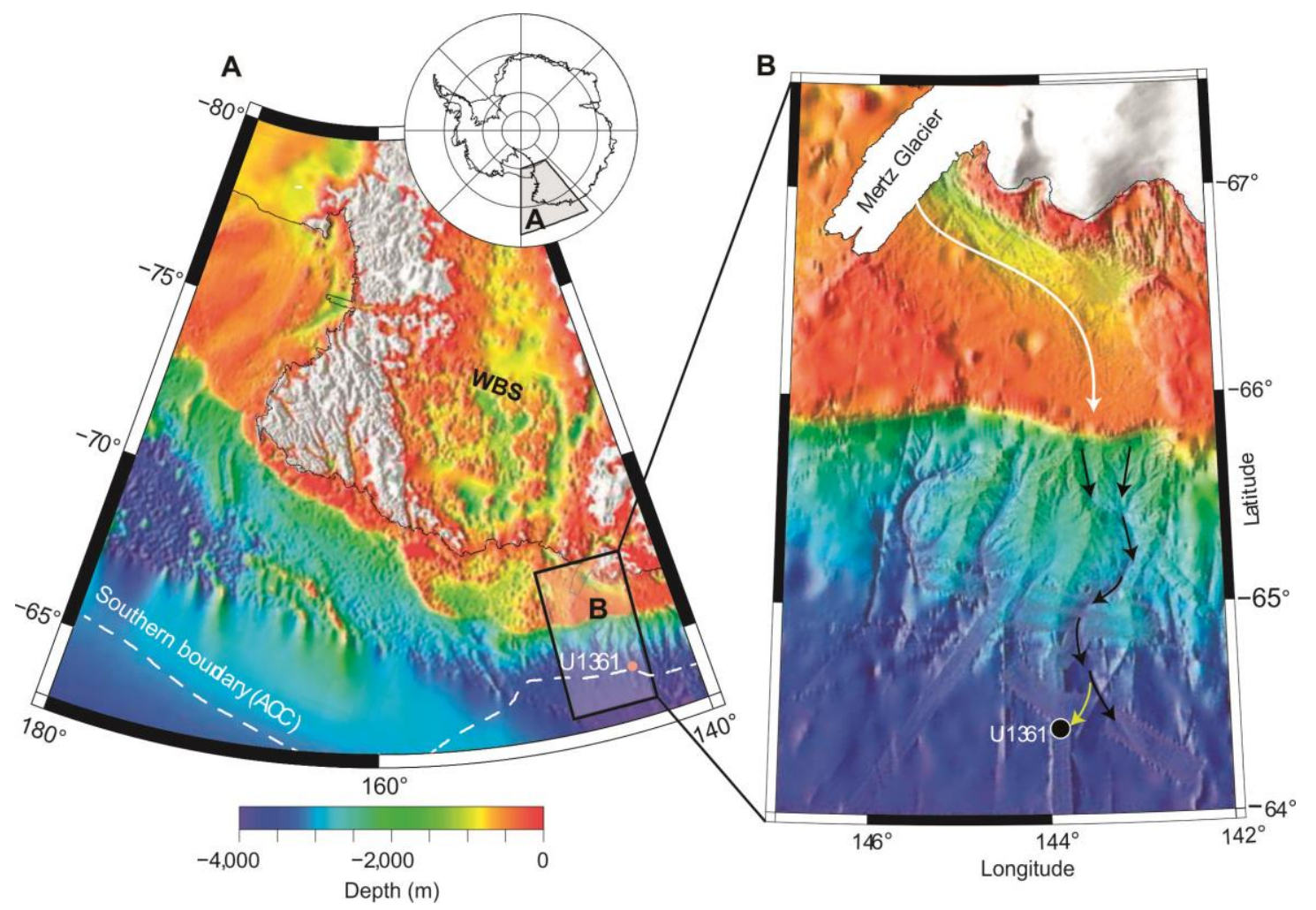

Figure 3. 2 A) Bathymetry of the Wilkes Land margin, including the location of Site U1361 and the depth profile of the WSB (with ice removed). Modern grounding line is shown by the thick black line. B) Mertz Glacier tongue (prior to break up in 2009) and drainage path from the shelf to rise. Figure modified from Patterson, et al., (2014). 


\subsubsection{BATHYMETRY OFFSHORE ADÉLIE COAST}

The Wilkes Land continental shelf (Figure 3. 3) at the Adélie Coast has an average water depth of $\sim 500-300 \mathrm{~m}$ (De Santis et al., 2003), with an overdeepened profile, the result of isostatic loading and glacial erosion (Ten Brink and Cooper, 1992). The inner and outer shelf topography is very irregular, with deep basins $(>1000 \mathrm{~m})$, flat shelf banks and troughs. The continental shelf troughs were eroded by ice streams during times of glacial advances, confined by the two broad and relatively shallow sedimentary banks (Adélie and Mertz Banks), illustrating where grounded ice was slow moving (Escutia et al., 2005; De Santis et al., 2007; Beaman et al., 2011). Several large submarine canyons are incised into the slope, and are separated by steep (200m) parallel ridges (De Santis et al., 2007; Beaman et al., 2011). Deposition dominates the eastern bank of the channel, with the asymmetry between the ridges the result of the Coriolis effect in the Southern Hemisphere (Donda et al., 2003; Escutia et al., 2005). The submarine channels and ridges begin to merge into a flat abyssal plain below $\sim 3500 \mathrm{~m}$ water depth. Site U1361 is located at the transitional zone between the continental rise and abyssal plain, at a water depth of $\sim 3454$ mbsl on a low relief levee of the Jussieu canyon (Figure 3. 3). Seismic stratigraphy indicates Site U1361 is near the levee crest (Figure 3. 1) and sediment supply is derived from the influence of turbidity currents, although with some interaction of bottom water currents (Figure 3. 1; De Santis et al., 2003; Donda et al., 2003; Escutia et al., 2003, 2005, 2011b). 

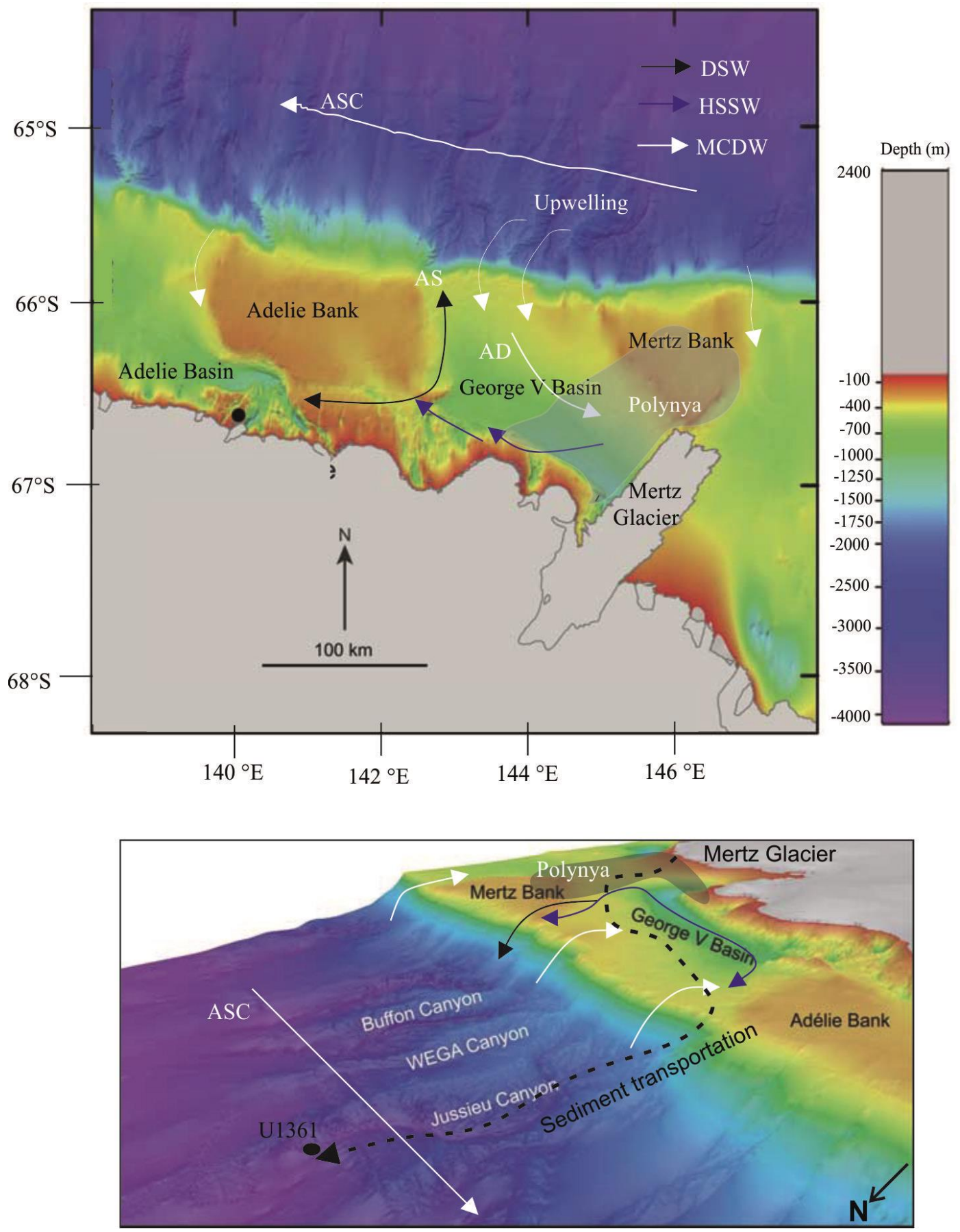

Figure 3. 3 Bathymetric map and pathways of water masses that contribute to the formation of the ALBW offshore Wilkes Land; modified from Beaman et al., (2011). AD = Adélie Depression, AS = Adélie Sill, ASC =Antarctic Slope Current, $D S W=$ Dense Shelf Water, HSSW =High-Salinity Shelf Water and MCDW= Modified Circumpolar Deep Water 


\subsection{SOUTHERN OCEAN}

The Southern Ocean has a significant influence of the world's climate, carbon cycle and ocean circulation and is dominated by the ACC. The ACC is the largest global ocean current flowing clockwise around Antarctica, averaging $\sim 130 \mathrm{~Sv}\left(10^{6} \mathrm{~m}^{3} \mathrm{~s}^{-1}\right)$ volume transport through the Drake Passage, estimated to travel $\sim 24,000 \mathrm{~km}$ (Barker \& Thomas, 2004; Carter et al., 2009). The ACC is considered to be entirely wind-driven (Rintoul, 2018), and is constrained by topography. It is fundamental to the global overturning circulation, as it connects all the major oceanic basins and prevents the north-south exchange of $\mathrm{CO}_{2}$, heat and moisture, isolating the Antarctic continent from the warm waters in the north (Rintoul et al., 2001). The exact timing of the initiation of the ACC is uncertain, inferred to have occurred sometime between 41 and $23 \mathrm{Ma}$ (Scher et al., 2015). The development of the ACC has been interpreted to have reduced the meridional heat transport, isolating the continent and being partially responsible for the Antarctic glaciation at the EOT (Kennett, 1977). However the relationship between the full tectonic opening of the Southern Ocean gateway between Antarctica and South America and initiation of the ACC remains unconstrained (Scher and Martin, 2006; Scher et al., 2015).

\subsection{ANTARCTIC BOTTOM WATER FORMATION AND OCEAN CIRCULATION AT WILKES LAND}

\subsubsection{BOTTOM WATER FORMATION IN ANTARCTICA}

The AABW is the coldest and densest branch of the global ocean circulation produced by strong atmospheric cooling (heat loss into the atmosphere), brine rejection from sea ice formation in coastal polynyas and ice/ocean interaction (Orsi et al., 1999; Bindoff et al., 2000a; Williams et al., 2008; Snow et al., 2018). There are three major sources of AABW: the Weddell Sea, the Ross Sea and Adélie Land Coast (Carter, et al., 2009). Formation at the Adélie Coast differs from the Ross and Weddell Seas as there are limited floating ice shelves and the continental shelf is relatively narrow and isn't geographically bound by land that can act as a barrier, confining the flow of saline shelf waters (Rintoul, 1985). 


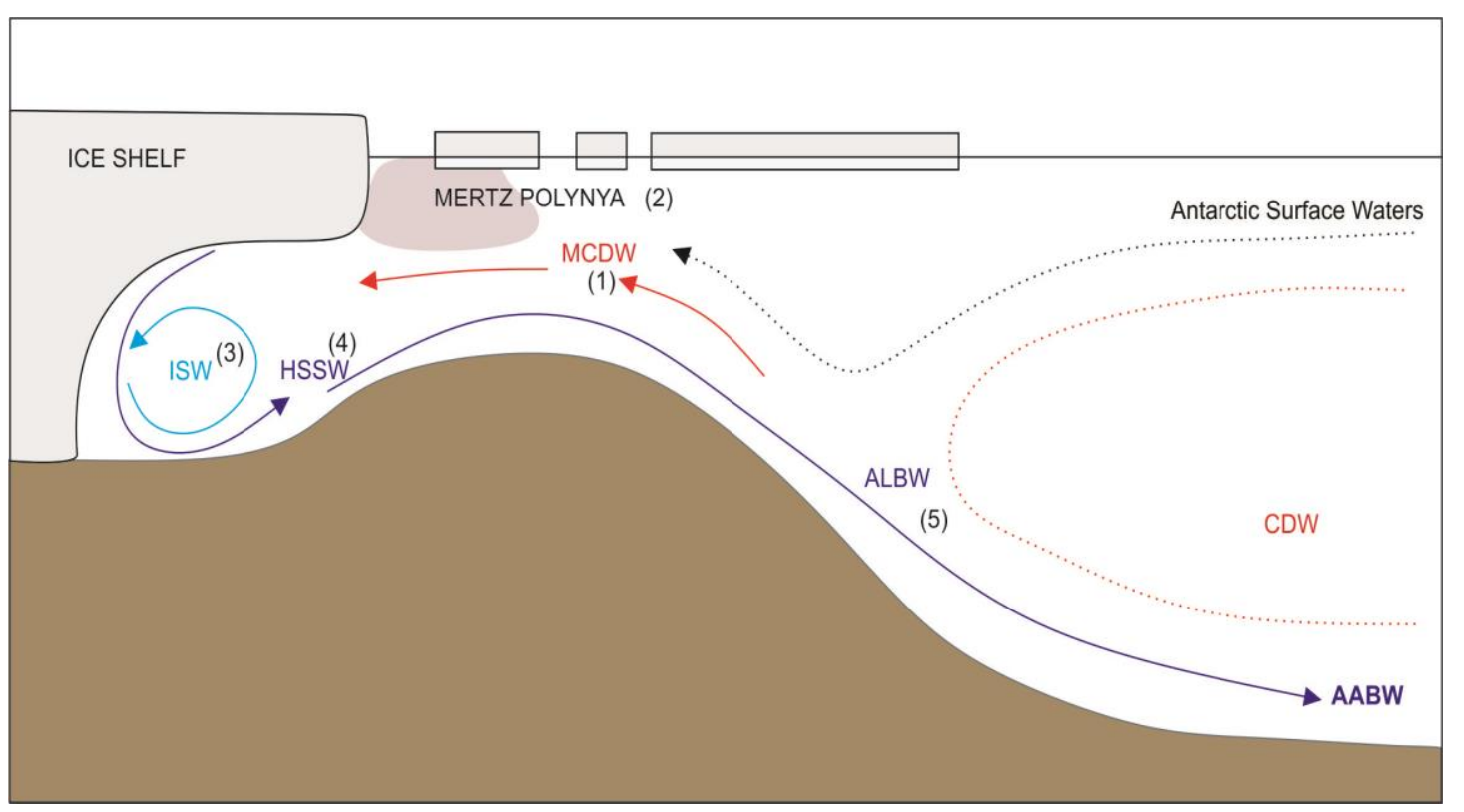

Figure 3. 4 Schematic diagram illustrating ocean circulation in the Adélie Depression. Labelled water masses as described in the text (below). Numbers refer to the order in which the $A A B W$ is formed $(1=$ start $)$. Pink shaded area $=$ brine rejection beneath the MGT within the Mertz Polynya. Figure based on concepts from Williams et al., (2010 and 2008).

\subsubsection{Formation OF THE AdÉlie LANd Bottom WATER}

The Adélie Land Bottom Water (ALBW) contributes 25\% to the global volume of AABW (Campagne et al., 2015; Snow et al., 2018), supplying cold, fresh and oxygenrich waters to the deep ocean (Williams and Bindoff, 2003). The production of the ALBW occurs when fresh warm Modified Circumpolar Deep Water (MCDW) flow southward across the shelf break into the Adélie Depression (Figure 3. 4). The Mertz Glacier Polynya system $\left(143-146^{\circ} \mathrm{E}\right)$ to the west of the Mertz Glacier Tongue (MGT) is the third most productive polynya in Antarctica (Campagne et al., 2015). It is believed to be the main source of the dense High-Salinity Shelf Water (HSSW), which circulates in the base of the depression and below the MGT. The contact of the dense HSSW with the base of the MGT produce Ice Shelf Waters (ISW), which ascend and supply a freshwater signal to the upper shelf waters. The shelf waters (ISW and HSSW) incorporate brine rejection from ice within the polynyas and MGT, resulting in the modified cold HSSW and Dense Shelf Water (DSW) being exported through the Adélie Sill (Williams and Bindoff, 2003; 
Williams et al., 2008; G. Williams et al., 2010). Once these waters leave the shelf they descend as dense cold, high salinity waters via falling plumes and gravity currents into the complex level channel system along the Wilkes Land margin (Carter et al., 2009; Caburlotto et al., 2010; G. Williams et al., 2010). The funnelling of this water through the canyons produces the ALBW, that is incorporated into the Antarctic Slope Current and mixed with Ross Sea Bottom Waters (Williams et al., 2008) to finally form the AABW (Figure 3. 4).

At present, the formation of the ALBW varies seasonally due to enhanced sea ice production and brine rejection during the wintertime. In February 2010, the calving event of the MGT (removing $80 \%$ of the tongue) had a significant impact on DSW production (Campagne et al., 2015). Ice-ocean models propose that ocean circulation and sea-ice production in the region changed rapidly following the event, with the export of DSW reducing by $23 \%$ due to the modification of the polynya system structure (Kusahara et al., 2011). Based on recent observations, an increase in glacial meltwater in the warming climate may further slowdown the DSW production. This would reduce ABBW formation, and ultimately result in ice mass loss for the AIS (Silvano et al., 2018). This modern-day observation demonstrates that under different climatic states the behaviour of the ALBW and thus the ABBW will vary, suggesting that large scale ice sheet variability during past G-I cycles would have had a significant input on the AABW production in the region (Patterson et al., 2014; Salabarnada et al., 2018). This thesis aims to qualitatively assess how such processes may have operated during the Late Miocene, when ice sheet glacial regime and oceanic processes may have been different. 


\section{CHAPTER FOUR: METHODS}

\subsection{CORE SAMPLing}

Site U1361 was cored in February to March 2010, with $87 \%$ recovery. Hole A reached a total depth of $388.0 \mathrm{mbsf}$ using advanced piston coring until $151.5 \mathrm{mbsf}$. The Extended Core Barrel (XCB) was used for the remainder (151.5 to $350 \mathrm{mbsf}$ ). The Miocene interval of core U1361A was recovered by XCB, with $79 \%$ core recovery but characterised by a style of drilling disturbance called biscuiting, resulting in brecciated $\mathrm{cm}$-scale intervals of sediments separated by intervals of core that are more cohesive and undisturbed. Initial lithostratigraphic, biostratigraphic and geochemistry descriptions are provided in Escutia, et al., (2011b). This thesis focused on the Late Miocene section between 302.05 and 349.85 mbsf and spans five core sections (33X-37X), which were sampled at $2000 \mathrm{yr}$ resolution. This equates to 450 samples over the $\sim 50$ meters of core (Table 1). Core sections 34 through to 37 were targeted, as they contained interbeds of nannofossil-rich mud, diatomaceous mud and terrigenous mud, while core 33 was selected to characterise sedimentary patterns and cycles post-dating the uppermost nannofossil-rich interval identified in the core. Prior to analysis each sample was freeze dried until all moisture was removed, and the raw weight of the total sample was determined.

\begin{tabular}{|c|c|c|}
\hline Hole & Core Number & Core top depth (mbsf) \\
\hline U1361A & 33 & 302.00 \\
\hline U1361A & 34 & 311.60 \\
\hline U1361A & 35 & 321.20 \\
\hline U1361A & 36 & 330.80 \\
\hline U1361A & 37 & 340.40 \\
\hline
\end{tabular}

Table 1 Site U1361 core data information for the selected study interval, including the hole, core number and the top depth (mbsf). This data is from Escutia et al., (2011b). 


\subsection{X-RAY FLUORESCENCE (XRF)}

Detailed bulk-chemical composition records were acquired to accurately determine sedimentological changes and an assessment of the relative contributions of biogenic and lithogenic fraction in the marine sediment. Discrete subsamples weighing $\sim 1-2 \mathrm{~g}$ were collected (444 samples) from freeze dried and homogenised material for non-destructive XRF measurements. The elemental composition of each subsample was measured using the Olympus Vanta M series XRF handheld scanner at VUW. Measurements were performed using two built in 'methods'. The Geochem (2) method was set to use two beams at $10 \mathrm{kv}$ and $40 \mathrm{kv}$, to measure the relative elemental composition of relatively light elements (e.g. Ca, $\mathrm{Si}$, and $\mathrm{Al}$ ), while the Soils method used three beams at 15, 40 and $50 \mathrm{kv}$ to measure the heavier elements (e.g. Ba and $\mathrm{Sr}$ ). Some elements are measured by both modes and data from the appropriate method is presented in the Results Chapter. For example, $\mathrm{Ca}$ in high concentrations $(>1.5 \%)$ is more accurately determined by the Geochem method whereas the Soil method is better for low concentrations.

The abundances of each element calculated in ppm and is according to the instrument's internal calibration. However, external standards were measured at the start and end of each sample run ( $\sim 2-3$ hours) to provide a calibration based on international standards from the USGS and Geological Survey of Japan (Appendix). Each standard was selected based on prior knowledge of the potential elements present within the samples to make sure they 'bracket' the expected range of abundances and matrix material. Raw data was corrected using the international XRF calibration standard, by determining a linear correlation between measured and expected values and applying an appropriate correction to each element of interest (Appendix). Refer to Appendix B for table of average, and standard deviation reproducibility of the three standards. The standards show the certainty in the measurement is stable, except when the detection limit is approached (e.g. standard deviation increases).

XRF data was essential to quantify the precise location of the facies shift into carbonaterich from biogenic silica-rich intervals between core section 33 and 34, as shipboard descriptions in this interval are low resolution (e.g. dm- to m-scale generalisations). Elemental abundances and ratios can also be used to rapidly determine abundances of biogenic material. For example, in the cores used in this study, $\mathrm{Ca}$ is primarily hosted in 
the nannofossil calcite, therefore $\mathrm{Ca} / \mathrm{Al}$ gives an indication of their relative abundance, assuming $\mathrm{Ca} / \mathrm{Al}$ for lithogenic material is fixed. Similarly, $\mathrm{Si} / \mathrm{Al}$ can be used to estimate biogenic silica (in this case mainly diatoms) content. Explanation of the uses of these elements is given in section 2.7. To test if $\mathrm{Ca} / \mathrm{Al}$ can be used to indicate intervals of calcium carbonate it was plotted against shipboard measurements of $\mathrm{CaCO}_{3}$ (Escutia et al., 2011b). $\mathrm{CaCO}_{3}$ in this study was also calculated from $\mathrm{Ca}$ following equation: $\mathrm{CaCO}_{3}$ $=\mathrm{Ca} / 10000 * 2.4973$, which was also plotted against shipboard $\mathrm{CaCO}_{3}$ measurements. If the correlation is strong it creates a method to quantitatively indicate intervals of nannofossil-rich sediments.

\subsection{ICEBERG RAFTED DEBRIS (IBRD)}

Ice Rafted Debris was determined using the method of Patterson et al., (2014) which was derived from Krissek, (1995). Grain size distributions at this site measured by Patterson et al., (2014) indicate that the $250 \mu \mathrm{m}$ to $2 \mathrm{~mm}$ grain size interval is a reliable indicator of IBRD, as it exceeds the size range found in the fine sand laminae of turbidite beds. For more information on the use of IBRD as the indicator of iceberg calving refer to section 2.4 .5 . In this study $\sim 450$ freeze-dried samples, were weighed ( 7-9 g) and immediately prior to sieving the samples were disaggregated ultrasonically in Millipore water for $\sim 10-15$ minutes to break up aggregate pellets (no mechanical force was used to break up the samples). Each sample was wet sieved at $250 \mu \mathrm{m}$, dried under a heat lamp and the $>250 \mu \mathrm{m}$ was sieved at $2 \mathrm{~mm}$ to remove large grains that were assumed to be present in representative amounts.

The $>250 \mu \mathrm{m}$ fraction of each sample was examined under the binocular microscope to assess if biogenic or authigenic material was present. All samples containing radiolarians, foraminifera and diatoms were subsequently crushed using light finger pressure, between clean paper, to break up the biogenic material without damaging lithic grains. Damage to lithic grains using this method was minimal and was checked before and after comparison under a microscope. These samples were sieved again at $250 \mu \mathrm{m}$ to assess that all biogenic material was removed from the coarse fraction. Samples containing authigenic minerals 
were not included in the final IBRD calculations. All samples were recorded as a fraction of the total dry sample weight.

\subsubsection{ICEBERg RAFTed Debris MASS ACCUMUlation RATE (IBRD MAR)}

The Mass Accumulation Rate (MAR) of the coarse fraction was calculated using the following equation. IBRD MAR $\left(\mathrm{g} \mathrm{cm}^{-3} \mathrm{kyr}^{-1}\right)=C S \% * D B D^{*} L S R$ in Patterson et al., (2014) modified from Krissek, (1995). The CS\% is the coarse sand weight percent ( $>250$ $\mu \mathrm{m}-2 \mathrm{~mm} /$ dry weight) as a fractional percent, DBD is the dry bulk density retrieved during shipboard measurements (Escutia, et al., 2011b) and for each sample was interpolated to the nearest DBD measurement and LSR is the interval linear sedimentation rate measured in centimetres per thousands of years (see section 4.7 for LSR method). The Patterson et al., (2014) method does not require a visual estimate of IBRD content to be determined, required by the Krissek, (1995) method, as biogenic material is removed, and samples with significant authigenic minerals and volcanic ashes are excluded from the calculation.

\subsubsection{Analytical Scanning Electron Microscope (SEM)}

Numerous IBRD samples contained grey/black and white grains that had distinctive diagenetic textures (Figure 4. 1). When possible, these were removed by hand with the use of a fine brush and microscope or gently crushed for grains that were easily disaggregated. All samples treated in this manner were reweighed after being visually reassessed for successful removal of authigenic grains without damaging the lithic grains. Suspected diagenetic minerals were imaged using the electron microscope (SEM) to characterise texture and composition. Six different types of grains were mounted onto separate carbon-tape stubs. The stubs were placed into the desiccator for $\sim 24$ hours to remove all moisture from the grain and tape and were subsequently coated in carbon by David Flynn, VUW. SEM images were taken using JEOL-JSM-6610LA and the element mapping was completed on 'Analysis station' software, under Energy Dispersive X-ray Spectrometry (EDS). EDS works in a similar manner to XRF, however provides a localized chemical analysis, by scanning each pixel it measures the intensities of each element in the sample. 


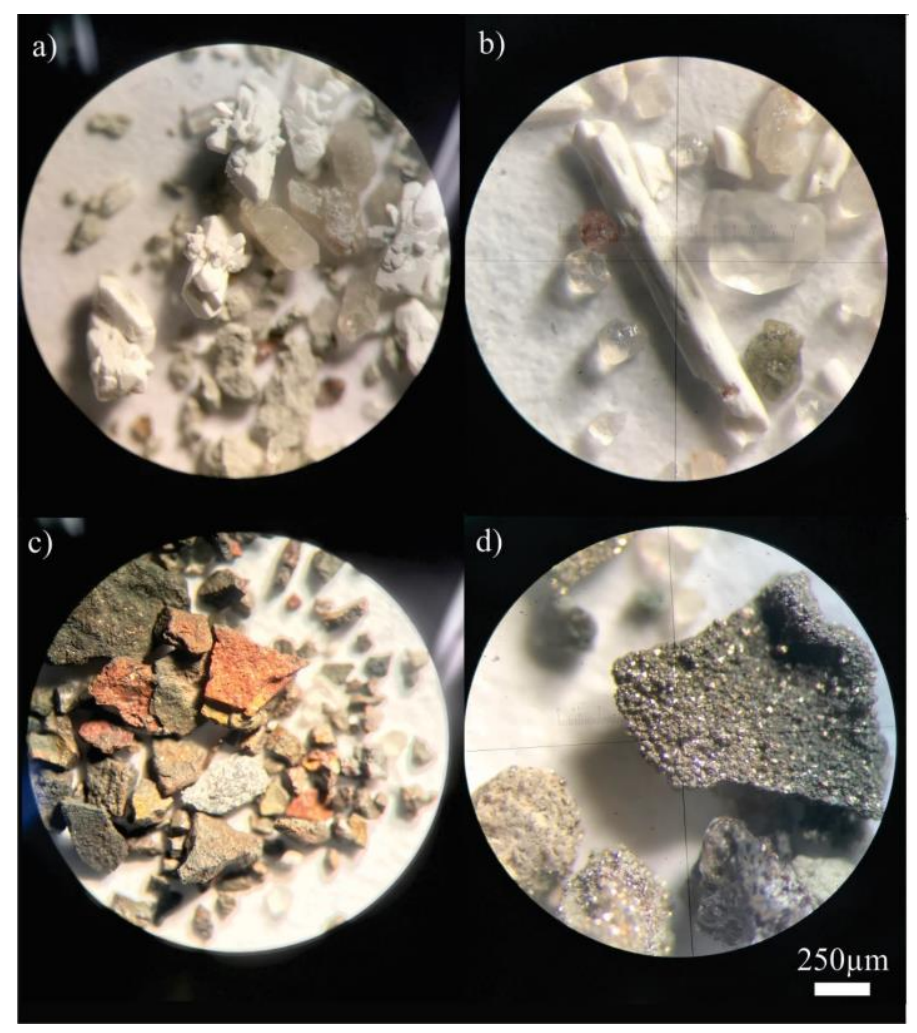

Figure 4. 1 Non-IBRD material found in the $250 \mu \mathrm{m}$ to $2 \mathrm{~mm}$ fraction. a) \& d) carbonate material at 327.26 and $337.65 \mathrm{mbsf}$, respectively b) dark material (pyrite/manganese) $330.96 \mathrm{mbsf}$ and c) orange/iron material $305.75 \mathrm{mbsf}$.

\subsection{GRAIN SIZE ANALYSIS}

\subsubsection{REMOVAL OF ORGANIC, CARBONATE AND BIOGENIC MATERIAL}

A total of 224 samples were selected for grain size analysis. Small subsamples of the unprocessed sample were collected, and a micro-splitter was used to provide homogenous splits of $\sim 0.1 \mathrm{~g}$. The samples were dissolved of organic material using $\sim 10 \mathrm{ml}$ of $10 \%$ hydrogen peroxide $\left(\mathrm{H}_{2} \mathrm{O}_{2}\right)$, over a period of $\sim 24$ hours. The subsamples were successively heated for 2 hours at $75^{\circ} \mathrm{C}$ to react of remaining agent and centrifuged two times $(10$ mintues each) with $\sim 45 \mathrm{ml}$ of $\mathrm{DI} \mathrm{H}_{2} \mathrm{O}$ at $4700 \mathrm{ppm}$, before being treated with $10 \%$ hydrochloric acid $(\mathrm{HCl})$ to remove carbonate material. This stage was fundamental as calcareous nannofossils are present in core sections 34-37. No heat was added, and 
samples were left to digest for 1 hour, before being washed and centrifuged three times for 10 minutes at $4700 \mathrm{ppm}$.

The last stage includes the removal of biogenic silica (bSi), including diatoms, radiolarians, sponge spicules and silicate minerals. Early testing of the sample involved a treatment in $10 \mathrm{ml}$ solution of $1 \mathrm{M}$ of sodium hydroxide $(\mathrm{NaOH})$ and heating at $75^{\circ} \mathrm{C}$ for 8 hours. Using this method there was incomplete dissolution of diatoms observed in smear slides. and the samples remaining were treated for another $\sim 72$ hours at $75^{\circ} \mathrm{C}$, stirring regularly. Smear slides revealed that this treatment was still insufficient to remove diatoms and sponge spicules. A test $\sim 10 \mathrm{ml}$ of $2 \mathrm{M} \mathrm{NaOH}$ was added to a new set of subsamples for a 24-hour period and smear slides indicated only trace amount of biogenic silica and that dissolution had occurred to a suitable degree to not comprise analysis. After a further $\sim 12$ hours, these samples were washed using $\mathrm{DI} \mathrm{H}_{2} \mathrm{O}$ water and centrifuged four times (10 minutes at 4700ppm). All subsequent samples were individually treated with $\sim 10 \mathrm{ml}$ of $2 \mathrm{M} \mathrm{NaOH}$, for $\sim 72$ hours and the samples were heated daily ( $3 \mathrm{x} \sim 6$ hours), stirred occasionally and tested on smear slides nearing 72 hours.

\subsubsection{LASER PARTicle Sizer ANALysis}

Following chemical treatment, each sub-sample was suspended in $\sim 80 \mathrm{ml}$ of $0.5 \mathrm{~g} / \mathrm{L}$ Calgon (sodium hexametaphosphate) and sonicated for a minimum of $\sim 15$ minutes to disperse grains and to prevent flocculation. Each sample was subsequently analysed using the LS 13320 Laser Diffraction Particle Size Analyser (LPS) at VUW. The LPS was run on 'quartz' optical mode which assumes all of the sample has a reflective index of 1.55, measuring 100 times in 60 seconds (averaged to provide the grain size distribution). To check for reproducibility, a LPS standard of $68 \mu \mathrm{m}$ glass beads was run initially, and selected samples were run three separate times (explained below). The data output from the LPS was run through the GRADISTAT package developed by Blott and Pye, (2001) to obtain grain size distribution graphs, providing the ability to infer grain size and patterns. Parameters were defined as clay $<8 \mu \mathrm{m}$, silt $8-63 \mu \mathrm{m}$ and sand $63-2000$ $\mu \mathrm{m}$. 


\subsubsection{GRAIN SIZE REPRODUCIBILITY}

To test reproducibility, randomly selected samples were separated into three $\sim \mathrm{g}$ subsamples (A, B \& C). Each sub-sample was chemically processed and run on the LPS separately, to see if similar grain size distributions were achieved, and the chemical treatment process and small sample sizes were not creating biases in the data set. The grain size distribution for the three repeats all showed excellent reproducibility (Figure 4. 2 ), with the average $r^{2}$ values ranging between 0.97 and 0.99 . A table containing the average and standard deviation of six samples that were repeated three times is presented in Appendix B, highlighting the similarity between runs.
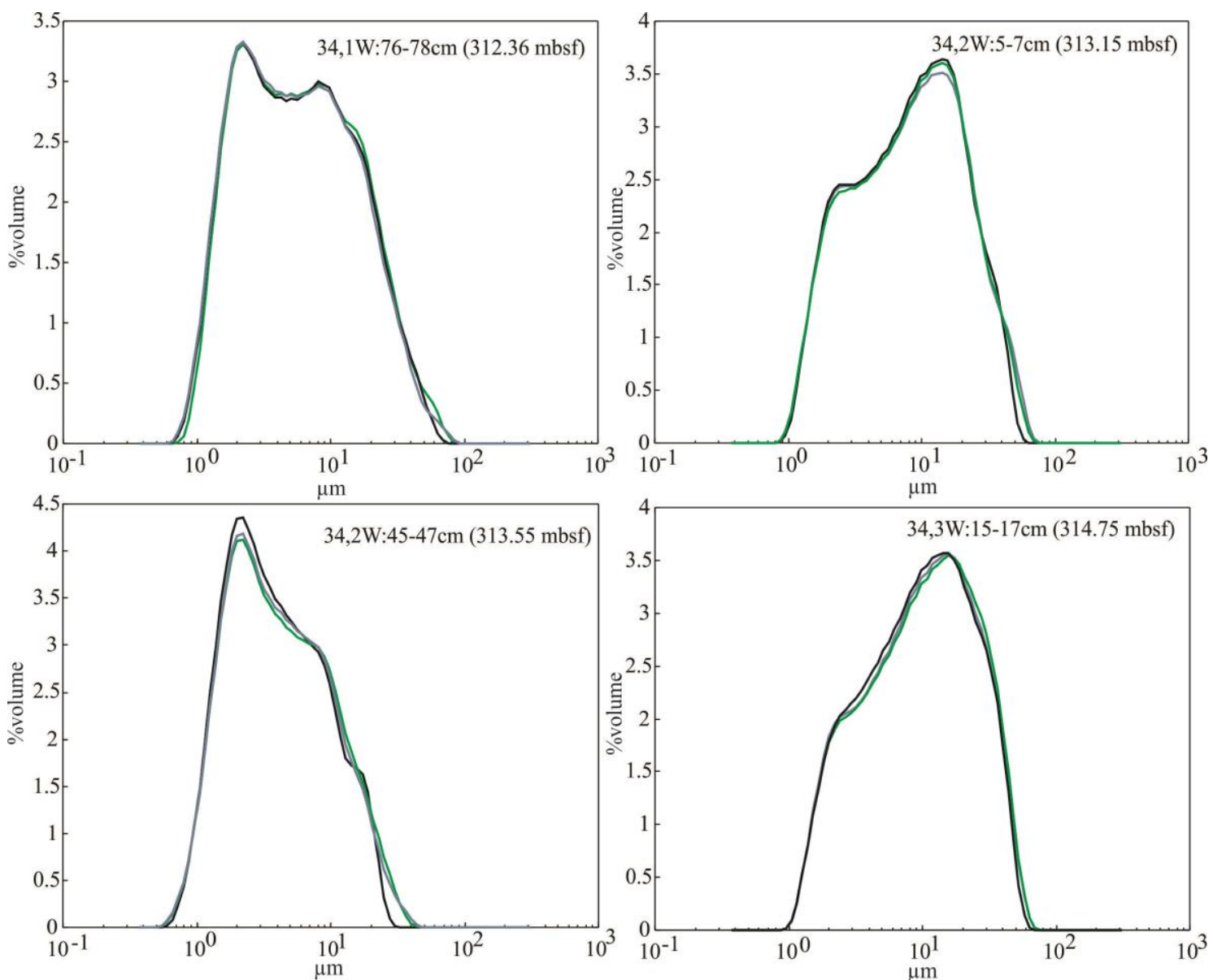

Figure 4. 2 Reproducibility of grain size data. These four examples illustrate that the 3 subsamples produced identical results, indicating internal consistency in the established grain size method. 


\subsection{BIOMARKER ANALYSIS}

Samples were prepared at VUW and analyses was completed at GNS Organic Geochemistry laboratory in Wellington. All biomarker analyses were conducted under the guidance of Bella Duncan, VUW, with methods adapted from her Ph.D. (Duncan, 2017). Biomarker analysis was completed to gain preliminary insight into the environmental conditions during the study interval and identify if suitable proxies existed in this core to reconstruct sea surface temperatures and to identify possible indicators of contemporaneous terrestrial vegetation. Only 11 samples were tested, targeting nannofossil-rich intervals.

Preparation: Due to possible risk of plastic contamination, samples were immediately removed from core plugs and wrapped in tinfoil post freeze drying. $\sim 10 \mathrm{~g}$ of each sample was homogenised into a fine powder and placed into a pre-weighed $50 \mathrm{ml}$ glass centrifuge tube. One 'glass bead' blank was added to the batch to check for any contamination during the extract and/or column chromatography stages. All glassware used was washed in detergent and placed in the furnace at $450{ }^{\circ} \mathrm{C}$ for 8 hours and subsequently rinsed with nhexane (HEX) and dichloromethane (DCM).

Extractions: $20 \mathrm{ml}$ of dichloromethane (DCM): methanol (MeOH) (3:1) was added to each sample and mixed thoroughly. After the samples were ultra-sonicated for 20 minutes, then placed in a $40^{\circ} \mathrm{C}$ water bath for one hour before being centrifuged for 5 minutes at $2000 \mathrm{ppm}$. The liquid was removed using glass pipettes, into $500 \mathrm{ml}$ glass test tubes (Bucchi tubes). Following the first extraction, a further $10 \mathrm{ml}$ of DCM: $\mathrm{MeOH}(3: 1)$ was added, and ultra-sonicated and centrifuged. This step was repeated twice more to achieve $50 \mathrm{ml}$ of DCM: $\mathrm{MeOH}$ in total. The tubes were evaporated down, with the total lipid extract (TLE) remaining.

Column chromatography: Using the short glass Pasteur pipets, a small amount of cleaned cotton wool was placed at the bottom, followed by $\sim 4 \mathrm{~cm}$ of silica gel and top with $\sim 2$ mm of furnaced sand. Each column was conditioned using 3 runs of n-hexane. At the beginning of each fraction, the TLE vial is re-dissolved using a few drops of solvent and added to the column (allowing to drain through completely each time). Four fractions were run, with a different solvent and volume added each time (Table 2). Each fraction 
was collected in the $10 \mathrm{ml}$ vials before being dried down and transferred into GC-vials (2 $\mathrm{ml})$ ready for analysis.

Table 2 Solvent used to extract each fraction during columns

\begin{tabular}{|c|c|c|}
\hline Fraction & Solvent & Solvent volume \\
\hline N1 & HEX & $4 \mathrm{ml}$ \\
\hline N2 & HEX:DCM $(2: 1)$ & $2 \mathrm{ml}$ \\
\hline N3 & DCM & $4 \mathrm{ml}$ \\
\hline N4 & $\mathrm{MeOH}$ & $5 \mathrm{ml}$ \\
\hline
\end{tabular}

Gas chromatography and mass spectroscopy: N1, N2 and N3 fractions were dissolved in $200 \mu \mathrm{HEX}$. An aliquot of $100 \mu \mathrm{l}$ was removed and placed into a $200 \mu 1$ insert held within a $2 \mathrm{ml}$ vial. Each sample was subsequently dried down, to be re-diluted by $20 \mu 1$ of $n$-Hexane in preparation for analysis. The N4 fraction was also dissolved in $200 \mu 1$ of $n$ Hexane, with $50 \mu 1$ was removed and placed directly into a $2 \mathrm{ml}$ vial. Once dried down, the samples were derivatized by diluting in $20 \mu \mathrm{FA}$ and $20 \mu \mathrm{l}$ BSTFA and heated for 1 hour at $80^{\circ} \mathrm{C}$. All fractions were analysed on the GC-Mass spectroscopy (GC-MS) at National Isotope Centre, GNS, to obtain results

Data processing was undertaken at VUW with calculations following those outlined in Duncan, (2017). In the N1 fraction: n-alkanes were integrated by identifying the different carbon chain lengths on the chromatogram, using the total ion current (TIC). The carbon chain length originates from different biological sources. The homogenous n-alkanes can be described the:

1) Carbon preference index (CPI) indicates if the sample is dominated by odd number of carbon atoms. A CP1 of $>1$ is indicative of a terrestrial plant. Calculated by: $C P I=0.5((\operatorname{Lodd}(n-C 25-33) / \operatorname{Leven}(n-C 24-32))+(\operatorname{Lodd}(n-C 25-33) / \operatorname{Leven}(n-C 26$ $-34)))$

2) Average chain length (ACL) indicates the dominant n-alkane with the samples defined as a carbon number. This is an indication of climate and the plant-based communities. Calculated by: $A C L=\Sigma(\operatorname{Codd} 25-33$.xodd 25-33)(xodd 25-33) 
Also, within the N1 fraction, hopanes were integrated using the TIC, potentially an indication of source maturity. Samples containing hopanes were initially identified using the mass fraction (M/Z 191), as this is the typical configuration with the first split at 191, and the remaining volume varies depending on the total ion current. The ratio between these splits provides information on the maturity level of the biomarker. Maturity refers to the degree of heating the sediment has been subject to. The configurations include:

- $\mathrm{B} \beta=$ Biological configuration (contemporary; lacking reworking)

- $\mathrm{A} \beta=$ thermally stable (mature source; been altered post deposition)

- $\mathrm{B} \alpha=$ combination

The calculation used $((B \beta /(B \beta+A \beta+B \alpha))$ helps to support $C P I$. The value output from that equation should range between $0-1 \quad(1=$ no biological change, and $1=$ thermally stable).

\subsection{FACIES ANALYSIS}

Detailed facies analysis provided a stratigraphic framework to base sedimentary processes and paleoenvironmental interpretations on. Lithological descriptions were constructed using: shipboard lithological logs, line-scanned colour images, photographs, grain size, geochemical and physical properties datasets. This combination of proxies was utilized to define the facies distributions at a higher resolution than was conducted during shipboard descriptions (Escutia, et al., 2011b). Shipboard analysis identified three lithofacies for the Late Miocene interval (C, D and E; Escutia, et al., 2011b)

Facies were recognised by using the following approach, which is crossed checked between the different datasets for consistency:

- Visual checks of core images and existing log - identified visible colour/ textural shifts and contacts of beds. 
- $\mathrm{XRF}$ data $-\mathrm{Ba} / \mathrm{Al}$ and $\mathrm{Si} / \mathrm{Al}$ indicated productivity diatom shifts, while $\mathrm{Ca} / \mathrm{Al}$ and $\mathrm{Sr} / \mathrm{Ca}$ indicated intervals of nannofossils. The Al/Ti ratio illustrates the composition of the lithogenic material, as neither $\mathrm{Al}$ or $\mathrm{Ti}$ is incorporated into the critters.

- Grain size data - was used to identify shifts in clay, silt and sand percentages. This can provide information on the depositional processes associated with each facies.

- Natural Gamma Radiation (NGR) and Magnetic susceptibility (MS) - used to identify periods of biogenic and clay input. NGR and MS were utilized, to minimise effects of coring disturbance, which made visual checks difficult in intervals. The physical properties and core photography/log data are from Escutia, et al., (2011b) and can be obtained from the online IODP data repository (http://web.iodp.tamu.edu). MS provides information on the composition of the sediment, associated to the presence of magnetic minerals. For example, sediments rich in biogenic material will have a low MS value due to reduced terrigenous content. NGR is a measure of the gammarays emitted, with clay-rich minerals producing majority of the radiation (Escutia et al., 2011b).

\subsection{Age Model}

The age model for Site U1361A was constrained by paleomagnetic boundaries, and biostratigraphy developed using the CONOP database for Southern Ocean diatom and radiolarians. Two versions of hybrid CONOP age model (strict and relaxed modes) defined by Cody et al., (2012), were adopted to create a 'time envelope' of maximum and minimum age ranges (see Crampton et al., (2016) for details), and used to constrain the best fit of the magnetostratigraphic to the geomagnetic timescale (Tauxe et al., 2012). If the paleomagnetic tie points in Table 3 are correct, then the sedimentation over the $50 \mathrm{~m}$ of core appears to vary from 4.4 to $8.9 \mathrm{~cm} / \mathrm{kyr}$ (average $6.02 \mathrm{~cm} / \mathrm{kyr}$ ). This is consistent with the age model envelope developed from the CONOP model. However, this also produced a large amount of uncertainty with the calculated ages, which is discussed in detail in section 5.4, and resulted in the use of separate techniques (outlined below) to improve age model resolution. 
Table 3 Late Miocene Site U1361 tie points, modified from Tauxe, et a., 2012. Refer to Figure 5. 10 for a visual stratigraphic representation. Tie point 1, is the only tie point used in the final age model constraints.

\begin{tabular}{|c|c|c|c|}
\hline Tie point & Polarity Chron & Age (Ma) & Depth (mbsf) \\
\hline 1 & C5n.2n (bottom) & 11.056 & 313.726989 \\
\hline 2 & C5r.1n (bottom) & 11.188 & 325.604921 \\
\hline 3 & C5r.2n (bottom) & 11.657 & 353.810839 \\
\hline
\end{tabular}

Multitaper method (MTM) spectral analysis was used to identify significant frequencies in the depth domain of four selected datasets (mean grain size, silt $\%, \mathrm{CS} \%$ and $\mathrm{Si} / \mathrm{Al}$ ). This method allowed for the detection of harmonic (regular periodicity) and significant band (irregular periodicity) signals. The spectral peaks were tested against the null hypothesis, which states no orbital signal is found at the confidence levels of 90, 95 and 99\% (Ghil et al., 2002). MTM analysis was completed by using the ratios of the period (m) of the significant cycle identified in all four datasets, and assuming these are consistent with ratios derived from orbital solutions. If consistency was identified, this allows an assumed sedimentation rate to be estimated (i.e. LSR $\mathrm{cm} / \mathrm{ka}=\mathrm{m} /$ cycle divided by $\mathrm{ka}$ ), and compared to the average sedimentation rate within in core U1361A, and to the less certain paleomagnetic tie points ( 2 and 3; Table 3 ). Refer to results section 5.4 for details on the age model development and the decision on what LSR was more suitable to use in this interval.

To assess this approach in a more quantitative manner, Average Spectral Misfit (ASM) was also performed on the mean grain size (MGS) and silt \% datasets to evaluate the potential for astronomical signal but independent of the identified tie points. ASM finds the optimal sedimentation rate $(\mathrm{cm} / \mathrm{kyr})$ for the given stratigraphic interval that has preserved an orbital-paced record, relative to depth not time (Meyers and Sageman, 2007). ASM is measured in cycles/ka, calculating the 'misfit' (average distance) between the identified significant frequencies in the dataset and optimal astronomical targets. This method provided a statistical test, as it rejects the null hypothesis (no orbital signal) when critical significance level passes 0.5\% (Meyers and Sageman, 2007; Meyers et al., 2012). ASM was adopted in the development of the age model, as it provided a suitable method of calculating the constant sedimentation rate, from only the one absolute tie point 
(11.056 Ma) and provided the opportunity to test the certainty of the developed age model.

\subsection{SPECTRAL ANALYSIS}

Spectral analysis was conducted on silt \% and MGS datasets in the Astrochron package for R (Meyers, 2014), to identify the orbital frequencies within the selected interval. This is a key tool for identifying periodic patterns in the sedimentary sequence (Meyers, et al., 2014). To reduce noise and standalone peaks, the datasets were 'trimmed' to remove any outliers, and linearly interpolated to the average sampling interval in Astrochron. Evolutionary harmonic analysis (EHA) was conducted to investigate the stability of the sedimentation rate, as the sedimentation rate may be aligned with shifting orbital frequencies (Meyers et al., 2012). EHA was conducted with a window size of $400 \mathrm{kyr}$ (amount of data used in each power spectra slice) in a step of 4 ka (frequency the 'window' shifts). 


\section{CHAPTER FIVE: RESULTS}

\subsection{GRAIN SIZE ANALYSIS}

The grain size of the lithogenic fraction from Site U1361 is dominated by silt (60-80\%). However, the relative abundances of clay, silt and sand fluctuate over the record, with a repetitive variation occurring every $\sim 2-5 \mathrm{~m}$ (Figure 5.2 ). Ternary diagrams confirm that all samples range from $50-75 \%$ silt and $<50 \%$ clay (Figure 5.1 ). The highest silt percentage (silt \%) is associated with the diatom and nannofossil-rich sediments, whilst high clay percentage (clay \%) is associated with the faintly laminated sediments (Facies 4; Figure 5. 1). Percentage sand ( $\mathrm{sand} \%$; 63-200 $\mu \mathrm{m}$ ) is minimal throughout the core (ranging between 5 and $20 \%$ ) and is highest in the nannofossil-rich intervals. The lack of long-term trends in the mean grain size curve indicate that there was no dramatic shift in the long-term rate in which sediment was accumulating (e.g. no sharp changes) or in depositional processes. The grain size distributions for the four lithofacies defined in the studied interval are summarised in (Table 4).

Table 4 Characteristics of grain size frequency distributions. Refer to Figure 5. 1.

\begin{tabular}{|l|l|}
\hline Sediment type & Distribution description \\
mud & $\begin{array}{l}\text { Mud fraction skewed towards silt, with a dominant mode at } ~ 20 \\
\mu \mathrm{m}, \text { and a minor mode in the clay fraction }(\sim 2 \mu \mathrm{m}) . \\
\text { Sporadic discrete peaks in the sand fraction (Facies 1) }\end{array}$ \\
\hline $\begin{array}{l}\text { Nannofossil-rich } \\
\text { mud }\end{array}$ & $\begin{array}{l}\text { Distribution in mud fraction is even between clay and silt, with a } \\
\text { lack of a common mode between samples. Discrete peak in the } \\
\text { sand fraction (Facies } 2)\end{array}$ \\
\hline $\begin{array}{l}\text { Diatom- } \\
\text { nannofossil- } \\
\text { bearing mud }\end{array}$ & $\begin{array}{l}\text { Distribution of mud fraction towards silt (similar to Facies 1). } \\
\text { Lack of discrete peaks in the sand fraction (Facies 3) }\end{array}$ \\
\hline $\begin{array}{l}\text { Faintly } \\
\text { laminated mud }\end{array}$ & $\begin{array}{l}\text { Mud fraction skewed, with a dominant mode in clay fraction } \\
(\sim 1.5-2 \mu \mathrm{m}) . \text { 'Tail' in the coarse silt fraction (Facies 4) }\end{array}$ \\
\hline
\end{tabular}



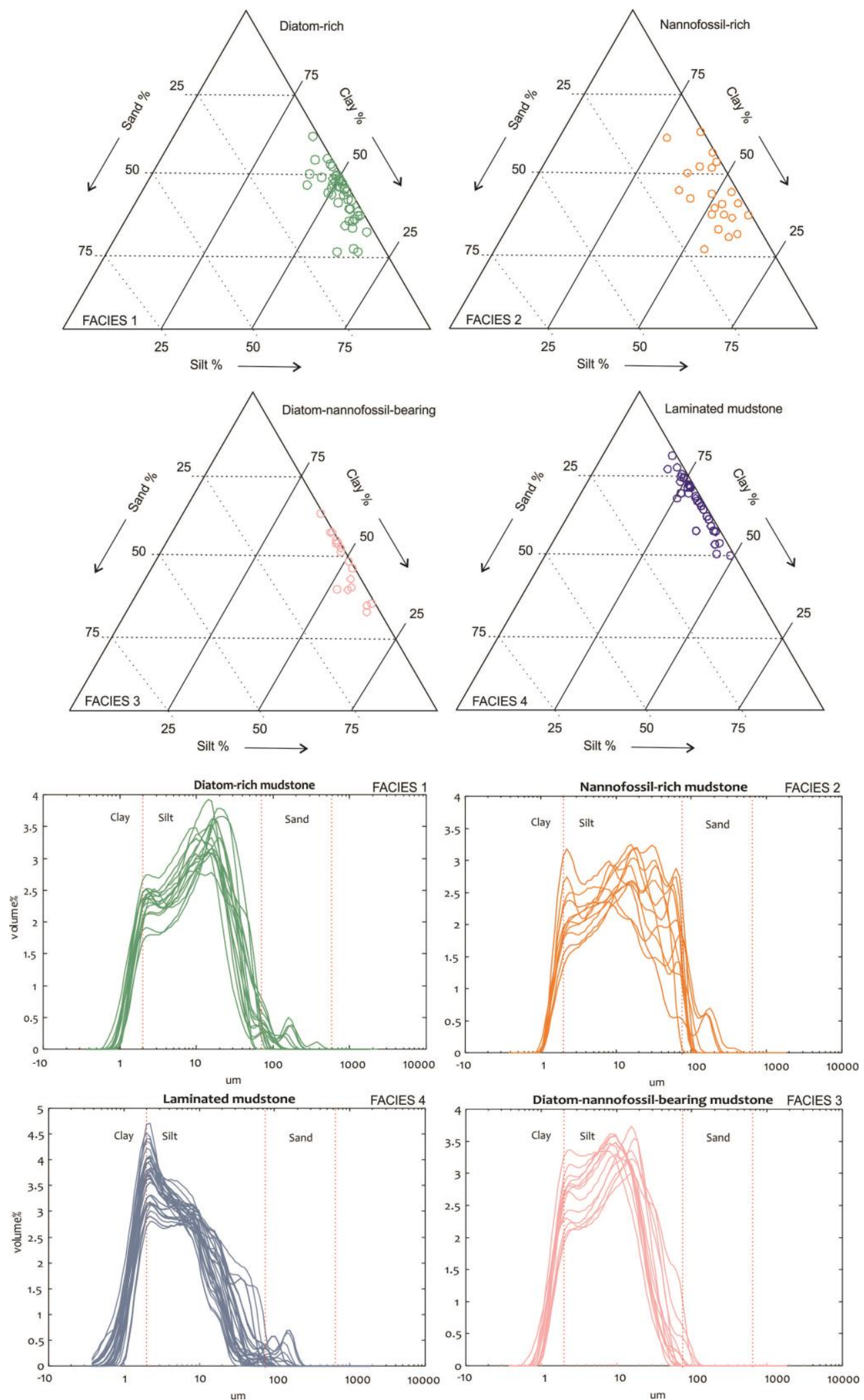

Figure 5. 1 Ternary diagrams and grain size frequency distributions: demonstrating textural variability between the four facies defined at Site U1361. Parameters are defined as: clay $<8 \mu \mathrm{m}$ (see methods), silt 8-63 $\mu \mathrm{m}$ and sand 63-2000 $\mu \mathrm{m}$. 


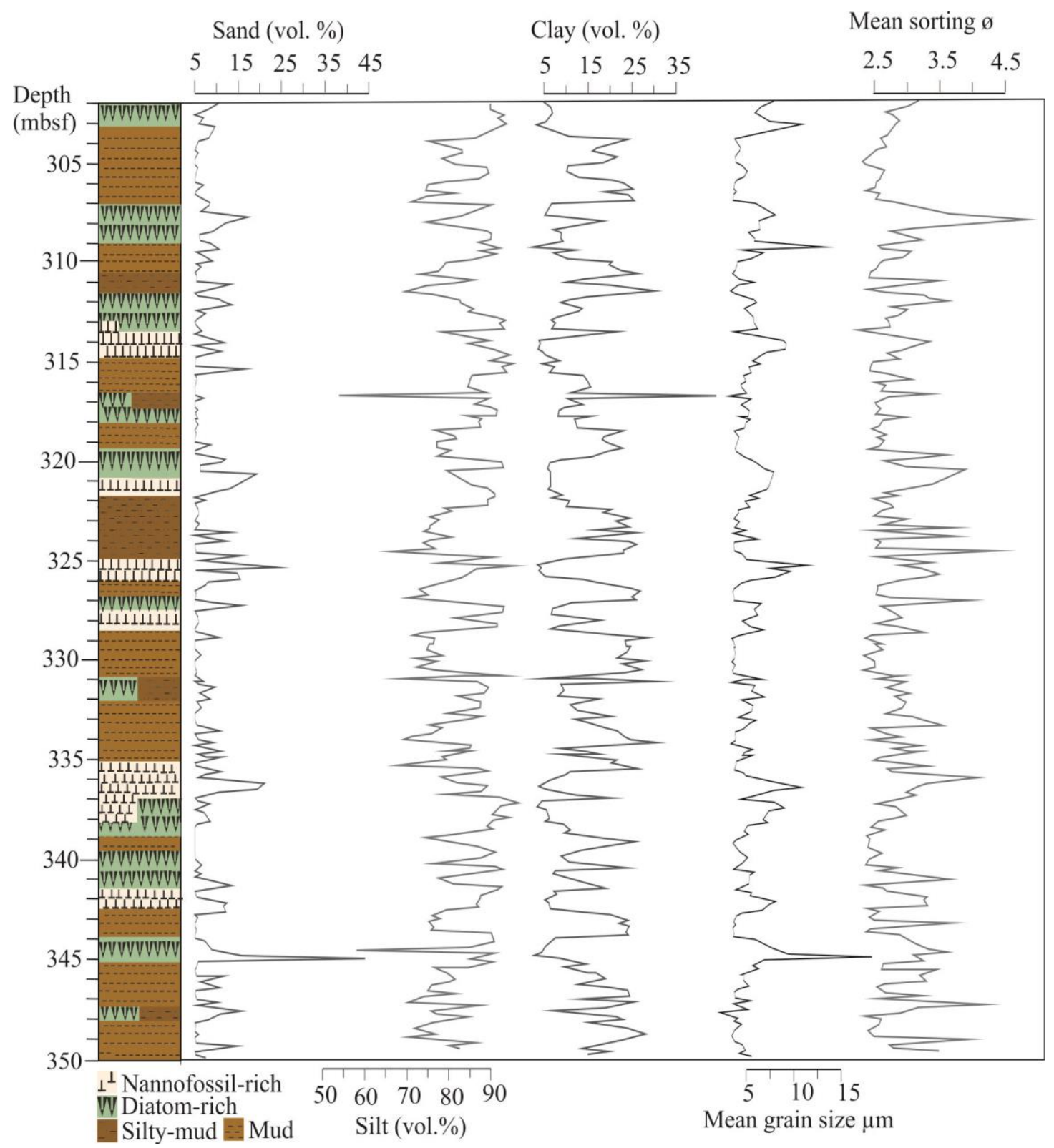

Figure 5. 2 Site U1361 grain size data, including percentage of clay $(<4 \mu \mathrm{m})$, silt (4-63 $\mu \mathrm{m})$ and sand (63-2000 $\mu \mathrm{m})$ fractions. Figure contains mean grain size and sorting parameter defined by Folk and Ward in GRADISTAT (Blott and Pye, 2001) 


\subsubsection{ICEBERG RAFTED Debris MaSs ACCUMUlation RATE}

The correlation between IBRD MAR and sorting, suggests that the coarse-grained fraction at Site U1361 is an ice-rafted signal, with peaks correlating to poor to very poorly sorted sediments $(>2 \varnothing)$. Based on the argument by Passchier, (2011), this indicates that the sediment above $250 \mu \mathrm{m}$ are not 'lag' deposits, and abundance can be considered a 'real' iceberg calving signal. However, the assumption that winnowing of clay-rich fraction results in a well-sorted sediment is not always correct, as the removal of the clay to fine silt mode may also result in a more poorly sorted sediment. Although, if the source sediment of the terrigenous material is consistent, it is likely that current winnowing has a relationship with sorting. To more rigorously test this, the cross plot between coarse sand percent (CS \%) and mean sorting (Figure 5. 3) illustrates a poor relationship $\left(\mathrm{r}^{2}=\right.$ 0.0015), suggesting that the calculated IBRD at Site U1361 can be considered a primarily iceberg calving signal during the Late Miocene.

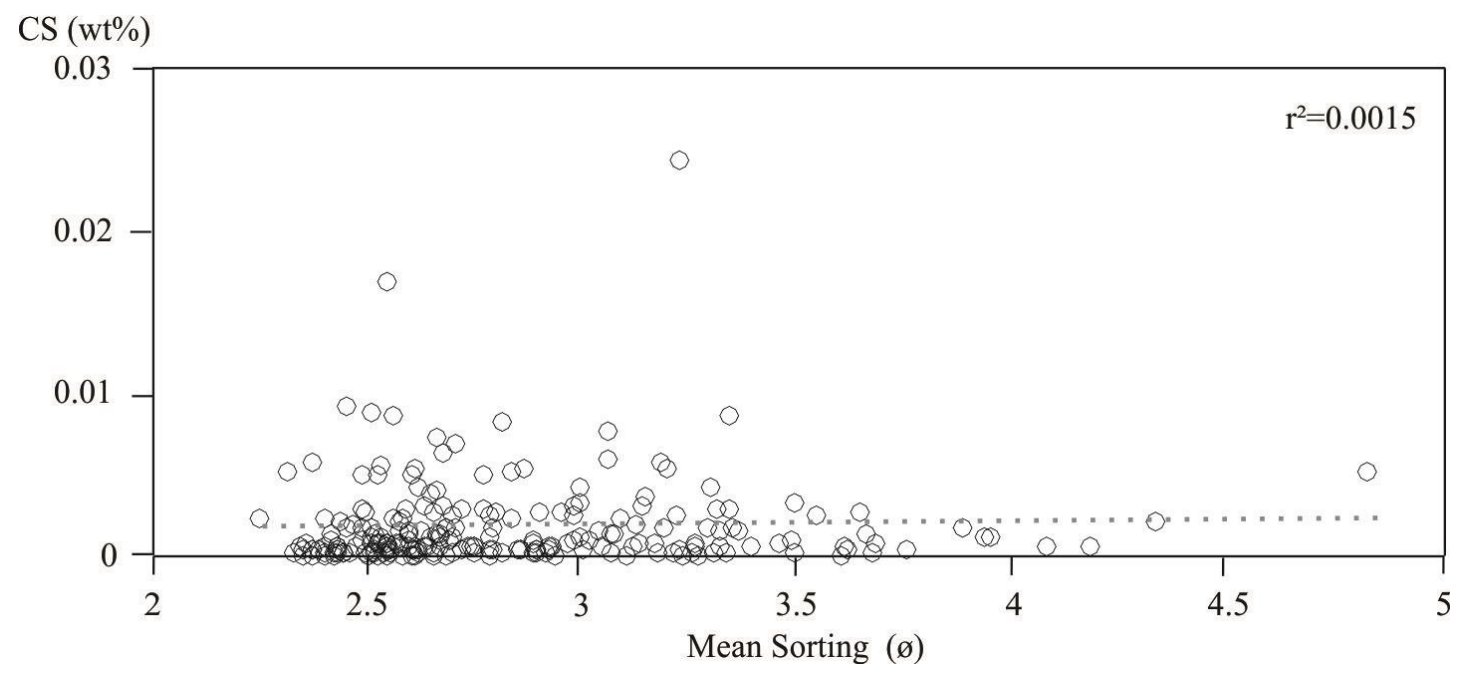

Figure 5. 3 Cross plot of coarse sand percentage (CS\%) and sorting at Site U1361, classifies a very poor relationship $\left(r^{2}=0.0015\right)$. 
IBRD MAR

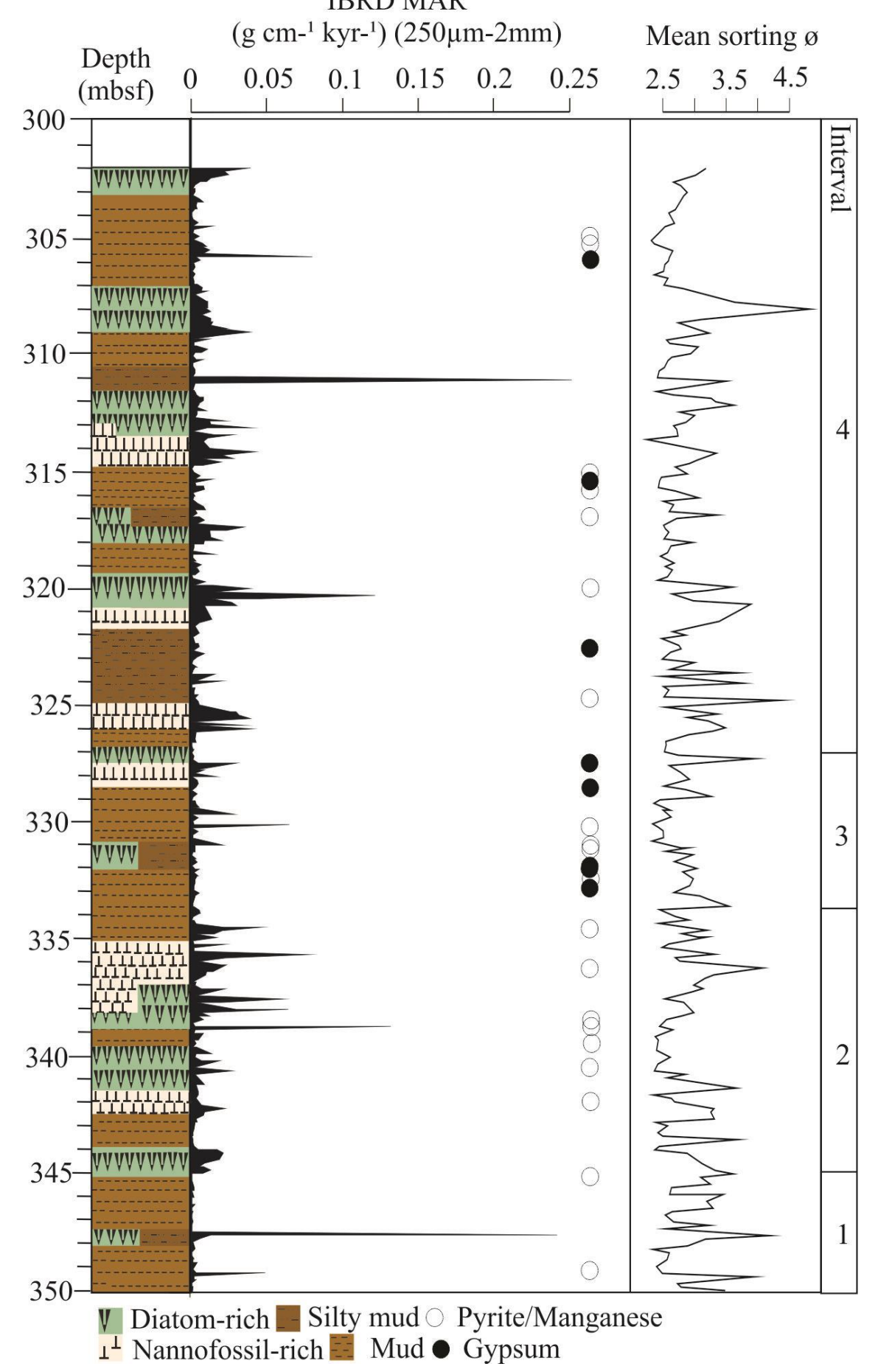

Figure 5. 4 Site U1361 Iceberg Rafted Debris (IBRD) Mass Accumulation Rate (MAR) $\left(\mathrm{g} \mathrm{cm}^{-2} \mathrm{kyr}^{-1}\right)$, compared to the sorting of the terrigenous material. Sorting was defined by Folk and Ward, in GRADISTAT (Blott and Pye, 2001). The dots indicate the location down the core of gypsum and pyrite/manganese nodules removed from the $250 \mu \mathrm{m}$ to $2 \mathrm{~mm}$ fraction. 
Regular intervals of elevated IBRD MAR $(250 \mu \mathrm{m}$ to $2 \mathrm{~mm})$ occur every $\sim 5-10 \mathrm{~m}$ throughout the core (Figure 5. 4). However, there are also intervals when IBRD MAR is less significant, remaining at background levels. Visually the IBRD MAR record can be characterised by four distinct intervals (indicated on Figure 5. 4).

Interval 1 ( $\sim 350$ to $345 \mathrm{mbsf}$ ): IBRD MAR is minimal, except for two discrete peaks centred at $\sim 349$ and 348 mbsf. The peak at $\sim 348$ mbsf is the largest in the record, however, it may be spurious as it lacks supporting data points.

Interval 2 ( $\sim 345$ to $334 \mathrm{mbsf})$ : IBRD MAR increases significantly, with values reaching 0.05-0.1 $\mathrm{g} \mathrm{cm}^{2} \mathrm{kyr}^{-1}$, and peaks becoming more prolonged. Values are above background level for much for this interval.

Interval 3 ( $\sim 334$ to 327 mbsf): IBRD MAR decreases to background values, but with three small distinct peaks around $\sim 330$ mbsf. This pattern is similar to interval 1 and is a noticeable change from interval 2 .

Interval 4 ( $\sim 327$ to $302 \mathrm{mbsf}$ ): IBRD MAR increases for the remainder of the record. During this phase IBRD MAR is more persistent, with the large peaks superimposed at a higher level than background IBRD seen previously. In this interval of the core, the peaks distinctly appear to occur every $\sim 5 \mathrm{~m}$.

The majority of IBRD MAR peaks positively correlate with intervals of diatom and/or nannofossil-rich sediments, with an increase in IBRD occurring at the transition in these sediment types. IBRD MAR commonly decreases in the mud-rich intervals, although IBRD is still present, particularly in the upper part of the studied record (e.g. above $\sim 335$ mbsf). 


\subsection{X-RAY FLUORESCENCE (XRF)}

The Pearsons correlation matrix was used to determine geochemical element associations (Table 5), and indicates whether the elements are either positively or negatively correlated depending on whether they are hosted in the lithogenic (Al, Ti); biogenic (Ca, Sr); mixed lithogenic/biogenic $(\mathrm{Si})$; or authigenic $(\mathrm{Mn}, \mathrm{Ba})$ material. Aluminium was chosen as the reference terrigenous element in this study, as it appears to be stable (Table 5, appendix $\mathrm{B}$ ) and the $\mathrm{Al} / \mathrm{Ti}$ ratio suggests there was no major source change in the composition of lithogenic material (Figure 5. 5) at this time (ranging between 15-19; explained in detail in section 6.1). Therefore, the ratio of the other elements against aluminium is fixed and variations in that ratio will only reflect changes in that element (e.g. variations in the ratio of $\mathrm{Si} / \mathrm{Al}$ are reflecting the input of additional silica without further aluminium contribution). The ratios selected for this study are based on previous Antarctic studies, which have identified the most suitable elements to demonstrate variations in either biogenic and/or authigenic material (see section 2.7).

Table 5 Pearsons Linear correlation between XRF-scanned elements. Elements with strong correlation are highlighted in 'dark grey', and moderate in 'light grey'.

\begin{tabular}{|l|r|r|r|r|r|r|r|r|r|}
\hline & \multicolumn{1}{l|}{ Mg } & \multicolumn{1}{l|}{ Al } & \multicolumn{1}{l|}{ Ca } & Ti & Fe & Sr & Ba & Si & Mn \\
\hline $\mathbf{M g}$ & 1 & & & & & & & & \\
\hline $\mathbf{A l}$ & 0.162 & 1 & & & & & & & \\
\hline $\mathbf{C a}$ & -0.011 & -0.452 & 1 & & & & & & \\
\hline $\mathbf{T i}$ & 0.088 & 0.797 & -0.483 & 1 & & & & & \\
\hline $\mathbf{F e}$ & 0.289 & 0.628 & 0.286 & 0.628 & 1 & & & & \\
\hline $\mathbf{S r}$ & -0.063 & -0.519 & 0.898 & -0.485 & -0.336 & 1 & & & \\
\hline $\mathbf{B a}$ & 0.077 & 0.742 & 0.315 & 0.611 & 0.405 & -0.361 & 1 & & \\
\hline $\mathbf{S i}$ & -0.055 & 0.108 & 0.579 & 0.149 & 0.012 & -0.448 & 0.063 & & \\
\hline $\mathbf{M n}$ & 0.041 & -0.190 & 0.689 & 0.234 & -0.086 & 0.476 & -0.126 & -0.525 & 1 \\
\hline
\end{tabular}


The following section outlines the trends and significant features of the selected XRF elements and the relationship between the main ratios.

- Barium and aluminium show a strong positive correlation (0.74; Table 5). When compared in a cross plot the relatonship is not as evident, especially in intervals of low $\mathrm{Ba} / \mathrm{Al}$, when the curve becomes very noisy (Figure 5. 5).

- Variations in silica/aluminium (Si/Al) are distinct down the core, with cyclic peaks above background levels occurring every $\sim 5 \mathrm{~m}$. Peaks in $\mathrm{Si} / \mathrm{Al}$ directly correlate to an increase in diatom-rich sediments, and the ratio of $\mathrm{Ba} / \mathrm{Al}$ (Figure 5. 5).

- The ratio between calcium and aluminium $(\mathrm{Ca} / \mathrm{Al})$ is not consistent down the core, with only six short intervals when $\mathrm{Ca} / \mathrm{Al}$ values are above background values $(>2)$, which appears to directly correlate to nannofossil-rich sediments (Figure 5. 5).

- Aluminium and titanium strongly covary (0.7; Table 5; Figure 5. 5). When compared as a ratio, $\mathrm{Al} / \mathrm{Ti}$ exhibits a relatively small range between $15-19$. At the meter scale $\mathrm{Al} / \mathrm{Ti}$ is cyclic with gradual increases and then a rapid decline.

- The strontium/calcium $(\mathrm{Sr} / \mathrm{Ca})$ ratio is strongly cyclic with sharp transitions to low $\mathrm{Sr} / \mathrm{Ca}$ ratios $(<8)$, which directly coincide with the nannofossil-rich sediments. The ratios in the remainder of the record are consistently around $\sim 15$, however, above $\sim 313$ mbsf values increase to $>8$. $\mathrm{Sr} / \mathrm{Ca}$ ratio shows a distinct shift towards higher values above $\sim 320$ mbsf (Figure 5. 5).

- Manganese $(\mathrm{Mn})$ displays several distinctive 'spikes' above background values. These peaks are positively correlated with high $\mathrm{Ca} / \mathrm{Al}$ ratios, and are confined to nannofossil-rich sediments (Figure 5. 5). 


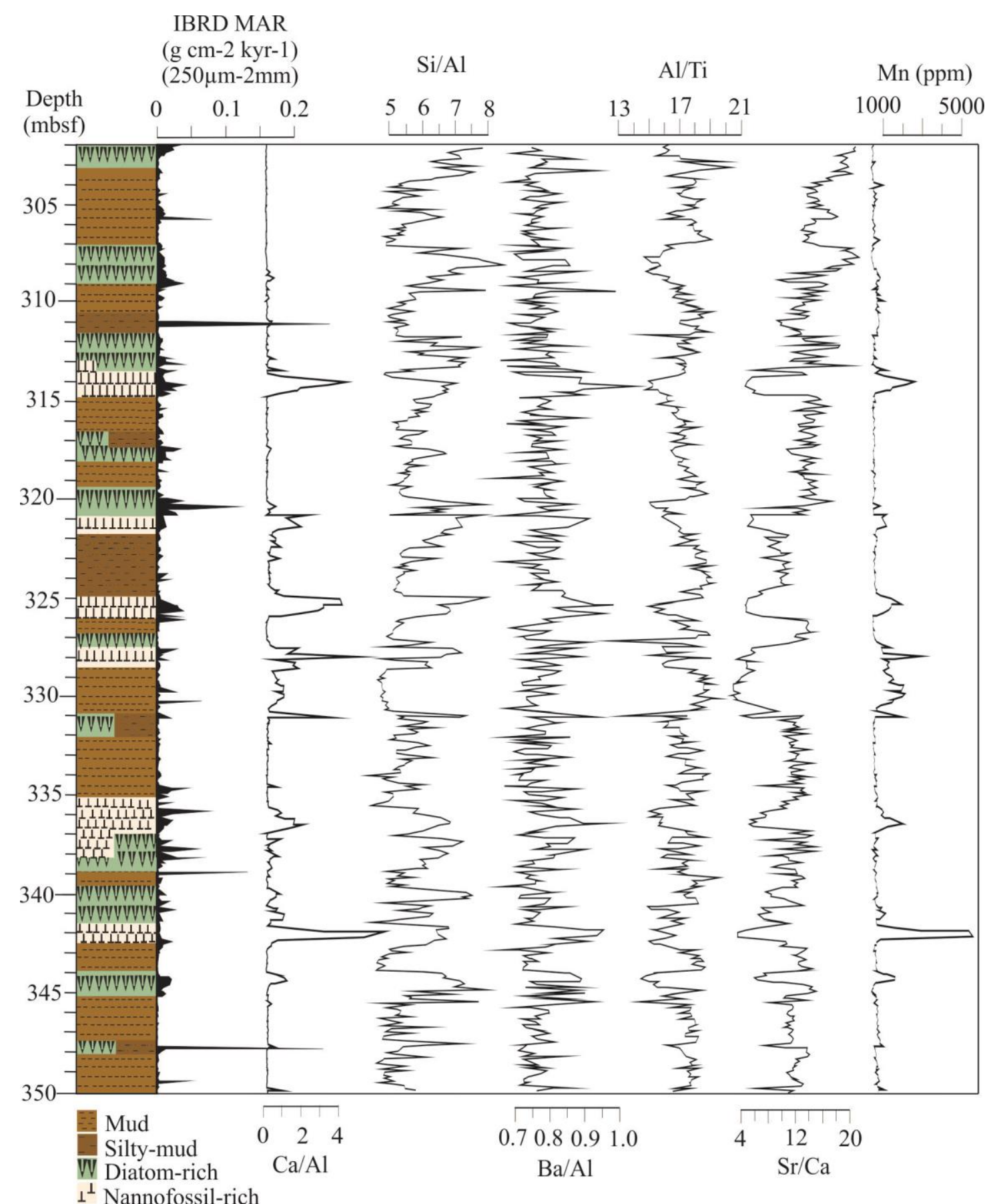

Figure 5. 5 Site U1361 XRF ratios - IBRD, Ca/Al, Si/Al, Ba/Al, Al/Ti, Sr/Ca and Mn values. 
The relationship between $\mathrm{Si} / \mathrm{Al}$ and $\mathrm{Ca} / \mathrm{Al}$ is not consistent down the core. The two ratios are positively correlated between $\sim 350$ and $330 \mathrm{mbsf}$, however, this switches to a negative correlation at $\sim 314$ mbsf. This change also marks the point above which $\mathrm{Ca} / \mathrm{Al}$ remains at background levels. Subsequently, $\mathrm{Si} / \mathrm{Al}$ peaks correlate to low $\mathrm{Ca} / \mathrm{Al}$ for the top $\sim 15 \mathrm{~m}$ of the studied interval (Figure 5. 5). The variation of magnitude between $\mathrm{Si} / \mathrm{Al}$ or $\mathrm{Ca} / \mathrm{Al}$ has a visible correlation to sediment composition. In intervals when both $\mathrm{Si} / \mathrm{Al}$ and $\mathrm{Ca} / \mathrm{Al}$ are above background levels, but at less significant values, it appears that both biogenic sources are present, e.g. at $\sim 327 \mathrm{mbsf}$ and are co-varying. $\mathrm{Sr} / \mathrm{Ca}$ is anti-phased with $\mathrm{Ca} / \mathrm{Al}$, with rapid drops in $\mathrm{Sr} / \mathrm{Ca}$ (to $\sim 3$ ) strongly correlated to intervals of nannofossil-rich sediments. $\mathrm{Al} / \mathrm{Ti}$ has a strong inverse relationship with both $\mathrm{Si} / \mathrm{Al}$ and $\mathrm{Ca} / \mathrm{Al}$, as peaks in $\mathrm{Al} / \mathrm{Ti}$ correlate with $\mathrm{Sr} / \mathrm{Ca}$ peaks and intervals of mud-rich sediments. An increase in IBRD MAR visibly brackets shifts in $\mathrm{Si} / \mathrm{Al}, \mathrm{Ca} / \mathrm{Al}$ and $\mathrm{Al} / \mathrm{Ti}$ (Figure 5. 5), with the majority of the IBRD pulses associated with an increase in diatom and/or nannofossilrich sediments, compared to the terrigenous muds. The largest IBRD peaks occur at the transition to peak $\mathrm{Si} / \mathrm{Al}$ and $\mathrm{Ca} / \mathrm{Al}$.

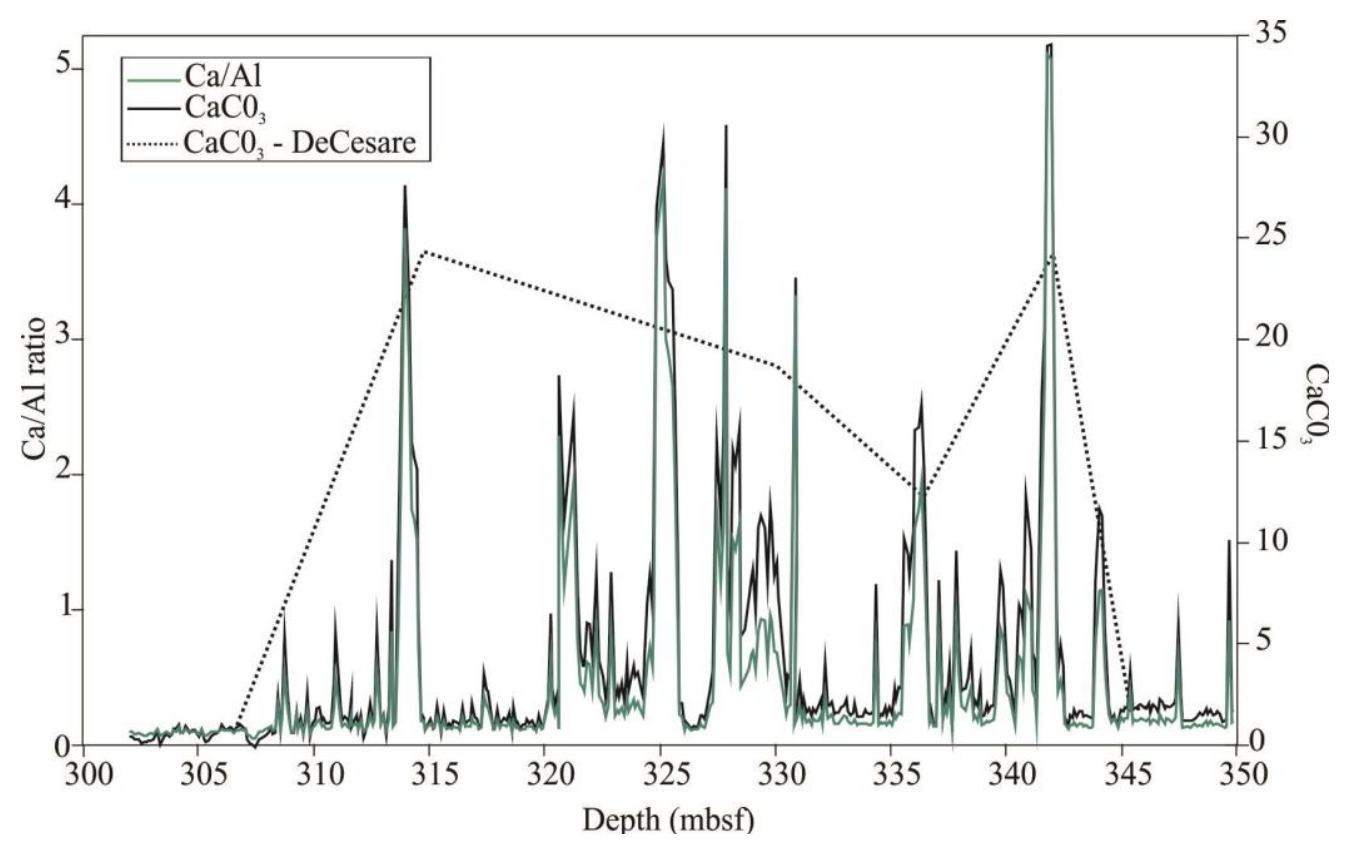

Figure 5. $6 \mathrm{CaCO}_{3}$ values for Site U1361, calculated from $\mathrm{Ca}$ (ppm), plotted with $\mathrm{Ca} / \mathrm{Al}$. The dotted line represents the shipboard data from DeCesare and Pekar, (2016), which highlights a tight correlation. 
Based on observations, it was interpreted that the $\mathrm{Ca}$ in the sediments is primarily biogenic in origin $\left(\mathrm{CaCO}_{3}\right)$ since the largest $\mathrm{Ca}$ peaks coincide with carbonate-rich intervals of the core. This allowed the nannofossil-rich sediments to be more tightly constrained, relative to the preliminary shipboard report. $\mathrm{CaCO}_{3}$ values calculated in this study and from Expedition 318 shipboard measurements (DeCesare and Pekar, 2016), are relatively consistent (Figure 5. 6). Slight differences between datasets are likely associated with the depth at which the samples were measured.

The physical property logs retrieved from the IODP data repository combined with the geochemical XRF ratios, were used as an indication of sedimentological changes (i.e. increase in clay or microfossils) to assist in the establishment of the lithofacies scheme (refer to section 4.6 for details). Diatom-rich sediments are characterised by enhanced $\mathrm{Si} / \mathrm{Al}$, low MS $(<2)$ and low NGR $(<30)$, which is similar to the nannofossil-rich intervals $(\mathrm{Ca} / \mathrm{Al})$, except the NGR values appear to be more extreme $(<26$; Figure 5. 7). Terrigenous mud-rich sediments (A1/Ti) are associated to a high MS (>50) and high NGR $(>40$; Figure 5.7).

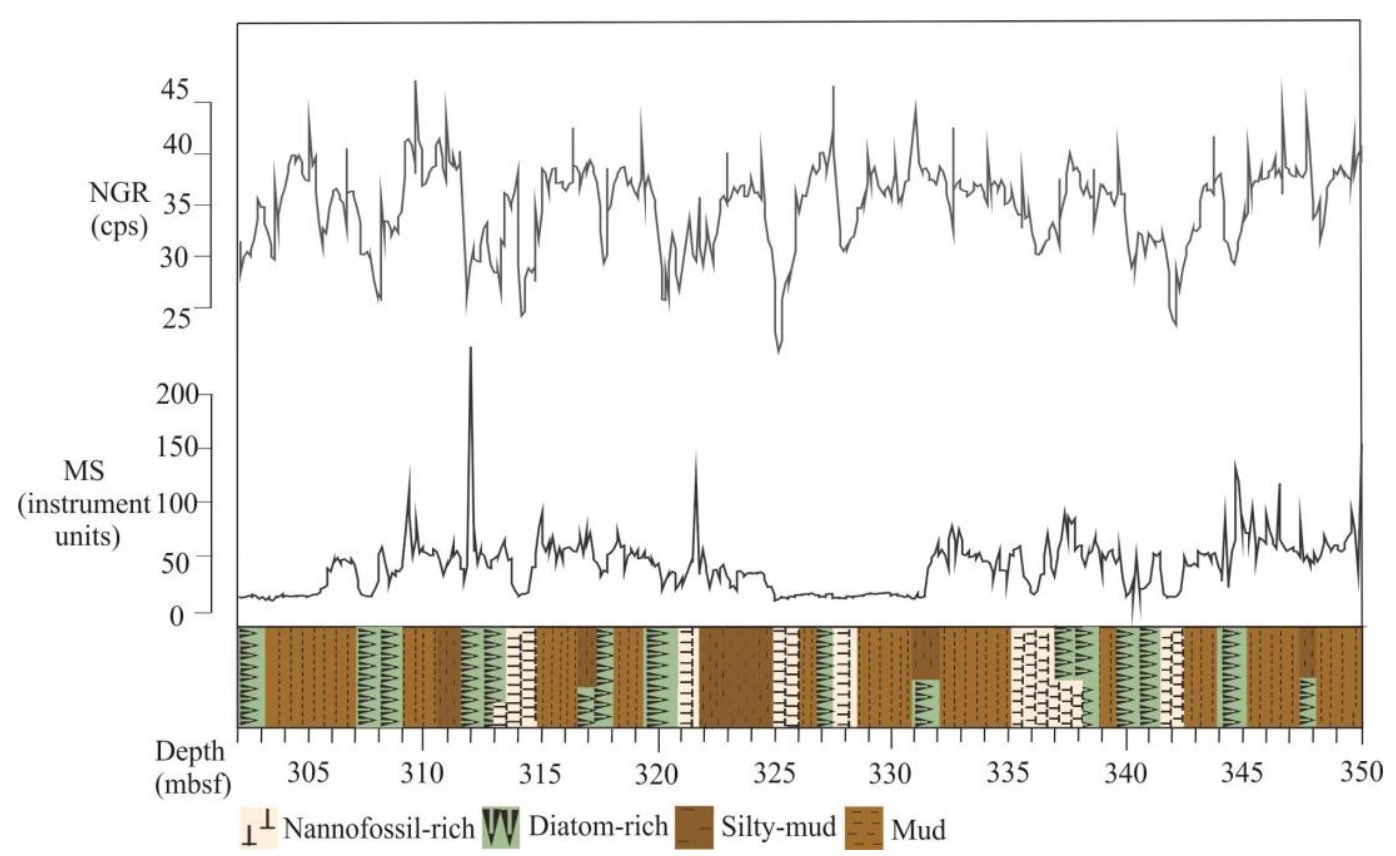

Figure 5. 7 Physical properties: Magnetic suscepitability (MS) and Natural gamma radiation (NGR) from Site U1361. This data was retrieved from the IODP online source (not dataset produced in this thesis) used alongside geochemical data to defined facies. 


\subsubsection{DIAGENETIC MINERAL IMAGING AND COMPOSITION}

The majority of $>250 \mu \mathrm{m}$ grains observed under the optical microscope were quartz and small rock fragments, interpreted as IBRD. However, three types of grains that were potentially bio- or authigenic origin were also identified in the $>250 \mu \mathrm{m}$ fraction (Figure 4. 1). A white/grey grain was recognized in three unique shapes; acicular, euhedral or prismatic with overgrowths (Figure 4. 1 \& Figure 5.8). Elemental mapping by EDS established the composition was calcium sulphate $\left(\mathrm{CaSO}_{4}\right)$ commonly known as gypsum. This grain type is often associated with the nannofossil-rich intervals of the core. Pyrite $\left(\mathrm{FeS}_{2}\right)$ and manganese (Mn; Figure 5.8) grains were recognized by the cubic habit system of pyrite and the framboidal texture of micro-Mn nodules. Elemental mapping was able to confirm pyrite (Figure 5.8). 'Mn' grains were not EDS scanned but XRF suggested enhanced $\mathrm{Mn}$ in intervals where these grains were present.
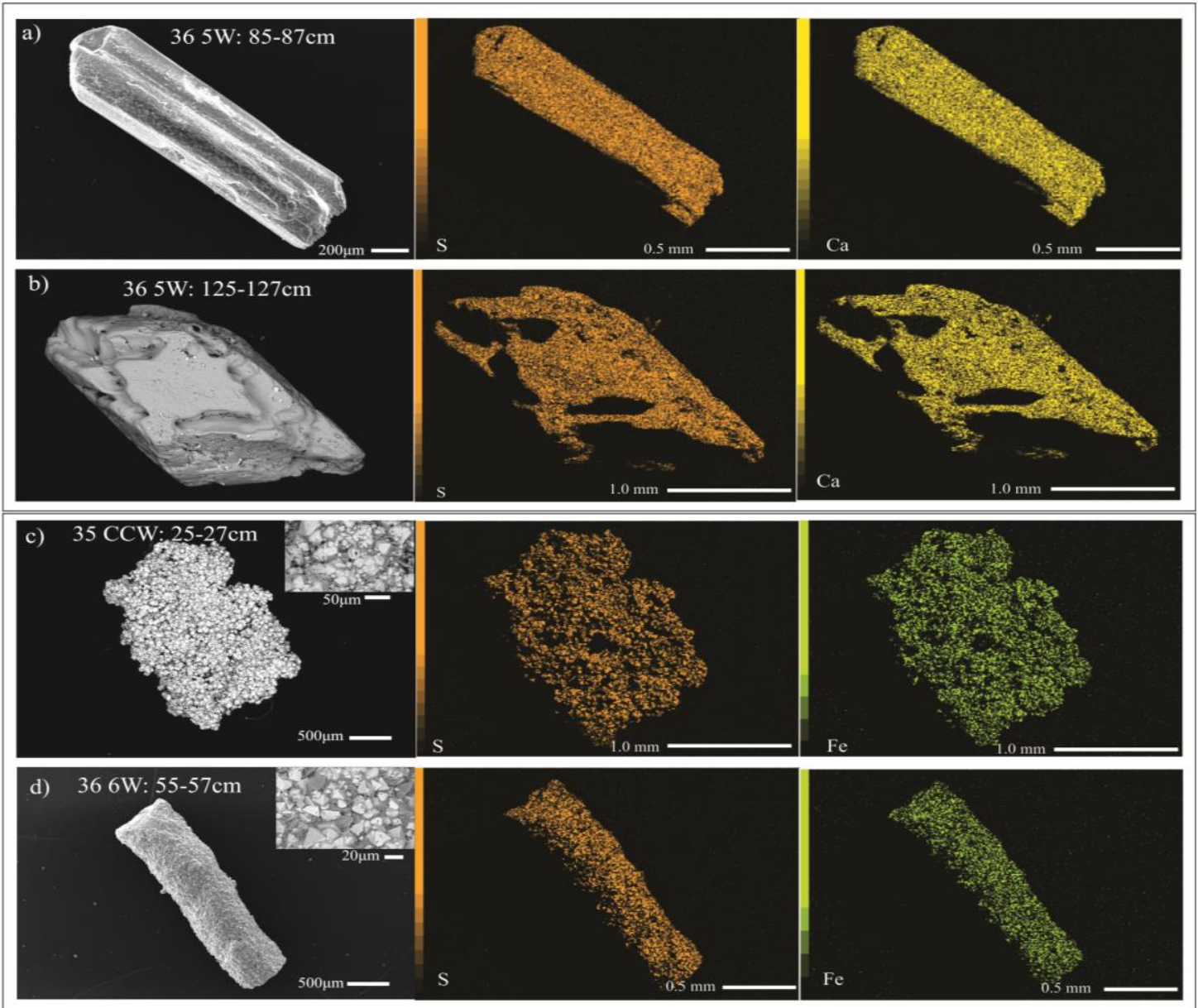

Figure 5.8 SEM and EDS results for Site U1361. a \& b) gypsum grains calcium sulphate $\left(\mathrm{CaSO}_{4}\right) . c \&$ d) pyrite grains - Iron sulfide $\left(\mathrm{FeS}_{2}\right)$ 


\subsection{Facies AnAlysis}

Four lithofacies are identified between $\sim 350$ and 302 mbsf, based on differences in colour, grain size, biogenic silica $(\mathrm{Si} / \mathrm{Al})$, carbonate $(\mathrm{Ca} / \mathrm{Al})$, bioturbation, sedimentary features, IBRD content and physical properties (section 4.6) These lithofacies are consistent with those defined by previous Antarctic studies on depositional processes and environments. Facies 1, 2 and 4 (Figure 5.9) defined below are equivalent to Facies D, $\mathrm{C}$ and E, respectively published in the initial IODP report for Site U1361 (Escutia et al., 2011b). However, additional analyses completed in this project allowed for more detailed characterization and interpretation of processes involved in their deposition. Even though this is the Results Chapter, facies are often defined by and linked to depositional processes and setting, and therefore the interpretation of each facies immediately follows the facies description. Summary descriptions and interpretations are provided in Table 6.

Table 6 Summary table of the four facies.

\begin{tabular}{|l|l|l|}
\hline Facies & Description & Interpretation \\
\hline Facies 1 & $\begin{array}{l}\text { Diatom-rich } \\
\text { mud }\end{array}$ & $\begin{array}{l}\text { Turbidite overbank levee deposition with significant } \\
\text { pelagic (diatom) settling, iceberg rafting and influence } \\
\text { of currents on suspension settling. Reworking by } \\
\text { bioturbation }\end{array}$ \\
\hline Facies 2 & $\begin{array}{l}\text { Nannofossil-rich } \\
\text { mud }\end{array}$ & $\begin{array}{l}\text { Turbidite overbank levee deposition with significant } \\
\text { calcareous pelagic settling (and preservation), iceberg } \\
\text { rafting and influence of currents on suspension } \\
\text { settling. Reworking by bioturbation }\end{array}$ \\
\hline Facies 3 & $\begin{array}{l}\text { nannofossil- } \\
\text { bearing mud }\end{array}$ & $\begin{array}{l}\text { Turbidite overbank levee deposition, with moderate } \\
\text { calcareous and diatom pelagic settling (and } \\
\text { preservation), iceberg rafting and influence of currents } \\
\text { on suspension settling. Reworking by bioturbation }\end{array}$ \\
\hline Facies 4 & $\begin{array}{l}\text { Faintly } \\
\text { laminated mud }\end{array}$ & $\begin{array}{l}\text { Turbidite overbank levee with influence of currents on } \\
\text { suspension settling Reduced but still present } \\
\text { bioturbation and IBRD. }\end{array}$ \\
\hline
\end{tabular}




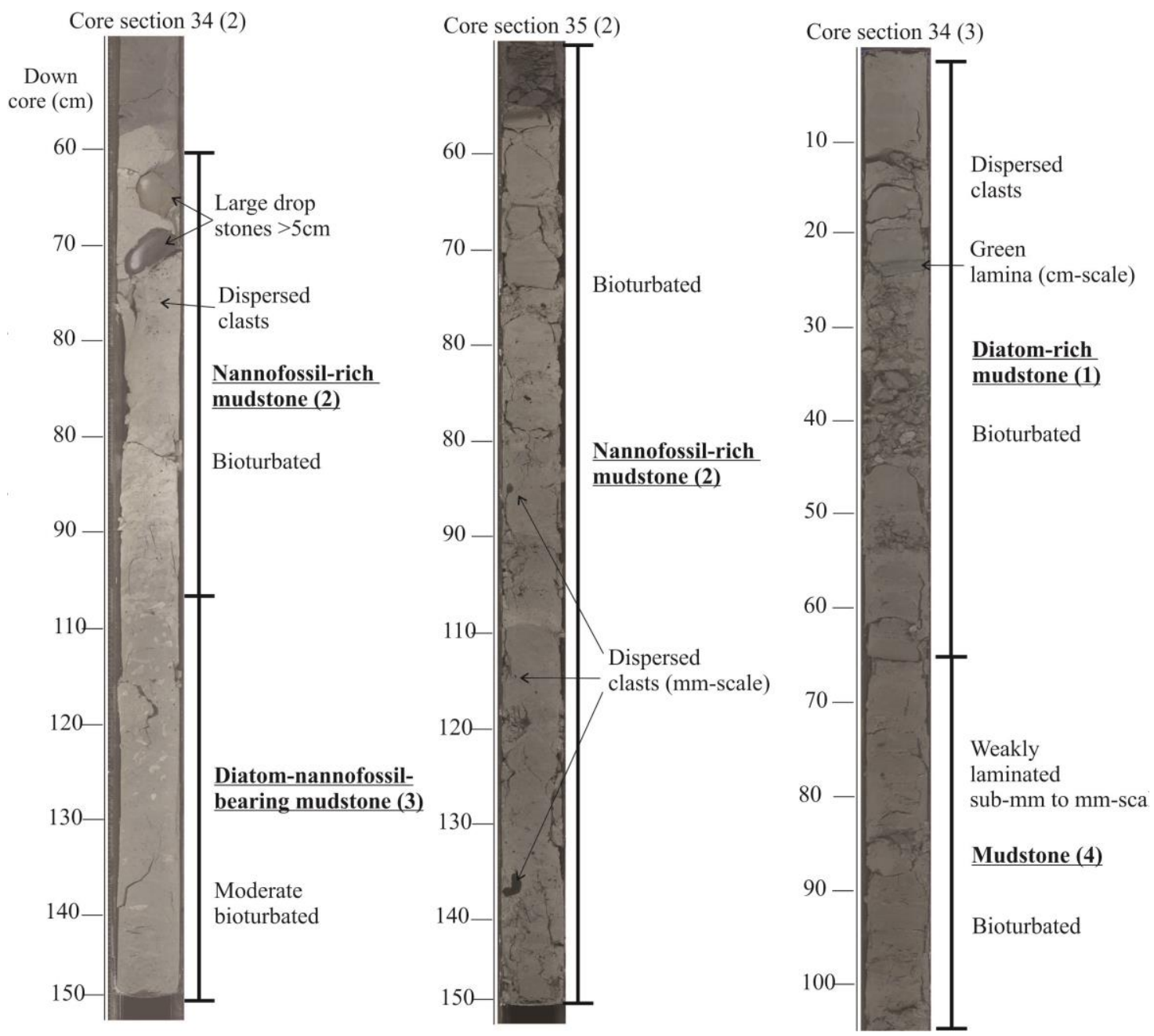

Figure 5. 9 Example sections of core from Site U1361. Annotations show the visual changes in sediment colour (greyscale), bioturbation and clast abundance between the four facies.

\section{Facies 1: Diatom-rich mudstone}

Description: Facies 1 is a diatom-rich light grey to greenish dark grey mud (Figure 5.9). This moderately to highly bioturbated facies, contains large burrows ( $\sim 2 \mathrm{~cm}$ wide) that are commonly pyritized (black rings) and as a result of the spilt core face, exhibits a mottled texture. Bioturbation obscures most primary depositional features, although rare discontinuous silt lenses do occur. IBRD is common, although the concentration varies between the repeating cycles (increasing in the upper core). Clasts larger than $5 \mathrm{~cm}$ are present, but sparse. Green cm-scale laminae and contorted bedding are also evident in intervals (Figure 5.9). Grain size distribution of the lithogenic fraction indicates a strong 
mode at $\sim 20 \mu \mathrm{m}$ (Figure 5. 1) and the finer-grain faction is reduced compared to the laminated mud facies (Facies 4, below). Geochemical analysis characterises the diatomrich lithofacies by elevated levels of $\mathrm{Si} / \mathrm{Al}$ and $\mathrm{Ba} / \mathrm{Al}$ (Figure 5. 5). Facies 1 correlates to low NGR and MS values, suggesting that the sediments are relatively low in clay content and/are microfossil rich compared to other facies (Figure 5. 7).

Interpretation: This facies is indicative of highly productive surface waters in close proximity of the site, resulting in the accumulation of biogenic material on the sea floor acting to dilute background terrigenous sedimentation. This is consistent with the pelagite/hemipelagite model described in Stow and Piper, (1984), whereby a decrease in turbidite activity allows enhanced pelagic/hemipelagic deposition. The grain size distribution illustrated reduced abundance of clays, inferring the existence of weak bottom water currents and/or bioturbation acting to restrict the deposition of fine-grained sediment at Site U1361 during intervals of the Late Miocene. However, the lack of sharp (erosional) surfaces, coarse gravel layers (i.e. lag deposits), and a dominant (but broad) silt model at $\sim 20 \mu \mathrm{m}$ suggest currents were not strong enough to result in a significant hiatus or biasing of IBRD concentrations (explained in more detail section 6.1.2; Bindoff et al., 2000b). Seismic profiles indicate continuous levee deposition throughout the cored interval (Escutia et al., 2011b), inferring that the terrigenous material was being delivered by turbidity overbank spill and reworked or entrained by strengthened bottom currents reducing settling of the clay fraction. Enhanced bioturbation and pelagic deposition of diatoms could be a consequence of increased highly productive open waters, associated with the supply of oxygenated water (ventilated) masses on the continental shelf, that subsequently sink to form the AABW at the site (Patterson et al., 2014). Heightened ventilation is inferred to be a consequence of wind-driven upwelling, which also enhanced surface water productivity through the increased supply of nutrients at this time (Salabarnada et al., 2018).

\section{Facies 2: Nannofossil- rich mudstone}

Description: Facies 2 is a nannofossil-rich, light grey to white mudstone. The core surface exhibits a mottled texture, interpreted as intense bioturbation (Figure 5. 9; left) but is otherwise structureless. Gravel-sized grains are frequent throughout (mm-cm scale), occasionally occurring in small clusters. Gabbro and metamorphic clasts larger than $5 \mathrm{~cm}$ 
are common. The identification of this facies is based on $\mathrm{Ca} / \mathrm{Al}$ and $\mathrm{Sr} / \mathrm{Ca}$, as explained previously (section 5.2; Figure 5. 5). Grain size distribution of the lithogenic material is variable, and typically poorly sorted with no common mode between samples (Figure 5. 1), although it has the highest abundance of grains coarser than fine sands (including IBRD), relative to the other facies. Facies 2 has similar NGR and MS values to the diatom-rich facies (Facies 1; Figure 5. 7).

Interpretation: The nannofossil-rich mudstones represent a similar depositional setting to the diatoms (Facies 1), with the exception that surface ocean productivity is characterised by coccolithophore plankton whose skeletal remains produce nannofossils. Unlike the diatom-rich and laminated facies (4, below), the nannofossil-rich muds occur only six times at Site U1361 between the present and 12 Ma Figure 5. 10). This indicates that environmental conditions, light and nutrient levels in particular, must have favoured coccoliths, at the expense of diatom productivity for a brief period of time in the Late Miocene. Additionally, carbonate preservation in deep Antarctic waters during the Late Miocene must have been sufficient, allowing this material to become incorporated into the stratigraphic record. While grain size is variable, it does display a higher abundance of sand (>63 $\mu \mathrm{m}$; Figure 5. 1) suggesting alongslope or downslope currents removed the finer-grained material (or prevented deposition), or an increase in IBRD. The stronger currents coincide with high levels of bioturbation, indicative of highly oxygenated water masses feeding the site and ventilating surface waters during this interval (Caburlotto et al., 2010). Shipboard analysis described the coccoliths (Reticulofenestra minuta and Reticulofenestra minutula; Escutia et al., 2011b) as being moderately to well preserved, indicating minimal transportation in stable conditions, and thus likely represent a pelagic signal. The potential environmental drivers and implications of the nannofossil production and preservation are considered in greater detail in the discussion chapter (section 6.1.3).

\section{Facies 3: Diatom-nannofossil-bearing mudstone}

Description: The diatom-nannofossil-bearing mudstone, is greenish grey in colour, with moderate bioturbation and borrowing. Sand sized clasts are common, and larger $(<2.5$ $\mathrm{cm}$ ) angular clasts are rare. Visually (i.e. texture and structures) Facies 3 is hard to separate from Facies 1 and 2, although compositionally both $\mathrm{Si} / \mathrm{Al}$ and $\mathrm{Ca} / \mathrm{Al}$ values are 
lower. Facies 3 is finer grained with higher clay abundance than seen in Facies 1 (Figure 5. 1), but has consistent low NGR, and low MS value (Figure 5. 7). The diatomnannofossil-bearing mudstone was not defined in initial Leg 318 shipboard reports, but XRF allowed a quantitative mechanism to subdivide facies originally identified. In practice Facies 3 represents a continuum between Facies 1 and 2 .

Interpretation: The depositional environment is essentially the same as Facies 1 and 2, except for a mixed biosiliceous (diatom) and carbonate (nannofossil) pelagic influence. The finer grain size (of the lithogenic fraction) compared to Facies 1 suggests a slight reduction in current energy influencing suspension settling, but the presence of bioturbation infers bottom water oxygenation (or slow sedimentation rates) still influenced deposition during these intervals of the Late Miocene.

\section{Facies 4: Faintly laminated mudstone}

Description: Facies 4 is olive-grey in colour mudstone. It is moderately stratified, with stratification being defined by fine, parallel sub-mm to $\mathrm{mm}$-scale silt laminations that are often highly rhythmic (Figure 5.9). The laminations have sharp upper and lower contacts, and no evidence of grading. Bioturbation is variable ranging from weak to intense enough to completely obscure depositional laminae. The frequency of IBRD is reduced, although appears to increase within this facies during the middle of the record (between 315 and $345 \mathrm{mbsf}$ ). Facies 4 contains the finest overall grain size distribution, with a dominant clay mode (Figure 5. 1). Both Si and Ca content remain low throughout (Figure 5. 5), and consequently it is characterised by high NGR and high MS value (Figure 5. 7).

Interpretation: Seismic profiles from the Wilkes Land continental shelf (Escutia et al., 2011b) indicate persistent overbank levee turbidite deposits during the Late Miocene at Site U1361. A similar facies was identified in Oligocene strata at nearby Site U1356 (also situated on a levee system), and has been interpreted as overbank spill deposition with the suspended material entrained and reworked by along slope currents (Salabarnada et al., 2018). This same process is interpreted for Facies 4 at Site U1361, as the seismic architecture at the site indicates turbidity currents supply sediments, however, the rhythmic, sub-mm to mm-scale parallel laminations with sharp tops and bottoms are direct evidence of traction currents. The lack of grading, low biogenic content and the 
occasional IBRD layer suggests that deposition was primarily regulated by bottom current flow, which is consistent with low strength contourites defined in Rebesco et al., (2014). This indicates that current speeds were reduced, as there is no sedimentological evidence of winnowing, with the preservation of the laminae either suggesting enhanced sediment supply or reduction in oxygenated bottom water (Rebesco et al., 2014). However, intervals of bioturbation are present in this interval and suggest that periods of enhanced bottom waters did operate at this time although is greatly reduced compared to Facies 1, 2 and 3 (expanded in section 6.1.; Lucchi and Rebesco, 2007; Caburlotto et al., 2010).

\subsection{AGE MODEL FOR CORE U1361A}

The initial age model for the study interval between 350 and $300 \mathrm{mbsf}$ at Site U1361 is based on Tauxe et al., (2012). This earlier work only confidently identify one paleomagnetic reversal to the geomagnetic timescale (Ogg, 2012) by using the biostratigraphic constraints defined in the CONOP model of average age ranges (Cody et al., 2008). However, there remained uncertainty in this interpretation due to relatively poor age constraints for some biostratigraphic markers (Figure 5.10), particularly in the Late Miocene. As discussed in the methods (section 4.7), this thesis adopts a hybrid CONOP with 'strict' and 'relaxed' modes defined by Cody et al., (2012), as it is considered to be most appropriate for sites proximal to the Antarctic margin. This new age model resolves the biostratigraphic inconsistencies and allows the base of the long duration normal reversal (C5n.2n) at $313.48 \mathrm{mbsf}$ to be confidently dated at 11.056 Ma. Shipboard magnetostratigraphy also identified two other short duration normal reversals (Escutia et al., 2011b), that were not tied confidently to the geomagnetic timescale by Tauxe et al., (2012). This results in the potential of three tie points to be identified over the study interval and therefore to be used to tie to short duration normal events in the geomagnetic timescale within the age envelope (Figure 5.10). However, following the conservative approach of Tauxe et al., (2012) only Tie Point 1 at $11.056 \mathrm{Ma}, 313.48 \mathrm{mbsf}$ was used to provide an absolute age constraint. This tie point and the use of an age envelope provided a guide to possible variations in sedimentation rates for time series analysis experiments. 


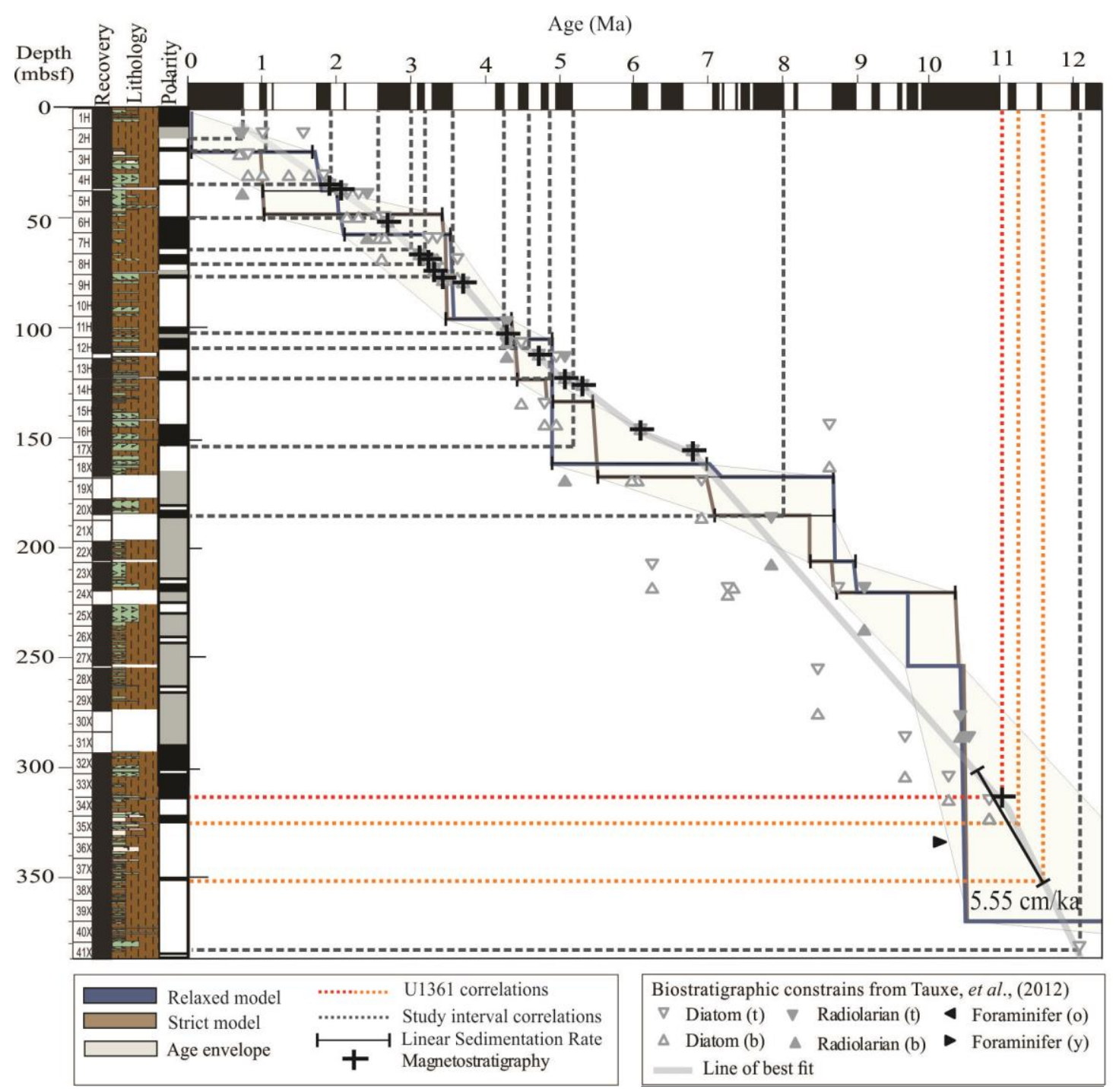

Figure 5.10 Age-depth plot for Site U1361 and magnetostratigraphic tie points. Model is based on the hybrid CONOP model by Cody et al., (2012) and polarity changes have been reassessed from Tauxe et al., (2012). The reversals mentioned in the text above are highlighted on the figure red/orange dashed lines, and black cross marks the location of selected paleomagnetic Tie Point 1 (11.056 Ma). The black line represents the best fit sedimentation rate based on average spectral misfit, constrained by Tie Point 1 . Note, the fit of the lower confidence paleomagnetic reversals at $\sim 326$ and $\sim 354$ mbsf (but not used as an absolute age constraint in this model). 


\subsubsection{SPECTRAL ANALYSIS IN DEPTH DOMAIN}

Multitaper method (MTM) analysis was run in the depth domain on four variables representing different aspects of sedimentation (MGS, silt \%, CS \% and Si/Al). To avoid the noise and spurious peaks of the datasets creating bias on the result, the 'outliers' in each dataset were removed (using the 'trim' function in the Astrochron R package; Meyers, 2014) and frequencies significant at the 90-95\% confidence interval were assessed to provide consistency between datasets. All four datasets demonstrated that the highest spectral power occurs at wavelengths of 5.5-5.9 $\mathrm{m}$ and some contain weaker peaks at 2.0 and $1.1 \mathrm{~m}$ (Figure $5.11 \&$ Table 7). Using the average of the shortest significant wavelength at $1.17 \mathrm{~m}$, the ratio of all significant wavelengths is $4.95: 1.75: 1$. This is very similar to the ratio of the primary Milankovitch cycles representing eccentricity (105 kyr), obliquity (41 kyr) and precession (23 kyr), which when normalised to precession, yields 4.56:1.78:1. Using this information, and independent age control from paleomagnetic reversals suggests an overall sedimentation rate of $5.55 \mathrm{~cm} / \mathrm{ka}$, and therefore the $5.79 \mathrm{~m}$ cycle can be attributed to eccentricity, $2.044 \mathrm{~m}$ cycle to obliquity and $1.17 \mathrm{~m}$ cycle to precession. The $5.5 \mathrm{~cm} / \mathrm{ka}$ sedimentation rate is consistent with the time envelope created in the physical age model (Figure 5. 10).

Table 7 Wavelengths of the cycle $(m)$ identified in the Late Miocene interval of Site U1361, attributed to Milankovitch cycles for each dataset. LSR was calculated from the $100 \mathrm{kyr}$ cycle wavelength $(508 \mathrm{~cm} / 105 \mathrm{kyr})$. The ratio is calculated to the average wavelength of precession.

\begin{tabular}{|l|l|l|l|}
\hline & $\mathbf{1 0 5} \mathbf{~ k y r}$ & $\mathbf{4 0} \mathbf{~ k y r}$ & $\mathbf{2 3} \mathbf{~ k y r}$ \\
\hline MGS & $5.834 \mathrm{~m}$ & - & $1.15 \mathrm{~m}$ \\
\hline Silt \% & $5.834 \mathrm{~m}$ & $2.044 \mathrm{~m}$ & $1.19 \mathrm{~m}$ \\
\hline CS\% & $5.51 \mathrm{~m}$ & - & - \\
\hline Si/Al & $5.965 \mathrm{~m}$ & - & - \\
\hline Average & $5.78 \mathrm{~m}$ & $2.044 \mathrm{~m}$ & $1.17 \mathrm{~m}$ \\
\hline Ratio of 1.17 & 4.95 & 1.75 & 1 \\
\hline & & & $\mathbf{L S R}=\mathbf{5 . 5} \mathbf{c m} / \mathbf{k a}$ \\
\hline
\end{tabular}



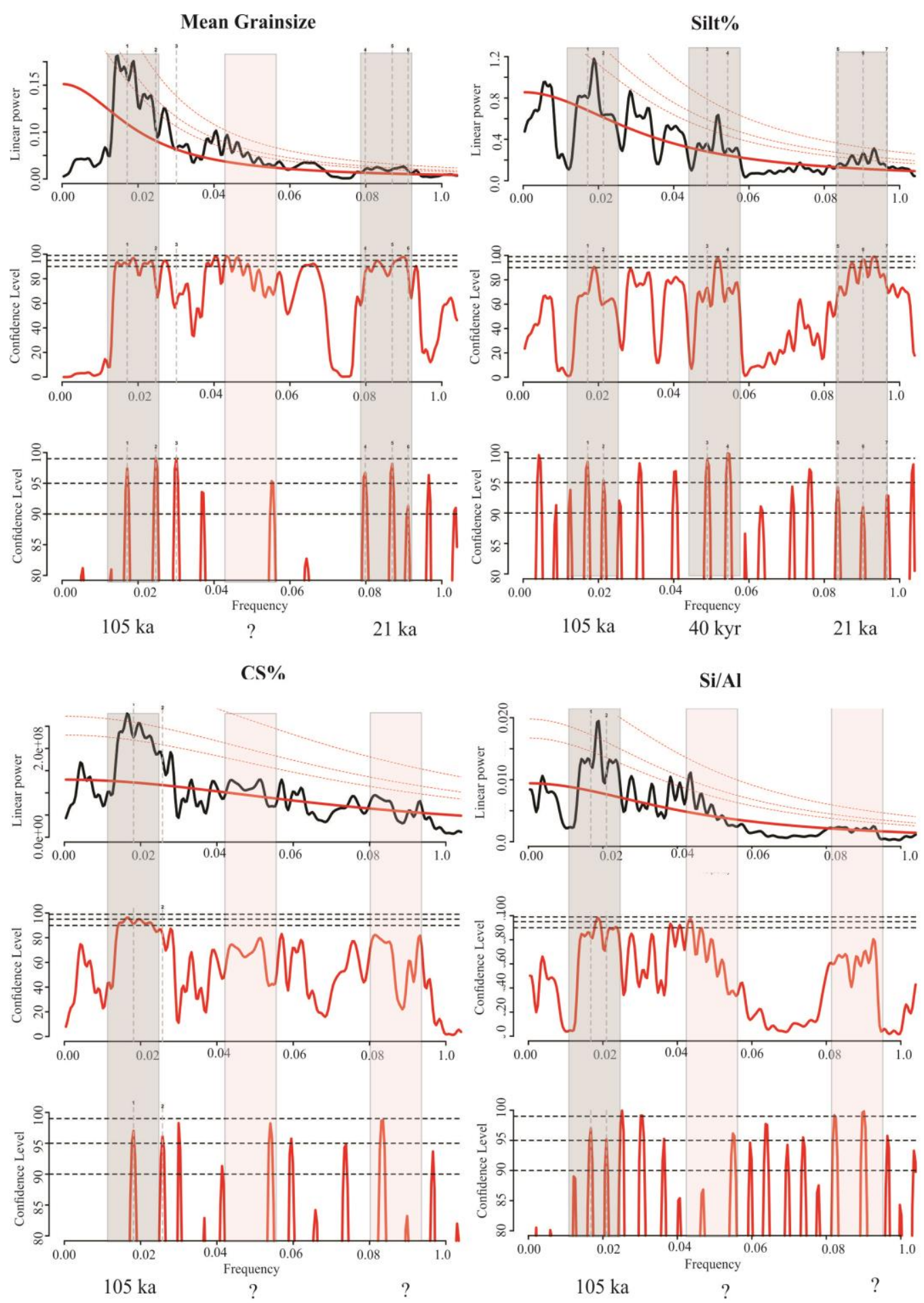

Cycles identified

Cycles not identified

Figure 5. 11 MTM plots for the four datasets; MGS, silt \%, CS \% and Si/Al for Site U1361. Refer to table 5 for the wavelength in meters of each orbital cycle. In the top image of each dataset, the thick red line represents the best fit, and the dashed lines are the 90, 95 and 99\% confidence interval. Second box: confidence level and third box: harmonic test at significant frequencies. 
The silt percentage dataset demonstrates power and harmonics in all three anticipated orbital bands (100, 40 and $23 \mathrm{kyr}$ ) and mean grain size also shows a harmonic and significant power in the precession bands. In contrast, Si/Al and CS \% do not exhibit significant power in either the $40 \mathrm{kyr}$ and $23 \mathrm{kyr}$ orbital bands (Table 7). However, examination of the MTM spectra indicates strong red noise in these two datasets, and although not statistically significant, the strongest power at high frequencies occurs in the expected precession band (Figure 5. 11). Further testing into the significance of these peaks could be conducted by more intensive pre-processing of the data to remove the rednoise component (e.g. prewhitening) but is beyond the scope of the present work.

Assuming the significant sediment cycles occur at Milankovitch frequencies, the age model can be further assessed by applying Average Spectral Misfit (ASM) of Meyers and Sageman, (2007) in the Astrochron R package (Meyers, 2014). Using this approach, all significant harmonic peaks can be "tuned" to the best fit orbital solution, using perturbations of sediment rates between a known range of values. Due to the red noise present in the $\mathrm{CS} \%$ and $\mathrm{Si} / \mathrm{Al}$ data, higher frequency peaks are obscured, and only silt $\%$ and MGS were used for the ASM test. Results indicate that when the slightly different wavelengths of MGS and silt \% are used, the sedimentation rate differs to that calculated prior $(\sim 5.5 \mathrm{~cm} / \mathrm{ka})$. ASM model fits to Milankovitch pacing’s, and while the constant sedimentation values are similar (silt \% is $5.057 \mathrm{~cm} / \mathrm{ka}$ and MGS $5.661 \mathrm{~cm} / \mathrm{ka}$; Figure 5. 12) the differences are likely associated by noise within the spectra, creating false or missing significant Milankovitch frequencies.

Assessment of the MTM results suggested the MGS has the cleanest signal of the $105 \mathrm{kyr}$ cycle, represented by a broad significant peak. Even though silt \% contains all three Milankovitch frequencies, the harmonic at eccentricity frequency is defined by a very narrow spectral peak resulting in wavelengths being identified at both eccentricity and obliquity (Figure 5. 11). It is reasonable to expect them to show a consistent signal, as they are both part of the same sedimentary cycle process. However, what is important is that all datasets are in agreement with the largest cycle being equal to the $105 \mathrm{kyr}$ (5.8 $\mathrm{m} /$ cycle). Therefore, the null hypothesis is rejected, indicating that the variations at Site U1361 are consistent an orbital signal. To place the datasets onto a timescale, the sedimentation rate of $5.6 \mathrm{~cm} / \mathrm{kyr}$ was anchored to an independent age control point at 
11.056 Ma (i.e. Tie Point 1). Consequently, the samples represent the period 11.72 to $10.85 \mathrm{Ma}$, with no other tuning conducted on the datasets. Also, the application of the tuned age model meant the short-duration reversals at $\sim 11.18$ and $11.65 \mathrm{Ma}$ now aligned with the paleomagnetic sub-chron C5r.1n and C5r.2n, respectively (Figure 5. 10). Although these points were not used to constrain the chronostratigraphy, it suggests that these reversals are real events and further supports the use in the construction the age model for Site U1361

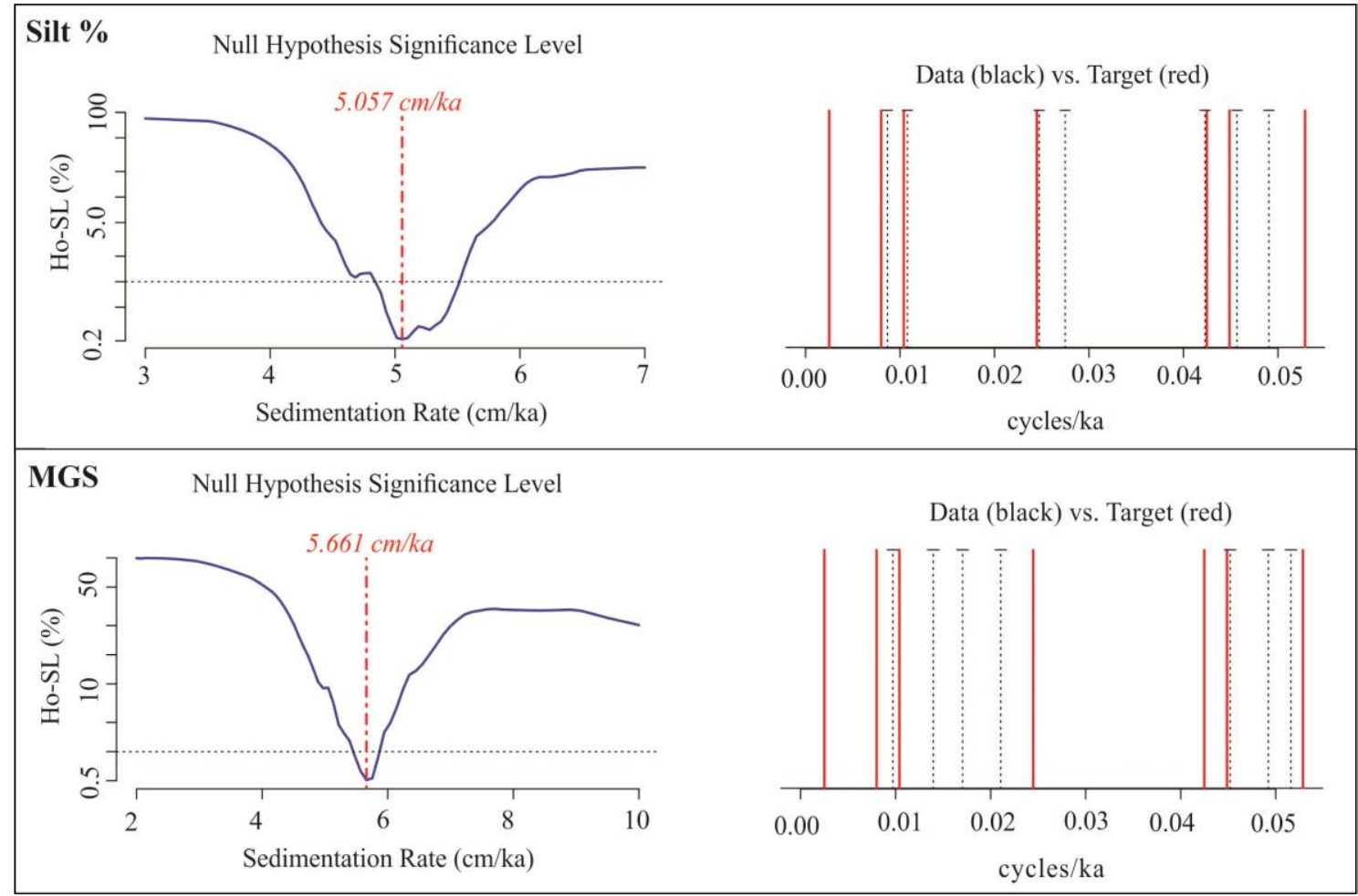

Figure 5. 12 ASM results for silt \% and MGS for Site U1361. These sedimentation rates are consistent with the assumption of a dominant $105 \mathrm{kyr}$ cycle (i.e. $5.55 \mathrm{~cm} / \mathrm{ka}$ ). $M G S$ was selected as the most suitable constant sedimentation rate to adopt, thus a LSR of $5.6 \mathrm{~cm} / \mathrm{kyr}$ was used to calculate the IBRD MAR and the ages of the samples.

\subsection{EVOLUTIONARY SPECTRAL ANALYSIS IN THE TIME DOMAIN}

Spectral analysis on the untuned MGS, assuming a constant sedimentation rate (see above, section 5.4.1) is dominated by significant spectral power at the $100 \mathrm{kyr}$ eccentricity period (Figure 5. 13). Spectral peaks express a narrow bandwidth and exhibit no 'wandering' over the length of the record. This dataset demonstrates short intervals of 
low amplitude $40 \mathrm{kyr}$ cyclicity at $\sim 11.15,11.35$ and $11.5 \mathrm{Ma}$, however, since the dataset examined has little spectral power in the obliquity band, it is therefore difficult to attribute a causal relationship between axial tilt and sedimentation at Site U1361. Spectral analysis of the untuned silt $\%$ in the time domain, also exhibits the high spectral power centred on the eccentricity frequency through the entire record, however, does not provide a very clean bandwidth, with 'wandering' in the upper record, compared to MGS. These datasets, particularly MGS, highlight the dominance of eccentricity-paced sedimentation throughout the study interval, reinforcing the practice of tuning to the dominant eccentricity frequency in the final age model.

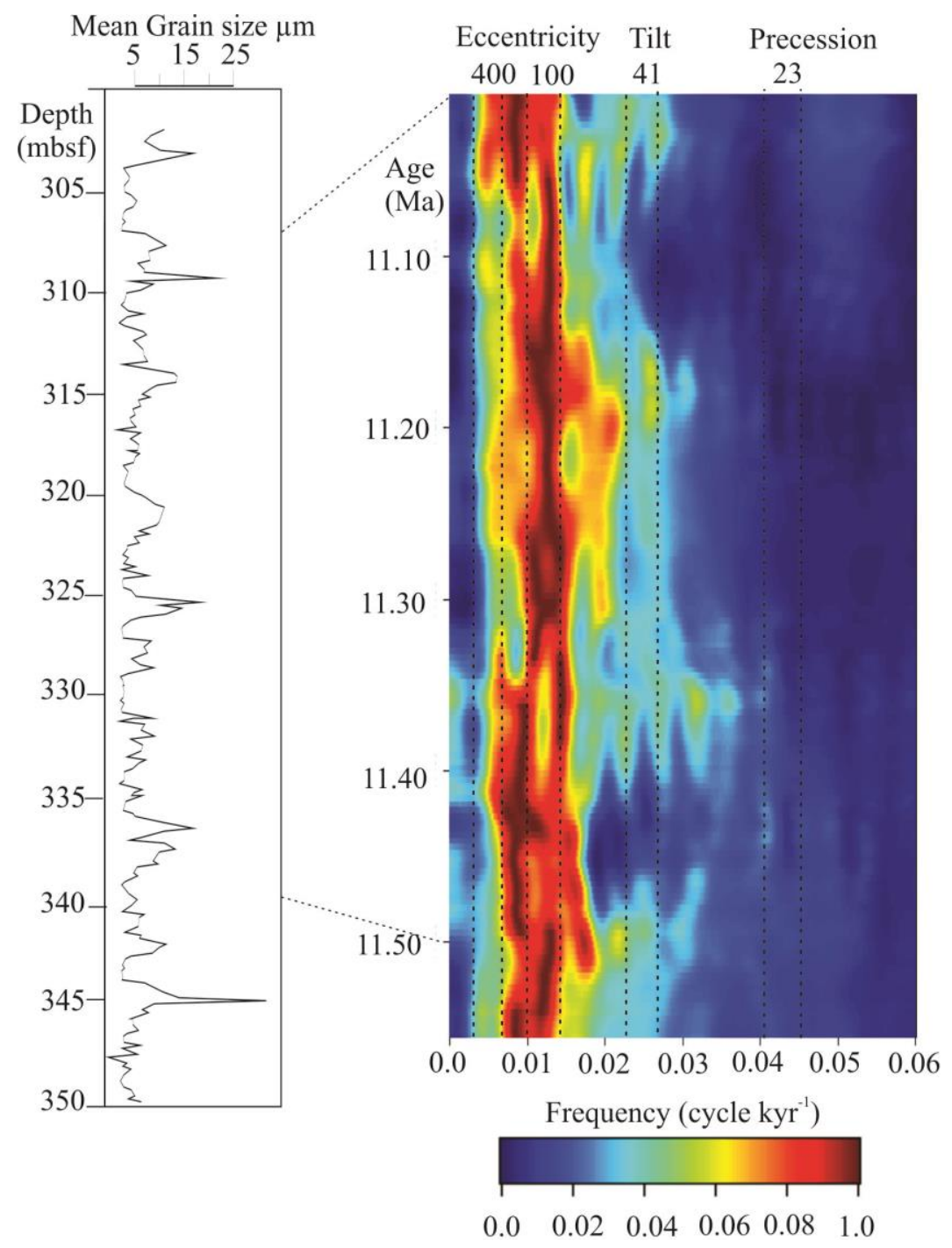

Figure 5. 13 EHA of MGS at Site U1361 vs age. Plot is fixed by a constant sedimentation rate $(5.66 \mathrm{~cm} / \mathrm{ka})$ and tie point $(11.056 \mathrm{Ma})$. MGS curve represents the raw data vs depth (contains outliers: removed for spectral analysis e.g. EHA) 


\subsection{BIOMARKER ANALYSIS}

This preliminary study investigated biomarker abundance and their potential use as environmental proxies during the Late Miocene at U1361. Since the biomarker analysis in this study did not provide a direct result, the initial interpretations are provided below, rather than in the discussion. Only preliminary data processing was completed, to identify peaks in molecular mass, as explained in section 4.5. A summary table of the values calculated is presented in Appendix A. Of the eleven samples analysed, alkenones (in the $\mathrm{N} 3$ fraction) were found to be absent. The N1 fraction contained n-alkanes in all samples, and four-samples contained hopanes. The average carbon preference index (CPI) for the n-alkanes was 1.8 and ranged from 1.2-2.6. The average chain length (ACL) is $\mathrm{C}_{26}$, with a total ion current of 366 . These values cannot be interpreted as climatically meaningful on their own. The hopanes and hopenes from $\mathrm{C}_{27}$ to $\mathrm{C}_{31}$ were identified by their mass fraction and integrated. Unfortunately, this did not provide a result, with $B \beta /(B \beta+A \beta+$ $\mathrm{B} \alpha$ values around 0.5 , suggesting that there is probably a mixture of an immature source and a mature (reworking) signal, but was consistent with the CPI values (Duncan et al., 2018). While the biomarker data cannot be interpreted directly in terms of a contemporaneous vegetation supply during the Late Miocene, it indicates terrestrial biomarkers are present and suggest high-resolution analysis of the material in the future could complement more traditional palynomorph work.

To date, U1361 shipboard data suggests the presence of well preserved, although likely reworked sporomorphs, ranging from barren to trace abundances over the study interval (Escutia et al., 2011b). No further studies have been completed on the pollen content from U1361, but these findings are broadly consistent with the biomarker results. At nearby Site U1356, palynomorph analysis inferred that at $\sim 10.8$ Ma there was high abundances of Nothofagus (Southern Beach), but also a general decrease in taxon diversity. This was interpreted to signify a cooling climate (Sangiorgi et al., 2018), with future analysis required to understand the relationship between locations and if terrestrial vegetation existed did it coincide with the intervals of nannofossil-rich sediments. 


\section{CHAPTER SIX: DISCUSSION}

This section interprets the depositional environment at Site U1361 during the Late Miocene, with fifteen sedimentary cycles identified between $\sim 11.7$ and $10.8 \mathrm{Ma}$ based on repeating facies succession (Figure 6.1). The base of each cycle is defined by a faintly laminated mudstone (Facies 4), which lacks biogenic silica and carbonate. Facies 4 typically grades up (over the m-scale) into a diatom-rich mudstone (Facies 1), characterised by an increase in bioturbation and presence of IBRD. In some cycles Facies 4 grades into a diatom-nannofossil-bearing mudstone (Facies 3) or a nannofossil-rich mudstone (Facies 2), also characterised by increased IBRD and extensive bioturbation. The contact with the overlying cycle is gradational on a cm-scale to $\mathrm{dm}$-scale, with the start of the next cycle defined by the recurrence of Facies 4 . As discussed in the individual facies descriptions and interpretations (section 5.3), the Late Miocene facies assemblages are controlled by turbidity overbank spill on the levee system, with the main differences in deposition between G-I cycles dependant on; the interaction with bottom currents (e.g. the Antarctic Slope Current, or downslope AABW flow), the scale of pelagic plankton deposition (e.g. degree of surface production and preservation), bottom water oxygenation and the rate of sedimentation accumulation influencing the intensity of bioturbation. 


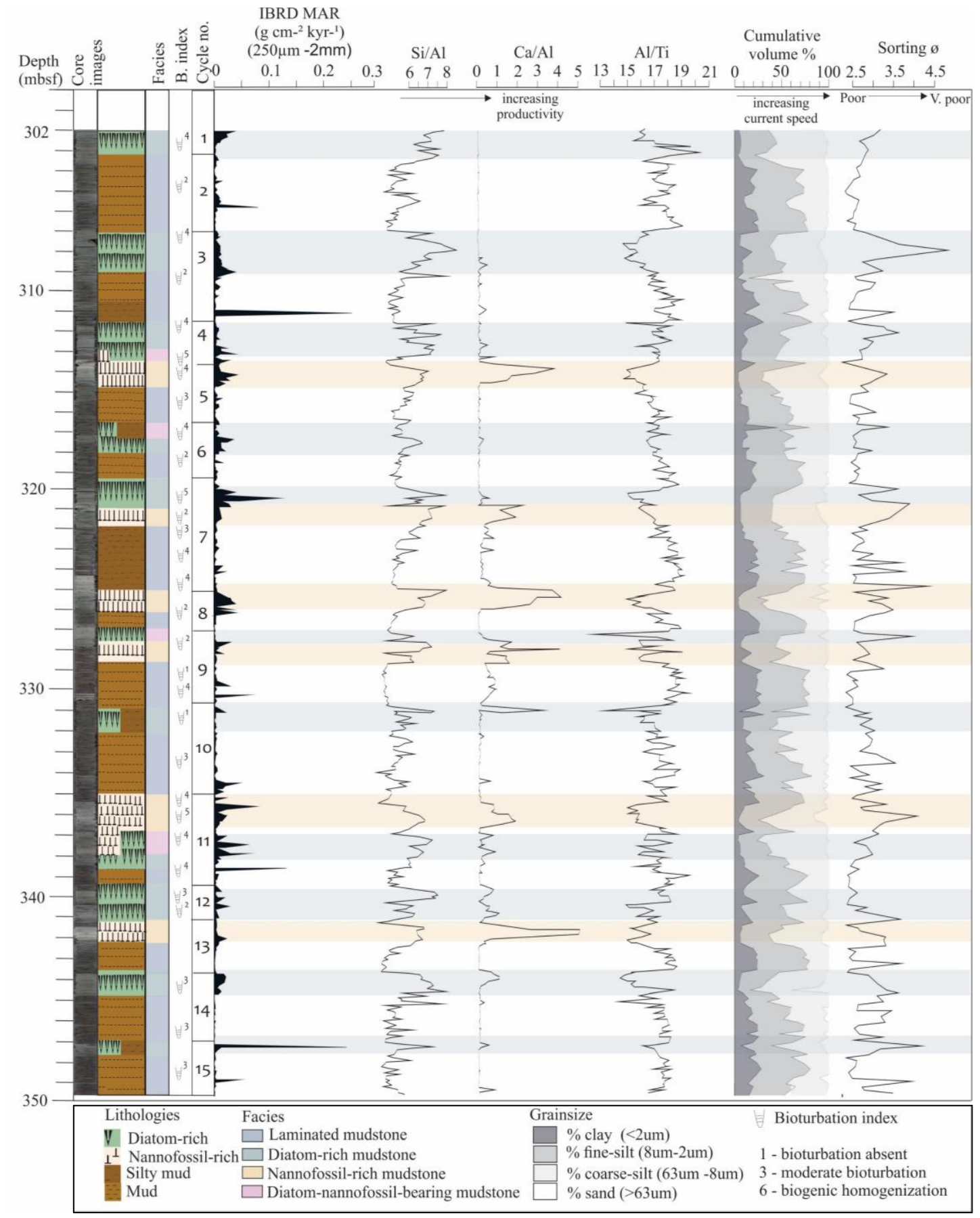

Figure 6. 1 Stratigraphic log and core images at Site U1361, with facies, degree of bioturbation, stratigraphic cycles, elemental ratios and grain size (cumulative abundance and sorting). Grey bands represent intervals of increased plankton productivity and yellow bands highlight nannofossil-rich intervals. 


\subsection{INTERGLACIAL TO GLACIAL SEDIMENTATION AND DEPOSITIONAL PROCESSES}

\subsubsection{GLACIAL SEDIMENTATION}

The faintly laminated mudstone facies (Facies 4) represents deposition during intervals of glacial maxima. This interpretation is consistent with previous Antarctic studies, that have commonly characterised glacial facies in terms of low biogenic content, identified by low $\mathrm{Si} / \mathrm{Al}$ and $\mathrm{Ca} / \mathrm{Al}$ and increase in terrigenous muds (Figure 6. 1; Lucchi and Rebesco, 2007; Caburlotto et al., 2010; Cook et al., 2013; Patterson et al., 2014). In the Plio-Pleistocene interval of Site U1361, the presence of terrigenous dominated facies was interpreted to signify a substantial increase of sediment eroded and delivered to the continental shelf edge by expanding ice streams. Subsequently, turbidity currents transferred this sediment to the deep sea and into the continental rise canyons (Patterson et al., 2014; Wilson et al., 2018). These turbidity currents are thought to be triggered by slope instability and initiated by ice sheet sediment delivery, or the formation and flow of dense water (e.g. AABW; Escutia et al., 2005; Patterson et al., 2014). However, the faintly laminated sediments deposited during the Late Miocene investigated in this study, are indicative of more continuous sedimentation not 'instantaneous' turbidite deposition. Instead, deposition is consistent with non-erosive fine-grained turbidity overflows that spill onto the channel levee and become entrained by the bottom water activity and eventually deposited. The thin sub-mm to mm-scale horizontal laminae, combined with a lack cross-bedding structures, and a dominant grain size (non-IBRD) of $<150 \mu \mathrm{m}$ (e.g. Figure 5. 1) are indicative of low current strength and predominance of settling rather than winnowing processes (Stow and Faugères, 2008; Rebesco et al., 2014). This interpretation is consistent with modern-day flow speeds at the drill site which range between 1.8 to $6.6 \mathrm{cms}^{-1}$ (Bindoff et al., 2000b), which is well below speeds required for winnowing of the fine-grained fraction $\left(>20 \mathrm{cms}^{-1}\right)$ (McCave and Hall, 2006).

The difference in glacial depositional processes between the Late Miocene and PlioPleistocene may reflect either a change in bottom current activity and/or the configuration of the Jussieu Canyon levee channel during the Late Miocene. Analysis of multi-channel seismic data suggests that during the Early Miocene, a low-relief levee system was 
initiated on the Wilkes Land continental shelf with sedimentation inferred to be controlled by local contour currents. This led to the Late Miocene being interpreted to represent the early stages of levee development, in a low energy environment. Sediment and seismic data indicate that an increase in turbidity currents and as a consequence levee expansion did not occur until the end of Late Miocene when the expansion of the EAIS on the continental shelf was thought to have occurred (De Santis et al., 2003; Donda et al., 2007). This shift in depositional style is also interpreted to mark the transition from a seaward-dipping progradational continental shelf in the Late Miocene time, towards a landward-dipping (overdeepened) shelf by the Plio-Pleistocene. These large-scale physical changes on the continental shelf would have fundamentally altered sediment delivery mechanisms and rates, with sediment being delivered directly to the shelf break in the Late Miocene, instead of being trapped on the shelf during the Plio-Pleistocene (Fretwell et al., 2013).

Such evidence combined with sedimentary features suggests that the fine-grained contourite facies at Site U1361 during the Late Miocene glacial intervals reflects the lowrelief of the channel levee, associated to the increased influence of bottom current activity. As the presence of turbidites would suggest that the flow must have triggered directly at the head of the more well-defined channel system, as seen during the Pliocene (De Santis et al., 2003; Caburlotto et al., 2006). However, it is important to consider that it is unlikely that the levee would not have changed dramatically between G-I cycles over the study interval, and therefore the levee configuration potentially reflects the greater sedimentation patterns at this time (i.e. bottom currents influencing suspension settling).

Pre-existing seismic profiles and stratigraphy across the basin do not provide absolute age control, but changes in the stratal geometry evident in the seismic lines are consistent with a shift in sedimentation at $\sim 11.0$ Ma recorded in this study and continues into the Plio-Pleistocene (Patterson et al., 2014). Unfortunately, there is large uncertainty surrounding the exact timing of this levee transition, which is potentially gradational over several millions of years, therefore, being able to directly relate it to deposition at Site U1361 is difficult (De Santis et al., 2007). However, a large shelf-wide unconformity (WL-U7; De Santis et al., 1999; Donda et al., 2003) and the shift in deep-sea sedimentation has been identified at other 
IODP Expedition 318 sites (Escutia et al., 2011a). This unconformity has generally been interpreted as a significant expansion of the EAIS at Wilkes Land within this time period (refer to section 3.11; Figure 3. 1). For example, at Site U1356, this event has been associated with a hiatus occurring between $\sim 13.4$ and $11.0 \mathrm{Ma}$ and to the migration of the channel levee system depocenter with the expansion of the EAIS (Sangiorgi et al., 2018). Consistent with the change in levee configuration is the significant decrease in grain size during the Plio-Pleistocene glacial intervals of core U1361 compared to the Late Miocene (Patterson et al., 2014; Figure 6. 2). This could be related to an increase in the coarse fraction within a bypassing turbidity current, as the levee relief increased (i.e. spill over component is finer grained), or alternatively a change in current strength influncing suspension settling.

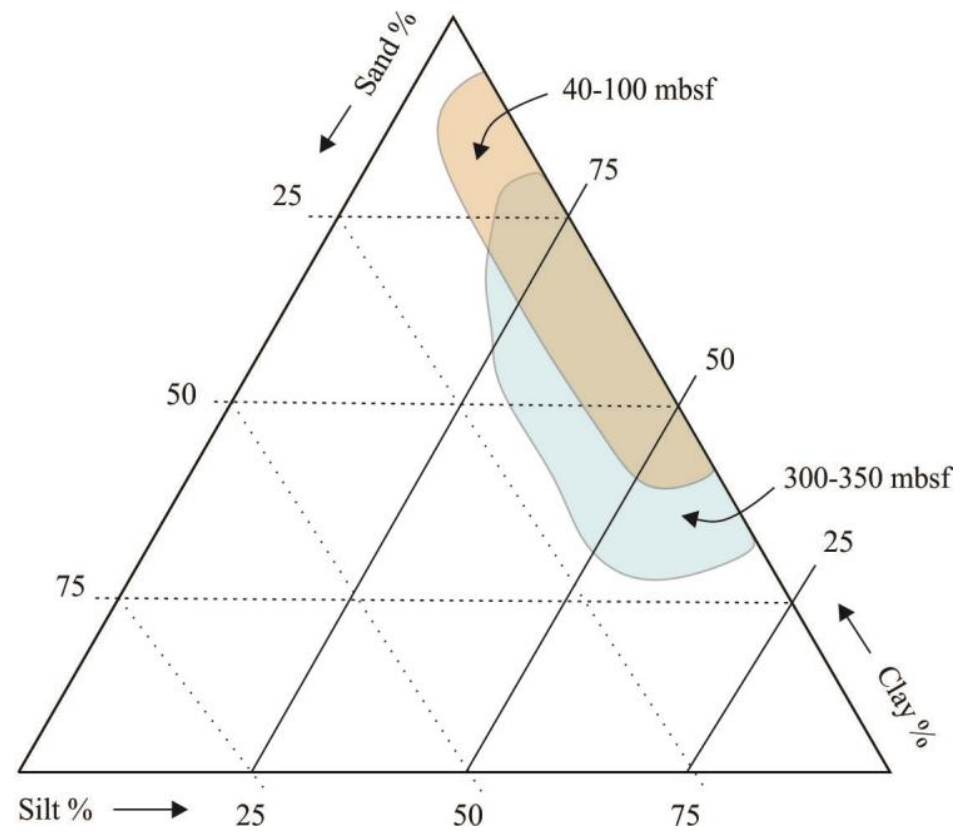

Figure 6. 2 Ternary grain size diagram highlighting differences between the Late Miocene (blue) and the Plio-Pleistocene (orange) record from Patterson, et al., (2014) at Site U1361.

The $\mathrm{Sr} / \mathrm{Ca}$ values recorded during intervals of terrigenous muds (e.g. glacial periods; Figure 5. 5) are consistent with a granitic source (Roser and Pyne, 1989). This suggests that the ratio during glacial intervals is only representing the lithogenic fraction. Cook et al., (2013) associated periods of reduced diatom accumulation as having lithogenic material most likely derived from lower Palaeozoic granites, sourced from the nearby Ninnis Glacier. It is possible that the same lithology has been deposited during the Late 
Miocene, as $\mathrm{Al} / \mathrm{Ti}$ ratios are high $(\sim 18-19)$ as expected for granites (Rothwell and Croudace, 2015) but additional provenance work is required to confirm this.

The deposition and preservation of sub-mm to mm-scale faint laminations are consistent with suppressed biological activity on the seafloor, either due to reduced oxygenation or enhanced sedimentation outpacing rates of biological mixing or some combination of both (Lucchi et al., 2002; Lucchi and Rebesco, 2007). However, bioturbation is still common within intervals of this facies (section 5.3), providing evidence for periods oxygenated water supply even during glacial periods. This suggests that the continental shelf water masses that fed the deep sea were well ventilated, due to wind-mixing and strong water column turnover (Jacobs, 1991). At present, surface waters in coastal polynyas are subject to very cold, dry air flowing off the Antarctic continent, acting to remove newly formed sea ice offshore leaving the surface ocean exposed to the cold air. This results in the formation of dense cold, saline and oxygen-rich water to flow downslope to deeper environments (Bindoff et al., 2000a; Williams et al., 2008). However, in the absence of available proxies to identify the influence of a polynya and sea ice on Late Miocene sedimentation at Site U1361, the interpretation of the processes governing bottom water oxygenation remains speculative.

\subsubsection{INTERGLACIAL SEDIMENTATION}

The diatom-rich (Facies 1) and nannofossil-rich (Facies 2) facies, both of which are characterised by increased IBRD and extensive bioturbation are interpreted to represent deposition during glacial minima. The interglacial facies are associated with open-water (i.e. a decrease in perennial sea ice) and an in increase in primary productivity as the grounding line migrated inland (Figure 6. 3; Cook et al., 2013; Patterson et al., 2014). At Site U1361 interglacials are represented by a marked reduction in terrigenous input. The bulk of the sediment is dominated by biogenic material (silica and/or carbonate), diluting the terrigenous over bank deposits reworked by bottom currents (Stow and Faugères, 2008). The increase in mean grain size (Figure 6. 1) during the deglaciation supports the notion that these sediments have been influnced by bottom currents (e.g. increase in current speed) acting to restrict deposition of clay particles (McCave and Hall, 2006; Bahr et al., 2014; Rebesco et al., 2014). For example, the remobilization of coarser grains (e.g. silt) 
by the along slope currents (i.e. Antarctic Slope Current) is evident proximal to Site U1361 (Jacobs, 1991). The higher degree of bioturbation suggests more oxygenated conditions, likely achieved by increased ventilation and mixing of water masses due to enhanced current activity at this time. This is supported by the strong correlation between $\mathrm{Ca}$ (representing biogenic carbonate) and $\mathrm{Mn}$, as the variations in $\mathrm{Mn}$ can be interpreted as redox change variations (Jaccard et al., 2016; Figure 5. 5). Al/Ti also has a strong relationship with mean grain size, such that a decrease in $\mathrm{Al} / \mathrm{Ti}$ correlates with an increase in grain size. This likely reflects current entrainment of clays, resulting in density (and thus elemental) sorting during deglaciations, although further work would be required to deconvolve the relative influence of particle size and sediment provenance on $\mathrm{Al} / \mathrm{Ti}$.

Since the Antarctic Slope Current is wind driven (Jacobs, 1991; Thompson et al., 2018), a reduction in clay content related to current speed also implies an association with increased upwelling at Site U1361 during deglaciations. An increase in current velocity acts to invigorate plankton productivity attributed to greater nutrient (e.g. silica, iron, nitrogen) availability at the ocean surface (Anderson and Burckle, 2009; Wilks et al., 2017). Such conditions presumably prevailed during deposition of diatom-rich facies (Facies 1) at Site U1361, as diatoms live in the photic zone (i.e. they are light dependent) and production rates correspond to the maximum supply of dissolved nutrients through upwelling of deep water (Hutchins et al., 2001; Anderson and Burckle, 2009; Wilks et al., 2017). Previous studies have attributed diatom-rich intervals to the upwelling of the warm, nutrient-rich CDW, accompanied by the southward expansion of the westerly wind fields due to the reduced pole-equator temperature gradient (Patterson et al., 2014; Salabarnada et al., 2018). Under such conditions, the upwelling of $\mathrm{CO}_{2}$ from the deep ocean is likely enhanced and increased convection facilitates the mixing, oxygenation and downward transport of surface waters, which in turn promotes bioturbation (Toggweiler et al., 2006; Anderson and Burckle, 2009; Schmidtko et al., 2014). Facies 2, the nannofossil-rich mudstone is identified by peaks in $\mathrm{Ca} / \mathrm{Al}$ (Figure 6. 1) and an equivalent drop in $\mathrm{Sr} / \mathrm{Ca}$, to values consistent with nannofossil composition based on measurements from Bathurst, (1974). The environmental interpretation of preservation is discussed in greater detail below (section 6.1.3). 

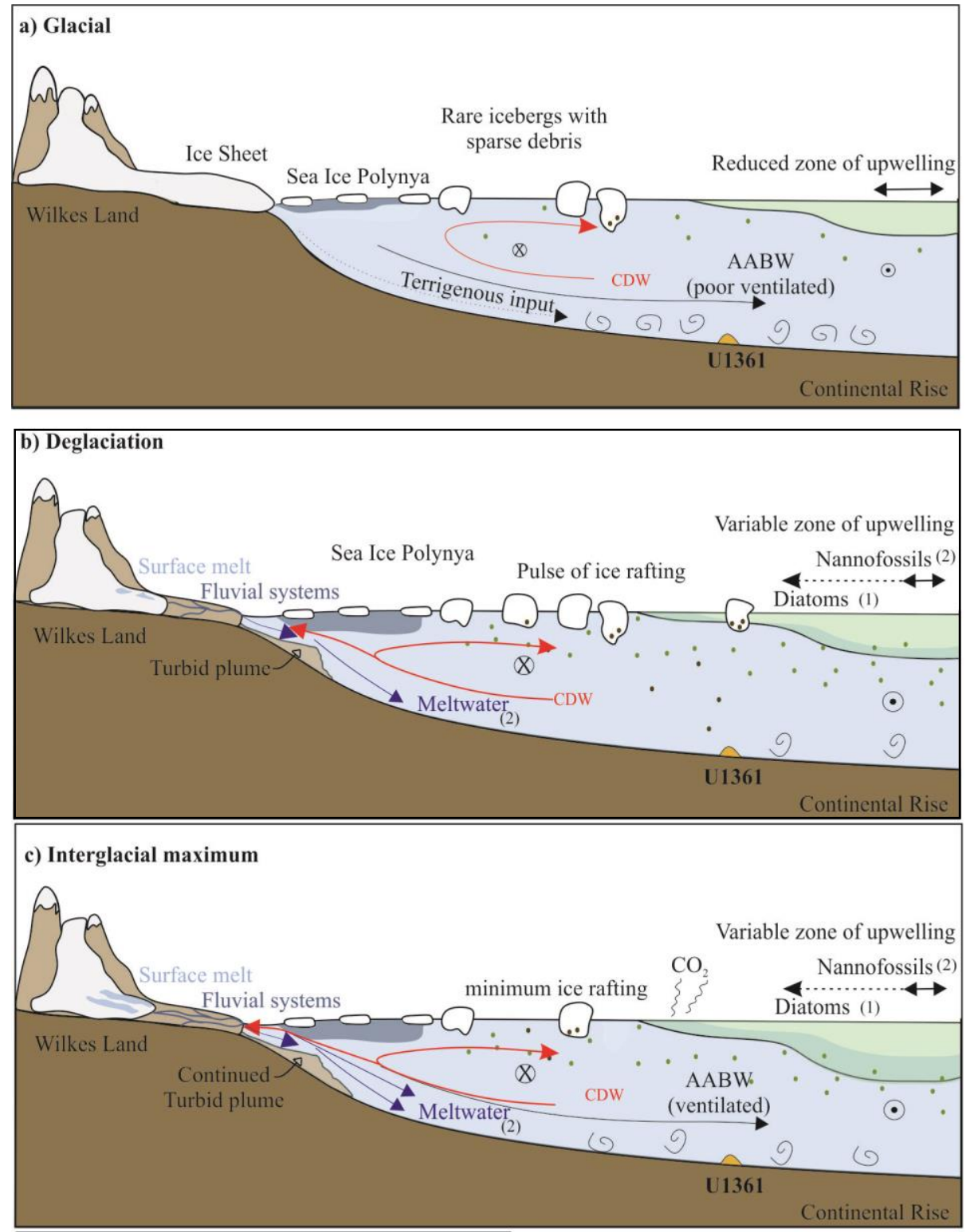

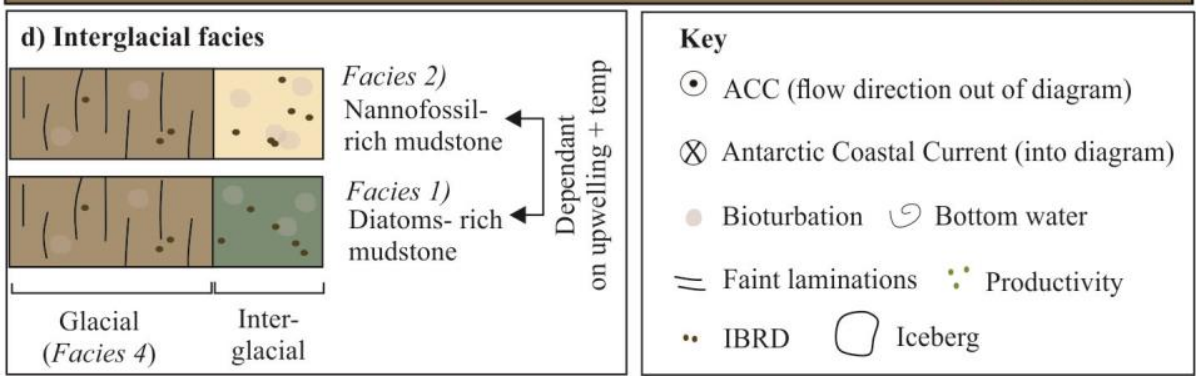

Figure 6. 3 Schematic diagram illustrating the interpretation of a) glacial, b) deglacial and c) interglacial maximum climate stages influence on sedimentation at Site U1361.d) illustrates the two interglacial facies varying in biogenic material (carbonate or silica) and the mechanism on local oceanography in the form of meltwater input and upwelling which influenced production. The Antarctic Coastal Current is denoted by a circle with a black cross, with flow direction into the diagram and the ACC is represented by a circle with a black dot with flow direction out of the diagram 


\subsubsection{SignifiCANCE OF NANNOFOSSILS DURING THE LATE MiOCEnE INTERGLACIALS}

In Neogene Antarctic sedimentary records, there is a general absence of calcareous nannofossils, even during the Pliocene warm intervals. Kennett and Hodell, (1993) attributed this a complete lack of coccolithophore productivity in Antarctic water, with the nonappearance of nannofossils (except in trace occurrences) suggesting that Antarctic waters were likely below $3{ }^{\circ} \mathrm{C}$ during the Plio-Pleistocene preventing growth (Burckle and Pokras, 1991). Present-day observations show the preservation of coccolithophores do not occur south of the Antarctic Divergence (e.g. southern Boundary Front of the ACC) due to the corrosive nature of the bottom waters dissolving the calcareous rain from the photic zone. These factors are the primary drivers of why nannofossils are not deposited and preserved in Antarctica at present (Kennett and Hodell, 1993). Thus, the occurrence of nannofossil-rich sedimentation during the Late Miocene $(\sim 11.7$ to $11.0 \mathrm{Ma})$ at Site U1361 suggests that this interval was favourable to both coccolithophore production and preservation (Pospichal, 2003).

To interpret the nannofossil deposits at Site U1361, two mechanisms are hypothesised; 1) a shift in Southern Ocean frontal systems, and/or 2) the influence of surface melt on EAIS causing turbid pulses of freshwater and IBRD into the surrounding ocean (Figure 6. 3). Previous studies have proposed the occurrence of nannofossil-rich sedimentation to the influence of more northern-scoured water masses into the CDW, and the warmer temperature of the water masses that 'outcrop' close to the continent (Sangiorgi et al., 2015; DeCesare and Pekar, 2016; Salabarnada et al., 2018). Such conditions act to restrict upwelling and increase ocean surface temperatures, providing the preferred environment for nannofossil growth. Studies have demonstrated that coccoliths can endure lower nutrient conditions than diatoms, e.g. are not silica dependant (Balch et al., 2016; Wilks et al., 2017) and based on TEX $\mathrm{L}_{66}$ values at nearby Site U1356, SSTs ranged between 4 and $10{ }^{\circ} \mathrm{C}\left( \pm 4{ }^{\circ} \mathrm{C}\right)$ at $\sim 11.0 \mathrm{Ma}$ (Sangiorgi et al., 2018). This signifies that temperatures were warm enough to support the production of coccolithophores at Site U1361 during the Late Miocene (Balch et al., 2016).

Various sedimentology studies have also indicated that the Late Miocene ( 12.7-8.5 Ma) was an interval of enhanced meltwater, attributed to increased surface melt processes influencing the EAIS at numerous sites around its margin, including Pyrdz Bay, Ross Sea 
and the Totten Glacier region (e.g. Hambrey and McKelvey, 2000; McKay et al., 2009; Gulick et al., 2017, respectively). As Wilkes Land is located between these regions, and the IBRD MAR record indicates a more terrestrial-based ice sheet (explained in section 6.2 , below), it seems reasonable that enhanced meltwater processes were also operating near Site U1361. The pulses of turbid freshwater into the ocean during the deglaciation would have increased ocean stratification and restricted the upwelling of nutrient-rich deep waters, providing the competitive advantage to coccoliths (Figure 6. 3). Based on the relationship between the proxies, the influence of meltwater is likely the primary mechanism behind the coccolith blooms during the Late Miocene, creating a 'unique' sedimentary cycle. Figure 6.4 provides an example of an interglacial cycle, noting the relative timing of nannofossil (i.e. $\mathrm{Ca} / \mathrm{Al}$ ) production in relation to the other proxies. The simultaneous pulses of IBRD and nannofossil-rich mudstone during the deglaciation and that persists through the interglacial phase (Figure 6.4), suggests that calving at the margin during these intervals is related to the pulses of enhanced meltwater into the surrounding ocean. Additionally, there is a noticeable increase in current speeds (i.e. mean grain size) suggesting the influence of bottom water currents is also heightened during this interval of the Late Miocene.

Interestingly, the nannofossil-rich sediments do not occur during every glacial termination (Figure 6. 1). For example, nannofossil-rich sedimentation appears at only six glacial terminations between $\sim 11.7-11.0 \mathrm{Ma}$, and although other aspects of the sedimentary cycle continue in the younger deposits, IBRD and nannofossils are reduced (Figure 6. 1). The reduction of IBRD indicates that (at least locally) glaciers were less dynamic and the subsequent oceanographic effects of decreased iceberg melt near the Antarctic margin enhanced overturning/upwelling and diatom production. Diatom-rich sedimentation become the only form of biogenic productivity for the remainder of core U1361A and at other Expedition 318 sites (Figure 6. 1 \& 5. 10). Crampton et al., (2016) also noted a prolonged shift in diatom turnover (e.g. extinctions and speciation events) between $\sim 11.5$ and $9.5 \mathrm{Ma}$ (Figure 2. 3). While the magnitude was reduced compared to other turnover pulses, there is potential it is associated with this shift in nutrient abundance of Southern Ocean surface waters, as the $\delta^{18} \mathrm{O}$ record indicates no significant climate change over the interval. 


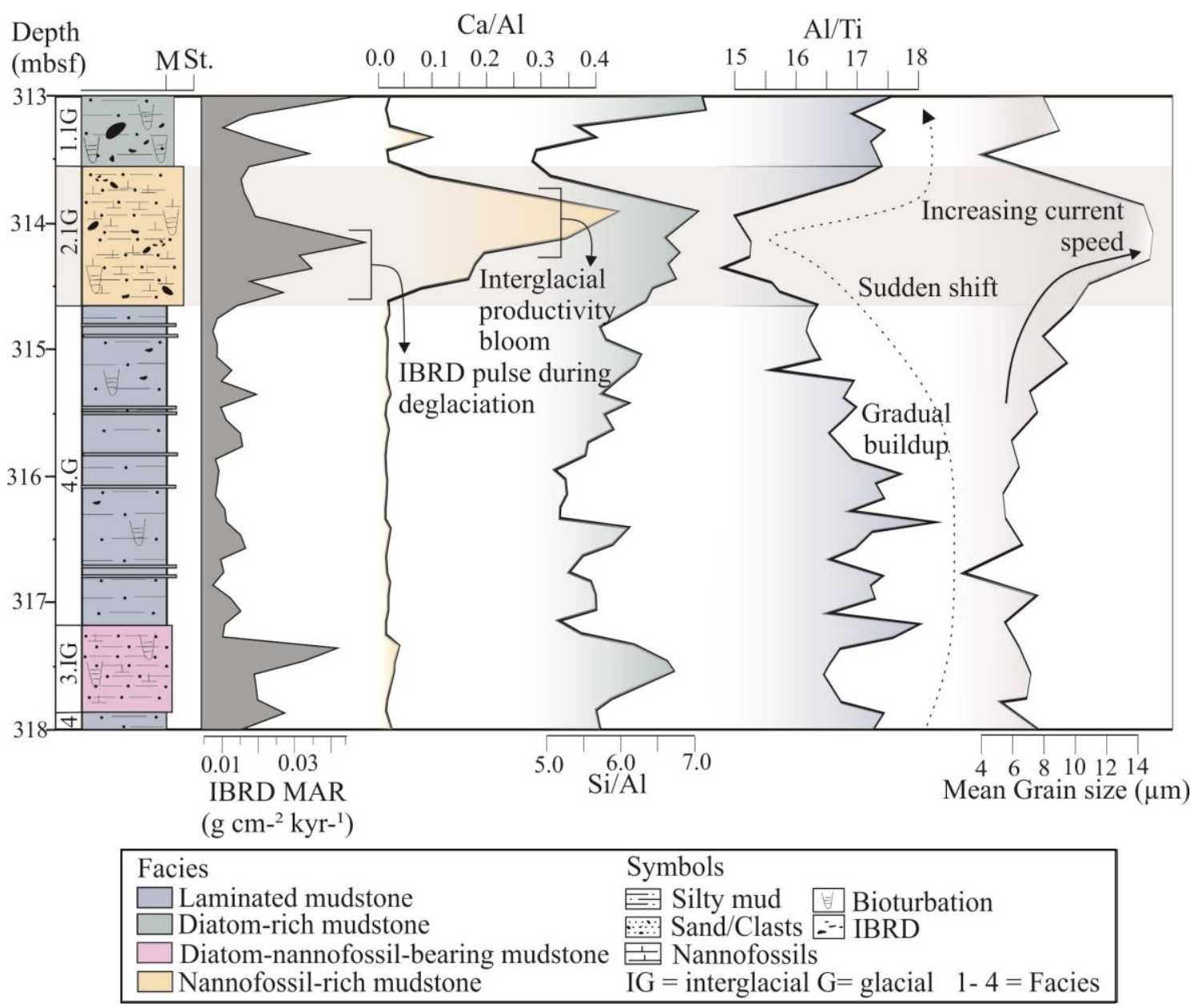

Figure 6. 4 Graphic and environmental proxy logs from $\sim 313$ to $318 \mathrm{mbsf}$ from Site U1361 showing the relationship between the two main productivity indicators (Si/Al, $\mathrm{Ca} / \mathrm{Al}$ ), and Al/Ti as a lithogenic provenance/ grain size indicator. Mean grain size is interpreted here to reflect along slope bottom current strength, relating to suspension settling velocity and IBRD MAR (iceberg discharge) are also shown.

The occurrence of nannofossils at Site U1361 during the Late Miocene, contradicts interpretations of a highly stable EAIS since c. $\sim 14$ Ma (Marchant and Denton, 1996; Marchant et al., 1996b), as coccolith production indicates that enhanced meltwater processes influenced the EAIS $\sim 2-3 \mathrm{Ma}$ after the MCT $(\sim 14 \mathrm{Ma})$. The presence of nannofossils is not restricted to Wilkes Land at this time, with sediments drilled on the Maud Rise region of the South Atlantic sector of East Antarctica (ODP Sites 689 and 690) also containing Late Miocene calcareous nannofossils deposits. Nannofossils were recorded at the Site 689 until $\sim 10 \mathrm{Ma}$, with the decline interpreted to represent the cooling 
of Antarctic waters (Barker and Kennett, 1988). Although this slightly lags the decline in nannofossil deposition at Wilkes Land, uncertainties in age model resolution between Site U1361 and ODP sites 689/690 could still have allowed these two events to coincide. Future work to update the $689 / 690$ age models could be undertaken to assess whether these events are synchronous, but this is beyond the scope of the presented study. However, nearby Wilkes Land Site U1359 (collected during Expedition 318) also contained nannofossil-rich interval $\left(\mathrm{CaCO}_{3}\right.$ up to $\sim 39.7 \mathrm{wt} \%$ ) at $\sim 372.45 \mathrm{mbsf}$ (Escutia et al., 2011a) which is in agreement with deposition of the calcareous intervals at Site U1361, within the existing age uncertainties. Evidence of nannofossil-rich sedimentation from numerous sites around the East Antarctic margin indicate the production of nannofossils may have been driven by a continent-scale change, including the discussed changes in Southern Ocean frontal systems (Salabarnada et al., 2018), and enhanced meltwater outwash from the EAIS during this period of time (Hambrey and McKelvey, 2000b; McKay et al., 2009; Gulick et al., 2017), both of which imply a significantly warmer climate than present-day.

\subsection{ICEBERg RAFTED DEBRIS AS A PROXY AT SITE U1361}

Site U1361 has previously been identified as a suitable location to capture orbitally-paced IBRD signatures of broader ice sheet dynamics (see section 2.4.4). As with earlier IBRD studies (e.g. Patterson et al., 2014; Wilson et al., 2018) peaks in IBRD MAR during the Late Miocene interval are of a similar magnitude, occur in all facies, do not demonstrate a strong relationship with sorting and contains no sedimentological indicators of winnowing (section 5.3). A visual assessment of the coarse sand comprising IBRD demonstrated that the calculated IBRD MAR is purely lithogenic material. The coarse fraction $(250 \mu \mathrm{m}$ to $2 \mathrm{~mm})$ is not part of the Gaussian distribution that characterises the rest of the sediment, indicating this outlier component of the dataset is transported by ice (Figure 5. 1). MTM and EHA time series analysis methods both provide evidence of cyclic depositional behaviour (Figure 5.11 \& Figure 5. 13).

While the magnitude of IBRD MAR is similar to the Plio-Pleistocene section of the core (Patterson et al., 2014 and Wilson et al., 2018), some intervals during the Late Miocene 
are less distinct, and overall the volume of IBRD is significantly reduced. This could be caused by a decrease in iceberg calving at the margin or a change in sedimentation rate. There is a noticeable pulse of IBRD associated with the interglacial termination (i.e. prior to maximum productivity; Figure 6. 4). This suggests that the EAIS at Wilkes Land was dynamic over the $100 \mathrm{kyr}$ interval that characterise the dominant sedimentary cyclicity and that the pulses of IBRD align with the initial stages of oceanic warming. The total IBRD record can be hypothesized to represent the in-land retreat of the EAIS at the Adélie Coast to its terrestrial margin, as the absence of a marine-based ice sheet on the Wilkes Land Basin would have restricted iceberg calving at the margin between $\sim 11-11.7 \mathrm{Ma}$ (Figure 6. 3). This is consistent with the knowledge that when continental cryosphere is less developed, icebergs are going to be less abundant (Mercer, 1978). Similarly, previous studies suggest meltwater influences were more widespread around the EAIS margin at this time, indicating that the ice sheet was not stable, or at maximum extent (e.g. McKay et al., 2009).

\subsection{ORBITAL FORCING OF GLACIAL-INTERGLACIAL CYCLES}

A key objective of this thesis was to investigate the EAIS response to orbital forcing during the Late Miocene, by developing a high-resolution record of sediment variability. However, cycles identified using MTM analysis on the CS\% dataset, demonstrate a broad spectral peak with a wavelength of $\sim 5.5 \mathrm{~m}$, but lacked significant peaks at shorter wavelengths. Consistency of peaks amongst other datasets ( $\mathrm{Si} / \mathrm{Al}, \mathrm{Al} / \mathrm{Ti}$ and $\mathrm{Silt} \%$ ), particularly MGS, and statistical tests using ASM methods, determined that the $\sim 5.8$ and $1.1 \mathrm{~m}$ cycles can be reconciled to represent eccentricity (100 kyr) and precession (20 kyr) pacing, respectively. These results suggest that ice rafting (IBRD MAR) at the Wilkes Land EAIS margin during the Late Miocene between 11.7 and 10.8 Ma was strongly paced by eccentricity, with a possible precessional component. It is important to consider that an increase in MGS during interglacial periods could be reflecting a change in bottom current speed (see results chapter), rather than eccentricity modulating the amount of deep-water production in the Southern Ocean, controlling the ocean configuration and current strength. 
The eccentricity (100 kyr) cycle that dominates the IBRD signal in the interval between $\sim 11.7$ to $10.8 \mathrm{Ma}$ (Figure 6. 5), is also evident in two benthic $\delta^{18} \mathrm{O}$ records that cover this time. The $\delta^{18} \mathrm{O}$ record from the South China Sea (ODP Site 1146; Holbourn et al., 2013) exhibits high and low frequency fluctuations that correspond to obliquity (41 kyr) and eccentricity (100 kyr) between 12.9 and $8.4 \mathrm{Ma}$, but between $\sim 11.7$ and $10.8 \mathrm{Ma}$ the record is almost exclusively eccentricity paced (Figure 6. 5). The $\delta^{18} \mathrm{O}$ record from the South Atlantic (ODP Site 1085; Westerhold et al., 2005) fluctuates at strong $100 \mathrm{kyr}$ and $400 \mathrm{kyr}$ bands, indicating that global ice sheet volume responded to eccentricity. These records are consistent with the IBRD MAR record at Site U1361, suggesting that variations in the Antarctic ice volume were contributing significantly to the $\delta^{18} \mathrm{O}$ signal at this time, as sedimentary records from offshore Greenland indicate an absence of IBRD prior to $\sim 9 \mathrm{Ma}$, suggesting minimal Northern Hemisphere ice volume contribution to the $\delta^{18} \mathrm{O}$ record during this interval (St. John and Krissek, 2002).

When comparing the relationship of $\mathrm{Al} / \mathrm{Ti}, \mathrm{Ca} / \mathrm{Al}$ and $\mathrm{Si} / \mathrm{Al}$ to the $\delta^{18} \mathrm{O}$ record (Holbourn et al., 2013), it appears that when $\delta^{18} \mathrm{O}$ drops below $1.9 \%$ (i.e. during an interglacial), it usually correlates to the deposition of nannofossil-rich sediments (Figure 6. 6). This relationship holds true for much for the record, apart from at $\sim 342 \mathrm{mbsf}$ and the two final interglacial cycles ( 1 and 2 at $\sim 344$ and 347 mbsf, respectively), which are associated with peak Si/Al (i.e. diatoms-rich facies). This association with $\delta^{18} \mathrm{O}$ could be interpreted as evidence that the production of nannofossils is directly related to the more extreme deglaciation events (e.g. enhanced meltwater).

Combined, the datasets from Site U1361 suggests that during highly eccentric orbits current speeds begin to increase (e.g. increase in MGS) and the ice sheet retreats with a pulse of IBRD occurring during the deglacial transition. An increase in productivity continues during the interglacial period with current speeds remaining high (MGS) but IBRD decreasing as the ice sheet margin stabilises (Figure 6. 6). Patterson et al., (2014) proposed that a shift to eccentricity-paced ice sheet variability near the Plio-Pleistocene transition was related to a change towards a colder climate state. This was linked to shifts in a melt threshold, which controls the total integrated summer insolation (time and magnitude) received by the sea ice belt around the Antarctic margin (rather than insolation directly influencing surface melt on the ice sheet). The melt threshold is higher 
in a colder climate state, and thus the integrated summer energy above this threshold becomes increasingly controlled by precession as the duration of summer is lower. Therefore, it was proposed that ice sheet variability in the Pleistocene was regulated by sea ice extent (controlled by summer insolation intensity and precession) and that sea ice acted to reduce the impact of upwelled warm water masses in a colder climate state. Such water masses are influenced by the latitudinal temperature gradients and the duration of summer; both controlled by obliquity (Huybers and Tziperman, 2008; Naish et al., 2009; Patterson et al., 2014) (see section 2.3.3). The Late Miocene interval at Site U1361 requires a reassessment of this hypothesis, as the production of nannofossils are interpreted to have occurred in a warm climate with reduced seasonal sea ice (i.e. above $3{ }^{\circ} \mathrm{C}$ ) than the eccentricity/precession paced IBRD MAR signal during the Pleistocene interval of Site U1361 (Patterson et al., 2014). Also, the presence of nannofossil-rich sediments suggests a warmer climate state than the Pliocene interval that had an IBRD MAR signal of obliquity dominance (Patterson et al., 2014).

Although Patterson et al., (2014) only focused on the cooling event across the PlioPleistocene boundary, Levy et al., (2019) expanded on these concepts by investigating $\delta^{18} \mathrm{O}$ records over the past $\sim 34 \mathrm{Ma}$ and making links to evidence of ice sheet variability from the Antarctic margin. Levy et al., (2019) interpreted the low obliquity sensitivity (defined as the ratio of obliquity variance in a $\delta^{18} \mathrm{O}$ record to the variance of the theoretical obliquity solution for any given period) during the Late Miocene to represent a period of climatic cooling, and extensive sea ice that acted to protect the ice sheet from oceanic influence. This is contradicted by the majority of the evidence presented at Site U1361 between $\sim 11.7$ and $11.0 \mathrm{Ma}$, as the nannofossils suggest the climate was warmer, with reduced sea ice and enhanced surface meltwater pulses. However, surface melt control on ice sheet mass balance is supported by other evidence from the East Antarctic margin (Hambrey and McKelvey, 2000; McKay et al., 2009; Gulick et al., 2017) and indicates that a short interval of warming was superimposed on the long-term cooling trend, suggesting that the Late Miocene does not directly correlate to these generalised long-term models.

Levy et al., (2019) also proposes that during warmer climate states prior to $25 \mathrm{Ma}$, when EAIS had retreated towards its terrestrial margin, eccentricity and precession forcing 
became increasingly important, as surface melt processes dominated loss of glacial ice (rather than calving). If the Levy et al., (2019) hypothesis of orbital control on ice sheet mass balance is correct, the results in this thesis suggest that eccentricity-forcing IBRD MAR and marine productivity of nannofossils are the consequence of EAIS retreating to its terrestrial margin between $\sim 11.7$ and $11.0 \mathrm{Ma}$ (Figure 6. 6). This is in contrast to the long-term trends proposed by Levy et al., (2019) of increasing sea ice influence and oceanic controls on ice sheet mass balance after 14 Ma (i.e. MCT) suggesting this time $\sim 700$ kyr period was characterised by ice sheets that were significantly influenced by surface melt processes, rather than oceanic induced melting (increase in local insolation). This hypothesis can potentially be tested by future studies examining SSTs (e.g. TEX 86 , Alkenones, palaeontology), sea ice extent/duration (e.g. lipid biomarkers, palaeontology) and glacial meltwater input (e.g. sedimentary facies and stable isotopes) at Site U1361 and other drill core records from the Antarctic margin during the $\sim 700 \mathrm{kyr}$ interval of relative warmth in the Late Miocene. 

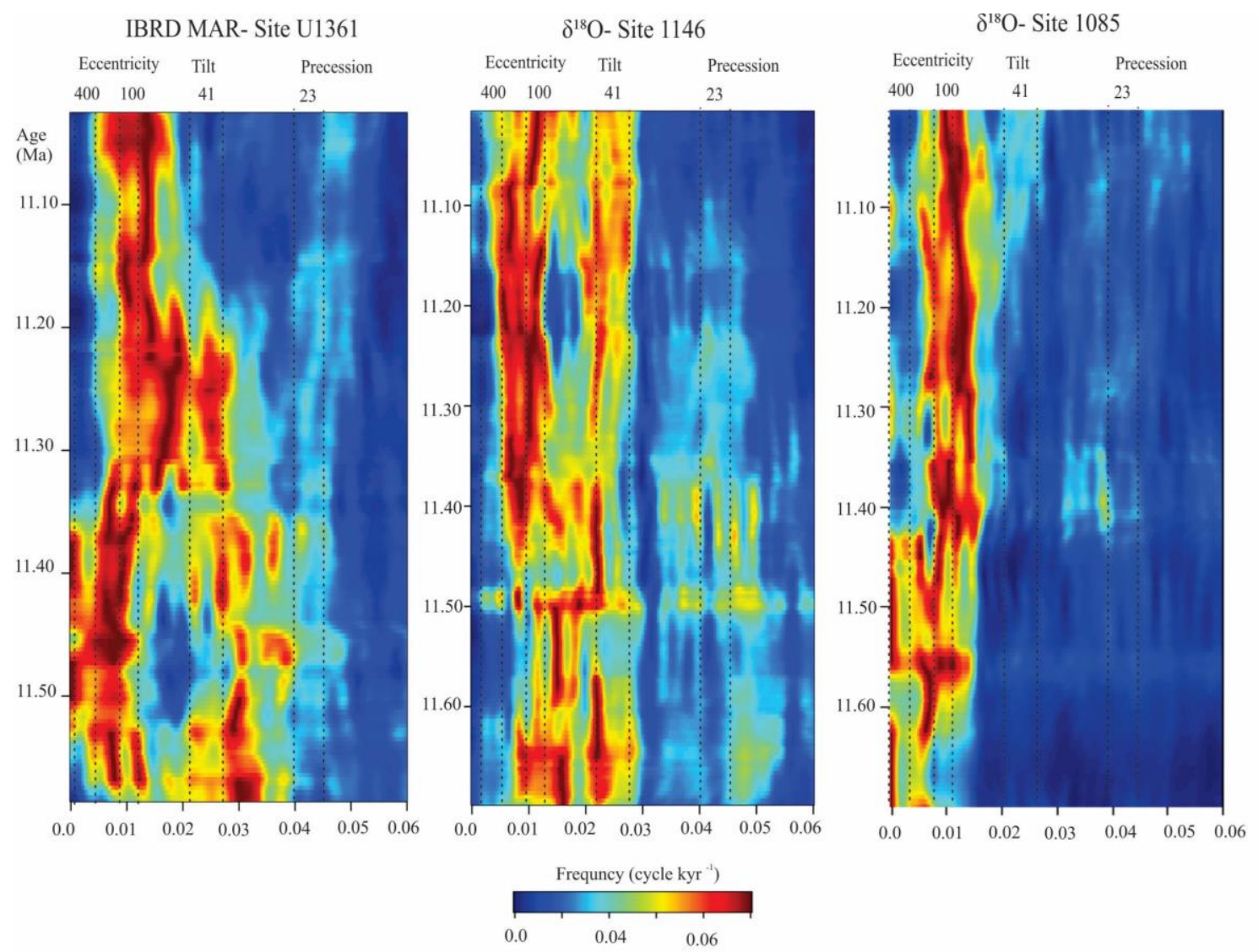

IBRD MAR U1361

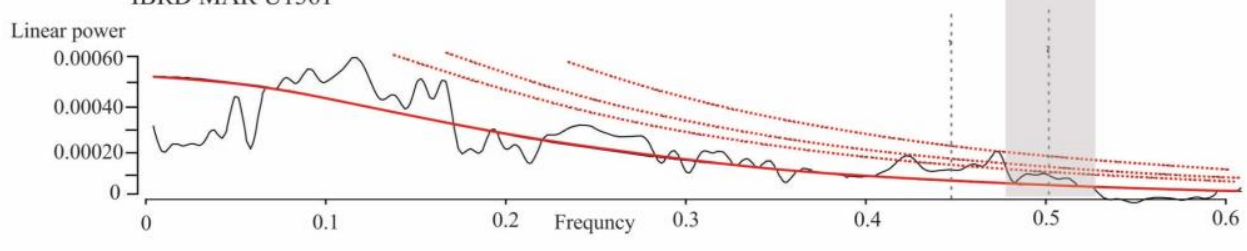

Site 1146

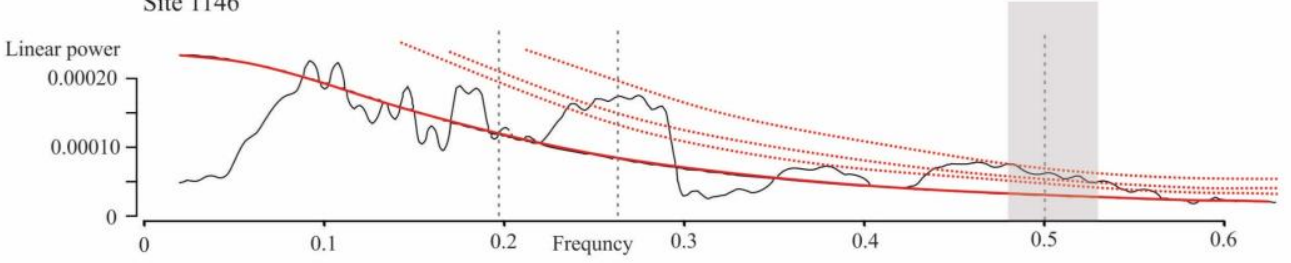

Site 1085

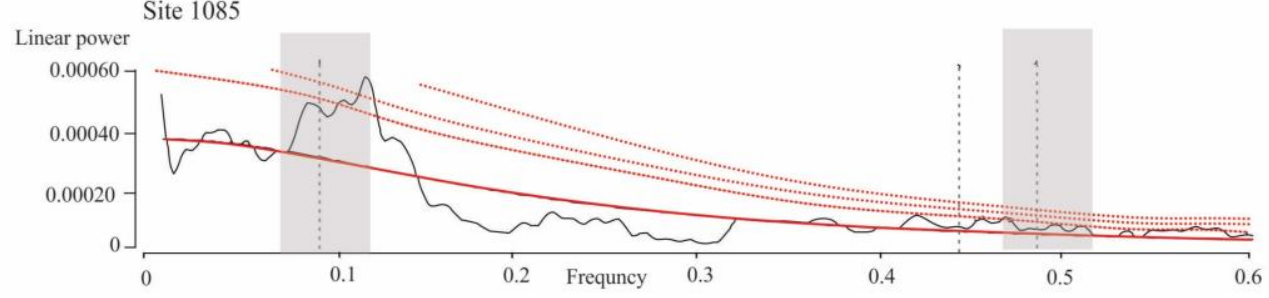

Figure 6. 5 EHA and MTM comparison between Site U1361 IBRD MAR dataset and $\delta^{18} \mathrm{O}$ from Site 1146 and 1158 (Holbourn et al., (2013) and Westerhold, et al., (2005), respectively 


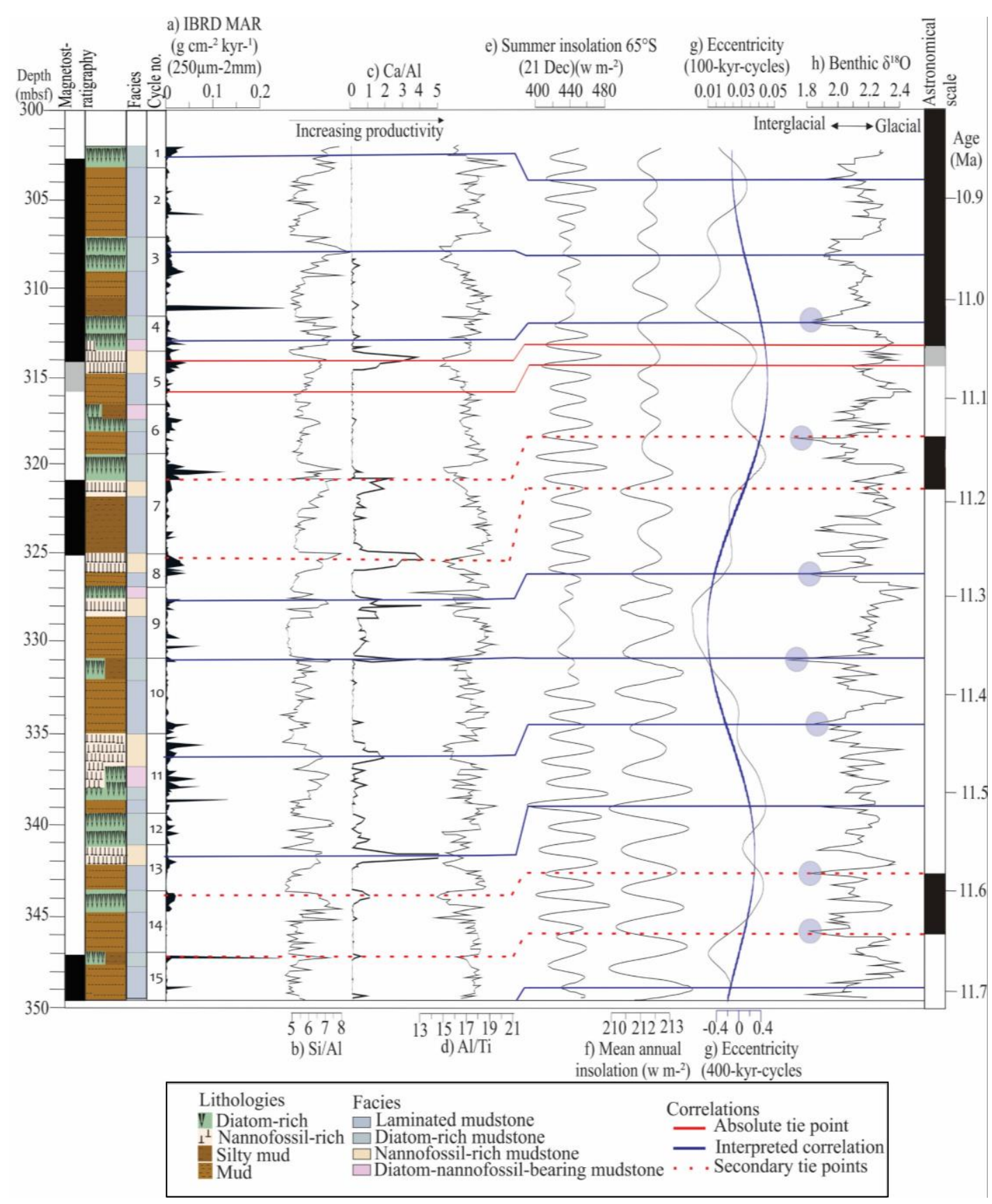

Figure 6. 6 Depth series of IODP Site U1361 sediment core datasets between $\sim 11.7$ and 10.8 Ma. a) IBRD MAR; b-d) XRF-based proxies (a-d correlate with the depth axis); e) summer insolation (January) at $65^{\circ} \mathrm{S}$; f) mean annual insolation at $65^{\circ} \mathrm{S} ; \mathrm{g}$ ) eccentricity (100 kyr and $400 \mathrm{kyr})$; h) benthic $\delta^{18} \mathrm{O}$ record (Holbourn et al., 2013). e to h) correlate to the time series. Also shown is the downcore distribution of lithofacies, lithological cycles and magnetic polarity stratigraphy (Tauxe, et al., 2012). The certainty of correlations is defined by the colour (refer to the key), and the blue dots on the $\delta^{18} \mathrm{O}$ curve indicate the extreme glaciations 


\section{CHAPTER SEVEN: CONCLUSIONS}

This study investigated the glacimarine sedimentary processes operating on the continental rise offshore Adélie Coast at the Wilkes Land margin during the glacialinterglacial cycles of the Late Miocene ( 11.7 to $10.8 \mathrm{Ma})$. The study focused on the environmental conditions which led to the deposition of an interval of 'anomalous' nannofossils (between $\sim 11.7$ and $11.0 \mathrm{Ma}$ ) by analysing five core sections between $\sim 302$ and $350 \mathrm{mbsf}$ at IODP Site U1361. A high-resolution record of grain size, water mass indicators (XRF) and iceberg rafted debris was developed, with additional spectral analysis to address the three objectives outlined in Chapter One. The interpretations made in this thesis remain a working hypothesis, as this time interval lacks supporting Antarctic records and a reliable $\mathrm{CO}_{2}$ record for direct comparison. The main findings are summarised below:

- An assessment of 450 samples were analysed for IBRD (250 $\mu \mathrm{m}$ and $2 \mathrm{~mm})$ content, and the MAR was calculated following the method developed by Patterson et al., (2014). A significant number of $>250 \mu \mathrm{m}$ samples contained biogenic and authigenic material, which were identified as gypsum and pyrite nodules by elemental mapping and were removed from the final IBRD dataset. The IBRD MAR values are consistent with previous studies, and the weak correlation with sorting (Ø) is indicative of a 'real' IBRD signal. IBRD MAR visually appears to fluctuate at orbital frequencies, in $\sim 5$ $\mathrm{m} /$ cycles.

- Geochemical analysis was completed on 444 samples providing a series of elemental proxies used to identify variations in ocean productivity and terrigenous input. $\mathrm{Ca} / \mathrm{Al}$ values above background levels and a drop in $\mathrm{Sr} / \mathrm{Ca}$ was interpreted as nannofossilrich sediments while a pulse in $\mathrm{Si} / \mathrm{Al}$ and $\mathrm{Ba} / \mathrm{Al}$ directly correlates to increased diatom production. $\mathrm{Al} / \mathrm{Ti}$ was used to highlight intervals of low productivity. Grain size analysis was assessed on 224 samples using the LPS at VUW. Results demonstrate that the silt-sized fraction dominates the record with variations in grain size occurring every $\sim 5 \mathrm{~m}$. The combination of geochemical (XRF) data, IBRD MAR, grain size 
parameters and physical properties (MS and NGR) allowed for the characterisation of four lithofacies in the Late Miocene interval at Site U1361.

- The deposition of the faintly laminated mudstone (Facies 4) was interpreted as glacial deposits, regulated by the entrainment of overbank flow spill by low current strength bottom waters (Rebesco et al., 2014). The contouritic nature of the glacial sediments during the Late Miocene, significantly differs to the primary turbidite deposition in the Plio-Pleistocene interval of the core (Patterson et al., 2014), and is more consistent with sedimentation during the Oligocene interval at nearby Site U1356 (Salabarnada et al., 2018). This is potentially associated to the early phase of the modern channel levee development at Site U1361. As during the initial stage of development, the low relief system on the continental shelf would have affected sediment volume, texture and delivery to the deep sea. The presence of bioturbation in some glacial intervals, potentially indicates periods of oxygenated bottom current activity to the site.

- Three interglacial facies were identified during $\sim 11.7$ and $10.8 \mathrm{Ma}$ and are dependent on the dominating biogenic source (i.e. silica, carbonate or both). The diatoms-rich sediments (Facies 1) are highly bioturbated and have winnowing of the fine-grained material, interpreted to represent open ocean conditions and an enhanced upwelling increasing availability of nutrient-rich waters (i.e. increased surface productivity). Previous studies have attributed this to the upwelling of the warm CDW, due to the shift in Southern Ocean winds (Sangiorgi et al., 2015). The occurrence of nannofossilrich facies (Facies 2) is not consistent with the interpretation above for interglacial sedimentation, interpreted to represent warmer surfaces waters, and the increase in meltwater processes on the EAIS margin, consistent with other Antarctic studies at this time (e.g. Hambrey and McKelvey, 2000a; McKay et al., 2009; Gulick et al., 2017). The large pulses of turbid meltwater and IBRD (during peak deglaciation) alongside a shift in the Southern Ocean frontal systems would have increased ocean stratification, altering nutrient delivery to surface waters. The nannofossil-rich mudstone repeats only six times between $\sim 11.7$ to $11.0 \mathrm{Ma}$, suggesting that the climate was warmer than present-day and the Plio-Pleistocene, as after $\sim 11.0 \mathrm{Ma}$ 
diatoms became the only biogenic depositional source for the remainder of the core at Site U1361.

- The relationship between the presented proxies is fundamental for characterising the shift in plankton productivity over the study interval. The pulses in iceberg rafting and productivity (i.e. $\mathrm{Si} / \mathrm{Al}, \mathrm{Ba} / \mathrm{Al}, \mathrm{Ca} / \mathrm{Al}$ and $\mathrm{Sr} / \mathrm{Ca}$ ) occur during the deglaciation, which were interpreted as the dynamic response of the EAIS during a warmer climate at the Wilkes Land margin. The rate of IBRD reduces as the margin stabilises, but high productive surface waters persist over the entire interglacial cycle. The increase in grain size (i.e. current speed) appears to slightly lag pulses in calving and productivity offshore Wilkes Land. This was interpreted as reflecting the influence of enhanced bottom water current activity during these intervals of the Late Miocene.

- MTM analysis run in the depth domain identified that all datasets (MGS, silt \%, CS\% and $\mathrm{Si} / \mathrm{Al}$ ) demonstrated a dominant 5.5 to $5.9 \mathrm{~m} /$ cycle, with this broad peak inferred to represent power in the 90-120 kyr eccentricity cycle. Due to the high uncertainties with the paleomagnetic age model, only the tie point at $\sim 11.056 \mathrm{Ma}$ was used to develop the age model for the Late Miocene interval of U1361A core, consistent with Tauxe et al., (2012). A conservative age model estimation was enhanced by ASM of the mean grain size time series over the interval and provided an average sedimentation rate of $5.6 \mathrm{~cm} / \mathrm{ka}$, consistent with the time envelope created by the hybrid CONOP model (Cody et al., 2012). These sedimentation rates are consistent with those implied by paleomagnetic reversals that provide tie points to the magnetostratigraphic timescale with lower confidence Spectral analysis results support the presence of the $\sim 100 \mathrm{kyr}$ (and subordinate $\sim 20 \mathrm{kyr}$ ) cyclicity in various proxies (CS\%, MGS, Si/Al and silt \%), indicating that the glacial-interglacial cyclicity occur every $5 \mathrm{~m}$ or $\sim 100 \mathrm{kyr}$ at Wilkes Land during the Late Miocene. The Wilkes Land margin of the EAIS appears to be fluctuating in-phase with the $\sim 100 \mathrm{kyr}$ paced $\delta^{18} \mathrm{O}$ record at Site 1085 and 1146 (Westerhold et al., 2005; Holbourn et al., 2013, respectively), indicating that Antarctica is contributing a significant signal to the $\delta^{18} \mathrm{O}$ signal during this interval. 
- The presence of turbid meltwater and nannofossils during the interglacials at the EAIS margin between $\sim 11.7$ and 11.0 Ma suggest a warmer climate state during the Late Miocene, relative to the Plio-Pleistocene. This study supports the growing amount of evidence that the EAIS margin was influenced by significant meltwater processes, which appear to have persisted at Wilkes Land until at least 11.0 Ma. This counters the long-standing view that the EAIS was relatively stable, due to a hyper-arid climate since 14 Ma. Following Levy et al., (2019) hypothesis, which proposes that increased obliquity sensitivity relates to the presence of a marine-terminating EAIS, the low obliquity sensitivity evident in the presented records suggest retreat of the EAIS near to its terrestrial margin between $\sim 11.7$ and $11.0 \mathrm{Ma}$. This style of ice sheet configuration is more likely to be paced by eccentricity and precession controlled surface melt processes (Levy et al., 2019), which is supported by the orbital scale records of iceberg rafting and productivity presented in this thesis. 


\section{REFERENCES}

Anderson, B. and Burckle, L. (2009) 'Wind-Driven Upwelling in the Southern Ocean and the Deglacial Rise in Atmospheric CO2', Science, 323, pp. 1443-1448.

Anderson, J. et al. (2011) 'Progressive Cenozoic cooling and the demise of Antarctica's last refugium', Proceedings of the National Academy of Sciences, 108(28), pp. 1135611360.

Armbrust, E. (2009) 'The life of diatoms in the world's oceans', Nature, 459(7244), pp. $185-192$.

Askin, R. and Raine, J. (2000) 'Oligocene and Early Miocene terrestrial palynology of the Cape Roberts Drillhole CRP-2/2A, Victoria Land Basin, Antarctica', Terra Antarctica, 7(4), pp. 493-501.

Badger, M. et al. (2013) ' $\mathrm{CO} 2$ drawdown following the middle Miocene expansion of the Antarctic Ice Sheet', Paleoceanography, 28(1), pp. 42-53.

Bahr, A. et al. (2014) 'Deciphering bottom current velocity and paleoclimate signals from contourite deposits in the Gulf of Cadiz during the last 140 kyr: An inorganic geochemical approach', Geochemistry, Geophysics, Geosystems, 15, pp. 3145-3160.

Balch, W. et al. (2016) 'Factors regulating the Great Calcite Belt in the Southern Ocean and its biogeochemical significance', Global Biogeochemical Cycles, 30(8), pp. 1124 1144.

Barker, P. and Kennett, J. (1988) 'Site 689', Proceedings of the Ocean Drilling Program, 113, pp. 301-343.

Barker, P. and Thomas, E. (2004) 'Origin, signature and palaeoclimatic influence of the Antarctic Circumpolar Current', Earth-Science Reviews, 66(1-2), pp. 143-162.

Barrett, P. (2013) 'Resolving views on Antarctic Neogene glacial history - The Sirius debate', Earth and Environmental Science Transactions of the Royal Society of Edinburgh, 104(1), pp. 31-53.

Bathurst, R. (1974) 'Marine Diagenesis of Shallow Water Calcium Carbonate Sediments', Annual Review of Earth and Planetary Sciences, 2(1), pp. 257-274.

Baumann, K., Boeckel, B. and Frenz, M. (2004) 'Coccolith contribution to South Atlantic carbonate sedimentation', Coccolithophores, pp. 367-402.

Beaman, R. et al. (2011) 'A new high-resolution bathymetry model for the Terre Adélie and George V continental margin, East Antarctica', Antarctic Science, 23(1), pp. 95-103.

Berger, A. and Loutre, M. (1991) 'Insolation values for the climate of the last 10 million years', Quaternary Science Reviews, 10, pp. 297-317.

Bertram, R. et al. (2018) 'Pliocene deglacial event timelines and the biogeochemical 
response offshore Wilkes Subglacial Basin, East Antarctica', Earth and Planetary Science Letters. Elsevier B.V., 494, pp. 109-116.

Bijl, P. et al. (2013) 'Eocene cooling linked to early flow across the Tasmanian Gateway', Proceedings of the National Academy of Sciences, 110(24), pp. 9645-9650.

Bindoff, N., Rintoul, S. and Massom, R. (2000) 'Bottom Water Formation and Polynyas in Adelie Land, Antarctica', In Papers and Proceedings of the Royal Society of Tasmania, 133(3), pp. 51-56.

Bindoff, N., Rosenberg, M. and Warner, M. (2000) 'On the circulation and water masses over the Antarctic continental slope and rise between 80 and $150^{\circ} \mathrm{E}$ ', Deep-Sea Research Part II: Topical Studies in Oceanography, 47(12-13), pp. 2299-2326.

Blott, S. and Pye, K. (2001) 'Gradistat: A Grain Size Distribution and Statistics Package for the Analysis of Unconcolidated Sediments', Earth Surface Processes and Landforms, 26, pp. 1237-1248.

Boggs, S. (2006) Principles of sedimentology and stratigraphy. Pearson Education.

Bolton, C. et al. (2016) 'Decrease in coccolithophore calcification and CO2 since the middle Miocene', Nature Communications, 7(10284), pp. 1-13.

Bouma, A. (1964) 'Turbidites', in Developments in sedimentology. Elsevier, pp. 247256.

Budillon, G., Gremes Cordero, S. and Salusti, E. (2002) 'On the dense water spreading off the Ross Sea shelf (Southern Ocean)', Journal of Marine Systems, 35(3-4), pp. 207227.

Burckle, L. and Pokras, E. (1991) 'Implications of a Pliocene stand of Nothofagus (Southern Beech) within 500 kilometres of the South pole', Antarctic Science, 3(4), pp. 389-403.

Caburlotto, A. et al. (2006) 'New insights into Quaternary glacial dynamic changes on the George V Land continental margin (East Antarctica)', Quaternary Science Reviews, 25(21-22), pp. 3029-3049.

Caburlotto, A. et al. (2010) 'Sedimentary processes on the Wilkes Land continental rise reflect changes in glacial dynamic and bottom water flow', International Journal of Earth Sciences, 99(4), pp. 909-926.

Calvert, S. and Pedersen, T. (1996) 'Sedimentary Geochemistry of Manganese: Implications for the Environment of Formation of Manganiferous Black Shale', Economic Geology, 91(3), pp. 36-47.

Campagne, P. et al. (2015) 'Glacial ice and atmospheric forcing on the Mertz Glacier Polynya over the past 250 years', Nature Communications, 6(6642), pp. 1-9.

Carter, L., McCave, I. and Williams, M. (2009) 'Circulation and Water Masses of the 
Southern Ocean: a Review', Developments in Earth and Environmental Sciences, 8, pp. 85-114.

Cerling, T. et al. (1997) 'Global vegetation change through the Miocene/Pliocene boundary', Nature, 389(6647), pp. 153-158.

Chisholm, S. (2000) 'Oceanography: Stirring times in the Southern Ocean', Nature, 407, pp. 685-687.

Cody, R. et al. (2008) 'Thinking outside the zone: High-resolution quantitative diatom biochronology for the Antarctic Neogene', Palaeogeography, Palaeoclimatology, Palaeoecology, 260(1-2), pp. 92-121.

Cody, R. et al. (2012) 'Selection and stability of quantitative stratigraphic age models: Plio-Pleistocene glaciomarine sediments in the ANDRILL 1B drillcore, McMurdo Ice Shelf', Global and Planetary Change. Elsevier B.V., 96-97, pp. 143-156.

Colwell, J. et al. (2006) 'The structure of the continental margin off Wilkes Land and Terre Adelie coast, east Antarctica', in Antarctica. Springer. Berlin, Heideelberg: Springer, pp. 327-339.

Cook, C. et al. (2013) 'Dynamic behaviour of the East Antarctic ice sheet during Pliocene warmth', Nature Geoscience, 6(9), pp. 765-769.

Cook, C. et al. (2014) 'Sea surface temperature control on the distribution of far-traveled Southern Ocean ice-rafted detritus during the Pliocene', Paleoceanography, 29, pp. 533548.

Coxall, H. et al. (2005) 'Rapid stepwise onset of Antarctic glaciation and deeper calcite compensation in the Pacific Ocean', Nature, 433(7021), pp. 53-57.

Cramer, B. et al. (2009) 'Ocean overturning since the Late Cretaceous: Inferences from a new benthic foraminiferal isotope compilation', Paleoceanography, 24(4), pp. 49-57.

Crampton, J. et al. (2016) 'Southern Ocean phytoplankton turnover in response to stepwise Antarctic cooling over the past 15 million years', Proceedings of the National Academy of Sciences, 113(25), pp. 6868-6873.

De Vleeschouwer, D. et al. (2017) 'Alternating Southern and Northern Hemisphere climate response to astronomical forcing during the past 35 m.y', Geology, 45(4), pp. $375-378$.

De Santis, L. et al. (1999) 'The Eastern Ross Sea continental shelf during the Cenozoic: Implications for the West Antarctic ice sheet development', Global and Planetary Change, 23(1-4), pp. 173-196.

De Santis, L., Brancolini, G. and Donda, F. (2003) 'Seismo-stratigraphic analysis of the Wilkes Land continental margin (East Antarctica): Influence of glacially driven processes on the Cenozoic deposition', Deep-Sea Research Part II: Topical Studies in Oceanography, 50(8-9), pp. 1563-1594. 
De Santis, L. et al. (2007) 'New insights into submarine geomorphology and depositional processes along the George V Land continental slope and upper rise (East Antarctica).', In 10th International Symposium on Antarctic Earth Sciences., US Geologi, pp. 1-5.

DeCesare, M. and Pekar, S. (2016) 'Data report; Foraminiferal stable isotope and percent calcium carbonate analysis from IODP Expedition 318 Hole U1361A', Proceedings of the Integrated Ocean Drilling Program, Expedition, pp. 1-15.

DeConto, R. et al. (2008) 'Thresholds for Cenozoic bipolar glaciation', Nature, 455(7213), pp. 652-656.

DeConto, R. and Pollard, D. (2003) 'Rapid Cenozoic glaciation of Antarctica induced by declining atmospheric CO2', Nature, 1317(2001), pp. 1313-1317.

Depoorter, M. et al. (2013) 'Calving fluxes and basal melt rates of Antarctic ice shelves', Nature, 502(7469), pp. 89-92.

Donda, F. et al. (2003) 'Seismic facies and sedimentary processes on the continental rise off Wilkes Land (East Antarctica): Evidence of bottom current activity', Deep-Sea Research Part II: Topical Studies in Oceanography, 50(8-9), pp. 1509-1527.

Donda, F. et al. (2007) 'Sedimentary processes in the Wilkes Land margin: a record of the Cenozoic East Antarctic Ice Sheet evolution', Journal of the Geological Society, 164(1), pp. 243-256.

Drewry, D. and Cooper, A. (1981) 'Processes and models of Antarctic glaciomarine sedimentation', Annals of Glaciology, 2, pp. 117-122.

Duncan, B. et al. (2016) 'Interglacial/glacial changes in coccolith-rich deposition in the SW Pacific Ocean: An analogue for a warmer world?', Global and Planetary Change. Elsevier B.V., 144, pp. 252-262.

Duncan, B. (2017) Cenozoic Antarctic climate evolution based on molecular and isotopic biomarker reconstructions from geological archives in the Ross Sea region. Univeristy of Wellington.

Duncan, B. et al. (2019) 'Lipid biomarker distributions in Oligocene and Miocene sediments from the Ross Sea region, Antarctica: Implications for use of biomarker proxies in glacially influenced settings', Palaeogeography, Palaeoclimatology, Palaeoecology. Elsevier, 516, pp. 71-89.

Dymond, J., Suess, E. and Lyle, M. (1992) 'Abstract. We used sediment traps to define the higher barium contents in the intermediate and combined our particle flux data with existing water linkages to ocean productivity and the degree of', Paleoceanography, 7(2), pp. 163-181.

Eglinton, T. and Eglinton, G. (2008) 'Molecular proxies for paleoclimatology', Earth and Planetary Science Letters, 275(1-2), pp. 1-16.

Elderfield, H. et al. (2012) 'Evolution of Ocean Temperature and Ice volume through the 
Mid-Pleistocene Climate Transition', Science, 337, pp. 704-709.

Escutia, C. et al. (1997) 'Cenozoic sedimentation on the Wilkes Land continental rise, Antarctica', The Antarctic Region: Geological Evolution and Processes, 7, pp. 791-795.

Escutia, C. et al. (2000) 'Morphology and Acoustic Character of the Antarctic Wilkes Land Turbidite Systems: Ice-Sheet-Sourced Versus River-Sourced Fans', Journal of Sedimentary Research, 70(1), pp. 84-93.

Escutia, C. et al. (2003) 'Sediment distribution and sedimentary processes across the Antarctic Wilkes Land margin during the Quaternary', Deep-Sea Research Part II: Topical Studies in Oceanography, 50(8-9), pp. 1481-1508.

Escutia, C. et al. (2005) 'Cenozoic ice sheet history from East Antarctic Wilkes Land continental margin sediments', Global and Planetary Change, 45(1-3), pp. 51-81.

Escutia, C. et al. (2011a) 'Expedition 318 summary', Proceedings of the Deep Sea Drilling Program: Tokyo (Integrated Ocean Drilling Program Management International, inc.).

Escutia, C. et al. (2011b) 'Site U1361', Proceedings of the Deep Sea Drilling Program: Tokyo (Integrated Ocean Drilling Program Management International, inc.), 318, pp. 157.

Falkowski, P. et al. (2000) 'The Global Carbon Cycle : A Test of Our Knowledge of Earth as a System', Science, 290(5490), pp. 291-296.

Ferraccioli, F. et al. (2001) 'Rifted crust at the East Antarctic Craton margin: Gravity and magnetic interpretation along a traverse across the Wilkes Subglacial Basin region', Earth and Planetary Science Letters, 192(3), pp. 407-421.

Ferraccioli, F. et al. (2009) 'Aeromagnetic exploration over the East Antarctic Ice Sheet: A new view of the Wilkes Subglacial Basin', Tectonophysics. Elsevier B.V., 478(1-2), pp. $62-77$.

Flower, B. and Kennett, J. (1994) 'The middle Miocene climatic transition: East Antarctic ice sheet development, deep ocean circulation and global carbon cycling', Palaeogeography, Palaeoclimatology, Palaeoecology, 108(3-4), pp. 537-555.

Francis, J. and Hill, R. (1996) 'Fossil Plants from the Pliocene Sirius Group, Transantarctic Mountains: Evidence for Climate from Growth Rings and Fossil Leaves', Palaios, 11(4), p. 389.

Fretwell, P. et al. (2013) 'Bedmap2: improved ice bed, surface and thickness datasets for Antarctica', The Cryosphere, 7, pp. 375-393.

Galeotti, S. et al. (2016) 'Antarctic Ice Sheet variability across the Eocene-Oligocene boundary climate transition', Science, 352(6281), pp. 76-79.

Gasson, E. et al. (2016) 'Dynamic Antarctic ice sheet during the early to mid-Miocene', 
Proceedings of the National Academy of Sciences, 113(13), pp. 3459-3464.

Ghil, M. et al. (2002) 'Advanced spectral methods for climatic time series', Reviews of Geophysics, 40(1), p. 3.1-3.37.

Gladstone, R., Bigg, G. and Nicholls, K. (2001) 'Iceberg trajectory modeling and meltwater injection in the Southern Ocean', Journal of Geophysical Research: Oceans, 106(C9), pp. 19903-19915.

Golledge, N. et al. (2015) 'The multi-millennial Antarctic commitment to future sea-level rise', Nature, 526(7573), pp. 421-425.

Golledge, N. et al. (2017) 'East Antarctic ice sheet most vulnerable to Weddell Sea warming', Geophysical Research Letters, 44(5), pp. 2343-2351.

Goodge, J. and Fanning, C. (2010) 'Composition and age of the East Antarctic shield in eastern Wilkes Land determined by proxy from oligocene-pleistocene glaciomarine sediment and beacon supergroup sandstones, Antarctica', Bulletin of the Geological Society of America, 122(7-8), pp. 1135-1159.

Gulick, S. et al. (2017) 'Initiation and long-term instability of the East Antarctic Ice Sheet', Nature. Nature Publishing Group, 552(7684), pp. 225-229.

Hambrey, M., Ehrmann, W. and Larsen, B. (1991) 'Cenozoic glacial record of the Prydz Bay continental shelf, East Antarctica', Proc. ODP Sci. Results, College Station, TX, 119, pp. 77-132.

Hambrey, M. and McKelvey, B. (2000a) 'Major Neogene fluctuations of the East Antarctic ice sheet: Stratigraphic evidence from the Lambert Glacier region', Geology, 28(10), pp. 887-890.

Hambrey, M. and McKelvey, B. (2000b) 'Neogene fjordal sedimentation on the western margin of the Lambert Graben, East Antarctica', Sedimentology, 47(3), pp. 577-607.

Hasenfratz, A. P. et al. (2019) 'The residence time of Southern Ocean surface waters and the 100,000-year ice age cycle', Science, 363(1080-1084), pp. 1-5.

Hays, J., Imbrie, J. and Shackleton, N. (1976) 'Variations in the Earth's Orbit : Pacemaker of the Ice Ages', Science, 194(4270), pp. 1121-1132.

Haywood, A. and Valdes, P. (2004) 'Modelling Pliocene warmth: Contribution of atmosphere, oceans and cryosphere', Earth and Planetary Science Letters, 218(3-4), pp. 363-377.

Herbert, T. et al. (2016) 'Late Miocene global cooling and the rise of modern ecosystems', Nature Geoscience, 9(11), pp. 843-847.

Holbourn, A. et al. (2013) 'Middle to late Miocene stepwise climate cooling: Evidence from a high-resolution deep water isotope curve spanning 8 million years', Paleoceanography, 28(4), pp. 688-699. 
Houben, A. et al. (2013) 'Reorganization of Southern Ocean', Science, 340, pp. 341-345.

Hutchins, D. et al. (2001) 'Control of phytoplankton growth by iron supply and irradiance in the subantarctic Southern Ocean: Experimental results from the SAZ Project', Journal of Geophysical Research: Oceans, 106(C12), pp. 31573-31583.

Huybers, P. (2006) 'Early Pleistocene Glacial Cycles and and the Integrated Summer Insolation Forcing', Science, 313, pp. 508-511.

Huybers, P. and Tziperman, E. (2008) 'Integrated summer insolation forcing and 40,000year glacial cycles: The perspective from an ice-sheet/energy-balance model', Paleoceanography, 23(1), pp. 1-18.

IPCC (2014) Climate Change 2014: Synthesis Report. Contribution of Working Groups I, II and III to the Fifth Assessment Report of the Intergovernmental Panel on Climate Change. [Core Writing Team, R.K. Pachauri and L.A. Meyer (eds.)]. IPCC, Geneva, Switzerland.

Jaccard, S. et al. (2016) 'Covariation of deep Southern Ocean oxygenation and atmospheric CO2 through the last ice age', Nature, 530(7589), pp. 207-210.

Jacobs, Hellmer, H. and Jenkins, A. (1996) 'Antarctic Ice Sheet melting in the southeast Pacific', Geophysical Research Letters, 23(9), pp. 957-960.

Jacobs, S. (1991) 'On the nature and significance of the Antarctic Slope Front', Marine Chemistry. Elsevier Science Publishers B.V., 35, pp. 9-24.

John, C. et al. (2011) 'Timing and magnitude of Miocene eustasy derived from the mixed siliciclastic-carbonate stratigraphic record of the northeastern Australian margin', Earth and Planetary Science Letters. Elsevier B.V., 304(3-4), pp. 455-467.

Joseph, L. et al. (2002) 'Antarctic environmental variability since the late Miocene: ODP Site 745, the East Kerguelen sediment drift', Earth and Planetary Science Letters, 201(1), pp. $127-142$.

Kennett, J. et al. (1975) 'Cenozoic paleoceanograpy in the southwest Pacific Ocean, Antarctic Glaciation, and the development of the Circum-Antarctic Current', Deep Sea Drilling Project Initial Reports, 29, pp. 1155-1169.

Kennett, J. (1977) 'Cenozoic evolution of Antarctic glaciation, the circum-Antarctic Ocean, and their impact on global paleoceanography', Journal of Geophysical Research, 82(27), pp. 3843-3860.

Kennett, J. and Hodell, D. (1993) 'Evidence for relative climatic stability of Antarctica during the early Pliocene: a marine perspective', Geografiska Annaler. Series A: Physical Geography, 75(4), pp. 205-220.

Killops, S. and Killops, V. (2013) Introduction to organic geochemistry. John Wiley \& Sons. 
Krissek, L. (1995) 'Late Cenozoic ice-rafting records from Leg 145 sites in the North Pacific: Late Miocene onset, late Pliocene intensification, and Pliocene-Pleistocene events', Proceedings of the Ocean Drilling Program, Scientific ResultS, 145, pp. 179194.

Kusahara, K., Hasumi, H. and Williams, G. (2011) 'Impact of the Mertz Glacier Tongue calving on dense water formation and export', Nature Communications. Nature Publishing Group, 2(159), pp. 1-6.

Laskar, J. et al. (2004) 'A long-term numerical solution for the insolation quantities of the Earth', Astronomy \& Astrophysics, 428, pp. 261-285.

Lazarus, D. et al. (2014) 'Cenozoic planktonic marine diatom diversity and correlation to climate change', PLOS ONE, 9(1), pp. 1-18.

Lear, C. et al. (2008) 'Cooling and ice growth across the Eocene-Oligocene transition', Geology, 36(3), pp. 251-254.

Levy, R. et al. (2016) 'Antarctic ice sheet sensitivity to atmospheric CO2 variations in the early to mid-Miocene', Proceedings of the National Academy of Sciences, 113(13), pp. 3453-3458.

Levy, R. et al. (2019) 'Antarctic ice-sheet sensitivity to obliquity forcing enhanced through ocean connections', Nature Geoscience. Springer US, 1, pp. 1-6.

Lewis, A. et al. (2006) 'The age and origin of the Labyrinth, western Dry Valleys, Antarctica: Evidence for extensive middle Miocene subglacial floods and freshwater discharge to the Southern Ocean', Geology, 34(7), pp. 513-516.

Lewis, A. et al. (2008) 'Mid-Miocene cooling and the extinction of tundra in continental Antarctica', Proceedings of the National Academy of Sciences, 105(31), pp. 1067610680.

Lewis, A. R. et al. (2007) 'Major middle Miocene climate change and the extinction of tundra communities: Evidence from the Transantarctic Mountains', In Antarctica; a keystone in a changing world-online. Proc. 10th Int. Symp. on Antarctic Earth Sciences (eds A. Cooper \& C. Raymond, the 10th ISAES Editorial Team). US Geological Survey and The National Academies., pp. 1449-1461.

Licht, K. (2009) 'Antarctic Glaciation History', Encyclopedia of Earth Sciences Series, pp. 24-29.

Liu, Z. et al. (2009) 'Eocene-Oligocene Climate Transition', Science, 323(5918), pp. 1187-1190.

Lowe, D. (1982) 'Sediment Gravity Flow: Depositional models with special reference to the deposits or high-density turbidity currents', Journal of Sedimentary Research, 52(1), pp. 279-297.

Lucchi, R. et al. (2002) 'Mid-late Pleistocene glacimarine sedimentary processes of a 
high-latitude, deep-sea sediment drift (Antarctic Peninsula Pacific margin)', Marine Geology, 189(3-4), pp. 343-370.

Lucchi, R. and Rebesco, M. (2007) 'Glacial contourites on the Antarctic Peninsula margin: insight for palaeoenvironmental and palaeoclimatic conditions', in Economic and Palaeoceanographic Significance of Contourite Deposits, pp. 111-127.

Lüthi, D. et al. (2008) 'High-resolution carbon dioxide concentration record 650,000800,000 years before present', Nature, 453(7193), pp. 379-382.

Marchant, D. et al. (1996a) 'Late Cenozoic Antarctic paleoclimate reconstructed from volcanic ashes in the Late Cenozoic Antarctic paleoclimate reconstructed from volcanic ashes in the Dry Valleys region of southern Victoria Land', Geological Society of America, 108(2), pp. 181-194.

Marchant, D. et al. (1996b) 'Late Cenozoic Antarctic paleoclimate reconstructed from volcanic ashes in the Late Cenozoic Antarctic paleoclimate reconstructed from volcanic ashes in the Dry Valleys region of southern Victoria Land', Geological Society of America Bulletin, 108(2), pp. 181-194.

Marchant, D. and Denton, G. (1996) 'Miocene and Pliocene paleoclimate of the Dry Valleys region, Southern Victoria land: A geomorphological approach', Marine Micropaleontology, 27(1-4), pp. 253-271.

McCave, I. and Hall, I. (2006) 'Size sorting in marine muds: Processes, pitfalls, and prospects for paleoflow-speed proxies', Geochemistry, Geophysics, Geosystems, 7(10), p. 9.

McKay, R. et al. (2008) 'Atmospheric transport and concentration of diatoms in surficial and glacial sediments of the Allan Hills, Transantarctic Mountains', Palaeogeography, Palaeoclimatology, Palaeoecology, 260(1-2), pp. 168-183.

McKay, R. et al. (2009) 'The stratigraphic signature of the late Cenozoic Antarctic Ice Sheets in the Ross Embayment', Bulletin of the Geological Society of America, 121(1112), pp. 1537-1561.

McKay, R. et al. (2012) 'Antarctic and Southern Ocean influences on Late Pliocene global cooling', Proceedings of the National Academy of Sciences, 109(17), pp. 64236428.

Mckay, R. et al. (2016) 'Antarctic Cenozoic climate history from sedimentary records : ANDRILL and beyond', Philosophical Transactions of the Royal Society A: Mathematical, Physical and Engineering Sciences, 374(2059), pp. 1-18.

Mengel, M. and Levermann, A. (2014) 'Ice plug prevents irreversible discharge from east Antarctica', Nature Climate Change, 4(6), pp. 451-455.

Mercer, J. (1978) 'West Antarctic ice sheet and C02 greenhouse effect: a threat of disaster', Nature, 271, pp. 321-325. 
Meyers, S. and Sageman, B. (2007) 'Quantification of deep-time orbital forcing by average spectral misfit', American Journal of Science, 307(5), pp. 773-792.

Meyers, S., Sageman, B. and Arthur, M. (2012) 'Obliquity forcing of organic matter accumulation during Oceanic Anoxic Event 2', Paleoceanography, 27(3), pp. 1-19.

Meyers, S. (2014) 'An R package for Astrochronology'. Available at: https://cran.rproject.org/web/packages/astrochron/index.html.

Middleton, G. (1993) 'Sediment Deposition from Turbidity Currents', Annual Review of Earth and Planetary Sciences, 21, pp. 89-114.

Milankovitch, M. (1941) 'Kanon der Erdbestrahlung und seine Anwendung auf das Eiszeitenproblem', Royal Serbian Academy Special Publication, 133, pp. 1-633.

Miller, K., Wright, J. and Fairbanks, R. (1991) 'Unlocking the ice house: OligoceneMiocene oxygen isotopes, eustasy, and margin erosion', Journal of Geophysical Research, 96, pp. 6829-6848.

Miller, K. et al. (2005) 'The Phanerozoic Record of Global Sea-Level Change', Science, 310, pp. 1293-1298.

Miller, K. et al. (2008) 'A View of Antarctic Ice-Sheet Evolution from Sea-Level and Deep-Sea Isotope Changes During the Late Cretaceous-Cenozoic', Antarctica: A Keystone in a Changing World, pp. 55-70.

Naish, T. et al. (2001) 'Orbitally induced oscillations in the East Antarctic ice sheet at the Oligocene/Miocene boundary’, Nature, 413(6857), pp. 719-723.

Naish, T. et al. (2009) 'Obliquity-paced Pliocene West Antarctic ice sheet oscillations', Nature, 458(7236), pp. 322-328.

Nodder, S. and Boyd, P. (2001) 'What grows up must fall down: the potential impact of climate change on plankton and carbon export', Water \& Atmosphere, pp. 28-30.

Ogg, J. (2012) 'Geomagnetic Polarity Time Scale', The Geologic Time Scale. Elsevier, pp. 88-89.

Orsi, A., Johnson, G. and Bullister, J. (1999) 'Circulation,mixing and production of Antarctic Bottom Water', Progress in Oceanography, 43, pp. 55-109.

Pagani, M., Freeman, K. and Arthur, M. (1999) 'Late Miocene Atmospheric CO 2 Concentrations and the Expansion of C 4 Grasses', Science, 285, pp. 876-878.

Pagani, M. (2009) 'Alkenones', Encyclopedia of Earth Sciences Series, pp. 4-6.

Pagani, M. et al. (2011) 'The Role of Carbon Dioxide During the Onset of Antarctic Glaciation', Science, 334(6060), pp. 1261-1264.

Pälike, H. et al. (2006) 'The Heartbeat of the Oligocene Climate System', Science, 314(5807), pp. 1894-1898. 
Passchier, S. (2011) 'Linkages between East Antarctic Ice Sheet extent and Southern Ocean temperatures based on a Pliocene high-resolution record of ice-rafted debris off Prydz Bay, East Antarctica', Paleoceanography, 26(4), pp. 1-13.

Patterson, M. et al. (2014) 'Orbital forcing of the East Antarctic ice sheet during the Pliocene and Early Pleistocene', Nature Geoscience, 7(11), pp. 841-847.

Piper, D. and Normark, W. (1983) 'Turbidite depositional patterns and flow characteristics, Navy Submarine Fan, California Borderland', Sedimentary, 30, pp. 681694.

Pollard, D. and Deconto, R. (2016) 'Contribution of Antarctica to past and future sealevel rise', Nature. Nature Publishing Group, 531(7596), pp. 591-597.

Pollard, D., DeConto, R. and Alley, R. (2015) 'Potential Antarctic Ice Sheet retreat driven by hydrofracturing and ice cliff failure', Earth and Planetary Science Letters. Elsevier B.V., 412, pp. 112-121.

Pospichal, J. (2003) '11. Calcareous Nannofossils from Continental Rise Site 1165, ODP Leg 188, Prydz Bay, Antarctica', In Cooper, A.K., O'Brien, P.E., and Richter, C. (Eds.), Proc. ODP, Sci. Results, pp. 1-14.

Prebble, J. et al. (2006) 'Vegetation and climate from two Oligocene glacioeustatic sedimentary cycles (31 and $24 \mathrm{Ma}$ ) cored by the Cape Roberts Project, Victoria Land Basin, Antarctica', Palaeogeography, Palaeoclimatology, Palaeoecology, 231(1-2), pp. 41-57.

Pritchard, H. et al. (2012) 'Antarctic ice-sheet loss driven by basal melting of ice shelves', Nature, 484(7395), pp. 502-505.

Pross, J. et al. (2012) 'Persistent near-tropical warmth on the antarctic continent during the early eocene epoch', Nature, 488(7409), pp. 73-77.

Ravelo, A. and Hillaire-Marcel, C. (2007) 'The Use of Oxygen and Carbon Isotopes of Foraminifera in Paleoceanography', Developments in Marine Geology: Proxies in Late Cenozoic Paleoceanography., 1, pp. 735-764.

Raymo, M. and Huybers, P. (2008) 'Unlocking the mysteries of the ice ages', Nature, 451(7176), pp. 284-285.

Raymo, M., Lisiecki, L. and Nisancioglu, K. (2006) 'Plio-Pleistocene Ice Volume, Antarctic Climate, and the Global d180 Record', Science, 313(5786), pp. 492-496.

Rebesco, M. (2005) 'Contourities’, in Sedimentary environments, pp. 513-527.

Rebesco, M. et al. (2014) 'Contourites and associated sediments controlled by deep-water circulation processes: State-of-the-art and future considerations', Marine Geology. The Authors, 352, pp. 111-154.

Rignot, E. et al. (2013) 'Ice Shelf Melting Around Antarctica', Science, 341(6143), pp. 
$266-270$.

Rintoul, S. (1985) 'On the Origin and Influence of Adelie Land Bottom Water', Ocean, Ice, and Atmosphere: Interactions at the Antarctic Continental Margin, 75, pp. 151-171.

Rintoul, S. (2018) 'The global influence of localized dynamics in the Southern Ocean', Nature, 558(7709), pp. 209-218.

Rintoul, S., Hughes, C. and Olbers, D. (2001) '4.6 The Antarctic Circumpolar Current System’, International Geophysics, 77, pp. 271-302.

Roser, B. and Pyne, A. (1989) Wholerock geochemistry, Antarctic Cenozoic history from the CIROS-1 drillhole, McMurdo Sound: Department of Scientific and Industrial Research. Bulletin, Wellington, New Zealand.

Rost, B. and Riebesell, U. (2004) 'Coccolithophores and the biological pump: responses to environmental changes', Coccolithophores, pp. 99-125.

Rothwell, R. and Croudace, I. (2015) 'Chapter 2: Twenty Years of XRF Core Scanning Marine Sediments: What Do Geochemical Proxies Tell Us?', in Micro-XRF Studies of Sediment Cores. Springer, Dordrecht, pp. 25-102.

Ruddiman, W. (2001) Earths Climate: past and future. Macmillian.

Ruddiman, W. (2006) 'Ice-driven CO2 feedback on ice volume', Climate of the Past Discussions, European Geosciences Union, 2(1), pp. 43-78.

Salabarnada, A. et al. (2018) 'Paleoceanography and ice sheet variability offshore Wilkes Land, Antarctica - Part 1: Insights from late Oligocene astronomically paced contourite sedimentation', Climate of the Past, 14(7), pp. 991-1014.

Sangiorgi, F. et al. (2015) 'Middle Miocene environmental and climatic evolution at the Wilkes Land margin, East Antarctica', Geophysical Research Abstracts, 17, p. 15194.

Sangiorgi, F. et al. (2018) 'Southern Ocean warming and Wilkes Land ice sheet retreat during the mid-Miocene', Nature Communications. Springer US, 9(317), pp. 1-11.

Scher, H. et al. (2015) 'Onset of Antarctic Circumpolar Current 30 million years ago as Tasmanian Gateway aligned with westerlies’, Nature, 523(7562), pp. 580-583.

Scher, H. and Martin, E. (2006) 'Timing and climatic consequences of the opening of Drake Passage', Science, 312(April), pp. 428-431.

Scherer, R. et al. (2008) 'Antarctic records of precession-paced insolation-driven warming during early Pleistocene Marine Isotope Stage 31', Geophysical Research Letters, 35(3), pp. 1-5.

Schmidtko, S. et al. (2014) 'Multidecadal warming of Antarctic waters: Supplementary Material', Science, 346(6214), pp. 1227-1231.

Seki, O. et al. (2010) 'Alkenone and boron-based Pliocene pCO2 records', Earth and 
Planetary Science Letters. Elsevier B.V., 292(1-2), pp. 201-211.

Shackleton, N. and Kennett, J. (1976) 'Paleotemperature history of the Cenozoic and the initiation of Antarctic glaciation; Oxygen and carbon isotope analyses in DSDP sites 277, 279 and 281', Initial Reports of the Deep Sea Drilling Project, 29, pp. 743-755.

Shanmugam, G. (2000) '50 Years of the Turbidite Paradigm (1950S-1990S): Deep Water Processes and Facies Models - a Critical Perspective', Marine and Petroleum Geology, 17(2), pp. 285-342.

Shanmugam, G. (2008) 'Deep-water Bottom Currents and their Deposits', Developments in Sedimentology, 60, pp. 59-81.

Shen, X. et al. (2018) 'Increased seasonality and aridity drove the C4 plant expansion in Central Asia since the Miocene-Pliocene boundary', Earth and Planetary Science Letters. Elsevier B.V., 502, pp. 74-83.

Shevenell, A., Kennett, J. and Lea, D. (2004) 'Middle Miocene Southern Ocean Cryosphere Expansion', Science, 305(5691), pp. 10-15.

Shevenell, A., Kennett, J. and Lea, D. (2008) 'Middle Miocene ice sheet dynamics, deepsea temperatures, and carbon cycling: A Southern Ocean perspective', Geochemistry, Geophysics, Geosystems, 9(2), pp. 1-14.

Sigman, D., Hain, M. and Haug, G. (2010) 'The polar ocean and glacial cycles in atmospheric CO2 concentration', Nature, 466(7302), pp. 47-55.

Silvano, A. et al. (2018) 'Freshening by glacial meltwater enhances melting of ice shelves and reduces formation of Antarctic Bottom Water', Science Advances, 4(4), pp. 1-12.

Snow, K. et al. (2018) 'Change in Dense Shelf Water and Adélie Land Bottom Water Precipitated by Iceberg Calving', Geophysical Research Letters, 45(5), pp. 2380-2387.

St. John, K. and Krissek, L. (2002) 'The late Miocene to Pleistocene ice-rafting history of Southeast Greenland', Boreas, 31, pp. 28-35.

Stow, D. (2002) Deep-water contourite systems: modern drifts and ancient series, seismic and sedimentary characteristics. Geological Society of London.

Stow, D. and Faugères, J. C. (2008) 'Chapter 13 Contourite Facies and the Facies Model', Developments in Sedimentology, 60(08), pp. 223-256.

Stow, D. and Bowen, A. (1980) 'A physical model for the transport and sorting of finegrained sediment by turbidity currents', Sedimentology, 27, pp. 31-46.

Stow, D. and Piper, D. (1984) 'Deep-water fine-grained sediments: facies models', Geology Society, London, Special Publications, 15(1), pp. 611-646.

Sugden, D., Marchant, D. and Denton, G. (1993) 'The Case for a Stable East Antarctic Ice Sheet', Geografiska Annaler. Series A, Physical Geography, 75(4), pp. 151-154. 
Sugden, D. and Denton, G. (2004) 'Cenozoic landscape evolution of the Convoy Range to Mackay Glacier area, Transantarctic Mountains: Onshore to offshore synthesis', Bulletin of the Geological Society of America, 116(7-8), pp. 840-857.

Takahashi, T. et al. (2012) 'The changing carbon cycle in the Southern Ocean', Oceanography, 25(3), pp. 26-37.

Takahashi, T. and Chipman, D. (2012) 'CO2 Transport in Deep Waters Off Wilkes Land', Oceanography, 25(3), pp. 24-25.

Talling, P. et al. (2012) 'Subaqueous sediment density flows: Depositional processes and deposit types', Sedimentology, 59(7), pp. 1937-2003.

Tauxe, L. et al. (2012) 'Chronostratigraphic framework for the IODP Expedition 318 cores from the Wilkes Land Margin: Constraints for paleoceanographic reconstruction', Paleoceanography and Paleoclimatology, 27(2), pp. 1-19.

Taylor-Silva, B. and Riesselman, C. (2018) 'Polar Frontal Migration in the Warm Late Pliocene: Diatom Evidence From the Wilkes Land Margin, East Antarctica', Paleoceanography and Paleoclimatology, 33(1), pp. 76-92.

Ten Brink, U. and Cooper, A. (1992) 'Modeling the bathymetry of Antarctic continental margins', Recent Progress in Antarctic Earth Science, pp. 763-722.

Thomas, R. and Bentley, C. (1978) 'A model for Holocene retreat of the West Antarctic Ice Sheet', Quaternary Research, 10(2), pp. 150-170.

Thompson, A. et al. (2018) 'The Antarctic Slope Current in a Changing Climate', Reviews of Geophysics, 56(4), pp. 741-770.

Toggweiler, J., Russell, J. and Carson, S. (2006) 'Midlatitude westerlies, atmospheric $\mathrm{CO} 2$, and climate change during the ice ages', Paleoceanography, 21(2), pp. 1-15.

Villa, G. et al. (2008) 'A Pleistocene warming event at $1 \mathrm{Ma}$ in Prydz Bay, East Antarctica: Evidence from ODP Site 1165', Palaeogeography, Palaeoclimatology, Palaeoecology, 260(1-2), pp. 230-244.

Warnke, D. (1970) 'Glacial erosion, ice rafting, and glacial-marine sediments; Antarctica and the Southern Ocean', American Journal of Science, 269(3), pp. 276-294.

Warny, S. et al. (2009) 'Palynomorphs from a sediment core reveal a sudden remarkably warm Antarctica during the middle Miocene', Geology, 37(10), pp. 955-958.

Watson, A. and Naveira Garabato, A. (2006) 'The role of Southern Ocean mixing and upwelling in glacial-interglacial atmospheric CO2 change', Tellus, Series B: Chemical and Physical Meteorology, 58(1), pp. 73-87.

Webb, P. et al. (1984) 'Cenozoic marine sedimentation and ice-volume variation on the East Antarctic craton.', Geology, 12(5), pp. 287-291. 
Weber, M. et al. (2014) 'Millennial-scale variability in Antarctic ice-sheet discharge during the last deglaciation', Nature, 510(7503), pp. 134-138.

Weertman, J. (1974) 'Stability of the Junction of an Ice Sheet and an Ice Shelf', Journal of Glaciology, 13(67), pp. 3-11.

Westerhold, T., Bickert, T. and Röhl, U. (2005) 'Middle to late Miocene oxygen isotope stratigraphy of ODP site 1085 (SE Atlantic): New constrains on Miocene climate variability and sea-level fluctuations', Palaeogeography, Palaeoclimatology, Palaeoecology, 217(3-4), pp. 205-222.

Wilks, J. et al. (2017) 'Biogeochemical flux and phytoplankton succession: A year-long sediment trap record in the Australian sector of the Subantarctic Zone', Deep-Sea Research Part I: Oceanographic Research Papers. Elsevier Ltd, 121(December 2016), pp. 143-159.

Williams, G. and Bindoff, N. (2003) 'Wintertime oceanography of the Adélie Depression', Deep-Sea Research Part II: Topical Studies in Oceanography, 50(8-9), pp. 1373-1392.

Williams, G. et al. (2008) 'Formation and export of dense shelf water from the Adélie depression, East Antarctica', Journal of Geophysical Research: Oceans, 113(4), pp. 112.

Williams, G. et al. (2010) 'Antarctic bottom water from the adélie and George v Land Coast, East Antarctica (140-149 ${ }^{\circ}$ E)', Journal of Geophysical Research: Oceans, 115(4), pp. 1-29.

Williams, T. et al. (2010) 'Evidence for iceberg armadas from East Antarctica in the Southern Ocean during the late Miocene and early Pliocene', Earth and Planetary Science Letters. Elsevier B.V., 290(3-4), pp. 351-361.

Williams, T. (2014) 'How Antarctic ice retreats', Nature, 510(7503), pp. 39-40.

Wilson, D. et al. (2012) 'Antarctic topography at the Eocene-Oligocene boundary', Palaeogeography, Palaeoclimatology, Palaeoecology. Elsevier B.V., 335-336, pp. 2434.

Wilson, D. et al. (2018) 'Ice loss from the East Antarctic Ice Sheet during late Pleistocene interglacials', Nature. Springer US, 561(7723), pp. 383-386.

Winnick, M. and Caves, J. (2015) 'Oxygen isotope mass-balance constraints on Pliocene sea level and East Antarctic Ice Sheet stability’, Geology, 43(10), pp. 879-882.

Woodard, S. C. et al. (2014) 'Antarctic role in Northern Hemisphere glaciation', Science, 346(6211), pp. 847-851.

You, Y. et al. (2009) 'Simulation of the Middle Miocene Climate Optimum', Geophysical Research Letters, 36(4), pp. 1-5. 
Zachos, J., Shackleton, N., et al. (2001) 'Climate response to orbital forcing across the oligocene-miocene boundary’, Science, 292(5515), pp. 274-278.

Zachos, J., Pagani, M., et al. (2001) 'Trends, rhythms and aberrations in global climate 65 mya to present', Science, 292(5517), pp. 686-693.

Zachos, J., Breza, J. and Wise, S. (1992) 'Early Oligocene ice sheet expansion on Antarctica: stable isotope and sedimentological evidence from Kerguelen Plateau, Southern Indian Ocean', Geology, 20(6), pp. 569-573.

Zachos, J., Dickens, G. and Zeebe, R. (2008) 'An early Cenozoic perspective on greenhouse warming and carbon-cycle dynamics', Nature, 451(7176), pp. 279-283.

Zachos, J., Quinn, T. and Salamy, K. (1996) 'High-resolution (104years) deep-sea foraminiferal stable isotope records of the Eocene-Oligocene climate transition', Paleoceanography, 11(3), pp. 251-266.

Zhang, Y. et al. (2013) 'A 40-million-year history of atmospheric CO 2', Philosophical Transactions of the Royal Society A: Mathematical, Physical and Engineering Sciences, 371(2001). 


\section{APPENDICES}

Appendix A: IODP Site U1361 biomarker results (n-alkanes and hopanes)

\begin{tabular}{|c|c|c|c|c|c|}
\hline Sample \# & $\begin{array}{l}\text { Core, section, } \\
\text { interval }(\mathrm{cm})\end{array}$ & $\begin{array}{l}\text { Depth } \\
\text { (mbsf) }\end{array}$ & $\begin{array}{l}\text { CPI (n- } \\
\text { alkanes) }\end{array}$ & $\begin{array}{l}\text { ACL (n- } \\
\text { alkanes) }\end{array}$ & $\begin{array}{c}\mathbf{C 3 1} \\
\text { (Hopanes) } \\
\mathbf{B} \boldsymbol{\beta} /(\mathbf{B} \boldsymbol{\beta}+ \\
\mathbf{A} \boldsymbol{\beta}+\mathbf{B} \boldsymbol{\alpha} \\
\end{array}$ \\
\hline BPB5A & $34,2 \mathrm{~W}: 78-80$ & 313.88 & 1.33 & 28.77 & \\
\hline BPB6A & $34,2 W: 97-99$ & 314.07 & 1.78 & 26.24 & \\
\hline BPB7A & $34,5 \mathrm{~W}: 5-7$ & 317.65 & 2.81 & 27.46 & 0.53 \\
\hline BPB8A & $34,6 \mathrm{~W}: 95-97$ & 320.05 & 1.19 & 26.35 & 0.68 \\
\hline BPB9A & $34,7 \mathrm{~W}: 64-66$ & 320.74 & 1.96 & 28.05 & \\
\hline BPB10 A & $34, \mathrm{CC}: 15-17$ & 320.78 & 0 & 0 & \\
\hline BPB11A & $34,1 \mathrm{~W}: 13-15$ & 321.33 & 1.74 & 27.05 & \\
\hline BPB12A & $35,1 \mathrm{~W}: 95-97$ & 322.15 & 2.61 & 26.95 & \\
\hline BPB13A & $35,2 \mathrm{~W}: 25-27$ & 322.95 & 1.71 & 25.90 & 0.32 \\
\hline BPB14A & $35,2 \mathrm{~W}: 105-107$ & 323.75 & 2.12 & 26.97 & 0.52 \\
\hline BPB15A & $35,3 \mathrm{~W}: 76-78$ & 324.96 & 1.23 & 26.05 & \\
\hline
\end{tabular}

Appendix B: IODP Site U1361 reproducibility of grain size subsamples and XRF standards. Grainsize data is seven examples, while XRF is all the elements used in this project, in the high (top), medium and low (bottom) abundances standards.

\begin{tabular}{|c|c|c|c|c|c|c|c|}
\hline \multicolumn{8}{|c|}{ REPRODUCIBILITY OF GRAIN SIZE SUBSAMPLES (EXAMPLES) } \\
\hline $\begin{array}{l}\text { Std. } \\
\text { d. }\end{array}$ & $\begin{array}{l}34 \text { 1W: } \\
\text { 35-37 }\end{array}$ & $\begin{array}{c}34 \text { 1W: } 76- \\
78\end{array}$ & $\begin{array}{c}342 \text { W: } 5- \\
7\end{array}$ & $\begin{array}{c}342 \mathrm{~W}: \\
45-47\end{array}$ & $\begin{array}{c}34 \\
2 W: 125- \\
127\end{array}$ & $\begin{array}{c}34 \text { 3W: } \\
15-17\end{array}$ & $\begin{array}{c}344 W: \\
67-69\end{array}$ \\
\hline A & 1.129849 & 1.288623 & 1.309881 & 1.497419 & 1.249949 & 1.332237 & 1.213939 \\
\hline B & 1.122125 & 1.287778 & 1.345755 & 1.438373 & 1.246553 & 1.329842 & 1.388953 \\
\hline $\mathrm{C}$ & 1.168134 & 1.286020 & 1.320928 & 1.449292 & 1.113629 & 1.347247 & 1.433627 \\
\hline Avg & 0.020117 & 0.001084 & 0.015001 & 0.025651 & 0.063477 & 0.007703 & 0.094803 \\
\hline
\end{tabular}

\begin{tabular}{|c|ccccccc|}
\hline \multicolumn{7}{|c|}{ REPRODUCIBILITY OF XRF STANDARDS (EXAMPLES) } \\
\hline BHVO-2 \\
\hline Batch & Al & Si & Ca & TI & Ba & Sr & Mn \\
\hline 1 & 83132 & 216311 & 88072 & 16125 & 144 & 425 & 1355 \\
4 & 79684 & 207985 & 87228 & 16057 & 136 & 426 & 1350 \\
9 & 79997 & 207592 & 86811 & 15753 & 163 & 422 & 1350 \\
14 & 78053 & 203057 & 84827 & 15377 & 193 & 421 & 1348 \\
\hline Avg. & 80216.5 & 208736.25 & 86734.5 & 15828 & 159 & 423.5 & 1350.75 \\
Std d. & 1837.98 & 4782.90 & 1191.31 & 295.67 & 21.94 & 2.06 & 2.59 \\
\hline
\end{tabular}




\begin{tabular}{|c|ccccccc|}
\hline \multicolumn{1}{|c|}{ SGR-1 } \\
\hline $\begin{array}{c}\text { Batc } \\
\mathbf{h}\end{array}$ & Al & Si & Ca & TI & Ba & Sr & Mn \\
\hline 1 & 34000 & 122150 & 69406 & 1455 & 279 & 388 & 253 \\
4 & 34856 & 122956 & 67979 & 1372 & 267 & 389 & 249 \\
9 & 34060 & 120800 & 67868 & 1298 & 257 & 385 & 250 \\
14 & 33833 & 120199 & 65688 & 1368 & 253 & 373 & 242 \\
\hline Avg. & 34187.25 & 121526.25 & 67735.25 & 1373.25 & 264 & 383.75 & 248.5 \\
Stdd & 394.96 & 1086.54 & 1328.50 & 55.62 & 10.05 & 6.38 & 4.03 \\
\hline
\end{tabular}

\begin{tabular}{|c|ccccccc|}
\hline \multicolumn{10}{|c|}{ JG-2 } \\
\hline $\begin{array}{c}\text { Batc } \\
\mathbf{h}\end{array}$ & Al & Si & Ca & TI & Ba & Sr & Mn \\
\hline 1 & 66792 & 343266 & 824 & 125 & 57 & 18 & 127 \\
4 & 66518 & 339432 & 896 & 207 & 81 & 19 & 152 \\
9 & 68667 & 343178 & 769 & 204 & 71 & 18 & 143 \\
14 & 68410 & 332073 & 1232 & 187 & 70 & 18 & 155 \\
\hline Avg. & 67596.75 & 339487.25 & 930.25 & 180.75 & 69.75 & 18.25 & 144.25 \\
Stdd & 951.07 & 4551.78 & 179.94 & 33.08 & 8.53 & 0.43 & 10.89 \\
\hline
\end{tabular}

Appendix C: IODP Site U1361 grain size data, percentage of clay, silt and sand. Mean grain size and sorting included.

\begin{tabular}{|c|c|c|c|c|c|c|c|}
\hline $\begin{array}{l}\text { Core, section, } \\
\text { interval }(\mathrm{cm})\end{array}$ & $\begin{array}{l}\text { Depth } \\
\text { (mbsf) }\end{array}$ & $\begin{array}{c}\text { Sand } \\
\text { (vol. \%) }\end{array}$ & $\begin{array}{l}\text { Silt } \\
\text { (vol. } \\
\%)\end{array}$ & $\begin{array}{c}\text { Clay } \\
<8 \mu \mathrm{m} \\
\text { (vol. \%) }\end{array}$ & $\begin{array}{c}\text { Mean } \\
\text { Grain } \\
\text { size } \mu \mathrm{m}\end{array}$ & $\begin{array}{l}\text { Sorting } \\
\quad \sigma\end{array}$ & $\begin{array}{l}\text { Facies } \\
\text { code }\end{array}$ \\
\hline $33,1 \mathrm{~W}, 5-7$ & 302.05 & 5.4 & 89.8 & 4.8 & 12.32 & 3.182 & $\mathrm{D}$ \\
\hline $33,1 \mathrm{~W}, 26-28$ & 302.26 & 3.7 & 89.8 & 6.5 & 9.656 & 3.016 & $\mathrm{D}$ \\
\hline $33,1 \mathrm{~W}, 55-57$ & 302.55 & 0 & 93.1 & 6.9 & 8.374 & 2.671 & $\mathrm{D}$ \\
\hline $33,1 \mathrm{~W}, 75-77$ & 302.75 & 1.9 & 91.7 & 6.4 & 9.455 & 2.78 & $\mathrm{D}$ \\
\hline $33,1 \mathrm{~W}, 105-107$ & 303.05 & 0.9 & 93.7 & 5.4 & 11.52 & 2.885 & $\mathrm{D}$ \\
\hline $33,1 \mathrm{~W}, 125-127$ & 303.25 & 4.6 & 92.1 & 3.3 & 18.18 & 2.831 & $\mathrm{D}$ \\
\hline $33,2 \mathrm{~W}, 25-27$ & 303.75 & 3.1 & 86.2 & 10.7 & 6.71 & 2.701 & $\mathrm{D}$ \\
\hline $33,2 \mathrm{~W}, 45-47$ & 303.95 & 0.8 & 75.2 & 24 & 4.085 & 2.597 & $\mathrm{LC}$ \\
\hline $33,2 \mathrm{~W}, 85-87$ & 304.35 & 0 & 83 & 17 & 5.292 & 2.687 & $\mathrm{LC}$ \\
\hline $33,2 \mathrm{~W}, 105-107$ & 304.55 & 0.7 & 83.2 & 16.1 & 5.164 & 2.532 & LC \\
\hline $33,2 \mathrm{~W}, 125-127$ & 304.75 & 0 & 78.4 & 21.6 & 4.175 & 2.431 & $\mathrm{LC}$ \\
\hline $33,3 \mathrm{~W}, 5-7$ & 305.05 & 0 & 81.6 & 18.4 & 4.354 & 2.315 & $\mathrm{LC}$ \\
\hline $33,3 \mathrm{~W}, 26-28$ & 305.26 & 0.6 & 88.9 & 10.5 & 5.569 & 2.368 & $\mathrm{LC}$ \\
\hline $33,3 \mathrm{~W}, 55-57$ & 305.55 & 0.3 & 89.5 & 10.2 & 6.799 & 2.653 & $\mathrm{LC}$ \\
\hline $33,3 \mathrm{~W}, 75-77$ & 305.75 & 0 & 87.1 & 12.9 & 6.067 & 2.604 & $\mathrm{LC}$ \\
\hline $33,3 \mathrm{~W}, 95-97$ & 305.95 & 0 & 79.3 & 20.7 & 4.557 & 2.588 & $\mathrm{LC}$ \\
\hline
\end{tabular}




\begin{tabular}{|c|c|c|c|c|c|c|c|}
\hline $33,3 \mathrm{~W}, 115-117$ & 306.15 & 1.9 & 75 & 23.1 & 4.098 & 2.532 & $\mathrm{LC}$ \\
\hline $33,3 \mathrm{~W}, 135-137$ & 306.35 & 0.3 & 74.5 & 25.2 & 3.837 & 2.508 & $\mathrm{LC}$ \\
\hline $33,4 \mathrm{~W}, 5-7$ & 306.55 & 0 & 81.2 & 18.8 & 4.397 & 2.368 & LC \\
\hline $33,4 \mathrm{~W}, 25-27$ & 306.75 & 0.9 & 74.9 & 24.2 & 3.906 & 2.579 & LC \\
\hline $33,4 \mathrm{~W}, 45-47$ & 306.95 & 3.4 & 71.1 & 25.5 & 3.732 & 2.52 & LC \\
\hline $33,4 \mathrm{~W}, 65-67$ & 307.15 & 3.2 & 90.1 & 6.7 & 8.449 & 2.812 & $\mathrm{D}$ \\
\hline $33,4 \mathrm{~W}, 115-117$ & 307.65 & 12.1 & 82.7 & 5.2 & 12.69 & 3.641 & $\mathrm{D}$ \\
\hline $33,5 \mathrm{~W}, 5-7$ & 308.05 & 7.1 & 74.5 & 18.4 & 9.177 & 4.82 & $\mathrm{D}$ \\
\hline $33,5 \mathrm{~W}, 45-47$ & 308.45 & 4 & 88.9 & 7.1 & 9.428 & 3.121 & $\mathrm{D}$ \\
\hline $33,5 \mathrm{~W}, 65-67$ & 308.65 & 1 & 90.1 & 8.9 & 7.013 & 2.749 & LC \\
\hline $33,5 \mathrm{~W}, 85-87$ & 308.85 & 1.2 & 90 & 8.8 & 8.324 & 3.066 & LC \\
\hline $33,5 \mathrm{~W}, 105-107$ & 309.05 & 3.6 & 87.1 & 9.3 & 8.224 & 3.227 & LC \\
\hline $33,5 \mathrm{~W}, 125-127$ & 309.25 & 5.5 & 92.1 & 2.4 & 22.81 & 2.56 & $\mathrm{D}$ \\
\hline $33,5 \mathrm{~W}, 145-147$ & 309.45 & 0.4 & 87.5 & 12.1 & 5.805 & 2.606 & $\mathrm{D}$ \\
\hline $33,6 \mathrm{~W}, 15-17$ & 309.65 & 1.7 & 91.1 & 7.2 & 10.06 & 3.057 & $\mathrm{D}$ \\
\hline $33,6 \mathrm{~W}, 35-37$ & 309.85 & 4 & 85.6 & 10.4 & 7.581 & 2.937 & $\mathrm{D}$ \\
\hline $33,6 \mathrm{~W}, 55-57$ & 310.05 & 0.4 & 79.2 & 20.4 & 4.671 & 2.644 & $\mathrm{LC}$ \\
\hline $33,6 \mathrm{~W}, 75-77$ & 310.25 & 1.4 & 78.8 & 19.8 & 4.579 & 2.579 & $\mathrm{LC}$ \\
\hline $33,6 \mathrm{~W}, 95-97$ & 310.45 & 0 & 77.5 & 22.5 & 4.221 & 2.523 & $\mathrm{LC}$ \\
\hline $33,6 \mathrm{~W}, 115-117$ & 310.65 & 0.5 & 73.1 & 26.4 & 3.648 & 2.445 & $\mathrm{LC}$ \\
\hline $33,7 \mathrm{~W}, 6-8$ & 310.86 & 0.4 & 85.8 & 13.8 & 5.087 & 2.413 & $\mathrm{LC}$ \\
\hline $33,7 \mathrm{~W}, 25-27$ & 311.05 & 8.1 & 81.8 & 10.1 & 8.098 & 3.494 & $\mathrm{LC}$ \\
\hline $33,7 \mathrm{~W}, 45-47$ & 311.25 & 5.5 & 74.6 & 19.9 & 4.794 & 3.141 & $\mathrm{LC}$ \\
\hline $33,7 \mathrm{~W}, 65-67$ & 311.45 & 0 & 69.7 & 30.3 & 3.261 & 2.403 & $\mathrm{LC}$ \\
\hline $33, \mathrm{CCW}, 12-14$ & 311.62 & 0.7 & 76.2 & 23.1 & 4.269 & 2.663 & $\mathrm{LC}$ \\
\hline $34,1 \mathrm{~W}, 15-17$ & 311.75 & 5.4 & 79.7 & 14.9 & 6.287 & 3.267 & $\mathrm{LC}$ \\
\hline $34,1 \mathrm{~W}, 35-37$ & 311.95 & 6.5 & 82.6 & 10.9 & 8.134 & 3.336 & $\mathrm{D}$ \\
\hline $34,1 \mathrm{~W}, 55-57$ & 312.15 & 8.4 & 82.8 & 8.8 & 8.727 & 3.615 & $\mathrm{D}$ \\
\hline $34,1 \mathrm{~W}, 76-78$ & 312.36 & 0.5 & 85.8 & 13.7 & 6.118 & 2.768 & $\mathrm{LC}$ \\
\hline $34,1 \mathrm{~W}, 95-97$ & 312.55 & 2.4 & 84.7 & 12.9 & 6.876 & 3 & $\mathrm{LC}$ \\
\hline $34,1 \mathrm{~W}, 115-117$ & 312.75 & 0.5 & 91.5 & 8 & 8.026 & 2.863 & $\mathrm{D}$ \\
\hline $34,1 \mathrm{~W}, 133-135$ & 312.93 & 0 & 93.4 & 6.6 & 8.112 & 2.667 & $\mathrm{D}$ \\
\hline $34,2 \mathrm{~W}, 5-7$ & 313.15 & 0.3 & 92.1 & 7.6 & 8.234 & 2.721 & $\mathrm{D}$ \\
\hline $34,2 \mathrm{~W}, 26-28$ & 313.36 & 0.1 & 93.2 & 6.7 & 8.921 & 2.74 & $\mathrm{D}$ \\
\hline $34,2 \mathrm{~W}, 45-47$ & 313.55 & 0 & 78.4 & 21.6 & 4.051 & 2.248 & $\mathrm{D}$ \\
\hline $34,2 \mathrm{~W}, 85-87$ & 313.95 & 6.6 & 89.6 & 3.8 & 14.350 & 3.069 & $\mathrm{~N}$ \\
\hline $34,2 \mathrm{~W}, 105-107$ & 314.15 & 11.3 & 84.6 & 4.1 & 14.94 & 3.34 & $\mathrm{~N}$ \\
\hline $34,2 \mathrm{~W}, 125-127$ & 314.35 & 5.9 & 90.5 & 3.6 & 14.730 & 3.045 & $\mathrm{D}$ \\
\hline $34,2 \mathrm{~W}, 145-147$ & 314.55 & 2.8 & 92.4 & 4.8 & 10.87 & 2.918 & $\mathrm{D}$ \\
\hline $34,3 \mathrm{~W}, 15-17$ & 314.75 & 0.2 & 94.5 & 5.3 & 9.741 & 2.695 & $\mathrm{D}$ \\
\hline $34,3 \mathrm{~W}, 35-37$ & 314.95 & 1.6 & 89.9 & 8.5 & 7.929 & 2.882 & $\mathrm{D}$ \\
\hline $34,3 \mathrm{~W}, 56-58$ & 315.16 & 0.1 & 95.2 & 4.7 & 9.450 & 2.474 & $\mathrm{D}$ \\
\hline $34,3 \mathrm{~W}, 77-79$ & 315.37 & 0 & 92.6 & 7.4 & 7.09 & 2.448 & $\mathrm{D}$ \\
\hline $34,3 \mathrm{~W}, 93-95$ & 315.53 & 0 & 93.8 & 6.2 & 7.594 & 2.430 & $\mathrm{D}$ \\
\hline $34,3 \mathrm{~W}, 115-117$ & 315.75 & 0.5 & 85.5 & 14 & 5.929 & 2.7 & LC \\
\hline
\end{tabular}




\begin{tabular}{|c|c|c|c|c|c|c|c|}
\hline $34,3 \mathrm{~W}, 137-139$ & 315.97 & 0.2 & 84.9 & 14.9 & 6.418 & 3.062 & $\mathrm{LC}$ \\
\hline $34,4 \mathrm{~W}, 6-8$ & 316.16 & 0 & 84.8 & 15.2 & 5.387 & 2.514 & $\mathrm{LC}$ \\
\hline $34,4 \mathrm{~W}, 25-27$ & 316.35 & 0 & 84.4 & 15.6 & 5.545 & 2.669 & $\mathrm{LC}$ \\
\hline $34,4 \mathrm{~W}, 45-47$ & 316.55 & 0.1 & 88.9 & 11 & 6.603 & 2.603 & DNB \\
\hline $34,4 \mathrm{~W}, 67-69$ & 316.77 & 1.9 & 53.9 & 44.2 & 2.866 & 3.346 & DNB \\
\hline $34,4 \mathrm{~W}, 85-87$ & 316.95 & 0 & 89.5 & 10.5 & 7.521 & 2.718 & DNB \\
\hline $34,4 \mathrm{~W}, 105-107$ & 317.15 & 0 & 86.2 & 13.8 & 5.513 & 2.51 & DNB \\
\hline $34,4 \mathrm{~W}, 125-127$ & 317.35 & 0.6 & 89.8 & 9.6 & 6.426 & 2.54 & DNB \\
\hline $34,4 \mathrm{~W}, 145-147$ & 317.55 & 0.1 & 91.5 & 8.4 & 7.157 & 2.595 & DNB \\
\hline $34,5 \mathrm{~W}, 17-19$ & 317.74 & 0.6 & 91.2 & 8.2 & 6.912 & 2.52 & LC \\
\hline $34,5 \mathrm{~W}, 35-37$ & 317.77 & 0 & 84.3 & 15.7 & 5.224 & 2.547 & $\mathrm{LC}$ \\
\hline $34,5 \mathrm{~W}, 17-19$ & 317.95 & 0.3 & 87.8 & 11.9 & 7.294 & 2.965 & LC \\
\hline $34,5 \mathrm{~W}, 53-55$ & 318.13 & 0.7 & 87.1 & 12.2 & 6.542 & 2.626 & $\mathrm{LC}$ \\
\hline $34,5 \mathrm{~W}, 75-77$ & 318.35 & 0 & 87.5 & 12.5 & 6.146 & 2.573 & LC \\
\hline $34,5 \mathrm{~W}, 97-99$ & 318.57 & 0.3 & 76.7 & 23 & 4.026 & 2.463 & LC \\
\hline $34,5 \mathrm{~W}, 117-119$ & 318.77 & 0 & 81.3 & 18.7 & 5.005 & 2.680 & LC \\
\hline $34,5 \mathrm{~W}, 135-137$ & 318.95 & 0 & 81.8 & 18.2 & 4.868 & 2.541 & LC \\
\hline $34,6 \mathrm{~W}, 6-8$ & 319.16 & 3.5 & 77.2 & 19.3 & 4.608 & 2.652 & LC \\
\hline $34,6 \mathrm{~W}, 26-28$ & 319.36 & 0 & 77.2 & 22.8 & 4.207 & 2.575 & LC \\
\hline $34,6 \mathrm{~W}, 45-47$ & 319.55 & 0 & 80.4 & 20 & 4.401 & 2.423 & $\mathrm{LC}$ \\
\hline $34,6 \mathrm{~W}, 65-67$ & 319.75 & 6.9 & 77.3 & 15.8 & 6.272 & 3.599 & LC \\
\hline $34,6 \mathrm{~W}, 85-87$ & 319.95 & 6 & 85.2 & 8.8 & 7.837 & 3.211 & $\mathrm{~N}$ \\
\hline $34,7 \mathrm{~W}, 6-8$ & 320.16 & 1.2 & 92.5 & 6.3 & 8.779 & 2.649 & $\mathrm{~N}$ \\
\hline $34,7 \mathrm{~W}, 25-27$ & 320.35 & 1.2 & 93 & 5.8 & 10.510 & 2.981 & $\mathrm{~N}$ \\
\hline $34,7 \mathrm{~W}, 45-47$ & 320.55 & 14.1 & 79.5 & 6.4 & 12.3 & 3.884 & $\mathrm{~N}$ \\
\hline $35,1 \mathrm{~W}, 13-15$ & 321.33 & 8 & 85.5 & 6.5 & 11.28 & 3.392 & DNB \\
\hline $35,1 \mathrm{~W}, 25-27$ & 321.45 & 4.9 & 89.2 & 5.9 & 10.800 & 3.138 & DNB \\
\hline $35,1 \mathrm{~W}, 45-47$ & 321.65 & 0 & 90.9 & 9.1 & 7.256 & 2.658 & DNB \\
\hline $35,1 \mathrm{~W}, 65-67$ & 321.85 & 2.3 & 90.9 & 6.8 & 9.203 & 2.855 & DNB \\
\hline $35,1 \mathrm{~W}, 85-87$ & 322.05 & 0 & 89.2 & 10.8 & 6.264 & 2.486 & DNB \\
\hline $35,1 \mathrm{~W}, 105-107$ & 322.25 & 0.7 & 89.3 & 10.0 & 7.265 & 2.75 & DNB \\
\hline $35,1 \mathrm{~W}, 125-127$ & 322.45 & 0.8 & 79 & 20.2 & 4.834 & 2.785 & $\mathrm{LC}$ \\
\hline $35,1 \mathrm{~W}, 145-147$ & 322.65 & 0.8 & 80.6 & 18.6 & 4.876 & 2.620 & $\mathrm{LC}$ \\
\hline $35,2 \mathrm{~W}, 17-19$ & 322.87 & 0 & 75.6 & 24.4 & 3.932 & 2.491 & $\mathrm{LC}$ \\
\hline $35,2 \mathrm{~W}, 33-35$ & 323.03 & 1 & 77.6 & 21.4 & 5.108 & 2.994 & $\mathrm{LC}$ \\
\hline $35,2 \mathrm{~W}, 55-57$ & 323.25 & 0 & 75.6 & 24.4 & 4.123 & 2.618 & $\mathrm{LC}$ \\
\hline $35,2 \mathrm{~W}, 75-77$ & 323.45 & 7.9 & 75.4 & 16.7 & 6.458 & 3.674 & $\mathrm{LC}$ \\
\hline $35,2 \mathrm{~W}, 95-97$ & 323.65 & 0 & 74.1 & 25.9 & 3.77 & 2.488 & $\mathrm{LC}$ \\
\hline $35,2 \mathrm{~W}, 117-119$ & 323.87 & 7.1 & 80.5 & 12.4 & 9.001 & 3.752 & $\mathrm{LC}$ \\
\hline $35,2 \mathrm{~W}, 135-137$ & 324.05 & 0 & 75.7 & 24.3 & 4.015 & 2.508 & $\mathrm{LC}$ \\
\hline $35,3 \mathrm{~W}, 5-7$ & 324.25 & 0 & 74 & 26.0 & 3.879 & 2.597 & $\mathrm{LC}$ \\
\hline $35,3 \mathrm{~W}, 25-27$ & 324.45 & 0.3 & 76.7 & 23 & 4.019 & 2.518 & $\mathrm{LC}$ \\
\hline $35,3 \mathrm{~W}, 45-47$ & 324.65 & 10.5 & 66.4 & 23.1 & 5.675 & 4.329 & $\mathrm{LC}$ \\
\hline $35,3 \mathrm{~W}, 65-67$ & 324.85 & 0.1 & 90.3 & 9.6 & 6.611 & 2.548 & $\mathrm{~N}$ \\
\hline $35,3 \mathrm{~W}, 97-99$ & 325.17 & 18.6 & 77.9 & 3.5 & 19.540 & 3.363 & $\mathrm{~N}$ \\
\hline $35,3 \mathrm{~W}, 117-119$ & 325.37 & 0.2 & 95.4 & 4.4 & 11.63 & 2.888 & $\mathrm{~N}$ \\
\hline
\end{tabular}




\begin{tabular}{|c|c|c|c|c|c|c|c|}
\hline $35,3 \mathrm{~W}, 133-135$ & 325.53 & 9.7 & 86.5 & 3.8 & 15.790 & 3.219 & $\mathrm{~N}$ \\
\hline $35,4 \mathrm{~W}, 6-8$ & 325.76 & 10.4 & 84.3 & 5.3 & 12.58 & 3.489 & $\mathrm{~N}$ \\
\hline $35,4 \mathrm{~W}, 26-28$ & 325.96 & 2.9 & 83.1 & 14.0 & 7.557 & 3.286 & $\mathrm{~N}$ \\
\hline $35,4 \mathrm{~W}, 45-47$ & 326.15 & 2.5 & 80.5 & 17 & 5.545 & 2.91 & LC \\
\hline $35,4 \mathrm{~W}, 65-67$ & 326.35 & 0 & 75.3 & 24.7 & 3.967 & 2.545 & LC \\
\hline $35,4 \mathrm{~W}, 85-87$ & 326.55 & 0.3 & 72.9 & 26.8 & 3.731 & 2.555 & LC \\
\hline $35,4 \mathrm{~W}, 105-107$ & 326.75 & 0 & 75 & 25.0 & 3.934 & 2.525 & LC \\
\hline $35,4 \mathrm{~W}, 125-127$ & 326.95 & 4 & 70.1 & 25.9 & 3.94 & 2.747 & LC \\
\hline $35,4 \mathrm{~W}, 145-147$ & 327.15 & 10.6 & 78.1 & 11.3 & 9.710 & 3.950 & $\mathrm{~N}$ \\
\hline $35,5 \mathrm{~W}, 25-27$ & 327.45 & 0 & 93.1 & 6.9 & 8.2 & 2.603 & DNB \\
\hline $35,5 \mathrm{~W}, 45-47$ & 327.65 & 0.7 & 92.7 & 6.6 & 8.934 & 2.782 & DNB \\
\hline $35,5 \mathrm{~W}, 83-85$ & 328.03 & 0.8 & 81.4 & 17.8 & 5.750 & 2.918 & $\mathrm{LC}$ \\
\hline $35,5 \mathrm{~W}, 105-107$ & 328.25 & 0 & 91.5 & 8.5 & 7.457 & 2.515 & $\mathrm{D}$ \\
\hline $35,5 \mathrm{~W}, 125-127$ & 328.45 & 2 & 91.5 & 6.5 & 10.120 & 2.857 & $\mathrm{D}$ \\
\hline $35,5 \mathrm{~W}, 145-147$ & 328.65 & 5.4 & 74.1 & 20.5 & 4.962 & 3.258 & LC \\
\hline $35,6 \mathrm{~W}, 15-17$ & 328.85 & 0 & 71.5 & 28.5 & 3.473 & 2.455 & LC \\
\hline $35,6 \mathrm{~W}, 35-37$ & 329.05 & 0 & 76.6 & 23.4 & 3.894 & 2.358 & LC \\
\hline $35,6 \mathrm{~W}, 55-57$ & 329.25 & 0 & 76.3 & 23.7 & 4.199 & 2.612 & LC \\
\hline $35,6 \mathrm{~W}, 65-67$ & 329.35 & 0 & 75.3 & 24.7 & 3.934 & 2.506 & LC \\
\hline $35,6 \mathrm{~W}, 95-97$ & 329.65 & 1.4 & 74.8 & 23.8 & 4.191 & 2.632 & LC \\
\hline $35,6 \mathrm{~W}, 113-115$ & 329.83 & 0 & 78.4 & 21.6 & 4.019 & 2.34 & LC \\
\hline $35,7 \mathrm{~W}, 15-17$ & 330.05 & 0 & 72 & 28.0 & 3.503 & 2.43 & LC \\
\hline $35,7 \mathrm{~W}, 24-26$ & 330.14 & 0 & 77.2 & 22.8 & 4.172 & 2.504 & LC \\
\hline $35,7 \mathrm{~W}, 55-57$ & 330.45 & 0.5 & 72.3 & 27.2 & 3.650 & 2.508 & LC \\
\hline $35,7 \mathrm{~W}, 73-75$ & 330.63 & 0 & 76.5 & 23.5 & 3.819 & 2.33 & LC \\
\hline $35, \mathrm{CCW}, 15-17$ & 330.85 & 1.9 & 92.8 & 5.3 & 9.899 & 2.786 & LC \\
\hline $36,1 \mathrm{~W}, 3-5$ & 330.85 & 0 & 83.8 & 16.2 & 6.008 & 2.889 & LC \\
\hline $36,1 \mathrm{~W}, 23-25$ & 331.03 & 0.9 & 69 & 30.1 & 3.370 & 2.546 & LC \\
\hline $36,1 \mathrm{~W}, 45-47$ & 331.25 & 4.5 & 86.7 & 8.8 & 8.39 & 2.975 & $\mathrm{D}$ \\
\hline $36,1 \mathrm{~W}, 66-68$ & 331.46 & 1.1 & 89.4 & 9.5 & 7.651 & 2.684 & $\mathrm{D}$ \\
\hline $36,1 \mathrm{~W}, 94-96$ & 331.74 & 3.4 & 88.4 & 8.2 & 10.320 & 3.034 & D \\
\hline $36,1 \mathrm{~W}, 115-117$ & 331.95 & 0.5 & 82.1 & 17.4 & 5.533 & 2.813 & $\mathrm{D}$ \\
\hline $36,1 \mathrm{~W}, 145-147$ & 332.25 & 1.5 & 87.5 & 11.0 & 7.987 & 2.98 & $\mathrm{D}$ \\
\hline $36,2 \mathrm{~W}, 26-28$ & 332.56 & 0 & 87.4 & 12.6 & 7.660 & 2.925 & $\mathrm{D}$ \\
\hline $36,2 \mathrm{~W}, 45-47$ & 332.75 & 0 & 79.7 & 20.3 & 4.84 & 2.677 & LC \\
\hline $36,2 \mathrm{~W}, 65-67$ & 332.95 & 0.2 & 87.8 & 12.0 & 8.566 & 3.087 & LC \\
\hline $36,2 \mathrm{~W}, 85-87$ & 333.15 & 0.5 & 84.8 & 14.7 & 7.293 & 3.226 & LC \\
\hline $36,2 \mathrm{~W}, 105-107$ & 333.35 & 5.6 & 75.3 & 19.1 & 5.916 & 3.539 & LC \\
\hline $36,2 \mathrm{~W}, 125-127$ & 333.55 & 0 & 78.3 & 21.7 & 4.218 & 2.449 & LC \\
\hline $36,2 \mathrm{~W}, 145-147$ & 333.75 & 0.8 & 75.9 & 23.3 & 4.272 & 2.698 & LC \\
\hline $36,3 \mathrm{~W}, 15-17$ & 333.95 & 4.1 & 71.2 & 24.7 & 4.213 & 2.902 & LC \\
\hline $36,3 \mathrm{~W}, 35-37$ & 334.15 & 0 & 69.3 & 30.7 & 3.264 & 2.439 & $\mathrm{LC}$ \\
\hline $36,3 \mathrm{~W}, 55-57$ & 334.35 & 6 & 85.2 & 8.8 & 7.846 & 3.198 & $\mathrm{LC}$ \\
\hline $36,3 \mathrm{~W}, 77-79$ & 334.57 & 0.7 & 85 & 14.3 & 6.198 & 2.799 & $\mathrm{LC}$ \\
\hline $36,3 \mathrm{~W}, 85-87$ & 334.65 & 2.7 & 79.6 & 17.7 & 5.687 & 3.055 & LC \\
\hline
\end{tabular}




\begin{tabular}{|c|c|c|c|c|c|c|c|}
\hline $36,3 \mathrm{~W}, 95-97$ & 334.75 & 6 & 85.2 & 8.8 & 7.846 & 3.189 & LC \\
\hline $36,3 \mathrm{~W}, 115-117$ & 334.95 & 0 & 78.5 & 21.5 & 4.472 & 2.593 & LC \\
\hline $36,3 \mathrm{~W}, 135-137$ & 335.15 & 0.3 & 79.4 & 20.3 & 4.38 & 2.488 & $\mathrm{LC}$ \\
\hline $36,4 \mathrm{~W}, 6-8$ & 335.36 & 5.9 & 67.8 & 26.3 & 3.988 & 3.315 & LC \\
\hline $36,4 \mathrm{~W}, 26-28$ & 335.56 & 2.2 & 86.9 & 10.9 & 5.937 & 2.697 & LC \\
\hline $36,4 \mathrm{~W}, 45-47$ & 335.75 & 0.8 & 89.3 & 9.9 & 6.443 & 2.769 & $\mathrm{LC}$ \\
\hline $36,4 \mathrm{~W}, 73-75$ & 336.03 & 15.7 & 78.1 & 6.2 & 12.04 & 4.076 & $\mathrm{~N}$ \\
\hline $36,4 \mathrm{~W}, 93-95$ & 336.23 & 14.3 & 81.9 & 3.8 & 18.110 & 3.308 & $\mathrm{~N}$ \\
\hline $36,4 \mathrm{~W}, 112-114$ & 336.42 & 5.4 & 89.2 & 5.4 & 12.22 & 3.165 & $\mathrm{~N}$ \\
\hline $36,4 \mathrm{~W}, 136-138$ & 336.66 & 0.1 & 87.7 & 12.2 & 7.919 & 2.989 & DNB \\
\hline $36,5 \mathrm{~W}, 6-8$ & 336.86 & 0.6 & 79.1 & 20.3 & 5.384 & 3.133 & DNB \\
\hline $36,5 \mathrm{~W}, 25-27$ & 337.05 & 3.3 & 92.1 & 4.6 & 12.450 & 2.951 & DNB \\
\hline $36,5 \mathrm{~W}, 45-47$ & 337.25 & 0.1 & 96.5 & 3.4 & 14.51 & 2.533 & DNB \\
\hline $36,5 \mathrm{~W}, 65-67$ & 337.45 & 2.1 & 92.4 & 5.5 & 11.270 & 2.832 & DNB \\
\hline $36,5 \mathrm{~W}, 105-107$ & 337.85 & 3.5 & 90.3 & 6.2 & 10.110 & 2.991 & DNB \\
\hline $36,5 \mathrm{~W}, 125-127$ & 338.05 & 0.5 & 94.2 & 5.3 & 11.04 & 2.792 & DNB \\
\hline $36,5 \mathrm{~W}, 145-147$ & 338.25 & 0 & 90.6 & 9.4 & 6.820 & 2.559 & DNB \\
\hline $36,6 \mathrm{~W}, 15-17$ & 338.45 & 0 & 89 & 11 & 6.114 & 2.446 & $\mathrm{LC}$ \\
\hline $36,6 \mathrm{~W}, 32-34$ & 338.62 & 0 & 90.4 & 9.6 & 6.955 & 2.657 & $\mathrm{LC}$ \\
\hline $36,6 \mathrm{~W}, 55-57$ & 338.85 & 0 & 80.6 & 19.4 & 4.39 & 2.382 & $\mathrm{LC}$ \\
\hline $36,6 \mathrm{~W}, 76-78$ & 339.06 & 0 & 74.4 & 25.6 & 3.736 & 2.43 & $\mathrm{LC}$ \\
\hline $36,7 \mathrm{~W}, 5-7$ & 339.45 & 0 & 86.6 & 13.4 & 5.191 & 2.403 & $\mathrm{LC}$ \\
\hline $36,7 \mathrm{~W}, 45-47$ & 339.85 & 0.1 & 91 & 8.9 & 6.888 & 2.616 & $\mathrm{D}$ \\
\hline $36,7 \mathrm{~W}, 65-67$ & 340.05 & 1.6 & 87.7 & 10.7 & 5.657 & 2.418 & $\mathrm{D}$ \\
\hline $36, \mathrm{CCW}, 5-7$ & 340.35 & 0 & 76.3 & 23.7 & 3.839 & 2.369 & $\mathrm{D}$ \\
\hline $37,1 \mathrm{~W}, 17-19$ & 340.57 & 1.4 & 91 & 7.6 & 8.196 & 2.849 & $\mathrm{D}$ \\
\hline $37,1 \mathrm{~W}, 33-35$ & 340.73 & 0.1 & 92.9 & 7 & 7.230 & 2.572 & $\mathrm{D}$ \\
\hline $37,1 \mathrm{~W}, 75-77$ & 341.15 & 8.4 & 77.5 & 14.1 & 7.078 & 3.658 & $\mathrm{D}$ \\
\hline $37,1 \mathrm{~W}, 93-95$ & 341.33 & 0 & 81 & 19 & 4.337 & 2.349 & $\mathrm{D}$ \\
\hline $37,1 \mathrm{~W}, 113-115$ & 341.53 & 0.2 & 92.5 & 7.3 & 7.641 & 2.637 & $\mathrm{~N}$ \\
\hline $37,1 \mathrm{~W}, 135-137$ & 341.75 & 0.5 & 91.6 & 7.9 & 7.327 & 2.684 & $\mathrm{~N}$ \\
\hline $37,2 \mathrm{~W}, 5-7$ & 341.95 & 7.3 & 87.5 & 5.2 & 12.640 & 3.306 & $\mathrm{~N}$ \\
\hline $37,2 \mathrm{~W}, 26-28$ & 342.16 & 6.5 & 87.4 & 6.1 & 11.4 & 3.261 & $\mathrm{~N}$ \\
\hline $37,2 \mathrm{~W}, 45-47$ & 342.35 & 7.1 & 86.5 & 6.4 & 9.912 & 3.315 & $\mathrm{~N}$ \\
\hline $37,2 \mathrm{~W}, 65-67$ & 342.55 & 0 & 87.1 & 12.9 & 5.593 & 2.397 & $\mathrm{~N}$ \\
\hline $37,2 \mathrm{~W}, 85-87$ & 342.75 & 0.6 & 79.4 & 20 & 4.411 & 2.572 & LC \\
\hline $37,2 \mathrm{~W}, 105-107$ & 342.95 & 0 & 76 & 24 & 3.882 & 2.422 & LC \\
\hline $37,2 \mathrm{~W}, 125-127$ & 343.15 & 0 & 77.9 & 22.1 & 4.229 & 2.495 & LC \\
\hline $37,2 \mathrm{~W}, 145-147$ & 343.35 & 0.4 & 75.2 & 24.4 & 3.676 & 3.676 & LC \\
\hline $37,3 \mathrm{~W}, 16-18$ & 343.56 & 0 & 76.4 & 23.6 & 3.974 & 2.445 & $\mathrm{LC}$ \\
\hline $37,3 \mathrm{~W}, 34-36$ & 343.74 & 0 & 75.8 & 24.2 & 3.803 & 2.373 & $\mathrm{LC}$ \\
\hline $37,3 \mathrm{~W}, 54-56$ & 343.94 & 2.3 & 90.1 & 7.6 & 8.359 & 2.886 & $\mathrm{D}$ \\
\hline $37,3 \mathrm{~W}, 93-95$ & 344.33 & 3.9 & 90.8 & 5.3 & 12.020 & 3.117 & $\mathrm{D}$ \\
\hline $37,3 \mathrm{~W}, 117-119$ & 344.57 & 10.7 & 84.8 & 4.5 & 15.32 & 3.33 & $\mathrm{D}$ \\
\hline $37,3 \mathrm{~W}, 133-135$ & 344.73 & 39.1 & 58.1 & 2.8 & 32.990 & 3.609 & $\mathrm{D}$ \\
\hline $37,4 \mathrm{~W}, 5-7$ & 344.95 & 0.7 & 90.8 & 8.5 & 10.32 & 3.102 & D \\
\hline
\end{tabular}




$\begin{array}{cccccccc}37,4 \mathrm{~W}, 23-25 & 345.13 & 0.4 & 85.1 & 14.5 & 7.862 & 3.252 & \mathrm{D} \\ 37,4 \mathrm{~W}, 45-47 & 345.35 & 0 & 90.4 & 9.6 & 9.121 & 2.633 & \mathrm{D} \\ 37,4 \mathrm{~W}, 65-67 & 345.55 & 0.4 & 84.7 & 14.9 & 5.71 & 2.61 & \mathrm{D} \\ 37,4 \mathrm{~W}, 77-79 & 345.67 & 6.6 & 76.6 & 16.8 & 5.949 & 3.454 & \mathrm{D} \\ 37,4 \mathrm{~W}, 105-107 & 345.95 & 1.3 & 79.7 & 19 & 5.951 & 3.193 & \mathrm{LC} \\ 37,4 \mathrm{~W}, 125-127 & 346.15 & 5.6 & 81.5 & 12.9 & 7.119 & 3.295 & \mathrm{LC} \\ 37,4 \mathrm{~W}, 145-147 & 346.35 & 0.2 & 80 & 19.8 & 4.821 & 2.651 & \mathrm{LC} \\ 37,5 \mathrm{~W}, 16-18 & 346.56 & 0 & 75.9 & 24.1 & 4.04 & 2.541 & \mathrm{LC} \\ 37,5 \mathrm{~W}, 33-35 & 346.73 & 0.5 & 75 & 24.5 & 4.167 & 2.667 & \mathrm{LC} \\ 37,5 \mathrm{~W}, 55-57 & 346.95 & 5.1 & 81.6 & 13.3 & 7.41 & 3.231 & \mathrm{LC} \\ 37,5 \mathrm{~W}, 74-76 & 347.14 & 0.6 & 74 & 25.4 & 3.897 & 2.552 & \mathrm{LC} \\ 37,5 \mathrm{~W}, 93-95 & 347.33 & 10.6 & 70.4 & 19 & 6.812 & 4.178 & \mathrm{D} \\ 37,5 \mathrm{~W}, 115-117 & 347.55 & 5.8 & 87.3 & 6.9 & 1.042 & 3.176 & \mathrm{D} \\ 37,5 \mathrm{~W}, 136-138 & 347.76 & 3 & 75.8 & 21.2 & 4.775 & 2.89 & \mathrm{LC} \\ 37,6 \mathrm{~W}, 5-7 & 347.95 & 0 & 77.1 & 22.9 & 3.908 & 2.347 & \mathrm{LC} \\ 37,6 \mathrm{~W}, 25-27 & 348.15 & 0.2 & 84.6 & 15.2 & 5.593 & 2.6 & \mathrm{LC} \\ 37,6 \mathrm{~W}, 45-47 & 348.35 & 0 & 76.1 & 23.9 & 4.113 & 2.563 & \mathrm{LC} \\ 37,6 \mathrm{~W}, 85-87 & 348.75 & 0 & 71.9 & 28.1 & 3.463 & 2.403 & \mathrm{LC} \\ 37,6 \mathrm{~W}, 105-107 & 348.95 & 0.3 & 76.8 & 22.9 & 4.102 & 2.488 & \mathrm{LC} \\ 37,6 \mathrm{~W}, 125-127 & 349.15 & 9.6 & 70.5 & 19.9 & 5.605 & 3.932 & \mathrm{LC} \\ 37,7 \mathrm{~W}, 5-7 & 349.35 & 0 & 86.3 & 13.7 & 6.403 & 2.731 & \text { LC } \\ 37,7 \mathrm{~W}, 25-27 & 349.55 & 0.2 & 80.1 & 19.7 & 5.105 & 2.791 & \text { LC } \\ 37,7 \mathrm{~W}, 44-46 & 349.74 & 2.5 & 82.6 & 14.9 & 7.661 & 3.483 & \text { LC }\end{array}$

Appendix D: IODP Site U1361 IBRD MAR

\begin{tabular}{cccccc}
\hline $\begin{array}{c}\text { Depth } \\
\text { (mbsf) }\end{array}$ & Age (Ma) & CS (wt\%) & $\begin{array}{c}\text { LSR } \\
(\mathbf{c m} / \mathbf{k . y} .)\end{array}$ & DBD (g/cm3) & $\begin{array}{c}\text { IBRD MAR } \\
\text { (g/cm2/k.y.) }\end{array}$ \\
\hline 302.35 & 10876 & 0.004158 & 5.66 & 0.94 & 0.022125 \\
302.45 & 10877.82 & 0.002789 & 5.66 & 0.94 & 0.014840 \\
302.55 & 10879.64 & 0.002160 & 5.66 & 0.94 & 0.011494 \\
302.65 & 10881.45 & 0.001282 & 5.66 & 0.94 & 0.006819 \\
302.75 & 10883.27 & 0.000454 & 5.66 & 0.94 & 0.002418 \\
302.85 & 10885.09 & 0.000133 & 5.66 & 0.94 & 0.000706 \\
302.95 & 10886.91 & 0.000526 & 5.66 & 0.94 & 0.002799 \\
303.05 & 10888.73 & 0.000403 & 5.66 & 0.94 & 0.002145 \\
303.15 & 10890.55 & 0.000260 & 5.66 & 0.94 & 0.001385 \\
303.25 & 10892.36 & 0.000118 & 5.66 & 0.94 & 0.000626 \\
303.35 & 10894.18 & 0.000992 & 5.66 & 0.981 & 0.005506 \\
303.45 & 10896 & 0.001622 & 5.66 & 0.981 & 0.009006 \\
303.55 & 10897.82 & 0.000681 & 5.66 & 0.981 & 0.003781 \\
303.65 & 10899.64 & 0.000577 & 5.66 & 0.981 & 0.003204 \\
303.75 & 10901.45 & 0.000724 & 5.66 & 0.981 & 0.004020
\end{tabular}




\begin{tabular}{|c|c|c|c|c|c|}
\hline 303.85 & 10903.27 & 0.000438 & 5.66 & 0.981 & 0.002431 \\
\hline 303.95 & 10905.09 & 0.000000 & 5.66 & 0.981 & 0.000000 \\
\hline 304.05 & 10906.91 & 0.000000 & 5.66 & 0.981 & 0.000000 \\
\hline 304.15 & 10908.73 & 0.000114 & 5.66 & 0.981 & 0.000634 \\
\hline 304.25 & 10910.55 & 0.000187 & 5.66 & 0.981 & 0.001036 \\
\hline 304.35 & 10912.36 & 0.000865 & 5.66 & 0.981 & 0.004805 \\
\hline 304.45 & 10914.18 & 0.000149 & 5.66 & 0.981 & 0.000825 \\
\hline 304.55 & 10916 & 0.002973 & 5.66 & 0.981 & 0.016506 \\
\hline 304.65 & 10917.82 & 0.000225 & 5.66 & 0.981 & 0.001247 \\
\hline 304.75 & 10919.64 & 0.000129 & 5.66 & 0.981 & 0.000718 \\
\hline 304.85 & 10921.45 & 0.000135 & 5.66 & 0.985 & 0.000755 \\
\hline 304.95 & 10923.27 & 0.001032 & 5.66 & 0.985 & 0.005753 \\
\hline 305.05 & 10925.09 & 0.000132 & 5.66 & 0.985 & 0.000736 \\
\hline 305.15 & 10926.91 & 0.000293 & 5.66 & 0.985 & 0.001632 \\
\hline 305.25 & 10928.73 & 0.001373 & 5.66 & 0.985 & 0.007654 \\
\hline 305.35 & 10930.55 & 0.002019 & 5.66 & 0.985 & 0.011254 \\
\hline 305.45 & 10932.36 & 0.001479 & 5.66 & 0.985 & 0.008246 \\
\hline 305.55 & 10934.18 & 0.002484 & 5.66 & 0.985 & 0.013851 \\
\hline 305.65 & 10936 & 0.001658 & 5.66 & 0.985 & 0.009244 \\
\hline 305.75 & 10937.82 & 0.001147 & 5.66 & 0.985 & 0.006396 \\
\hline 305.85 & 10939.64 & 0.000636 & 5.66 & 0.985 & 0.003548 \\
\hline 305.95 & 10941.45 & 0.001120 & 5.66 & 0.985 & 0.006246 \\
\hline 306.05 & 10943.27 & 0.000000 & 5.66 & 0.985 & 0.000000 \\
\hline 306.15 & 10945.09 & 0.000239 & 5.66 & 0.985 & 0.001331 \\
\hline 306.25 & 10946.91 & 0.000393 & 5.66 & 0.985 & 0.002189 \\
\hline 306.35 & 10948.73 & 0.000172 & 5.66 & 0.985 & 0.000958 \\
\hline 306.45 & 10950.55 & 0.000000 & 5.66 & 0.899 & 0.000000 \\
\hline 306.55 & 10952.36 & 0.000446 & 5.66 & 0.899 & 0.002268 \\
\hline 306.65 & 10954.18 & 0.000136 & 5.66 & 0.899 & 0.000694 \\
\hline 306.75 & 10956 & 0.000122 & 5.66 & 0.899 & 0.000623 \\
\hline 306.85 & 10957.82 & 0.000281 & 5.66 & 0.899 & 0.001429 \\
\hline 306.95 & 10959.64 & 0.000271 & 5.66 & 0.899 & 0.001379 \\
\hline 307.05 & 10961.45 & 0.000753 & 5.66 & 0.899 & 0.003834 \\
\hline 307.15 & 10963.27 & 0.001587 & 5.66 & 0.899 & 0.008077 \\
\hline 307.25 & 10965.09 & 0.001447 & 5.66 & 0.899 & 0.007363 \\
\hline 307.35 & 10966.91 & 0.002350 & 5.66 & 0.899 & 0.011958 \\
\hline 307.45 & 10968.73 & 0.000466 & 5.66 & 0.899 & 0.002374 \\
\hline 307.55 & 10970.55 & 0.001332 & 5.66 & 0.899 & 0.006778 \\
\hline 307.65 & 10972.36 & 0.002198 & 5.66 & 0.899 & 0.011183 \\
\hline 307.75 & 10974.18 & 0.002351 & 5.66 & 0.899 & 0.011961 \\
\hline 307.85 & 10976 & 0.002412 & 5.66 & 0.899 & 0.012271 \\
\hline 307.95 & 10977.82 & 0.002473 & 5.66 & 0.899 & 0.012581 \\
\hline 308.05 & 10979.64 & 0.002011 & 5.66 & 0.95 & 0.010813 \\
\hline
\end{tabular}




\begin{tabular}{|c|c|c|c|c|c|}
\hline 308.15 & 10981.45 & 0.002624 & 5.66 & 0.95 & 0.014109 \\
\hline 308.25 & 10983.27 & 0.001360 & 5.66 & 0.95 & 0.007315 \\
\hline 308.35 & 10985.09 & 0.001515 & 5.66 & 0.95 & 0.008145 \\
\hline 308.45 & 10986.91 & 0.002775 & 5.66 & 0.95 & 0.014920 \\
\hline 308.55 & 10988.73 & 0.002773 & 5.66 & 0.95 & 0.014910 \\
\hline 308.65 & 10990.55 & 0.003103 & 5.66 & 0.95 & 0.016682 \\
\hline 308.75 & 10992.36 & 0.002682 & 5.66 & 0.95 & 0.014420 \\
\hline 308.85 & 10994.18 & 0.003422 & 5.66 & 0.95 & 0.018398 \\
\hline 308.95 & 10996 & 0.004161 & 5.66 & 0.95 & 0.022376 \\
\hline 309.05 & 10997.82 & 0.004096 & 5.66 & 0.95 & 0.022024 \\
\hline 309.15 & 10999.64 & 0.004030 & 5.66 & 0.95 & 0.021671 \\
\hline 309.25 & 11001.45 & 0.000348 & 5.66 & 0.95 & 0.001873 \\
\hline 309.35 & 11003.27 & 0.002198 & 5.66 & 1.093 & 0.013598 \\
\hline 309.45 & 11005.09 & 0.000302 & 5.66 & 1.093 & 0.001866 \\
\hline 309.55 & 11006.91 & 0.000240 & 5.66 & 1.093 & 0.001484 \\
\hline 309.65 & 11008.73 & 0.000570 & 5.66 & 1.093 & 0.003524 \\
\hline 309.75 & 11010.55 & 0.001912 & 5.66 & 1.093 & 0.011826 \\
\hline 309.85 & 11012.36 & 0.001242 & 5.66 & 1.093 & 0.007686 \\
\hline 309.95 & 11014.18 & 0.000436 & 5.66 & 1.093 & 0.002694 \\
\hline 310.05 & 11016 & 0.000150 & 5.66 & 1.093 & 0.000930 \\
\hline 310.15 & 11017.82 & 0.000472 & 5.66 & 1.093 & 0.002919 \\
\hline 310.25 & 11019.64 & 0.001404 & 5.66 & 1.093 & 0.008687 \\
\hline 310.35 & 11021.45 & 0.000135 & 5.66 & 1.093 & 0.000834 \\
\hline 310.45 & 11023.27 & 0.000119 & 5.66 & 1.093 & 0.000733 \\
\hline 310.55 & 11025.09 & 0.000138 & 5.66 & 1.093 & 0.000852 \\
\hline 310.65 & 11026.91 & 0.000407 & 5.66 & 1.093 & 0.002520 \\
\hline 310.75 & 11028.73 & 0.000416 & 5.66 & 1.093 & 0.002571 \\
\hline 310.85 & 11030.55 & 0.000145 & 5.66 & 1.093 & 0.000898 \\
\hline 310.95 & 11032.36 & 0.000146 & 5.66 & 1.093 & 0.000902 \\
\hline 311.05 & 11034.18 & 0.000147 & 5.66 & 0.933 & 0.000774 \\
\hline 311.15 & 11036 & 0.000147 & 5.66 & 0.933 & 0.000778 \\
\hline 311.25 & 11037.82 & 0.000455 & 5.66 & 0.933 & 0.002401 \\
\hline 311.35 & 11039.64 & 0.000224 & 5.66 & 0.933 & 0.001183 \\
\hline 311.45 & 11041.45 & 0.000125 & 5.66 & 0.933 & 0.000659 \\
\hline 311.55 & 11043.27 & 0.000236 & 5.66 & 0.933 & 0.001248 \\
\hline 311.65 & 11045.09 & 0.000531 & 5.66 & 0.933 & 0.002806 \\
\hline 311.75 & 11046.91 & 0.001010 & 5.66 & 0.933 & 0.005334 \\
\hline 311.85 & 11048.73 & 0.001666 & 5.66 & 0.933 & 0.008800 \\
\hline 311.95 & 11050.55 & 0.001757 & 5.66 & 0.933 & 0.009277 \\
\hline 312.05 & 11052.36 & 0.001075 & 5.66 & 0.933 & 0.005678 \\
\hline 312.15 & 11054.18 & 0.001050 & 5.66 & 0.933 & 0.005546 \\
\hline 312.25 & 11056 & 0.000844 & 5.66 & 0.933 & 0.004456 \\
\hline
\end{tabular}




\begin{tabular}{|c|c|c|c|c|c|}
\hline 312.35 & 11057.82 & 0.002081 & 5.66 & 0.933 & 0.010988 \\
\hline 312.45 & 11059.64 & 0.000824 & 5.66 & 0.933 & 0.004349 \\
\hline 312.55 & 11061.45 & 0.000822 & 5.66 & 0.933 & 0.004343 \\
\hline 312.65 & 11063.27 & 0.000435 & 5.66 & 0.933 & 0.002296 \\
\hline 312.75 & 11065.09 & 0.001547 & 5.66 & 0.933 & 0.008170 \\
\hline 312.85 & 11066.91 & 0.002660 & 5.66 & 0.933 & 0.014045 \\
\hline 312.95 & 11068.73 & 0.003813 & 5.66 & 0.933 & 0.020133 \\
\hline 313.05 & 11070.55 & 0.003061 & 5.66 & 0.933 & 0.016165 \\
\hline 313.15 & 11072.36 & 0.002310 & 5.66 & 0.933 & 0.012197 \\
\hline 313.25 & 11074.18 & 0.000486 & 5.66 & 1.143 & 0.003146 \\
\hline 313.35 & 11076 & 0.002419 & 5.66 & 1.143 & 0.015651 \\
\hline 313.45 & 11077.82 & 0.002127 & 5.66 & 1.143 & 0.013758 \\
\hline 313.55 & 11079.64 & 0.001834 & 5.66 & 1.143 & 0.011865 \\
\hline 313.65 & 11081.45 & 0.001425 & 5.66 & 1.143 & 0.009220 \\
\hline 313.75 & 11083.27 & 0.001571 & 5.66 & 1.143 & 0.010166 \\
\hline 313.85 & 11085.09 & 0.001857 & 5.66 & 1.143 & 0.012011 \\
\hline 313.95 & 11086.91 & 0.002142 & 5.66 & 1.143 & 0.013855 \\
\hline 314.05 & 11088.73 & 0.002882 & 5.66 & 1.143 & 0.018647 \\
\hline 314.15 & 11090.55 & 0.003623 & 5.66 & 1.143 & 0.023438 \\
\hline 314.25 & 11092.36 & 0.004364 & 5.66 & 1.143 & 0.028230 \\
\hline 314.35 & 11094.18 & 0.003105 & 5.66 & 1.143 & 0.020089 \\
\hline 314.45 & 11096 & 0.001847 & 5.66 & 1.143 & 0.011948 \\
\hline 314.55 & 11097.82 & 0.003542 & 5.66 & 1.143 & 0.022914 \\
\hline 314.65 & 11099.64 & 0.001229 & 5.66 & 1.143 & 0.007950 \\
\hline 314.75 & 11101.45 & 0.000227 & 5.66 & 1.143 & 0.001471 \\
\hline 314.85 & 11103.27 & 0.000000 & 5.66 & 1.014 & 0.000000 \\
\hline 314.95 & 11105.09 & 0.000266 & 5.66 & 1.014 & 0.001528 \\
\hline 315.05 & 11106.91 & 0.000235 & 5.66 & 1.014 & 0.001349 \\
\hline 315.15 & 11108.73 & 0.001073 & 5.66 & 1.014 & 0.006157 \\
\hline 315.25 & 11110.55 & 0.000474 & 5.66 & 1.014 & 0.002723 \\
\hline 315.35 & 11112.36 & 0.002459 & 5.66 & 1.014 & 0.014115 \\
\hline 315.45 & 11114.18 & 0.000451 & 5.66 & 1.014 & 0.002588 \\
\hline 315.55 & 11116 & 0.000764 & 5.66 & 1.014 & 0.004386 \\
\hline 315.65 & 11117.82 & 0.001563 & 5.66 & 1.014 & 0.008968 \\
\hline 315.75 & 11119.64 & 0.001702 & 5.66 & 1.014 & 0.009769 \\
\hline 315.85 & 11121.45 & 0.000150 & 5.66 & 1.014 & 0.000860 \\
\hline 315.95 & 11123.27 & 0.000349 & 5.66 & 1.014 & 0.002003 \\
\hline 316.05 & 11125.09 & 0.000249 & 5.66 & 1.014 & 0.001431 \\
\hline 316.15 & 11126.91 & 0.000150 & 5.66 & 1.014 & 0.000862 \\
\hline 316.25 & 11128.73 & 0.000678 & 5.66 & 1.014 & 0.003890 \\
\hline 316.35 & 11130.55 & 0.000777 & 5.66 & 1.002 & 0.004408 \\
\hline 316.45 & 11132.36 & 0.001595 & 5.66 & 1.002 & 0.009044 \\
\hline 316.55 & 11134.18 & 0.001876 & 5.66 & 1.002 & 0.010638 \\
\hline
\end{tabular}




\begin{tabular}{|c|c|c|c|c|c|}
\hline 316.65 & 11136 & 0.000454 & 5.66 & 1.002 & 0.002573 \\
\hline 316.75 & 11137.82 & 0.000629 & 5.66 & 1.002 & 0.003570 \\
\hline 316.85 & 11139.64 & 0.000000 & 5.66 & 1.002 & 0.000000 \\
\hline 316.95 & 11141.45 & 0.001011 & 5.66 & 1.002 & 0.005732 \\
\hline 317.05 & 11143.27 & 0.001610 & 5.66 & 1.002 & 0.009131 \\
\hline 317.15 & 11145.09 & 0.000683 & 5.66 & 1.002 & 0.003875 \\
\hline 317.25 & 11146.91 & 0.000561 & 5.66 & 1.002 & 0.003182 \\
\hline 317.35 & 11148.73 & 0.001170 & 5.66 & 1.002 & 0.006636 \\
\hline 317.45 & 11150.55 & 0.001779 & 5.66 & 1.002 & 0.010090 \\
\hline 317.55 & 11152.36 & 0.002388 & 5.66 & 1.002 & 0.013543 \\
\hline 317.65 & 11154.18 & 0.002489 & 5.66 & 1.002 & 0.014117 \\
\hline 317.75 & 11156 & 0.002590 & 5.66 & 1.002 & 0.014691 \\
\hline 317.85 & 11157.82 & 0.004131 & 5.66 & 1.002 & 0.023429 \\
\hline 317.95 & 11159.64 & 0.001726 & 5.66 & 0.991 & 0.009680 \\
\hline 318.05 & 11161.45 & 0.001653 & 5.66 & 0.991 & 0.009274 \\
\hline 318.15 & 11163.27 & 0.000293 & 5.66 & 0.991 & 0.001643 \\
\hline 318.25 & 11165.09 & 0.000268 & 5.66 & 0.991 & 0.001506 \\
\hline 318.35 & 11166.91 & 0.000119 & 5.66 & 0.991 & 0.000665 \\
\hline 318.45 & 11168.73 & 0.003251 & 5.66 & 0.991 & 0.018237 \\
\hline 318.55 & 11170.55 & 0.000670 & 5.66 & 0.991 & 0.003760 \\
\hline 318.65 & 11172.36 & 0.000156 & 5.66 & 0.991 & 0.000874 \\
\hline 318.75 & 11174.18 & 0.000512 & 5.66 & 0.991 & 0.002872 \\
\hline 318.85 & 11176 & 0.000000 & 5.66 & 0.991 & 0.000000 \\
\hline 318.95 & 11177.82 & 0.001256 & 5.66 & 0.991 & 0.007043 \\
\hline 319.05 & 11179.64 & 0.000462 & 5.66 & 0.991 & 0.002590 \\
\hline 319.15 & 11181.45 & 0.000697 & 5.66 & 1.002 & 0.003952 \\
\hline 319.25 & 11183.27 & 0.001075 & 5.66 & 1.002 & 0.006098 \\
\hline 319.35 & 11185.09 & 0.000466 & 5.66 & 1.002 & 0.002645 \\
\hline 319.45 & 11186.91 & 0.000000 & 5.66 & 1.002 & 0.000000 \\
\hline 319.55 & 11188.73 & 0.000143 & 5.66 & 1.002 & 0.000810 \\
\hline 319.65 & 11190.55 & 0.001761 & 5.66 & 1.002 & 0.009987 \\
\hline 319.75 & 11192.36 & 0.000283 & 5.66 & 1.002 & 0.001604 \\
\hline 319.85 & 11194.18 & 0.002696 & 5.66 & 1.002 & 0.015290 \\
\hline 319.95 & 11196 & 0.002904 & 5.66 & 1.002 & 0.016470 \\
\hline 320.05 & 11197.82 & 0.003112 & 5.66 & 1.041 & 0.018337 \\
\hline 320.15 & 11199.64 & 0.003320 & 5.66 & 1.041 & 0.019564 \\
\hline 320.25 & 11201.45 & 0.003455 & 5.66 & 1.041 & 0.020360 \\
\hline 320.35 & 11203.27 & 0.003591 & 5.66 & 1.041 & 0.021156 \\
\hline 320.45 & 11205.09 & 0.003726 & 5.66 & 1.041 & 0.021952 \\
\hline 320.55 & 11206.91 & 0.002690 & 5.66 & 1.041 & 0.015852 \\
\hline 320.65 & 11208.73 & 0.001655 & 5.66 & 1.041 & 0.009752 \\
\hline 320.75 & 11210.55 & 0.001838 & 5.66 & 1.041 & 0.010831 \\
\hline
\end{tabular}




\begin{tabular}{|c|c|c|c|c|c|}
\hline 320.85 & 11212.36 & 0.002021 & 5.66 & 1.041 & 0.011910 \\
\hline 320.95 & 11214.18 & 0.002204 & 5.66 & 1.041 & 0.012989 \\
\hline 321.05 & 11216 & 0.002388 & 5.66 & 1.041 & 0.014067 \\
\hline 321.15 & 11217.82 & 0.002571 & 5.66 & 1.041 & 0.015146 \\
\hline 321.25 & 11219.64 & 0.002754 & 5.66 & 0.994 & 0.015492 \\
\hline 321.35 & 11221.45 & 0.001953 & 5.66 & 0.994 & 0.010989 \\
\hline 321.45 & 11223.27 & 0.001043 & 5.66 & 0.994 & 0.005870 \\
\hline 321.55 & 11225.09 & 0.000473 & 5.66 & 0.994 & 0.002662 \\
\hline 321.65 & 11226.91 & 0.000686 & 5.66 & 0.994 & 0.003861 \\
\hline 321.75 & 11228.73 & 0.000739 & 5.66 & 0.994 & 0.004158 \\
\hline 321.85 & 11230.55 & 0.001067 & 5.66 & 0.994 & 0.006002 \\
\hline 321.95 & 11232.36 & 0.000386 & 5.66 & 0.994 & 0.002169 \\
\hline 322.05 & 11234.18 & 0.000182 & 5.66 & 0.994 & 0.001022 \\
\hline 322.15 & 11236 & 0.000286 & 5.66 & 0.994 & 0.001607 \\
\hline 322.25 & 11237.82 & 0.000390 & 5.66 & 0.994 & 0.002192 \\
\hline 322.35 & 11239.64 & 0.000796 & 5.66 & 0.994 & 0.004480 \\
\hline 322.45 & 11241.45 & 0.001006 & 5.66 & 0.994 & 0.005662 \\
\hline 322.55 & 11243.27 & 0.000347 & 5.66 & 0.994 & 0.001954 \\
\hline 322.65 & 11245.09 & 0.000000 & 5.66 & 0.994 & 0.000000 \\
\hline 322.75 & 11246.91 & 0.001530 & 5.66 & 1.038 & 0.008988 \\
\hline 322.85 & 11248.73 & 0.000816 & 5.66 & 1.038 & 0.004795 \\
\hline 322.95 & 11250.55 & 0.000375 & 5.66 & 1.038 & 0.002206 \\
\hline 323.05 & 11252.36 & 0.000106 & 5.66 & 1.038 & 0.000623 \\
\hline 323.15 & 11254.18 & 0.000000 & 5.66 & 1.038 & 0.000000 \\
\hline 323.25 & 11256 & 0.000642 & 5.66 & 1.038 & 0.003772 \\
\hline 323.35 & 11257.82 & 0.000378 & 5.66 & 1.038 & 0.002221 \\
\hline 323.45 & 11259.64 & 0.000170 & 5.66 & 1.038 & 0.000997 \\
\hline 323.55 & 11261.45 & 0.000000 & 5.66 & 1.038 & 0.000000 \\
\hline 323.65 & 11263.27 & 0.003010 & 5.66 & 1.038 & 0.017685 \\
\hline 323.75 & 11265.09 & 0.001916 & 5.66 & 1.038 & 0.011257 \\
\hline 323.85 & 11266.91 & 0.000822 & 5.66 & 1.038 & 0.004828 \\
\hline 323.95 & 11268.73 & 0.004085 & 5.66 & 1.038 & 0.023997 \\
\hline 324.05 & 11270.55 & 0.000000 & 5.66 & 1.038 & 0.000000 \\
\hline 324.15 & 11272.36 & 0.000000 & 5.66 & 0.953 & 0.000000 \\
\hline 324.25 & 11274.18 & 0.000520 & 5.66 & 0.953 & 0.002806 \\
\hline 324.35 & 11276 & 0.000332 & 5.66 & 0.953 & 0.001789 \\
\hline 324.45 & 11277.82 & 0.000286 & 5.66 & 0.953 & 0.001541 \\
\hline 324.55 & 11279.64 & 0.000871 & 5.66 & 0.953 & 0.004700 \\
\hline 324.65 & 11281.45 & 0.000500 & 5.66 & 0.953 & 0.002696 \\
\hline 324.75 & 11283.27 & 0.000888 & 5.66 & 0.953 & 0.004788 \\
\hline 324.85 & 11285.09 & 0.001057 & 5.66 & 0.953 & 0.005700 \\
\hline 324.95 & 11286.91 & 0.002495 & 5.66 & 0.953 & 0.013456 \\
\hline 325.05 & 11288.73 & 0.003932 & 5.66 & 0.953 & 0.021212 \\
\hline
\end{tabular}




\begin{tabular}{|c|c|c|c|c|c|}
\hline 325.15 & 11290.55 & 0.004057 & 5.66 & 0.953 & 0.021883 \\
\hline 325.25 & 11292.36 & 0.004181 & 5.66 & 0.953 & 0.022555 \\
\hline 325.35 & 11294.18 & 0.004306 & 5.66 & 0.953 & 0.023226 \\
\hline 325.45 & 11296 & 0.004430 & 5.66 & 0.953 & 0.023897 \\
\hline 325.55 & 11297.82 & 0.004555 & 5.66 & 1.481 & 0.038181 \\
\hline 325.65 & 11299.64 & 0.000000 & 5.66 & 1.481 & 0.000000 \\
\hline 325.75 & 11301.45 & 0.004411 & 5.66 & 1.481 & 0.036971 \\
\hline 325.85 & 11303.27 & 0.000600 & 5.66 & 1.481 & 0.005033 \\
\hline 325.95 & 11305.09 & 0.000583 & 5.66 & 1.481 & 0.004886 \\
\hline 326.05 & 11306.91 & 0.000565 & 5.66 & 1.481 & 0.004739 \\
\hline 326.15 & 11308.73 & 0.000434 & 5.66 & 1.481 & 0.003640 \\
\hline 326.25 & 11310.55 & 0.000359 & 5.66 & 1.481 & 0.003011 \\
\hline 326.35 & 11312.36 & 0.000284 & 5.66 & 1.481 & 0.002382 \\
\hline 326.45 & 11314.18 & 0.000388 & 5.66 & 1.481 & 0.003250 \\
\hline 326.55 & 11316 & 0.000000 & 5.66 & 1.481 & 0.000000 \\
\hline 326.65 & 11317.82 & 0.000021 & 5.66 & 1.481 & 0.000174 \\
\hline 326.75 & 11319.64 & 0.000125 & 5.66 & 1.481 & 0.001045 \\
\hline 326.85 & 11321.45 & 0.000155 & 5.66 & 1.481 & 0.001301 \\
\hline 326.95 & 11323.27 & 0.000000 & 5.66 & 1.481 & 0.000000 \\
\hline 327.05 & 11325.09 & 0.000115 & 5.66 & 1.145 & 0.000748 \\
\hline 327.15 & 11326.91 & 0.000231 & 5.66 & 1.145 & 0.001496 \\
\hline 327.25 & 11328.73 & 0.000112 & 5.66 & 1.145 & 0.000725 \\
\hline 327.35 & 11330.55 & 0.001181 & 5.66 & 1.145 & 0.007652 \\
\hline 327.45 & 11332.36 & 0.002058 & 5.66 & 1.145 & 0.013336 \\
\hline 327.55 & 11334.18 & 0.002935 & 5.66 & 1.145 & 0.019020 \\
\hline 327.65 & 11336 & 0.000443 & 5.66 & 1.145 & 0.002869 \\
\hline 327.75 & 11337.82 & 0.001510 & 5.66 & 1.145 & 0.009784 \\
\hline 327.85 & 11339.64 & 0.000326 & 5.66 & 1.145 & 0.002115 \\
\hline 327.95 & 11341.45 & 0.003059 & 5.66 & 1.145 & 0.019824 \\
\hline 328.05 & 11343.27 & 0.000115 & 5.66 & 1.145 & 0.000746 \\
\hline 328.15 & 11345.09 & 0.000612 & 5.66 & 1.145 & 0.003966 \\
\hline 328.25 & 11346.91 & 0.000795 & 5.66 & 1.145 & 0.005154 \\
\hline 328.35 & 11348.73 & 0.000674 & 5.66 & 1.145 & 0.004370 \\
\hline 328.45 & 11350.55 & 0.000553 & 5.66 & 1.145 & 0.003586 \\
\hline 328.55 & 11352.36 & 0.000131 & 5.66 & 1.248 & 0.000925 \\
\hline 328.65 & 11354.18 & 0.000567 & 5.66 & 1.248 & 0.004008 \\
\hline 328.75 & 11356 & 0.000333 & 5.66 & 1.248 & 0.002350 \\
\hline 328.85 & 11357.82 & 0.000098 & 5.66 & 1.248 & 0.000692 \\
\hline 328.95 & 11359.64 & 0.000000 & 5.66 & 1.248 & 0.000000 \\
\hline 329.05 & 11361.45 & 0.000336 & 5.66 & 1.248 & 0.002376 \\
\hline 329.15 & 11363.27 & 0.000439 & 5.66 & 1.248 & 0.003102 \\
\hline 329.25 & 11365.09 & 0.000748 & 5.66 & 1.248 & 0.005286 \\
\hline
\end{tabular}




\begin{tabular}{|c|c|c|c|c|c|}
\hline 329.35 & 11366.91 & 0.000099 & 5.66 & 1.248 & 0.000697 \\
\hline 329.45 & 11368.73 & 0.002693 & 5.66 & 1.248 & 0.019026 \\
\hline 329.55 & 11370.55 & 0.003974 & 5.66 & 1.251 & 0.028141 \\
\hline 329.65 & 11372.36 & 0.000000 & 5.66 & 1.251 & 0.000000 \\
\hline 329.75 & 11374.18 & 0.000708 & 5.66 & 1.251 & 0.005015 \\
\hline 329.85 & 11376 & 0.000140 & 5.66 & 1.251 & 0.000994 \\
\hline 329.95 & 11377.82 & 0.000193 & 5.66 & 1.251 & 0.001370 \\
\hline 330.05 & 11379.64 & 0.000114 & 5.66 & 1.251 & 0.000809 \\
\hline 330.15 & 11381.45 & 0.000035 & 5.66 & 1.251 & 0.000247 \\
\hline 330.25 & 11383.27 & 0.000384 & 5.66 & 1.251 & 0.002720 \\
\hline 330.35 & 11385.09 & 0.000733 & 5.66 & 1.251 & 0.005193 \\
\hline 330.45 & 11386.91 & 0.000121 & 5.66 & 1.251 & 0.000854 \\
\hline 330.55 & 11388.73 & 0.000140 & 5.66 & 1.251 & 0.000991 \\
\hline 330.65 & 11390.55 & 0.000226 & 5.66 & 1.251 & 0.001602 \\
\hline 330.75 & 11392.36 & 0.000234 & 5.66 & 1.251 & 0.001654 \\
\hline 330.85 & 11394.18 & 0.003448 & 5.66 & 1.251 & 0.024416 \\
\hline 330.95 & 11396 & 0.001669 & 5.66 & 0.997 & 0.009417 \\
\hline 331.05 & 11397.82 & 0.000486 & 5.66 & 0.997 & 0.002740 \\
\hline 331.15 & 11399.64 & 0.000448 & 5.66 & 0.997 & 0.002529 \\
\hline 331.25 & 11401.45 & 0.000119 & 5.66 & 0.997 & 0.000672 \\
\hline 331.35 & 11403.27 & 0.000000 & 5.66 & 0.997 & 0.000000 \\
\hline 331.45 & 11405.09 & 0.000557 & 5.66 & 0.997 & 0.003144 \\
\hline 331.55 & 11406.91 & 0.000282 & 5.66 & 0.997 & 0.001591 \\
\hline 331.65 & 11408.73 & 0.000744 & 5.66 & 0.997 & 0.004199 \\
\hline 331.75 & 11410.55 & 0.000045 & 5.66 & 0.997 & 0.000254 \\
\hline 331.85 & 11412.36 & 0.000494 & 5.66 & 0.997 & 0.002790 \\
\hline 331.95 & 11414.18 & 0.001036 & 5.66 & 0.997 & 0.005845 \\
\hline 332.05 & 11416 & 0.000233 & 5.66 & 0.997 & 0.001314 \\
\hline 332.15 & 11417.82 & 0.000860 & 5.66 & 0.997 & 0.004852 \\
\hline 332.25 & 11419.64 & 0.000709 & 5.66 & 0.997 & 0.004004 \\
\hline 332.35 & 11421.45 & 0.000365 & 5.66 & 0.997 & 0.002060 \\
\hline 332.45 & 11423.27 & 0.000401 & 5.66 & 0.997 & 0.002260 \\
\hline 332.55 & 11425.09 & 0.000445 & 5.66 & 1.022 & 0.002573 \\
\hline 332.65 & 11426.91 & 0.000225 & 5.66 & 1.022 & 0.001304 \\
\hline 332.75 & 11428.73 & 0.000218 & 5.66 & 1.022 & 0.001260 \\
\hline 332.85 & 11430.55 & 0.000139 & 5.66 & 1.022 & 0.000802 \\
\hline 332.95 & 11432.36 & 0.001005 & 5.66 & 1.022 & 0.005812 \\
\hline 333.05 & 11434.18 & 0.000273 & 5.66 & 1.022 & 0.001581 \\
\hline 333.15 & 11436 & 0.000386 & 5.66 & 1.022 & 0.002233 \\
\hline 333.25 & 11437.82 & 0.000323 & 5.66 & 1.022 & 0.001868 \\
\hline 333.35 & 11439.64 & 0.000132 & 5.66 & 1.022 & 0.000762 \\
\hline 333.45 & 11441.45 & 0.000123 & 5.66 & 1.022 & 0.000712 \\
\hline 333.55 & 11443.27 & 0.000261 & 5.66 & 1.022 & 0.001508 \\
\hline
\end{tabular}




\begin{tabular}{|c|c|c|c|c|c|}
\hline 333.65 & 11445.09 & 0.000867 & 5.66 & 1.251 & 0.006137 \\
\hline 333.75 & 11446.91 & 0.000931 & 5.66 & 1.251 & 0.006593 \\
\hline 333.85 & 11448.73 & 0.000858 & 5.66 & 1.251 & 0.006076 \\
\hline 333.95 & 11450.55 & 0.000139 & 5.66 & 1.251 & 0.000985 \\
\hline 334.05 & 11452.36 & 0.000000 & 5.66 & 1.251 & 0.000000 \\
\hline 334.15 & 11454.18 & 0.000254 & 5.66 & 1.251 & 0.001798 \\
\hline 334.25 & 11456 & 0.000500 & 5.66 & 1.251 & 0.003540 \\
\hline 334.35 & 11457.82 & 0.003508 & 5.66 & 1.251 & 0.024841 \\
\hline 334.45 & 11459.64 & 0.003807 & 5.66 & 1.251 & 0.026956 \\
\hline 334.55 & 11461.45 & 0.004106 & 5.66 & 1.251 & 0.029070 \\
\hline 334.65 & 11463.27 & 0.002372 & 5.66 & 1.251 & 0.016799 \\
\hline 334.75 & 11465.09 & 0.000500 & 5.66 & 1.251 & 0.003539 \\
\hline 334.85 & 11466.91 & 0.002379 & 5.66 & 1.251 & 0.016842 \\
\hline 334.95 & 11468.73 & 0.000137 & 5.66 & 1.251 & 0.000972 \\
\hline 335.05 & 11470.55 & 0.000217 & 5.66 & 1.251 & 0.001537 \\
\hline 335.15 & 11472.36 & 0.003693 & 5.66 & 1.251 & 0.026150 \\
\hline 335.25 & 11474.18 & 0.000211 & 5.66 & 1.251 & 0.001493 \\
\hline 335.35 & 11476 & 0.000214 & 5.66 & 1.251 & 0.001518 \\
\hline 335.45 & 11477.82 & 0.001790 & 5.66 & 0.99 & 0.010027 \\
\hline 335.55 & 11479.64 & 0.002744 & 5.66 & 0.99 & 0.015376 \\
\hline 335.65 & 11481.45 & 0.003699 & 5.66 & 0.99 & 0.020725 \\
\hline 335.75 & 11483.27 & 0.004653 & 5.66 & 0.99 & 0.026074 \\
\hline 335.85 & 11485.09 & 0.001522 & 5.66 & 0.99 & 0.008528 \\
\hline 335.95 & 11486.91 & 0.004054 & 5.66 & 0.99 & 0.022719 \\
\hline 336.05 & 11488.73 & 0.003896 & 5.66 & 0.99 & 0.021830 \\
\hline 336.15 & 11490.55 & 0.003737 & 5.66 & 0.99 & 0.020942 \\
\hline 336.25 & 11492.36 & 0.002819 & 5.66 & 0.99 & 0.015795 \\
\hline 336.35 & 11494.18 & 0.002012 & 5.66 & 0.99 & 0.011272 \\
\hline 336.45 & 11496 & 0.001719 & 5.66 & 0.99 & 0.009632 \\
\hline 336.55 & 11497.82 & 0.000955 & 5.66 & 0.99 & 0.005354 \\
\hline 336.65 & 11499.64 & 0.000192 & 5.66 & 0.99 & 0.001076 \\
\hline 336.75 & 11501.45 & 0.000565 & 5.66 & 0.99 & 0.003167 \\
\hline 336.85 & 11503.27 & 0.000393 & 5.66 & 0.99 & 0.002202 \\
\hline 336.95 & 11505.09 & 0.001268 & 5.66 & 0.99 & 0.007104 \\
\hline 337.05 & 11506.91 & 0.004613 & 5.66 & 0.99 & 0.025847 \\
\hline 337.15 & 11508.73 & 0.002628 & 5.66 & 0.99 & 0.014724 \\
\hline 337.25 & 11510.55 & 0.000643 & 5.66 & 0.99 & 0.003602 \\
\hline 337.35 & 11512.36 & 0.000861 & 5.66 & 0.99 & 0.004825 \\
\hline 337.45 & 11514.18 & 0.001875 & 5.66 & 1.191 & 0.012636 \\
\hline 337.55 & 11516 & 0.002888 & 5.66 & 1.191 & 0.019469 \\
\hline 337.65 & 11517.82 & 0.000602 & 5.66 & 1.191 & 0.004056 \\
\hline 337.75 & 11519.64 & 0.002866 & 5.66 & 1.191 & 0.019323 \\
\hline
\end{tabular}




\begin{tabular}{|c|c|c|c|c|c|}
\hline 337.85 & 11521.45 & 0.002264 & 5.66 & 1.191 & 0.015261 \\
\hline 337.95 & 11523.27 & 0.001661 & 5.66 & 1.191 & 0.011199 \\
\hline 338.05 & 11525.09 & 0.001059 & 5.66 & 1.191 & 0.007138 \\
\hline 338.15 & 11526.91 & 0.001917 & 5.66 & 1.191 & 0.012921 \\
\hline 338.25 & 11528.73 & 0.000705 & 5.66 & 1.191 & 0.004749 \\
\hline 338.35 & 11530.55 & 0.001288 & 5.66 & 1.191 & 0.008683 \\
\hline 338.45 & 11532.36 & 0.000127 & 5.66 & 1.191 & 0.000856 \\
\hline 338.55 & 11534.18 & 0.000276 & 5.66 & 1.191 & 0.001858 \\
\hline 338.65 & 11536 & 0.000342 & 5.66 & 1.191 & 0.002305 \\
\hline 338.75 & 11537.82 & 0.000408 & 5.66 & 0.98 & 0.002264 \\
\hline 338.85 & 11539.64 & 0.000316 & 5.66 & 0.98 & 0.001752 \\
\hline 338.95 & 11541.45 & 0.001572 & 5.66 & 0.98 & 0.008721 \\
\hline 339.05 & 11543.27 & 0.001196 & 5.66 & 0.98 & 0.006635 \\
\hline 339.15 & 11545.09 & 0.000820 & 5.66 & 0.98 & 0.004548 \\
\hline 339.25 & 11546.91 & 0.000312 & 5.66 & 0.98 & 0.001732 \\
\hline 339.35 & 11548.73 & 0.000584 & 5.66 & 0.98 & 0.003237 \\
\hline 339.45 & 11550.55 & 0.000129 & 5.66 & 1.066 & 0.000779 \\
\hline 339.55 & 11552.36 & 0.000686 & 5.66 & 1.066 & 0.004140 \\
\hline 339.65 & 11554.18 & 0.001707 & 5.66 & 1.066 & 0.010301 \\
\hline 339.75 & 11556 & 0.002197 & 5.66 & 1.066 & 0.013255 \\
\hline 339.85 & 11557.82 & 0.000561 & 5.66 & 1.066 & 0.003387 \\
\hline 339.95 & 11559.64 & 0.000470 & 5.66 & 1.066 & 0.002839 \\
\hline 340.05 & 11561.45 & 0.001152 & 5.66 & 1.066 & 0.006951 \\
\hline 340.15 & 11563.27 & 0.003393 & 5.66 & 1.066 & 0.020471 \\
\hline 340.25 & 11565.09 & 0.001839 & 5.66 & 1.066 & 0.011095 \\
\hline 340.35 & 11566.91 & 0.000285 & 5.66 & 1.066 & 0.001719 \\
\hline 340.45 & 11568.73 & 0.002822 & 5.66 & 0.964 & 0.015396 \\
\hline 340.55 & 11570.55 & 0.002265 & 5.66 & 0.964 & 0.012358 \\
\hline 340.65 & 11572.36 & 0.001708 & 5.66 & 0.964 & 0.009321 \\
\hline 340.75 & 11574.18 & 0.000517 & 5.66 & 0.964 & 0.002823 \\
\hline 340.85 & 11576 & 0.000954 & 5.66 & 0.964 & 0.005207 \\
\hline 340.95 & 11577.82 & 0.001391 & 5.66 & 0.964 & 0.007592 \\
\hline 341.05 & 11579.64 & 0.001828 & 5.66 & 0.964 & 0.009976 \\
\hline 341.15 & 11581.45 & 0.000523 & 5.66 & 0.964 & 0.002852 \\
\hline 341.25 & 11583.27 & 0.000709 & 5.66 & 0.964 & 0.003869 \\
\hline 341.35 & 11585.09 & 0.000868 & 5.66 & 0.964 & 0.004735 \\
\hline 341.45 & 11586.91 & 0.000916 & 5.66 & 0.964 & 0.004996 \\
\hline 341.55 & 11588.73 & 0.000891 & 5.66 & 0.964 & 0.004859 \\
\hline 341.65 & 11590.55 & 0.000574 & 5.66 & 0.964 & 0.003133 \\
\hline 341.75 & 11592.36 & 0.000609 & 5.66 & 0.964 & 0.003324 \\
\hline 341.85 & 11594.18 & 0.000966 & 5.66 & 0.964 & 0.005272 \\
\hline 341.95 & 11596 & 0.001323 & 5.66 & 0.975 & 0.007303 \\
\hline 342.05 & 11597.82 & 0.002962 & 5.66 & 0.975 & 0.016347 \\
\hline
\end{tabular}




\begin{tabular}{|c|c|c|c|c|c|}
\hline 342.15 & 11599.64 & 0.004601 & 5.66 & 0.975 & 0.025390 \\
\hline 342.25 & 11601.45 & 0.002068 & 5.66 & 0.975 & 0.011413 \\
\hline 342.35 & 11603.27 & 0.001686 & 5.66 & 0.975 & 0.009306 \\
\hline 342.45 & 11605.09 & 0.001114 & 5.66 & 0.975 & 0.006145 \\
\hline 342.55 & 11606.91 & 0.000541 & 5.66 & 0.975 & 0.002984 \\
\hline 342.65 & 11608.73 & 0.000661 & 5.66 & 0.975 & 0.003649 \\
\hline 342.75 & 11610.55 & 0.000497 & 5.66 & 0.975 & 0.002742 \\
\hline 342.85 & 11612.36 & 0.000389 & 5.66 & 0.975 & 0.002148 \\
\hline 342.95 & 11614.18 & 0.000282 & 5.66 & 0.975 & 0.001555 \\
\hline 343.05 & 11616 & 0.000143 & 5.66 & 0.975 & 0.000791 \\
\hline 343.15 & 11617.82 & 0.000130 & 5.66 & 1.056 & 0.000775 \\
\hline 343.25 & 11619.64 & 0.000129 & 5.66 & 1.056 & 0.000771 \\
\hline 343.35 & 11621.45 & 0.000000 & 5.66 & 1.056 & 0.000000 \\
\hline 343.45 & 11623.27 & 0.000124 & 5.66 & 1.056 & 0.000740 \\
\hline 343.55 & 11625.09 & 0.000124 & 5.66 & 1.056 & 0.000743 \\
\hline 343.65 & 11626.91 & 0.000182 & 5.66 & 1.056 & 0.001090 \\
\hline 343.75 & 11628.73 & 0.000289 & 5.66 & 1.056 & 0.001730 \\
\hline 343.85 & 11630.55 & 0.000781 & 5.66 & 1.056 & 0.004671 \\
\hline 343.95 & 11632.36 & 0.003337 & 5.66 & 1.056 & 0.019945 \\
\hline 344.05 & 11634.18 & 0.004065 & 5.66 & 1.056 & 0.024297 \\
\hline 344.15 & 11636 & 0.003806 & 5.66 & 1.056 & 0.022747 \\
\hline 344.25 & 11637.82 & 0.003535 & 5.66 & 1.056 & 0.021131 \\
\hline 344.35 & 11639.64 & 0.003168 & 5.66 & 1.056 & 0.018935 \\
\hline 344.45 & 11641.45 & 0.001647 & 5.66 & 1.056 & 0.009845 \\
\hline 344.55 & 11643.27 & 0.001032 & 5.66 & 1.056 & 0.006166 \\
\hline 344.65 & 11645.09 & 0.001564 & 5.66 & 1.056 & 0.009349 \\
\hline 344.75 & 11646.91 & 0.002315 & 5.66 & 1.047 & 0.013717 \\
\hline 344.85 & 11648.73 & 0.001377 & 5.66 & 1.047 & 0.008160 \\
\hline 344.95 & 11650.55 & 0.000000 & 5.66 & 1.047 & 0.000000 \\
\hline 345.05 & 11652.36 & 0.000000 & 5.66 & 1.047 & 0.000000 \\
\hline 345.15 & 11654.18 & 0.000000 & 5.66 & 1.047 & 0.000000 \\
\hline 345.25 & 11656 & 0.000009 & 5.66 & 1.047 & 0.000055 \\
\hline 345.35 & 11657.82 & 0.000101 & 5.66 & 1.047 & 0.000600 \\
\hline 345.45 & 11659.64 & 0.000337 & 5.66 & 1.047 & 0.001995 \\
\hline 345.55 & 11661.45 & 0.000273 & 5.66 & 1.047 & 0.001620 \\
\hline 345.65 & 11663.27 & 0.000046 & 5.66 & 1.047 & 0.000270 \\
\hline 345.75 & 11665.09 & 0.000174 & 5.66 & 1.047 & 0.001032 \\
\hline 345.85 & 11666.91 & 0.000257 & 5.66 & 1.047 & 0.001526 \\
\hline 345.95 & 11668.73 & 0.000000 & 5.66 & 1.047 & 0.000000 \\
\hline 346.05 & 11670.55 & 0.000000 & 5.66 & 1.047 & 0.000000 \\
\hline 346.15 & 11672.36 & 0.000000 & 5.66 & 1.047 & 0.000000 \\
\hline 346.25 & 11674.18 & 0.000375 & 5.66 & 1.047 & 0.002222 \\
\hline
\end{tabular}




$\begin{array}{lcclll}346.35 & 11676 & 0.000000 & 5.66 & 1.047 & 0.000000 \\ 346.45 & 11677.82 & 0.000000 & 5.66 & 1.047 & 0.000000 \\ 346.55 & 11679.64 & 0.000127 & 5.66 & 0.966 & 0.000692 \\ 346.65 & 11681.45 & 0.000000 & 5.66 & 0.966 & 0.000000 \\ 346.75 & 11683.27 & 0.000000 & 5.66 & 0.966 & 0.000000 \\ 346.85 & 11685.09 & 0.000000 & 5.66 & 0.966 & 0.000000 \\ 346.95 & 11686.91 & 0.000158 & 5.66 & 0.966 & 0.000861 \\ 347.05 & 11688.73 & 0.000000 & 5.66 & 0.966 & 0.000000 \\ 347.15 & 11690.55 & 0.000000 & 5.66 & 0.966 & 0.000000 \\ 347.25 & 11692.36 & 0.000000 & 5.66 & 0.966 & 0.000000 \\ 347.35 & 11694.18 & 0.000884 & 5.66 & 0.966 & 0.004831 \\ 347.45 & 11696 & 0.001767 & 5.66 & 0.966 & 0.009662 \\ 347.55 & 11697.82 & 0.002651 & 5.66 & 0.966 & 0.014492 \\ 347.65 & 11699.64 & 0.001210 & 5.66 & 0.966 & 0.006617 \\ 347.75 & 11701.45 & 0.000276 & 5.66 & 0.941 & 0.001472 \\ 347.85 & 11703.27 & 0.000177 & 5.66 & 0.941 & 0.000945 \\ 347.95 & 11705.09 & 0.000375 & 5.66 & 0.941 & 0.001999 \\ 348.05 & 11706.91 & 0.000418 & 5.66 & 0.941 & 0.002228 \\ 348.15 & 11708.73 & 0.000417 & 5.66 & 0.941 & 0.002223 \\ 348.25 & 11710.55 & 0.000038 & 5.66 & 0.941 & 0.000202 \\ 348.35 & 11712.36 & 0.000000 & 5.66 & 0.941 & 0.000000 \\ 348.45 & 11714.18 & 0.000292 & 5.66 & 0.941 & 0.001556 \\ 348.55 & 11716 & 0.000139 & 5.66 & 0.941 & 0.000740 \\ 348.65 & 11717.82 & 0.000112 & 5.66 & 0.941 & 0.000598 \\ 348.75 & 11719.64 & 0.000829 & 5.66 & 0.941 & 0.004413 \\ 348.85 & 11721.45 & 0.000409 & 5.66 & 0.941 & 0.002180 \\ 348.95 & 11723.27 & 0.000124 & 5.66 & 1.026 & 0.000720 \\ 349.05 & 11725.09 & 0.000585 & 5.66 & 1.026 & 0.003396 \\ 349.15 & 11726.91 & 0.000400 & 5.66 & 1.026 & 0.002325 \\ 349.25 & 11728.73 & 0.000216 & 5.66 & 1.026 & 0.001254 \\ 349.35 & 11730.55 & 0.000264 & 5.66 & 1.026 & 0.001533 \\ 349.45 & 11732.36 & 0.000564 & 5.66 & 1.026 & 0.003276 \\ 349.55 & 11734.18 & 0.000000 & 5.66 & 1.026 & 0.000000 \\ 349.65 & 11736 & 0.000000 & 5.66 & 1.026 & 0.000000\end{array}$

Appendix E: IODP Site U1361 XRF elemental data used in this project.

\begin{tabular}{|c|c|c|c|c|c|c|c|c|}
\hline $\begin{array}{l}\text { Core, section, } \\
\text { interval }(\mathrm{cm})\end{array}$ & $\begin{array}{l}\text { Depth } \\
\text { (mbsf) }\end{array}$ & $\begin{array}{c}\mathbf{A l} \\
(\mathbf{p p m})\end{array}$ & $\begin{array}{c}\mathbf{T i} \\
(\mathbf{p p m})\end{array}$ & $\begin{array}{c}\mathrm{Sr} \\
(\mathbf{p p m})\end{array}$ & $\begin{array}{c}\text { Ba } \\
(\mathbf{p p m})\end{array}$ & Si (ppm) & $\begin{array}{c}\text { Mn } \\
(\mathbf{p p m})\end{array}$ & $\begin{array}{c}\mathbf{C a} \\
(\mathbf{p p m})\end{array}$ \\
\hline $33-1 \mathrm{~W}, 5-7$ & 302.1 & 43677.1 & 2671.8 & 142.9 & 326.4 & 342588.0 & 498.1 & 6833.6 \\
\hline $33-1 \mathrm{~W}, 15-17$ & 302.2 & 44342.3 & 2777.3 & 142.4 & 343.1 & 322981.2 & 404.7 & 6930.9 \\
\hline $33-1 \mathrm{~W}, 26-28$ & 302.3 & 48233.2 & 2948.9 & 135.5 & 334.3 & 327051.2 & 436.4 & 6512.2 \\
\hline
\end{tabular}




\begin{tabular}{|c|c|c|c|c|c|c|c|c|}
\hline & & & & & & & 463.7 & 6314.9 \\
\hline $33-1 \mathrm{~W}, 55-57$ & 302.6 & 39295.9 & 2533.4 & 109.2 & 344.7 & 282322.4 & 442.8 & 5786.8 \\
\hline $3-1 \mathrm{~W}, 65-67$ & 02.7 & 8015.2 & 822.8 & 19.9 & 373.8 & 314606.9 & 421.9 & 01.5 \\
\hline $3-1 \mathrm{~W}, 75-77$ & 02.8 & 8385.0 & 831.2 & 21.0 & 383.1 & 1.2 & 438.5 & 310.9 \\
\hline $33-1 \mathrm{~W}, 8$ & 02.9 & 46883.5 & 2376.8 & 15.5 & 359.8 & 323786.0 & 00.2 & 94.2 \\
\hline 33-1W, 95-97 & 303.0 & 43697.1 & 2543.5 & 23.0 & 339.8 & 330897.1 & 556.2 & 284.5 \\
\hline $33-1 \mathrm{~W}, 105-107$ & 303.1 & 50240.6 & 2710.8 & 29.8 & 373.8 & 326451.8 & 441.6 & 49.8 \\
\hline $33-1 \mathrm{~W}, 125-127$ & 303.3 & 45958.5 & 2260 & & 428.1 & & 3.7 & 00.6 \\
\hline$I, 135-137$ & 303.4 & 43245.9 & 2367.0 & 97.1 & 7.6 & 5.9 & 410.0 & 038.3 \\
\hline $33-1 \mathrm{~W}, 14$ & 303.5 & 45979.2 & 2664.7 & 126.0 & 336.7 & 332568.0 & 439.6 & 15.7 \\
\hline $33-2 \mathrm{~W}$, & 303.6 & 52305.1 & 3045.6 & 126.5 & 382.8 & 334 & 2.9 & 7097.1 \\
\hline $33-2 \mathrm{~W}$, & 303.7 & 50920.6 & 3142.4 & 128.0 & 378.5 & 319007.8 & 459.4 & 7700.6 \\
\hline $33-2$ & 303.8 & 53009.6 & 2912.4 & 19.8 & 360.9 & 296 & 424.8 & 899.2 \\
\hline $33-2$ & 303.9 & 56570.6 & 3150.4 & 112.5 & 430.4 & 8453.5 & 68.5 & 7726.6 \\
\hline $33-2 W, 45-47$ & 304.0 & 54658.4 & 3018.5 & 124.4 & 398.9 & 293094.2 & 479.5 & 7826.9 \\
\hline $33-2$ & 304.1 & 58560.6 & 3262.8 & 128.0 & 452.6 & 2938 & 1.4 & 770.6 \\
\hline $33-2 W, 6$ & 04.2 & 50943.0 & 3048.5 & 123.8 & 403.9 & 315063.1 & 488.4 & 9164.5 \\
\hline $33-2$ & 04.3 & 58365.2 & 3259.3 & 121.6 & 435.4 & & 507.9 & 55.1 \\
\hline $33-2 W, 8$ & 304.4 & 53942.5 & 3124.1 & 120.2 & 445.3 & 288858.4 & 483.7 & 7886.4 \\
\hline $33-2$ & 04.5 & 52889.2 & 3086.2 & 123.0 & 406.2 & 4.5 & 591.7 & 975.5 \\
\hline $33-2 \mathrm{~W}, 1$ & 304.6 & 57331.9 & 3395.3 & 12 & 425.8 & 9.2 & 01.7 & 754.1 \\
\hline $33-2 V$ & 304.7 & 537 & 3136.1 & 119.4 & 387.3 & 2850 & 500.4 & 7850.7 \\
\hline $33-2 y$ & 304.8 & & 3180.0 & & 6.9 & & & 13.9 \\
\hline $33-2 \mathrm{y}$ & 304.9 & 58914.3 & 3170.0 & 3.8 & 490.0 & 29829 & 628.3 & 8396.5 \\
\hline $33-2 \mathrm{~W}$ & 305.0 & 54645.7 & 3013.2 & 115.7 & 424.2 & 286 & 505.3 & 7879.6 \\
\hline $33-3$ & 305.1 & 56139.3 & 3112.2 & & 424.6 & 2656 & 562.3 & 987.1 \\
\hline 33-3W, & 305.2 & 49960.5 & 2869.6 & 117.5 & 393.5 & 7.9 & 437.4 & 3335.3 \\
\hline $33-3$ & 305.3 & 59087.3 & $324 c$ & & 450.1 & & 28.3 & 6630.7 \\
\hline $33-3$ & 305.4 & 51534.0 & 2998.1 & 102.8 & 388.5 & 371.8 & 479.9 & 6161.6 \\
\hline $33-3$ & 305.5 & & & & & & & 6398.4 \\
\hline $33-3$ & 305.6 & 4754 & 2930.8 & & 370.7 & & 476.3 & 6771.9 \\
\hline $33-3 \mathrm{~W}, \mathrm{C}$ & 305.7 & 51753.3 & 3007.2 & 127.1 & 387.5 & 18.5 & 39.0 & 7327.5 \\
\hline $33-3$ & 305.8 & 50988.3 & 3192.7 & & 380.4 & & 466.1 & 8162.2 \\
\hline $33-3 \mathrm{~W}, 85-87$ & 305.9 & 54132.3 & 3040.5 & 116.6 & 411.5 & 306146.5 & 420.9 & 7760.2 \\
\hline $33-3 \mathrm{~W}, 9$ & 306.0 & 54658.4 & 3018.5 & & 398.9 & 293094.2 & 479.5 & 8364.3 \\
\hline $33-3 \mathrm{~W}, 105-107$ & 306.1 & 56347.2 & 3190.8 & 124.6 & 446.1 & 308685.2 & 569.2 & 9351.6 \\
\hline $33-31$ & 306.2 & 6970.4 & 3178.6 & & 467.9 & 290 & 571.0 & 8788.8 \\
\hline $33-3 \mathrm{~W}, 125-127$ & 306.3 & 53259.5 & 2970.3 & 107.6 & 384.4 & 289851.1 & 456.1 & 8350.1 \\
\hline $33-3 \mathrm{~W}, 135-137$ & 306.4 & 56500.3 & 3137.1 & 129.3 & 424.6 & 294839.6 & 556.0 & 8642.9 \\
\hline $33-3 \mathrm{~W}, 145-147$ & 306.5 & 58639.3 & 3179.9 & 122.1 & 423.3 & 315080.2 & 554.1 & 8823.1 \\
\hline $33-4 W, 5-7$ & 306.6 & 58811.4 & 3232.0 & 114.1 & 437.9 & 282775.6 & 502.1 & 8467.5 \\
\hline $33-4 W, 15-17$ & 306.7 & 59060.8 & 3183.0 & 123.2 & 474.8 & 304834.0 & 486.2 & 8774.7 \\
\hline $33-4 W, 25-27$ & 306.8 & 59017.1 & 3164.0 & 119.4 & 441.2 & 299638.1 & 506.7 & 8668.7 \\
\hline $33-4 W, 35-37$ & 306.9 & 60322.2 & 3155.2 & 122.1 & 458.3 & 294382.3 & 786.5 & 9289.3 \\
\hline $33-4 W, 45-47$ & 307.0 & 58578.0 & 3249.1 & 130.3 & 450.9 & 285377.7 & 572.1 & 8852.2 \\
\hline
\end{tabular}




\begin{tabular}{|c|c|c|c|c|c|c|c|c|}
\hline $33-4 \mathrm{~W}, 55-57$ & 07.1 & 46342.3 & 2622.8 & 124.0 & 329.2 & 269794.4 & 577.3 & 7925.9 \\
\hline $33-4 W, 65-67$ & 07.2 & 46677.1 & 2895.9 & 130.2 & 393.9 & 336179.2 & 418.6 & 6403.1 \\
\hline $33-4 \mathrm{~W}$, & 97.3 & 9040.5 & 955.9 & 115.5 & 352.5 & 326113.3 & 159.4 & 057.6 \\
\hline $33-4 W, 85-87$ & 7.4 & 1957.6 & 140.3 & 110.1 & 411.2 & & 484.1 & 5695.6 \\
\hline $33-4 W, 95-97$ & 07.5 & 48654.8 & 3047.6 & 108.4 & 340.1 & 319727.2 & 392.9 & 5338.4 \\
\hline $33-4 W, 115-117$ & 07.7 & 43021.2 & 2733.9 & 141.3 & 310.9 & 331817.6 & 406.7 & 6609.9 \\
\hline $3-4 \mathrm{~W}, 125-127$ & 7.8 & 1506.4 & 2820.7 & 131.9 & 350.4 & 63.5 & 381.4 & 6938.8 \\
\hline $3-4 W, 145-147$ & 8.0 & 40560.1 & 2667.8 & 146.2 & 347.6 & & & 23.6 \\
\hline $33-5 \mathrm{~W}$, & 08.1 & 2838.1 & 2746.1 & 137.6 & 346.3 & 3.0 & 458.7 & 82.6 \\
\hline $33-5 \mathrm{~W}$, & 08.2 & 45204.1 & 2861.4 & 144.6 & 347.5 & 94.0 & 487.2 & 44.0 \\
\hline $33-5$ & 8.3 & & 2971.6 & 138.7 & 331.6 & & 508.5 & 451.9 \\
\hline $33-5 \mathrm{~W}$, & 8.4 & 46522.0 & 3020.1 & 140.4 & 411.9 & 53.0 & 641.2 & 7787.7 \\
\hline $33-5$ & 8.5 & 4298 & 2896.3 & 170.8 & 343.1 & 2.6 & 667.4 & 14458.6 \\
\hline $33-5 \mathrm{~W}, 55-57$ & 308.6 & 46629.0 & 3049.7 & 135.5 & 337.6 & 49.0 & 742.2 & 8372.9 \\
\hline $33-5 W, 65-67$ & 08.7 & 46989.3 & 3025.9 & 150.9 & 330.0 & 294523.4 & 705.0 & 10953.1 \\
\hline $33-5$ & 8.8 & 455 & 2781.3 & 238.5 & 350.0 & & 27.4 & 205.3 \\
\hline $33-5$ & 88.9 & 48110.0 & 2969.9 & 176.4 & 367.4 & $297^{\circ}$ & 773.3 & 16138.0 \\
\hline $33-5$ & 9.0 & 3.6 & 3035.4 & 151.1 & 399.2 & 4.3 & 673.8 & 74.3 \\
\hline $33-5 \mathrm{~W}, 105-107$ & 09.1 & 52311.6 & 3180.8 & 124.8 & 356.7 & 32.5 & 612.1 & 7480.7 \\
\hline $5-117$ & 9.2 & 53414.8 & 3083.2 & 129.6 & 439.5 & 5.4 & 714.4 & 8118.3 \\
\hline-127 & 09.3 & & & & & & 4.1 & \\
\hline-137 & 309.4 & 5.4 & 3005.9 & 140.5 & 412.4 & 7.1 & 707.0 & 8653.9 \\
\hline $33-5 V$ & 309.5 & & 3061 & 133.8 & 390.7 & & 88.9 & 040.1 \\
\hline $33-6 \mathrm{~W}$ & 309.6 & 54606.1 & 3081.2 & 118.8 & 411.1 & 9.6 & 784.3 & 7816.5 \\
\hline $33-6 \mathrm{~W}$, & 309.7 & 51852.2 & 3085.8 & 144.0 & 410.4 & 1.1 & 38.8 & 12057.4 \\
\hline $33-6$ & 99.7 & 3.0 & 3095.5 & 168.4 & 365.5 & & & 14781.2 \\
\hline $33-6 \mathrm{~W}$, & 09.9 & 4481.6 & 3095.3 & 106.1 & 432.7 & & 960.3 & 6887.3 \\
\hline $33-6$ & 10.0 & 54748.9 & 3072.4 & 125.5 & 395.6 & & & 9608.0 \\
\hline $33-6$ & 10.1 & 53921.7 & 3167.5 & 140.8 & 420.9 & 289 & 654.7 & 10533.6 \\
\hline $33-6$ & 10.2 & & 3266.4 & 149.5 & 440.3 & 290 & 8.7 & 12456.4 \\
\hline 77 & 10.3 & .5 & 304 & 138.7 & 429.5 & & & 12147.0 \\
\hline 33-6W, & 310.4 & 55066.6 & 2977.6 & 137.1 & 452.6 & 2.8 & 599.3 & 9906.9 \\
\hline $33-6$ & 10.5 & 5724 & 3272.3 & 137.6 & 449.3 & & 6.5 & 10953.0 \\
\hline $33-6 \mathrm{~W}, 1$ & 310.6 & 60755.6 & 3175.9 & 139.6 & 435.4 & 299 & 693.5 & 12071.4 \\
\hline $5-117$ & 10.7 & 57264.5 & & 129.7 & 448.9 & & 736.0 & 9301.8 \\
\hline $33-6 \mathrm{~W}, 125-127$ & 310.8 & 57461.7 & 3097.0 & 132.9 & 436.3 & 311 & 746.7 & 9941.6 \\
\hline $33-7 \mathrm{~W}, 6-8$ & 10.9 & 55293.9 & 3161.4 & 169.1 & 411.2 & 2739 & 769.1 & 18108.9 \\
\hline $33-7 \mathrm{~W}, 15-17$ & 11.0 & 51049.3 & 2988.6 & 225.9 & 349.1 & 277763.3 & 760.9 & 22689.9 \\
\hline $33-7 \mathrm{~W}, 25-27$ & 311.1 & 50240.3 & 2953.5 & 192.5 & 359.9 & 2789 & 773.4 & 19722.0 \\
\hline $33-7 \mathrm{~W}, 35-37$ & 311.2 & 57134.3 & 3205.6 & 135.4 & 460.7 & & 739.1 & 12210.2 \\
\hline $33-7 \mathrm{~W}, 45-47$ & 311.3 & 54508.8 & 2985.0 & 131.1 & 415.2 & 285878.6 & 731.0 & 10363.1 \\
\hline $33-7 \mathrm{~W}, 55-57$ & 311.4 & 54247.4 & 3006.9 & 121.6 & 437.8 & 285023.7 & 649.9 & 10446.3 \\
\hline $33-7 \mathrm{~W}, 65-67$ & 311.5 & 56691.6 & 2989.7 & 128.9 & 398.8 & 293351.6 & 696.4 & 10159.2 \\
\hline $33-\mathrm{CCW}, 5-7$ & 11.6 & 56784.5 & 3140.4 & 124.6 & 450.9 & 293325.9 & 654.2 & 9669.4 \\
\hline 33-CCW, 12-14 & 311.6 & 54222.2 & 3073.7 & 161.0 & 429.0 & 294755.3 & 700.2 & 14476.4 \\
\hline $34-1 \mathrm{~W}, 5-7$ & 311.7 & 43345.9 & 2903.2 & 144.4 & 327.6 & 312419.5 & 431.5 & 8705.3 \\
\hline
\end{tabular}




\begin{tabular}{|c|c|c|c|c|c|c|c|c|}
\hline 17 & 311.8 & & & & & & & \\
\hline $34-1 \mathrm{~W}, 25-27$ & 1.9 & 5121.2 & 3071.9 & 131.6 & 435.8 & 296503.0 & 543.2 & 9800.3 \\
\hline $5-37$ & 12.0 & 8349.8 & 805.7 & 39.5 & 51.0 & & 534.1 & \\
\hline$J, 47-49$ & 2.1 & 8922.8 & 769.3 & 129.1 & & & 564.7 & 10700.0 \\
\hline $34-1$ & 12.2 & 40738.8 & 2418.8 & 125.0 & 26.3 & 2293.1 & 478.6 & 6735.8 \\
\hline $34-1$ & 12.3 & 5048.1 & 2659.5 & 124.9 & & & 497.1 & 6826.5 \\
\hline $34-1$ & 12.4 & 2590.0 & 2959.5 & 149.3 & 427.1 & 180.2 & 577.9 & 10139.4 \\
\hline $34-1$ & 2.5 & & 2890 & & & & & 77.6 \\
\hline $34-1$ & 2.6 & & 2730.4 & 34.2 & 4.4 & & 0.3 & 926.6 \\
\hline 34-1W, 1( & 12.7 & 4267.9 & 2540.8 & 142.4 & 58.3 & 323375.6 & 465.6 & 27.7 \\
\hline $34-1$ & 12.8 & 4.7 & 2848.9 & 288.0 & 296.8 & & 5.3 & 384.3 \\
\hline $34-1 \mathrm{~W}$ & 12.9 & 43939.3 & 2609.9 & 160.6 & 318.0 & 8.8 & 482.1 & 14287.2 \\
\hline $34-1$ & 12.9 & 4.7 & 2501.7 & 2.5 & 353.4 & & 494.5 & 9439.0 \\
\hline $34-11$ & 13.1 & 7.4 & 2458.3 & 124.9 & 354.3 & & 415.3 & 51.0 \\
\hline $34-2 \mathrm{~W}, 5-7$ & 13.2 & 44494.8 & 2631.7 & 142.0 & 300.9 & 318084.7 & 473.2 & 7174.1 \\
\hline $34-2$ & 13.3 & & 311 & 130.7 & & & 618.4 & 11.6 \\
\hline $34-2$ & 13.4 & 466 & 2707.4 & 261.4 & 421.3 & & 1093.8 & 44326.5 \\
\hline $34-2$ & 3.5 & & 3300.7 & 40.9 & 398.5 & & 802.7 & 55.4 \\
\hline $34-2$ & 13.6 & 563 & 3240.1 & 164.8 & 410.9 & & 592.8 & 39.0 \\
\hline $34-2$ & 3.7 & 0.5 & 2903.5 & 263.1 & 437.5 & 1.6 & 1030.3 & 09.4 \\
\hline $34-2$ & 14.0 & 0.9 & 1978.0 & 636.3 & 262.1 & & 2569.0 & 942.9 \\
\hline $34-2 V$ & 14.2 & 8.1 & 2109.5 & 510.4 & 336.3 & 5.5 & 2139.6 & 111599.3 \\
\hline $34-2$ & 4.3 & & 235 & & & & & 64.3 \\
\hline $34-2 y$ & 14.4 & 6.5 & 2426.5 & 391.6 & 312.2 & & 1352.3 & 43.7 \\
\hline $34-2 y$ & 314.5 & 6.7 & 2427.4 & 362.3 & 313.4 & & 1152.4 & 290.6 \\
\hline $34-2 V$ & 14.6 & 37976.5 & 2413.8 & 229.2 & 340.3 & & 569.7 & 927.2 \\
\hline $34-$ & 14.7 & 3.0 & 3100.1 & 144.1 & 360.7 & & 495.0 & 97.4 \\
\hline $34-3$ & 4.8 & & 283 & & & & & 69.3 \\
\hline $34-3$ & 14.9 & 0.5 & 3197.2 & 129.9 & 414.8 & 0.4 & 537.9 & 9.8 \\
\hline $34-3$ & 15.0 & & 3053.0 & & 390.3 & 2.7 & 597.2 & 663.5 \\
\hline $34-3$ & 5.1 & & 2973.3 & 137.4 & 380.9 & & 464.6 & 129.4 \\
\hline $34-3$ & 15.2 & & 3001.8 & 145.2 & 58.3 & 99.2 & 86.0 & 604.1 \\
\hline $34-$ & & .1 & 296 & & 402.6 & & 432 & 0.4 \\
\hline $34-3$ & 15.4 & 52306.5 & 3117.9 & 152.5 & 400.9 & 85.7 & 504.1 & 12738.6 \\
\hline $34-3$ & 15.5 & & 2952.2 & 127.4 & 361.6 & & 440.4 & 56.6 \\
\hline $34-3 \mathrm{~V}$ & 315.5 & 51266.5 & 3051.0 & 125.6 & 393.1 & 296066.0 & 481.7 & 7769.5 \\
\hline $34-3$ & 5.7 & & 3287.0 & & 3.4 & & 478.0 & 11628.8 \\
\hline $34-3 V$ & 315.8 & 51586.4 & 3084.0 & 120.0 & 458.3 & & 461.7 & 8832.7 \\
\hline $34-3 \mathrm{~W}, 125-127$ & 315.9 & 55855.2 & 3301.2 & 130.7 & 399.5 & 308367.2 & 535.9 & 8789.9 \\
\hline $34-3 \mathrm{~W}, 137-139$ & 316.0 & & 3173.7 & & 432.7 & & 515.9 & 9094.4 \\
\hline $34-3 \mathrm{~W}, 145-147$ & 316.1 & 56437.5 & 3262.8 & 126.7 & 381.4 & 296564.6 & 493.5 & 10206.4 \\
\hline & 16.2 & & 3184.8 & 124.2 & 464.9 & & 507.2 & 9850.4 \\
\hline $34-4 \mathrm{~W}, 16-18$ & 316.3 & 55548.4 & 3291.2 & 134.1 & 435.0 & 287959.1 & 527.5 & 8742.1 \\
\hline $34-4 \mathrm{~W}, 25-27$ & 16.4 & 59784.5 & 3280.6 & 127.6 & 443.9 & 309624.6 & 535.8 & 9490.9 \\
\hline $34-4 \mathrm{~W}, 33-35$ & 316.4 & 50215.5 & 2912.4 & 155.6 & 404.4 & 306487.2 & 466.0 & 12355.4 \\
\hline
\end{tabular}




\begin{tabular}{|c|c|c|c|c|c|c|c|c|}
\hline $34-4 \mathrm{~W}, 45-47$ & 316.6 & 49276.0 & 2904.2 & 133.4 & 401.8 & 290177.5 & 475.5 & 9493.4 \\
\hline $34-4 \mathrm{~W}, 55-57$ & 16.7 & 53912.0 & 3259.0 & 136.6 & 397.9 & 295762.4 & 501.3 & 56.4 \\
\hline $34-4 W, 67-69$ & 16.8 & & & 150.1 & & & & 526.1 \\
\hline $34-4 W, 75-77$ & 16.9 & 4761.2 & 181.2 & 55.6 & 414.8 & 306464.3 & 524.7 & 2861.5 \\
\hline $34-4 W$ & 17.0 & 52798.3 & 3053.4 & 160.2 & 434.3 & 73.7 & 506.1 & 932.0 \\
\hline 34-4W, 96-98 & 17.1 & 51287.3 & 103.4 & 141.2 & 384.2 & 290629.5 & 536.7 & \\
\hline $34-4 \mathrm{~W}, 105-107$ & 17.2 & 56149.1 & 3118.6 & 142.6 & 419.5 & 289846.9 & 559.0 & 9264.1 \\
\hline $4-4 \mathrm{~W}, 115-117$ & 17.3 & 54341.7 & 089.6 & 132.0 & 407.6 & 2972 & 521.6 & 91.4 \\
\hline $34-4 \mathrm{~W}, 125-127$ & 17.4 & 46483.2 & 2780.4 & 203.4 & 7.0 & 2870 & 13.6 & 988.7 \\
\hline $34-4 \mathrm{I}$ & 7.5 & .3 & .7 & 9.3 & & & & 67.1 \\
\hline $34-4$ & 17.6 & & 2918.4 & 169.9 & 9.3 & & 1.2 & \\
\hline $34-5 \mathrm{~W}, 1$ & 17.8 & 48085.3 & 2872.0 & 131.3 & 383.4 & 282419.0 & 490.3 & 8700.4 \\
\hline $34-5$ & 17.9 & & 3086.6 & 0.9 & 6.7 & & 520.0 & 73.8 \\
\hline $34-5$ & 18.0 & 52321.6 & 3025.2 & 153.0 & 421.3 & 0.6 & 480.6 & 11897.9 \\
\hline $34-5 \mathrm{~W}, 45-47$ & 18.1 & 3162.8 & 3094.9 & 136.7 & 435.4 & 290130.3 & 527.3 & 9255.0 \\
\hline $34-5 \mathrm{~W}, 53-55$ & 18.1 & 177.4 & 2963.7 & 139.0 & 414.0 & 0.2 & 81.4 & 10227.2 \\
\hline $34-5 \mathrm{~W}, 6$ & 18.3 & 6290.5 & 3329.6 & 140.1 & 417.8 & 313676.9 & 534.8 & 10706.4 \\
\hline $34-5$ & 8.4 & & 3109.7 & 134.5 & 5.3 & & 5.3 & \\
\hline $34-5 \mathrm{~W}$ & 8.5 & 50960.9 & 2935.9 & 129.9 & 411.5 & 2.9 & 478.2 & 11310.0 \\
\hline $34-5 \mathrm{~W}$, & 8.6 & & 159.9 & 127.5 & 2.3 & & 431.0 & 2.9 \\
\hline $34-5 \mathrm{~W}, 10$ & 18.7 & 56761.6 & 3185.6 & 153.4 & 43.9 & 13.3 & 580.1 & 153.7 \\
\hline $34-5 \mathrm{~W}, 117-119$ & 18.8 & 55784.0 & 3073.5 & 127.0 & 0.8 & 307170.2 & 520.5 & 9599.5 \\
\hline $34-5$ & & & & & & & 5.2 & 45.9 \\
\hline $34-5 V$ & 19.0 & 2888.6 & 3117.9 & 130.0 & 1.9 & 0.0 & 476.5 & 8648.7 \\
\hline $34-5 \mathrm{~V}$ & 19.1 & 0.6 & 3151.6 & 130.1 & 7.2 & 2.4 & 27.4 & 75.0 \\
\hline $34-6 \mathrm{~W}$ & 19.2 & 58291.0 & 3135.9 & 136.2 & & 292986.2 & 510.0 & 9537.0 \\
\hline $34-6 \mathrm{~V}$ & 19.3 & 6019.9 & 3093.0 & 140.7 & 423.7 & 9.3 & 497.1 & 9265.4 \\
\hline $34-6$ & 9.4 & & 293 & 131.7 & & & 17.8 & 12.9 \\
\hline $34-6 \mathrm{~W}, ?$ & 9.5 & 56074.0 & 3231.6 & 144.2 & 438.0 & 8.1 & 586.5 & 10269.6 \\
\hline $34-6 \mathrm{~W}, 4$ & 19.6 & 57580.2 & 3138.9 & 134.5 & & & & \\
\hline $34-6$ & 19.6 & 1.3 & 2902.1 & 129.9 & 432.0 & 293 & 522.9 & 8672.7 \\
\hline $34-6 \mathrm{~V}$ & 19.8 & & 3008.1 & 139.2 & & & 15.7 & 10956.3 \\
\hline $34-6$ & 19.9 & & 298 & 0.1 & & & 1.0 & \\
\hline $34-6 W, 85-87$ & 320.0 & 47251.8 & 2715.1 & 144.6 & 343.8 & 91.6 & 443.9 & 8355.0 \\
\hline & 320.2 & & 2656.8 & 177.9 & 346.1 & 315531.1 & 447.3 & 13376.9 \\
\hline $34-7 \mathrm{~W}, 19-21$ & 320.3 & 45712.4 & 3011.2 & 219.7 & 351.2 & 268795.0 & 797.2 & 29367.2 \\
\hline $34-7$ & 20.4 & & 2880.2 & 193.4 & & & 476.5 & \\
\hline $34-7$ & 320.5 & 47749.5 & 2941.6 & 169.0 & 398.7 & 3019 & 475.4 & 12230.3 \\
\hline $34-7 \mathrm{~W}, 45-47$ & 320.6 & 44419.8 & 2780.9 & 185.3 & 336.3 & 292891.4 & 503.8 & 15677.0 \\
\hline $34-7 \mathrm{~W}, 53-55$ & 320.6 & 54410.4 & 3188.4 & 121.1 & 361.6 & 270807.7 & 489.5 & 9124.6 \\
\hline 34-CCW, 5-7 & 320.7 & 33172.6 & 2046.6 & 423.0 & 254.2 & 259750.5 & 1121.9 & 78326.2 \\
\hline $34-\mathrm{CC}$ & 320.9 & 40069.1 & 2523.0 & 284.6 & 365.3 & 281267.6 & 909.6 & 48849.1 \\
\hline $35-1 \mathrm{~W}, 6-8$ & 321.3 & 35055.8 & 2076.8 & 343.9 & 298.6 & 252972.2 & 1140.8 & 69695.3 \\
\hline $35-1 \mathrm{~W}, 25-27$ & 321.5 & 43558.5 & 2544.2 & 275.7 & 324.4 & 290686.5 & 643.0 & 33356.5 \\
\hline $35-1 \mathrm{~W}, 36-38$ & 321.6 & 46813.7 & 2761.3 & 208.1 & 365.3 & 307615.5 & 592.9 & 22859.3 \\
\hline $35-1 \mathrm{~W}, 45-47$ & 321.7 & 43233.1 & 2501.7 & 214.4 & 360.0 & 296494.0 & 575.1 & 19518.5 \\
\hline
\end{tabular}




\begin{tabular}{|c|c|c|c|c|c|c|c|c|}
\hline $35-1 \mathrm{~W}$, & 21.7 & 7190.2 & & & & & 535.9 & \\
\hline & 21.9 & 4127.4 & 2581.6 & 23.4 & 355.8 & & 679.8 & 29418.8 \\
\hline$N, 76-78$ & 22.0 & 45290.0 & 2557.6 & 238.0 & & & 681.4 & 7 \\
\hline $35-1 \mathrm{~W}, 85-87$ & 2.1 & 8385.0 & 681.9 & 07.7 & 39.0 & & 626.5 & 21267.1 \\
\hline $35-1 \mathrm{~W}, 105-107$ & 22.3 & 1733.9 & 511.0 & 1.9 & 19.5 & & & 739.0 \\
\hline $5-1 \mathrm{~W}, 115-117$ & 22.4 & 53355.7 & 2922.2 & 0.6 & 40.8 & 298730.6 & 559.9 & 21165.2 \\
\hline $5-1 \mathrm{~W}, 12$ & 22.5 & 52699.1 & 2935.6 & 5.8 & 427.8 & 63.9 & 524.7 & 18978.7 \\
\hline-137 & 22.6 & 3946.1 & 2890.2 & & 420.6 & & 2.3 & \\
\hline-147 & 22.7 & 56484.0 & 3041.5 & 153.6 & 418.9 & 52.5 & 492.4 & 13817.2 \\
\hline $35-2 \mathrm{~W}, 6-8$ & 22.8 & 6010.5 & 3103.5 & 89.7 & 432.6 & 2.5 & 594.0 & 479.1 \\
\hline $35-2 \mathrm{~W}, 17-19$ & 22.9 & 43610.5 & 2419.1 & 64.9 & 360.8 & 280291.3 & 563.6 & 36725.7 \\
\hline $35-2 \mathrm{~W}, 33-35$ & 23.0 & 4606.4 & 2908.2 & 47.7 & 361.6 & 309429.6 & 495.6 & 13256.5 \\
\hline $35-2$ & 23.2 & 55177.5 & 2938.5 & 6.4 & 426.8 & & 1.7 & \\
\hline $35-2 \mathrm{~W}$, & 23.3 & 53212.4 & 3017.1 & 50.5 & 399.5 & 126.2 & 512.1 & 14474.2 \\
\hline $35-2$ & 23.4 & 0.7 & 289 & & 404.1 & & 1.0 & \\
\hline $35-2$ & 23.5 & 51912.9 & 2908.2 & 45.0 & 413.2 & 62.8 & 505.1 & 13323.2 \\
\hline $35-2$ & 3.6 & 4949.5 & 2934.5 & 79.8 & 438.3 & 4.4 & 3.7 & 35.4 \\
\hline $35-2$ & 23.7 & & & & 6.0 & & 1.6 & 24.5 \\
\hline $35-2 \mathrm{~W}, 1$ & 23.9 & 54946.7 & 2882.1 & 192.5 & 428.7 & 26.2 & 575.7 & 19771.6 \\
\hline $35-2$ & 324.0 & 0109.1 & 3200.3 & 178.9 & 463.8 & & 32.2 & 963.3 \\
\hline $35-2 \mathrm{~W}, 135-137$ & 324.1 & 54297.7 & 2891.3 & 185.8 & 445.5 & 287126.2 & 565.7 & 18908.2 \\
\hline $35-2 W, 145-147$ & 324.2 & 57045.2 & 3014.1 & 168.4 & 420.6 & 0.1 & 525.6 & 12.3 \\
\hline $35-3$ & 24.3 & 55897.4 & 2915.2 & 56.7 & 432.9 & 9.0 & 524.2 & 00.4 \\
\hline $35-3$ & 24.4 & 8.1 & 3083.2 & 202.2 & 431.7 & 7.0 & 567.3 & 47.1 \\
\hline $35-$ & 24.5 & & 282 & & & & & \\
\hline $35-3$ & 24.6 & 50597.1 & 2799.4 & 262.9 & 423.0 & 2.9 & 649.9 & 684.0 \\
\hline $35-$ & 4.7 & & 2958.1 & 226.7 & 27.2 & & 3.1 & \\
\hline $35-3$ & 24.8 & 0589.8 & 2752.1 & 52.9 & 421.9 & & 840.3 & 1.9 \\
\hline $35-3$ & 24.9 & 29016.0 & 1562.4 & 597.9 & 249.4 & 65.8 & 1387.4 & 206.7 \\
\hline $35-3$ & 25.2 & 29033.9 & 1828.8 & 566.4 & 269.6 & 92.1 & 1891.9 & 608.9 \\
\hline $35-3 \mathrm{~W}, 1$ & 25.3 & 32923.2 & 2025.5 & 484.4 & 323.6 & 86.9 & 1395.8 & 104989.0 \\
\hline $35-3$ & 5.4 & & 2170 & 6.0 & & & & \\
\hline 35-3W, & 25.5 & 34912.5 & 2178.7 & 477.7 & 296.3 & 11.1 & 1253.0 & 49.9 \\
\hline $35-3 \mathrm{~W}, 1$ & 5.7 & 36709.2 & 2380.9 & 412.1 & 350.3 & 71.6 & 1001.2 & 71982.7 \\
\hline $35-4 \mathrm{~W}$ & 325.8 & 44742.0 & 2745.2 & 286.9 & 384.6 & 29.9 & 629.0 & 40151.2 \\
\hline $35-4 \mathrm{~W}, 1$ & 325.9 & 48154.3 & 2869.2 & 160.9 & 413.2 & 63.7 & 445.8 & 13625.8 \\
\hline $35-$ & 26.0 & & 3033.4 & 142.1 & 413.2 & 52.8 & 466.5 & 511.4 \\
\hline $35-4 \mathrm{~W}, 36-38$ & 326.1 & 58673.0 & 3223.7 & 127.3 & 475.2 & 304683.5 & 479.9 & 9257.4 \\
\hline $35-4$ & 326.2 & 50883.0 & 3080.1 & 135.4 & 412.9 & 275080.2 & 454.4 & 9710.7 \\
\hline $35-4 \mathrm{~W}, 65-67$ & 326.4 & 55915.0 & 3166.7 & 115.0 & 385.0 & 289593.2 & 456.1 & 8492.0 \\
\hline $35-4 \mathrm{~W}$, & 26.5 & 58008.6 & 3389.8 & 129.8 & 431.7 & 297527.9 & 518.3 & 9451.8 \\
\hline $35-4 \mathrm{~W}, 85-87$ & 326.6 & 56056.7 & 3214.7 & 132.8 & 447.6 & 285032.5 & 475.0 & 9334.7 \\
\hline $35-4 \mathrm{~W}, 93-95$ & 326.6 & 54071.2 & 2873.6 & 129.8 & 419.8 & 274301.7 & 463.4 & 9018.1 \\
\hline $35-4 \mathrm{~W}, 105-107$ & 326.8 & 55488.0 & 2918.2 & 139.2 & 399.3 & 276730.2 & 508.3 & 11488.4 \\
\hline $35-4 \mathrm{~W}, 115-117$ & 326.9 & 61134.9 & 3349.0 & 130.7 & 441.6 & 299034.0 & 511.9 & 10965.5 \\
\hline
\end{tabular}




\begin{tabular}{|c|c|c|c|c|c|c|c|c|}
\hline & 27.0 & & & & & & & \\
\hline & 27.2 & & & 3.0 & 6.5 & & & \\
\hline $35-5 \mathrm{~V}$ & 27.3 & 18.5 & & & & & & \\
\hline & 27.3 & & & & & & & \\
\hline 7 & 7.5 & 6128.1 & 272.7 & 60.6 & 16.3 & & & \\
\hline & 27.7 & & & & & & & \\
\hline & 7.8 & & & 4.6 & & & & \\
\hline $35-5$ & 27.9 & & & & & & & \\
\hline & 28.0 & & & 39.2 & 14.6 & & & \\
\hline & 28.0 & & & 90.6 & & & & \\
\hline & & & & & & & & \\
\hline & & & & & & & & \\
\hline & 8.5 & & & & & & & \\
\hline & 8.5 & & & .5 & & & & \\
\hline & 8.7 & & & & & & & \\
\hline & & & & & & & & \\
\hline 3 & 29.0 & & & & & & & \\
\hline & 9.1 & & & & & & & \\
\hline & 29.2 & & & 143.4 & & & & \\
\hline & 9.3 & & & & & & & \\
\hline & 9.4 & & & & & & & \\
\hline & 9.5 & & & & & & & \\
\hline & & & & & & & & \\
\hline & 9.8 & & & 9.9 & & & & \\
\hline & & & & & & & & \\
\hline & 0.0 & & & & & & & \\
\hline $35-7$ & 30.1 & & & 39.2 & & & & \\
\hline & 30.1 & & & & & & & \\
\hline $35-7$ & 0.4 & & & 7.5 & 417.4 & & & 5.0 \\
\hline & & & & & & & & \\
\hline & 0.6 & & & & & & & \\
\hline $35-7$ & & & & & & & & \\
\hline $35-\mathrm{CC}$ & 0.8 & & & 8.4 & & & & \\
\hline $35-\mathrm{CC}$ & & & & & & & & 32.5 \\
\hline & & & & & & & & \\
\hline $36-1$ & 31.0 & & & 9.9 & 3.5 & & 566.3 & 26.6 \\
\hline & & & & & & & & \\
\hline $36-1$ & 31.1 & 7.6 & 3122.6 & 134.5 & 404.0 & & 482.6 & \\
\hline & & & & & & & & \\
\hline & & & & 145.7 & & & & 11675.4 \\
\hline & & & & & & & & \\
\hline & & & & 138.8 & & & & 10809.8 \\
\hline $36-1 \mathrm{~W}, 8$ & & & & & & & 476.7 & 12907. \\
\hline & & & & & & & 490.8 & 10417.2 \\
\hline & 331.9 & & 3406.5 & 130.5 & & 304523.5 & & 12648. \\
\hline $5-1 \mathrm{~W}, 115-117$ & 332.0 & 52529.4 & 3186.4 & 157.5 & 450.9 & 272224.3 & 562.9 & 15900 \\
\hline
\end{tabular}




\begin{tabular}{|c|c|c|c|c|c|c|c|c|}
\hline 6,10 & 32.1 & 57007.8 & 3296.5 & 146.5 & 403.1 & 285069.6 & 569.9 & 957.3 \\
\hline $6-1 \mathrm{~W}, 134-136$ & 32.1 & 50711.3 & 2953.2 & 217.4 & 405.9 & 277195.8 & 584.1 & 623.2 \\
\hline $45-147$ & 32.3 & 3073.4 & 973.3 & 142.4 & 378.3 & & & 506.7 \\
\hline $36-2 W, 5-7$ & 32.4 & 1238.7 & 113.5 & 52.4 & 411.3 & 7291.7 & 485.9 & \\
\hline $36-2 V$ & 32.4 & 49523.2 & 2924.5 & 155.9 & 393.2 & 1.3 & 500.6 & 810.5 \\
\hline $36-2 V$ & 32.6 & 54953.3 & 139.3 & 43.2 & 400.3 & & 489.7 & 217.3 \\
\hline $36-2 W, 33-35$ & 32.6 & 60556.5 & 3263.5 & 130.5 & 422.4 & 314426.3 & 513.8 & 1571.8 \\
\hline $36-2 W, 45-47$ & 32.8 & 60012.0 & 405.0 & 50.7 & 437.1 & & 568.3 & 2033.0 \\
\hline $36-2$ & 32.9 & 5336 & 142.9 & 150.9 & 408.3 & 9.6 & 16.8 & 462.7 \\
\hline $36-2$ & 3.0 & 860.9 & 9 & & & & & 57.3 \\
\hline $36-2$ & 33.1 & & 298.5 & 49.5 & 417.7 & 5.7 & & 909.8 \\
\hline $36-2$ & 3.2 & 538 & 3090.3 & 131.1 & 420.2 & 96.4 & 535.8 & 578.6 \\
\hline $36-2$ & 3.3 & & 092.0 & 147.4 & 4.6 & & & \\
\hline 07 & 333.4 & 542 & 119.9 & 135.0 & 440.3 & & 524.2 & 53.8 \\
\hline-117 & 33.5 & 5823 & 168.4 & 142.4 & 412.2 & 3.8 & 553.9 & 12820.2 \\
\hline 27 & 333.6 & 586 & 237.0 & 142.2 & 442.0 & 6.4 & 40.1 & 10840.6 \\
\hline-134 & 333.6 & 5423 & 3112.0 & 128.7 & 403.9 & 5.6 & 501.1 & 11311.9 \\
\hline $6-2 \mathrm{~V}$ & 33.8 & 6 & 62.9 & 124.2 & 377.2 & & 9.5 & \\
\hline $36-3$ & 3.9 & 6213 & 3280.1 & 142.4 & 8.7 & 8.3 & 631.3 & 10245.2 \\
\hline $36-3$ & 34.0 & 608 & 285.5 & 132.1 & 434.3 & & 546.7 & 4.6 \\
\hline $36-3$ & 34.1 & 620 & 3339.2 & 151.6 & 441.2 & & 3.4 & 80.6 \\
\hline $36-3$ & 334.2 & 591 & 3211.8 & 130.3 & 464.7 & 4.9 & 597.5 & 11697.5 \\
\hline $36-3$ & 334.3 & & & 140.7 & & & 25.0 & \\
\hline $36-3$ & 34.4 & 498 & 2980.3 & 250.7 & 365.7 & & 643.3 & 589.2 \\
\hline $36-3$ & 334.5 & & 3249.1 & 140.5 & 3.1 & & 13.0 & 601.5 \\
\hline $36-3 V$ & 334.6 & 5164 & 3048.0 & 142.5 & 451.0 & & 535.8 & 172.9 \\
\hline $36-3$ & 34.7 & 56027.7 & 282.1 & 137.4 & 435.0 & 5.4 & 576.8 & 284.0 \\
\hline $36-3$ & & & 3.5 & & & & & 4.4 \\
\hline $6-3$ & 334.8 & 6.6 & 367.5 & 160.1 & 435.5 & & 673.5 & 1502.2 \\
\hline $36-3$ & 35.0 & & & 151.4 & & & & 933.8 \\
\hline-127 & 335.1 & 5804 & 3232.8 & 135.9 & 456.7 & 7.3 & 576.1 & 10994.8 \\
\hline $36-3 \mathrm{~W}, 1$ & 335.2 & 615 & 3718.7 & 164.5 & 428.7 & 9.5 & 65.9 & 240.8 \\
\hline $6-3 \mathrm{~V}$ & & 604 & 467.7 & 160.9 & & & 8 & 49.9 \\
\hline $36-4 \mathrm{~W}, 6-8$ & 335.4 & 60713.9 & 3365.1 & 159.4 & 490.4 & 19.6 & 625.1 & 16319.2 \\
\hline $36-4 \mathrm{~W}$ & 335.4 & 61229.2 & 3470.1 & 180.0 & 468.8 & & 704.3 & 16935.3 \\
\hline $36-4 \mathrm{~W}, 26-28$ & 335.6 & 49830.8 & 3171.2 & 319.7 & 434.5 & 292177.7 & 915.1 & 38478.1 \\
\hline $36-$ & & & & 299.4 & & & 999.8 & 27.7 \\
\hline $36-4 V$ & 335.8 & 47712.1 & 3020.9 & 245.9 & 368.5 & 74.5 & 882.8 & 31881.0 \\
\hline $36-4 \mathrm{~W}$, & 336.0 & 42309.2 & 2801.6 & 360.8 & 350.6 & 265691.2 & 1047.2 & 47923.5 \\
\hline $36-4 \mathrm{~W}$, & 336.0 & 40674.9 & 2551.1 & 362.3 & 348.3 & 266569.0 & 1309.2 & 67215.5 \\
\hline $36-4 \mathrm{~W}$ & 336.2 & 37584.1 & 2396.2 & 374.7 & 336.4 & 257388.8 & 1977.4 & 60020.2 \\
\hline $36-4 \mathrm{~W}, 105-107$ & 336.4 & 36203.3 & 2284.1 & 397.9 & 346.4 & 247195.3 & 1963.0 & 76529.9 \\
\hline $36-4 \mathrm{~W}, 112-114$ & 336.4 & 39654.3 & 2532.7 & 353.2 & 323.6 & 258014.3 & 1206.6 & 61193.2 \\
\hline $36-4 \mathrm{~W}, 136-138$ & 336.7 & 53219.2 & 2997.2 & 135.9 & 394.3 & 319080.2 & 569.7 & 9626.3 \\
\hline $36-4 \mathrm{~W}, 145-147$ & 336.8 & 50651.8 & 2908.5 & 141.2 & 390.8 & 291463.4 & 584.9 & 12265.8 \\
\hline
\end{tabular}




\begin{tabular}{|c|c|c|c|c|c|c|c|c|}
\hline & & & & & & & & \\
\hline $36-5 \mathrm{~W}, 16-18$ & 7.0 & 9959.7 & 724.7 & 132.6 & 99.0 & & 582.8 & 829.7 \\
\hline-27 & 7.1 & 2249.1 & 554.7 & 85.6 & 67.6 & & 15.2 & \\
\hline 47 & & & & & & & & \\
\hline $36-5$ & 7.4 & & 500.8 & 1.4 & 4.7 & & 0.5 & \\
\hline $36-5 \mathrm{~W}, 65-67$ & 7.5 & 7732.7 & 2606.7 & & 82.2 & & & \\
\hline & & & & & 2.9 & & 2.9 & \\
\hline $36-5$ & 7.7 & .8 & 862.4 & & & & & \\
\hline & & & & & & & & \\
\hline$-5 \mathrm{~V}$ & 7.9 & 2.5 & 2649.8 & 237.7 & 49.7 & & 600.3 & \\
\hline & & & & & & & & \\
\hline 138 & 8.2 & 7.0 & 863.6 & 6.5 & 8.5 & & 570.7 & \\
\hline $5-5 \mathrm{~W}$ & 8.3 & .2 & & & 03.9 & & & \\
\hline $36-6$ & & & 3.4 & & 6.7 & & 7.7 & \\
\hline $36-6 \mathrm{~W}$ & 8.5 & 50284.4 & 2866.5 & 196.3 & 354.9 & & 542.1 & 22689.9 \\
\hline $36-6$ & & & & & & & & \\
\hline 4 & & & & & & & & \\
\hline & & & & & & & & \\
\hline 7 & & & 3045.1 & 173.7 & 00.1 & & 8.7 & \\
\hline 7 & & & & & 4.8 & & 4.6 & \\
\hline $36-6$ & & & & & & & & \\
\hline $5-6$ & & & & & & & & \\
\hline $5-6$ & & & & & & & & \\
\hline $6-6 V$ & & & & & 39.5 & & & \\
\hline $36-$ & & & 3216.6 & & 379.0 & & 8.8 & \\
\hline $36-7$ & & & & & & & & \\
\hline $5-7$ & & & & & 6.4 & & & \\
\hline & & & & & & & & \\
\hline 5 & & & 436.6 & 37.6 & & & & \\
\hline $36-7$ & & & & & & & & \\
\hline $5-7$ & & & & & & & & \\
\hline $36-\mathrm{C}$ & & & & & & & 2.5 & \\
\hline & & & & & & & & \\
\hline $37-1$ & 0.6 & & 3086.8 & 239.1 & 391.9 & & 894.6 & 34116.1 \\
\hline & & & & & & & & \\
\hline $37-1$ & 107 & 52921.9 & 3257.2 & 200.3 & 383.8 & 9.4 & 774.3 & 24002.8 \\
\hline & & & & & & & & \\
\hline & & & & & & & & 43226.0 \\
\hline $37-1$ & 41.2 & 52497.0 & 3015.0 & 183.8 & 383.8 & 278362.4 & 611.5 & 19693.6 \\
\hline $37-1$ & & & & & 422.4 & & & 21380.2 \\
\hline $71 \mathrm{~W} \quad 0305$ & & & & & & & & 13890.6 \\
\hline & & & & & 319.5 & & 1587.2 & 65022.6 \\
\hline $37-1 \mathrm{~W}, 125-127$ & & 31858.4 & & 478.0 & 287.3 & 216947.2 & 2911.6 & \\
\hline $37-1 \mathrm{~W}, 135-137$ & & & & & 262.9 & & & 178089.2 \\
\hline $37-2 \mathrm{~W}, 5-7$ & 42.0 & & 1663.7 & 517.7 & 260.7 & 180445.4 & 5556.6 & \\
\hline $37-2 \mathrm{~W}, 26-28$ & 342.2 & 42666.0 & 2653.8 & 234.9 & 347.5 & 286474.7 & 837.6 & 32478. \\
\hline
\end{tabular}




\begin{tabular}{|c|c|c|c|c|c|c|c|c|}
\hline & & & & & 402.3 & & & \\
\hline $37-2 W, 45-47$ & 42.4 & 7272.5 & 3081.2 & & & & & \\
\hline $37-2 \mathrm{~W}$ & 42.5 & 0067.1 & 3177.8 & 193.6 & 408.2 & & 534.4 & 9648.6 \\
\hline $37-2$ & 42.6 & & .9 & & & & & \\
\hline $37-2 \mathrm{~W}, 78-80$ & 42.7 & 4410.4 & 188.4 & 21.1 & 61.6 & & 9.5 & 124.6 \\
\hline $37-2 \mathrm{~W}$, & & 9789.1 & 295.7 & & 24.9 & 7.7 & & 96.8 \\
\hline $37-2 W, 9$ & 42.9 & 3373.0 & & 127.7 & & & 2.6 & 10522.6 \\
\hline $37-2 W, 105-107$ & 43.0 & 57838.2 & 3161.0 & 136.8 & 418.8 & 5.8 & 611.6 & 11606.5 \\
\hline $17-119$ & 43.1 & 0795.9 & 3408.5 & & & & & \\
\hline $5-127$ & 43.2 & 9674.2 & 3242.3 & 137.5 & 445.8 & 3.9 & 04.2 & 0145.7 \\
\hline-139 & 43.3 & 8889.1 & 3168.0 & 48.4 & 451.1 & & & 0.8 \\
\hline-147 & 43.4 & 4.9 & 3418.0 & 38.8 & 450.1 & & 610.6 & 80.6 \\
\hline $37-3 \mathrm{~W}$ & 43.5 & 9816.9 & 3353.5 & & 440.0 & 99.7 & 597.4 & 10925.7 \\
\hline $37-3$ & 43.6 & & & & & & & \\
\hline $37-3$ & 43.7 & 69.0 & 3488.8 & 132.7 & 465.1 & & 688.1 & 10814.0 \\
\hline $37-$ & 3.7 & & 322 & & & & & \\
\hline $37-3$ & 43.9 & 46613.2 & 3042.3 & 264.8 & 92.8 & 2.2 & 998.1 & 62.7 \\
\hline $37-$ & 43.9 & & 2946.8 & 264.0 & 393.5 & 34.4 & 1154.1 & 4.1 \\
\hline $37-$ & 44.1 & & & 286.6 & & & 5 & 4.4 \\
\hline $37-3$ & 4.1 & 2.0 & 2883.2 & 330.1 & 372.3 & & 1576.2 & 51578.1 \\
\hline $37-3$ & 44.3 & & & 0 & & & & \\
\hline $37-3$ & 44.3 & 4.9 & 2941.8 & 82.3 & 342.8 & & 7.5 & 18009.5 \\
\hline $37-31$ & 44.5 & 44.6 & 2988.5 & 162.3 & 348.8 & & 78.2 & \\
\hline $7-3$ & 4.6 & & & & & & 4.3 & \\
\hline $37-3 \mathrm{~W}$ & 4.7 & 3.7 & 2730.0 & 150.3 & 22.4 & & 443.0 & 87.6 \\
\hline $37-3$ & & & & & & & & \\
\hline $37-31$ & 44.9 & 4.8 & 3288.5 & 135.3 & 440.0 & & 5.3 & 9843.6 \\
\hline & 45.0 & & & & & & & \\
\hline $37-$ & & & & 124.0 & & & 2 & \\
\hline $37-5$ & 45.1 & & 2996.2 & 38.6 & 0.0 & 6.7 & 3.2 & 2793.2 \\
\hline $37-4$ & 45.2 & & 3042.7 & & 408.9 & & 5.3 & \\
\hline $37-4$ & 45.4 & 44434.0 & 3083.2 & 149.6 & 412.4 & 59.8 & 504.1 & 18238.1 \\
\hline $37-4$ & & & & & & & & \\
\hline $37-4$ & 5.6 & 2848.2 & 3198.4 & 147.0 & 372.0 & 34.1 & 658.7 & 89.9 \\
\hline $37-5$ & & & & & 432.7 & & & 40.9 \\
\hline $37-4$ & & 58827.3 & 3322.7 & 143.7 & 468.4 & 80.9 & 703.2 & 13137.4 \\
\hline $37-4$ & 5.8 & 33.7 & 3241.8 & 145.6 & 440.2 & 23.6 & 679.5 & 13566.7 \\
\hline $37-4 \mathrm{~V}$ & & & & 139.5 & 436.0 & & 637.6 & 12439.2 \\
\hline $37-4 W, 113-115$ & 346.0 & 58373.7 & 3274.4 & 146.6 & 442.5 & 302390.3 & 675.5 & 12412.2 \\
\hline $37-4 \mathrm{~W}, 125-127$ & 346.2 & 56628.3 & 3315.7 & 152.2 & 437.5 & 318692.8 & 702.1 & 13191.9 \\
\hline $37-4 W, 133-135$ & 346.2 & 59130.1 & 3287.4 & 137.0 & 426.4 & 277127.3 & 710.5 & 11597.1 \\
\hline $37-4 \mathrm{~W}, 145-147$ & & & 3253.4 & & 445.7 & & 663.0 & 12843.9 \\
\hline & & 57246.3 & 3167.7 & & 440.8 & 305518.2 & 698.9 & 12506.0 \\
\hline $37-5 \mathrm{~W}, 16-18$ & & & & & & & & 12307.8 \\
\hline $37-5 \mathrm{~W}, 22-24$ & 346.6 & 52578.6 & 2989.2 & 147.8 & 384.8 & 325345.7 & 664.0 & 13640.2 \\
\hline
\end{tabular}




\begin{tabular}{|c|c|c|c|c|c|c|c|c|}
\hline & 6.7 & & & & 465.2 & & 779.9 & \\
\hline & 6.9 & & & 5.4 & 64.2 & & & \\
\hline & & & & & & & & \\
\hline & & & & & & & & \\
\hline & 7.1 & & & & 3.6 & & 61.1 & \\
\hline 87 & & & & & & & & \\
\hline & & & & 160.6 & & & 1.7 & \\
\hline 07 & 7.5 & & & & & & & \\
\hline & & & & & & & & \\
\hline & & & & & & & & 82.5 \\
\hline & & & & & & & & \\
\hline 37 & & & & & & & & 66.4 \\
\hline $37-6$ & & & & & & & 2.9 & \\
\hline & & & & & & & & \\
\hline $37-6$ & 8.3 & & & & & & & 61.9 \\
\hline $37-$ & 8.4 & & & & & & 0.3 & \\
\hline 59 & & & & & & & & \\
\hline & & & & & 8.2 & & & \\
\hline & & & & & & & & \\
\hline & & & & & & & & \\
\hline 97 & & & & & & & & \\
\hline & & & & & & & 720.0 & \\
\hline & 9.1 & & & 128.6 & 5.6 & & 730.6 & 9. \\
\hline & 49.2 & & & & & & & \\
\hline $37-6 \mathrm{~W}$ & 49.3 & 61761.6 & 3470.7 & 137.0 & 447.5 & 17.8 & 793.0 & 11708.1 \\
\hline & & & & & & & & \\
\hline $37-7 \mathrm{~W}$, & 105 & 8549.8 & 3310.5 & 135.3 & 432.8 & & 678.8 & 10278.0 \\
\hline & & & & & & & & \\
\hline $7-7 \mathrm{~W}, 35-37$ & 49.7 & 47161.9 & 2819.3 & 295.9 & & 256305.9 & 1026.1 & 47009.0 \\
\hline & 49.7 & & & & & & & 11943. \\
\hline 37-CCW, 5-7 & 49.9 & 54475.1 & 3284.4 & 131.6 & 414.8 & 314741.2 & 728.8 & 12080. \\
\hline
\end{tabular}

\section{Appendix CD1}

Includes:

- Raw biomarker data

- Biomarker sample list

- Raw grain size data (different spreadsheet for each core section)

- XRF raw data (each spreadsheet contains standards which are unique to that run of samples)

- $\mathrm{XRF}$ processing template (instructions included in document)

- Core section data (ID and depth of sample) 